\title{
Sulfur Pellet Responses to a Bare and Steel-Reflected Pulse of the Oak Ridge National Laboratory Health Physics Research Reactor
}

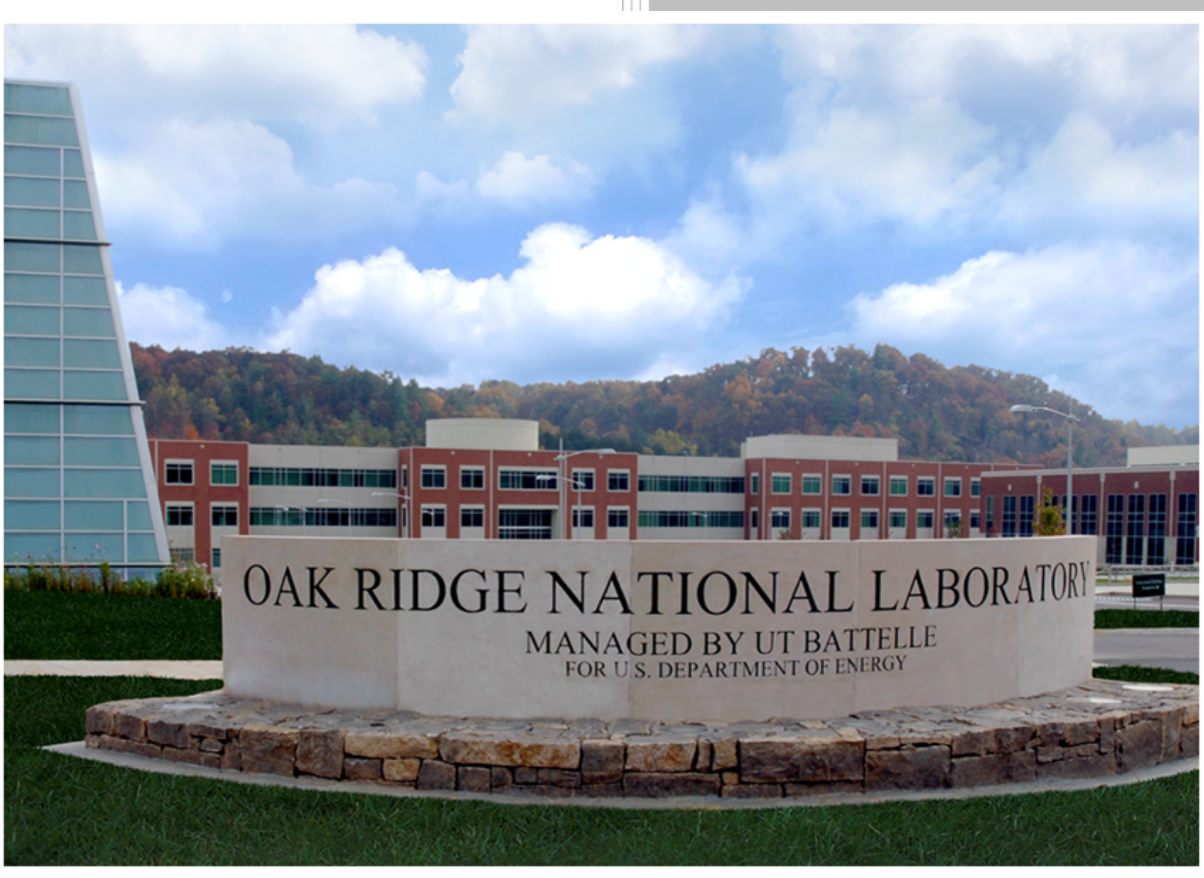

\section{Approved for public release.} Distribution is unlimited. 


\section{DOCUMENT AVAILABILITY}

Reports produced after January 1, 1996, are generally available free via US Department of Energy (DOE) SciTech Connect.

Website www.osti.gov

Reports produced before January 1, 1996, may be purchased by members of the public from the following source:

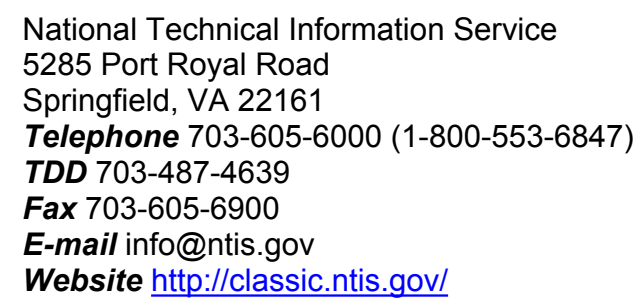

Reports are available to DOE employees, DOE contractors, Energy Technology Data Exchange representatives, and International Nuclear Information System representatives from the following source:

Office of Scientific and Technical Information

PO Box 62

Oak Ridge, TN 37831

Telephone 865-576-8401

Fax 865-576-5728

E-mail reports@osti.gov

Website http://www.osti.gov/contact.html

This report was prepared as an account of work sponsored by an agency of the United States Government. Neither the United States Government nor any agency thereof, nor any of their employees, makes any warranty, express or implied, or assumes any legal liability or responsibility for the accuracy, completeness, or usefulness of any information, apparatus, product, or process disclosed, or represents that its use would not infringe privately owned rights. Reference herein to any specific commercial product, process, or service by trade name, trademark, manufacturer, or otherwise, does not necessarily constitute or imply its endorsement, recommendation, or favoring by the United States Government or any agency thereof. The views and opinions of authors expressed herein do not necessarily state or reflect those of the United States Government or any agency thereof. 
Reactor and Nuclear Systems Division

\title{
SULFUR PELLET RESPONSES TO A BARE AND STEEL-REFLECTED PULSE OF THE ORNL HEALTH PHYSICS RESEARCH REACTOR
}

\author{
Mathieu N. Dupont \\ Ellen Saylor
}

September 2020

Prepared by OAK RIDGE NATIONAL LABORATORY

Oak Ridge, TN 37831-6283

managed by

UT-BATTELLE, LLC

for the

US DEPARTMENT OF ENERGY

under contract DE-AC05-00OR22725 



\section{ACKNOWLEDGMENTS}

The author wishes to thank Cathy Romano and Ellen Saylor for recovering and organizing the Health Physics Research Reactor (HPRR) documentation early in the project. Thanks to Cihangir Celik for the extensive advice on the calculation methodology and experiment/simulation discrepancy investigation. Special thanks to former HPRR staff members Calvin Hopper, Fred Haywood, and John Mihalczo, who provided valuable input that allowed for correction of some modeling assumptions regarding the reactor building and sulfur pellet counting. Finally, thanks to the US Department of Energy / National Nuclear Security Administration Nuclear Criticality Safety Program (DOE/NNSA NCSP), who funded this work. 


\section{DETAILED DESCRIPTION}

\subsection{OVERVIEW OF EXPERIMENT}

The experiments analyzed in this report were conducted at the Health Physics Research Reactor (HPRR), also known as the Fast Burst Reactor. The reactor was designed and built at Oak Ridge National Laboratory (ORNL) in 1961. The HPRR was an unmoderated, unshielded fast reactor that used highly enriched uranium and molybdenum alloy as fuel. The reactor was initially sent to the Nevada Test Site in 1962 [1], where it was used to evaluate radiation doses received as a result of the Hiroshima and Nagasaki bombings during World War II. A few years later, the reactor was sent back to ORNL to be part of the Dosimetry Application Research (DOSAR) facility shown in Figure 1, which included a reactor building shown on the left (west) of the picture and a control and laboratory building in the upper right corner (northeast). The critical assembly was used for numerous technical studies, including systems calibration, dosimetry, radiobiology of plants and animals, testing of radiation alarms, as well as teaching and training in radiation dosimetry and nuclear engineering. Between 1963 and 1987, the HPRR was operated for thousands of hours, achieving criticality close to 10,000 times [2] and motivating many publications. The HPRR was decommissioned in 1987.

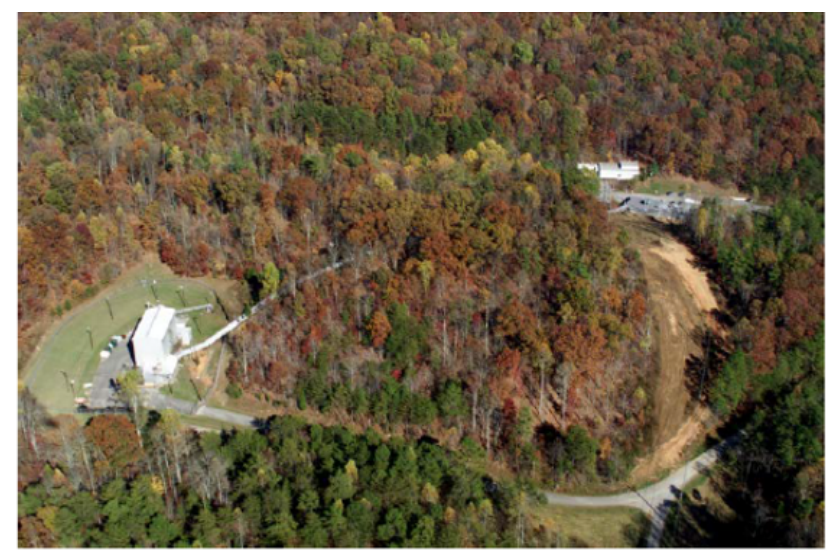

Figure 1. DOSAR Facility [3].

The goal of this effort was to use historical data from operation of the HPRR to create a criticality accident alarm system (CAAS) benchmark to be included in the International Handbook of Evaluated Criticality Safety Benchmark Experiments (ICSBEP Handbook) [4]. A thorough inspection was performed of all available documentation and information available. The most promising experiments that were selected for evaluation were those described in the 1987 ORNL report entitled Health Physics Research Reactor Reference Dosimetry, ORNL-6240 [5]. The report includes reference dosimetry results of the shielded and unshielded configurations of the HPRR after burst operations. Because of changes to the reactor positioning and storage systems that were made in 1985, the previous dosimetry reports became obsolete, and the newly designed experiments were needed to create the HPRR's adjusted dosimetry data. The various results reported in ORNL-6240 include reference doses and dose equivalents from different conventions at different distances and elevations as determined using the detected neutron fluence and conversion factors. The HPRR neutron fluence was obtained through different methods, including sulfur pellet analysis and threshold detector unit data. Information about the HPRR spectrum was also obtained through Bonner sphere measurements. This benchmark is focused on a part of the measured sulfur fluences reported in Appendix H of ORNL-6240. Standard commercial sulfur pellets were placed at different distances from the HPRR centerline during burst operation and were activated due to the ${ }^{32} \mathrm{~S}(\mathrm{n}, \mathrm{p})^{32} \mathrm{P}$ reaction. The resulting ${ }^{32} \mathrm{P}$ activity was then measured and the information about the corresponding sulfur fluence and/or neutron dose could be extracted. Many of those measurements have 
been performed with the HPRR in its bare configuration or with different shields (combinations of Lucite, concrete, steel). All the necessary, precise information about material and/or dimensions of the different shields was not found, so it was decided to focus only on the unshielded and steel-shielded configurations to minimize the benchmark uncertainty. A total of 31 cases $(24$ unshielded and 7 shielded cases at different positions) of sulfur fluence were selected before evaluation to develop the benchmark.

\subsection{DESCRIPTION OF EXPERIMENTAL CONFIGURATION}

The HPRR was placed in the reactor room of the DOSAR building. The reactor room was approximately $9 \mathrm{~m}$ wide, $21 \mathrm{~m}$ long and $15 \mathrm{~m}$ high, with a west cavity approximately $4.5 \mathrm{~m}$ wide and long and $4 \mathrm{~m}$ high. It was operated above the west storage pit, approximately $4.5 \mathrm{~m}$ from the west cavity, centered between the main walls of the building at a height of $1.4 \mathrm{~m}$ from the concrete floor, held by a hydraulic lift. During the steel shield experiments, the shield was placed 2 meters from the HPRR centerline. The sulfur pellets were positioned at the same height as the HPRR centerline at different distances for the bare configuration and for the steel shield configuration, as shown in Table 1 and Table 2. No information about how the sulfur pellets were held at such a height has been found. Note that the two last sulfur pellet positions of the bare configurations at 20 and $30 \mathrm{~m}$ are outside the building. The information about the rest of the HPRR reactor room is scarce, and Figure 2 is one of the few pictures that provides a global view of what may have been the experiment setup. As shown in Figure 2, the reactor room contained many elements, but almost no information has been found concerning dimensions and material compositions in the available literature reports. A simplified overview of the experimental configuration and dimensions with the steel shield is shown in Figure 3. Note the north direction reference that will be used to describe orientation of the experiment components. The following sections provide more details about the setup and dimensions of the HPRR building, reactor room components, sulfur pellets, and steel shield during the sulfur pellet irradiation experiments. Due to the complexity and the importance of the source, the HPRR is described in Section 1.4.

Table 1. Distances of sulfur pellets from the HPRR centerline in the bare configuration

\begin{tabular}{cccc}
\hline $\begin{array}{c}\text { Position } \\
\text { number }\end{array}$ & Distance (m) & $\begin{array}{c}\text { Position } \\
\text { number }\end{array}$ & Distance (m) \\
\hline 1 & 0.12 & 13 & 2 \\
2 & 0.144 & 14 & 2.5 \\
3 & 0.2 & 15 & 3 \\
4 & 0.3 & 16 & 3.5 \\
5 & 0.4 & 17 & 4 \\
6 & 0.5 & 18 & 5 \\
7 & 0.62 & 19 & 7 \\
8 & 0.75 & 20 & 9 \\
9 & 1 & 21 & 12 \\
10 & 1.25 & 22 & 15 \\
11 & 1.5 & 23 & 20 \\
12 & 1.75 & 24 & 30 \\
\hline
\end{tabular}

Table 2. Distances of sulfur pellets from the HPRR centerline in the steel shield configuration

\begin{tabular}{cc}
\hline $\begin{array}{c}\text { Position } \\
\text { number }\end{array}$ & Distance (m) \\
\hline 1 & 2.5 \\
2 & 3 \\
3 & 3.5 \\
4 & 4 \\
5 & 5 \\
6 & 7 \\
7 & 9 \\
\hline
\end{tabular}




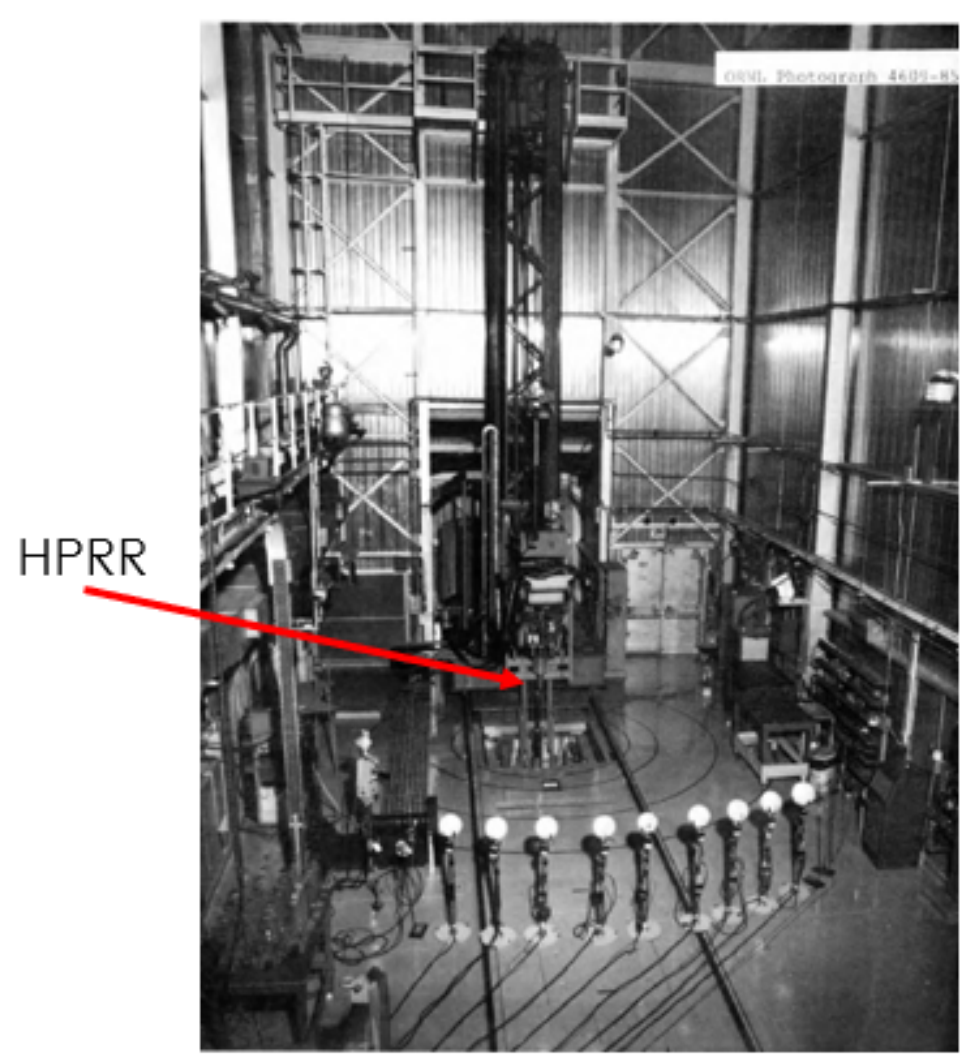

Figure 2. Picture of the HPRR reactor room [5].

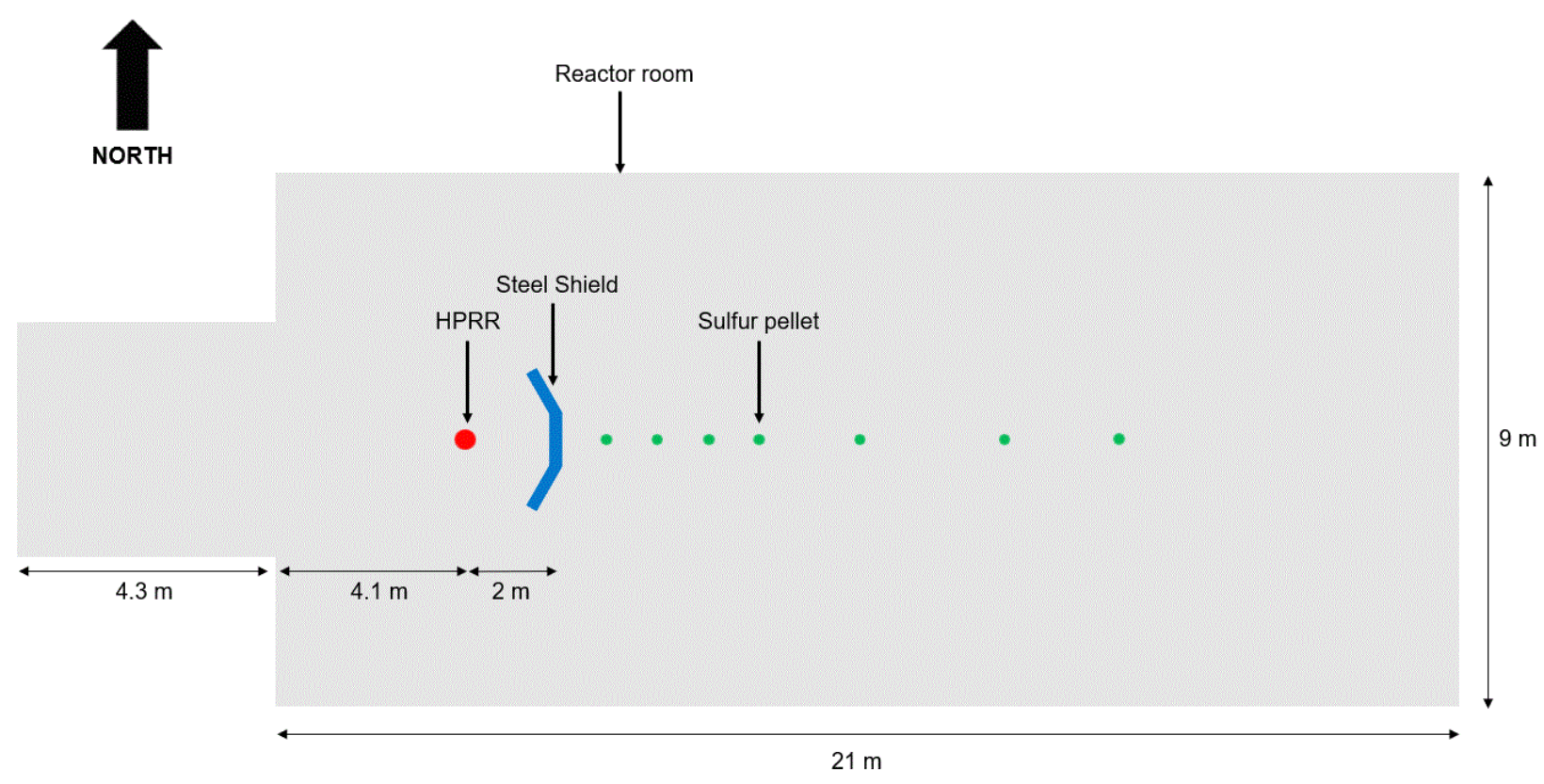

Figure 3. Overview of experiment configuration, approximated dimensions, top view (not in scale). 


\subsubsection{HPRR Reactor Building}

Most of the information about the HPRR reactor building containing the HPRR critical assembly is from the Building 7709 drawing shown in Figure 4. Other sources of information include building descriptions in operating manuals or dosimetry reports about the HPRR. In particular, the latest HPRR operation manual, ORNL_TM_9870 [6], contains substantial useful information about the HPRR and its components. Other components, such as stairs allowing access to the catwalk from the outside of the building or stairs entering the building from the west gate, are also mentioned in the Building 7709 drawing and/or in other documents not explicitly detailed in this report. 


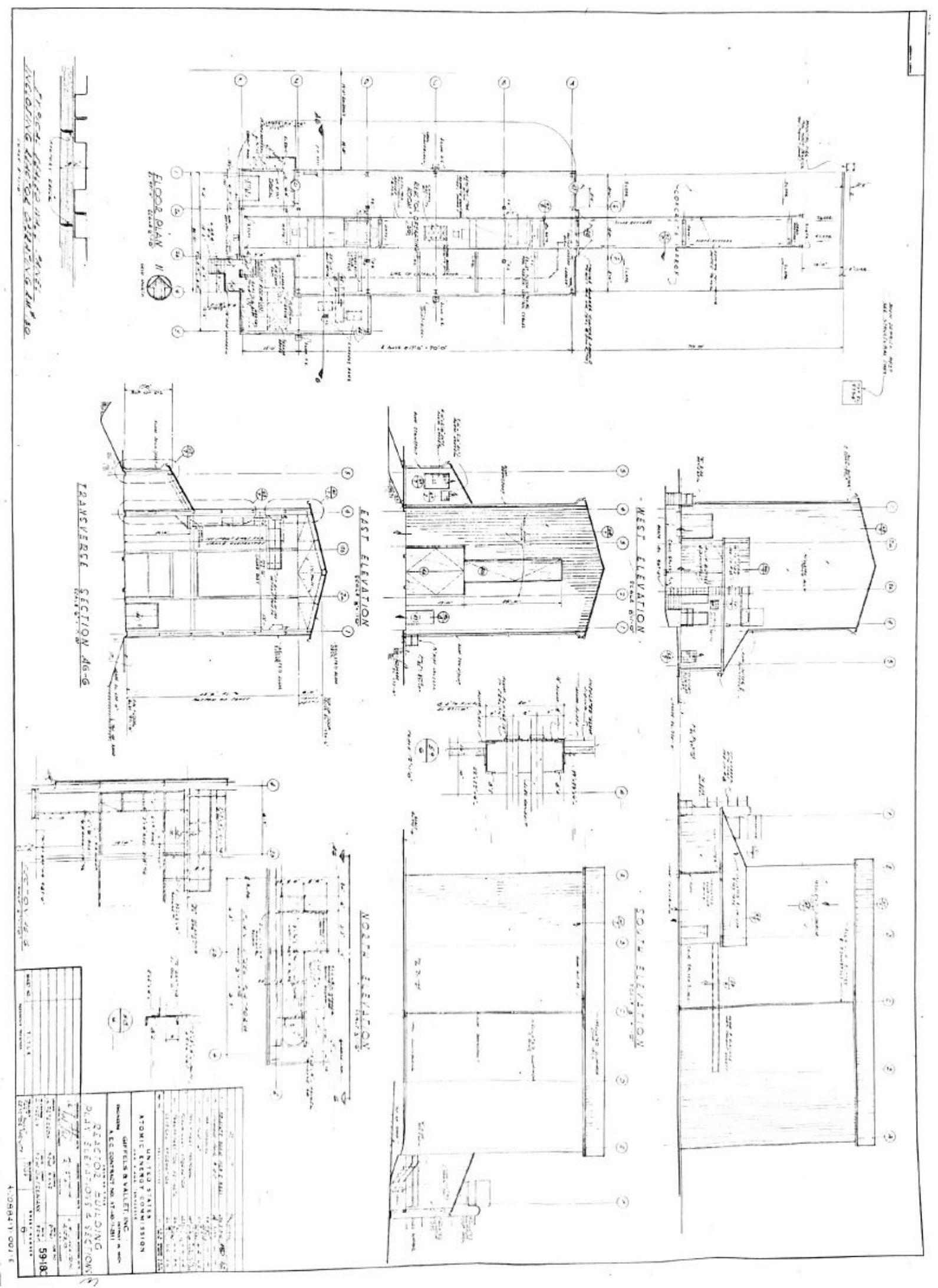

Figure 4. Building 7709 drawing, HPRR reactor building. 


\subsubsection{Reactor room}

In Figure 4, the reactor room's internal length is $70 \mathrm{ft}(2133.60 \mathrm{~cm})$ and the width is $30 \mathrm{ft}(914.40 \mathrm{~cm})$ without the west cavity. The west cavity extends $14 \mathrm{ft}(426.72 \mathrm{~cm})$ on the west end of the reactor room, is $12 \mathrm{ft} 3 \mathrm{in} .(373.38 \mathrm{~cm})$ wide in the north-south direction, $16 \mathrm{ft}(487.68 \mathrm{~cm})$ high at the highest point, and $12 \mathrm{ft}(365.76 \mathrm{~cm})$ high at the lowest point, forming a wedge roof between the two points. The building's top height is $50 \mathrm{ft}(1,524 \mathrm{~cm})$ with a straight height of $44 \mathrm{ft}(1,341.12 \mathrm{~cm})$ and a wedge roof that is $6 \mathrm{ft}$ $(182.88 \mathrm{~cm})$ high.

\subsubsection{Annex room}

The annex room was used to store mechanical and electrical equipment. The annex room is located on the southwest of the reactor room, is $30 \mathrm{ft}(914.40 \mathrm{~cm})$ long and $18 \mathrm{ft} 9 \mathrm{in} .(571.50 \mathrm{~cm})$ wide, starting from the west cavity and extending $10 \mathrm{ft}(304.80 \mathrm{~cm})$ on the south direction from the reactor building room. The annex building height is $12 \mathrm{ft}(365.76 \mathrm{~cm})$ without the roof, and $16 \mathrm{ft}(487.68 \mathrm{~cm})$ at the top of the wedge roof. The west cavity wedge roof is shared with the annex room.

\subsubsection{Building walls}

As shown in Figure 4, the walls of the reactor and annex rooms are described as being $3 \mathrm{ft} 4 \mathrm{in}$. thick $(101.6 \mathrm{~cm})$. The building walls are formed by one layer of structural steel and another layer of corrugated aluminum on the outside of the building, with each layer providing isolation of about $1 \mathrm{ft} 8 \mathrm{in}$. thick (50.8 $\mathrm{cm})$. According to ORNL staff observations, this wall thickness value is too large, and the walls are actually much thinner. According to ORNL-TM-9870 [6], the reactor room building length is $72 \mathrm{ft}$ $(2194.56 \mathrm{~cm})$ and the width is $32 \mathrm{ft}(975.36 \mathrm{~cm})$ without the west cavity. Subtracting the values from the building drawing and the latest operation manual, the wall thickness could actually be $1 \mathrm{ft}(30.48 \mathrm{~cm})$ and the structural-steel and corrugated aluminum layers could be $0.5 \mathrm{ft}(15.24 \mathrm{~cm})$ each.

\subsubsection{Reactor storage pits}

The west and east reactor pits were used to store the HPRR between operations. Since the 1985 reconfiguration of the facility, the HPRR was only stored in the west pit. No information was found about the precise location of the reactor storage pits in relation to the building walls, but an estimate was made using the Building 7709 drawing. The west reactor pit center is estimated to be located $27.5 \mathrm{ft}(838.2 \mathrm{~cm})$ from the west end of the reactor room, which is $13.5 \mathrm{ft}(411.48 \mathrm{~cm})$ from where the west cavity starts. The east reactor pit center is estimated to be located $19.5 \mathrm{ft}(594.36 \mathrm{~cm})$ from the east end of the building. According to ORNL-TM-9870 [6], each pit is $5 \mathrm{ft}(152.4 \mathrm{~cm})$ wide and long and $7 \mathrm{ft}(213.36 \mathrm{~cm})$ deep. The pits are lined with $1 \mathrm{ft}(30.48 \mathrm{~cm})$ of concrete on the sides and base. A stainless-steel plate that is $5 \mathrm{ft}$ $(152.4 \mathrm{~cm})$ wide and long and 7 in. $(17.78 \mathrm{~cm})$ thick acts as a door and can be slid open to let the HPRR through during operation. In the experiments of interest, the west pit door is opened, and the east pit door is closed.

\subsubsection{West gate}

The west gate is a double door located on the northwest end of the reactor room and is $8 \mathrm{ft}(243.84 \mathrm{~cm})$ high and $6 \mathrm{ft}(182.88 \mathrm{~cm})$ wide. No information about the door material or thickness was found, but it was estimated to be $1 \mathrm{ft}(30.48 \mathrm{~cm})$ thick, the same as the building walls. 


\subsubsection{East gate}

The east gate is located on the east end of the reactor room and is centered on the east side of the building. It is formed by two parts: a regular double door gate (referred to as the east bottom gate in the remainder of this report) that is $15 \mathrm{ft}(457.2 \mathrm{~cm})$ high, $12 \mathrm{ft}(365.76 \mathrm{~cm})$ wide, and is estimated to be $1 \mathrm{ft}(30.48 \mathrm{~cm})$ thick. A thinner and taller part starting above the east bottom gate (referred to as the east top gate in the remainder of this report) is $26 \mathrm{ft}(792.48 \mathrm{~cm})$ high, $6 \mathrm{ft}(182.88 \mathrm{~cm})$ wide, and is estimated to be $1 \mathrm{ft}$ $(30.48 \mathrm{~cm})$ thick. It is not known if the top and bottom parts of the east gate could be opened independently. The east top gate was probably used to guide the reactor positioning device and/or other large equipment through the reactor room.

\subsubsection{East door}

The east door is located on the northeast end of the reactor room and is $8 \mathrm{ft}(243.84 \mathrm{~cm})$ high and approximately $5 \mathrm{ft}(152.4 \mathrm{~cm})$ wide. No information about the door material or thickness was found, but it was estimated to be the same thickness as the building walls $(30.48 \mathrm{~cm})$.

\subsubsection{Catwalk}

The catwalk was used by individuals to navigate in the reactor room along the entire west-to-east axis of the reactor room. It was placed about $16 \mathrm{ft}(487.68 \mathrm{~cm})$ high, was approximately $3 \mathrm{ft}(91.44 \mathrm{~cm})$ wide, and was sided with a handrail about $3 \mathrm{ft}(91.44 \mathrm{~cm})$ high. The catwalk is observable on the left side of Figure 1. The photo was taken from the southeast location of the catwalk in the reactor room.

\subsubsection{Crane}

An overhead bridge crane with a 5-ton capacity spanned the width of the building and was able to travel the full west-east length. No information about the crane dimensions were found. The crane was accessible from a platform and stairs that start from the catwalk. The crane platform was $19 \mathrm{ft}(579.12$ $\mathrm{cm})$ above the catwalk at a height of $35 \mathrm{ft}(1,066.80 \mathrm{~cm})$ from the reactor room's concrete floor.

\subsubsection{Hydraulic lift}

The hydraulic lift was used to carry the HPRR out of the storage pit and could hold the critical assembly centerline at a height of 1.4 to $1.5 \mathrm{~m}$ from the concrete floor during typical operations. The hydraulic lift is visible in Figure 5. In this picture, the HPRR is positioned above the west storage pit. No information about materials and dimensions of the hydraulic lift were found. 


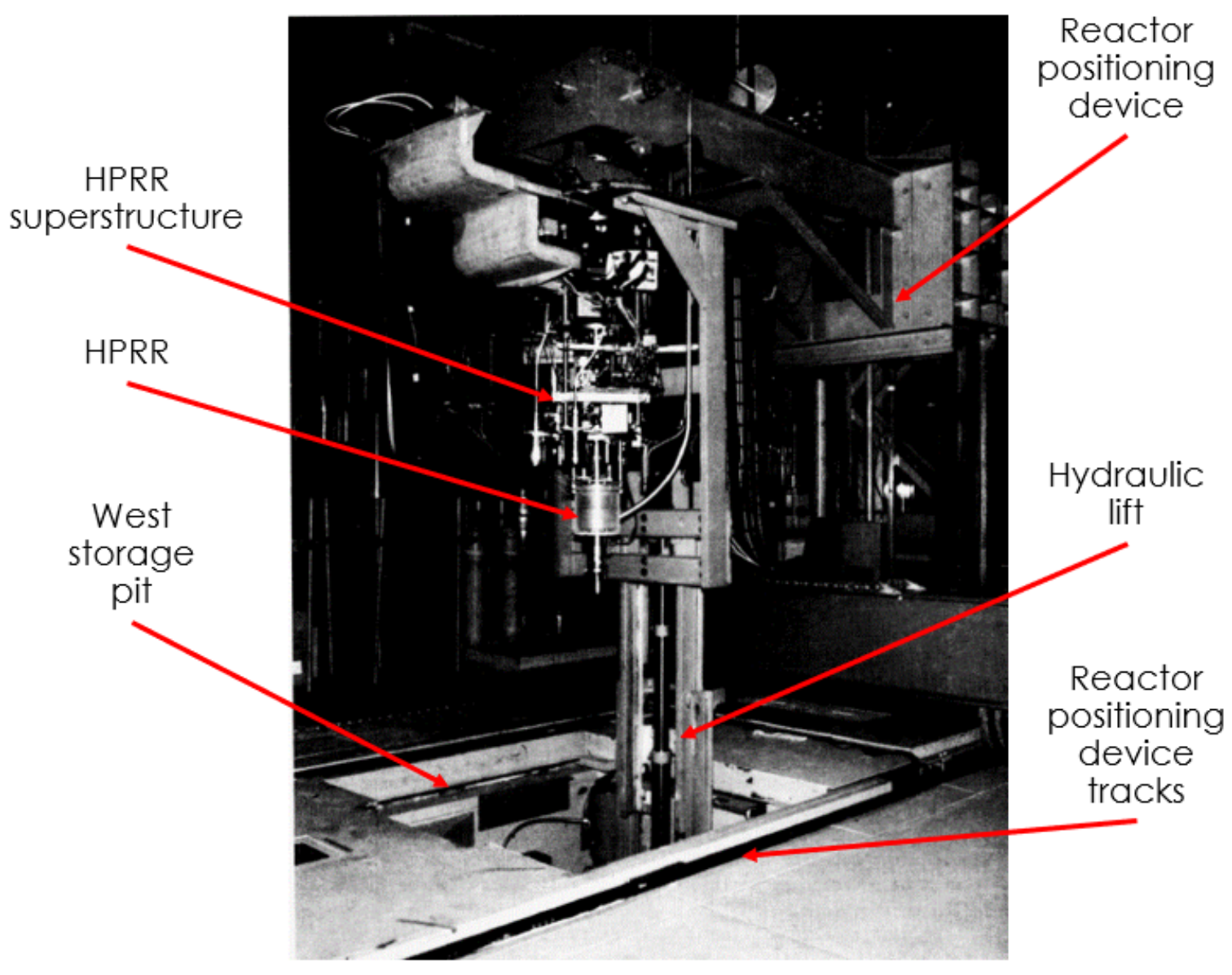

Figure 5. Photo of the HPRR above the west storage pit [6].

\subsubsection{Reactor positioning device}

The reactor positioning device, shown in Figure 6, was used to move the HPRR in and out of the reactor room. It could be moved along the entire west-east axis of the building, extending outside the building on the east concrete pad by means of a set of tracks on the floor. The HPRR critical assembly could be moved up to a height of $5.2 \mathrm{~m}$ above the concrete floor. The reactor positioning device was not used during experiments, when the HPRR was held in place using the hydraulic lift. The location of the reactor positioning device during the experiments of interest in this benchmark evaluation is unknown. No information about materials and dimensions of the reactor positioning device were found. 


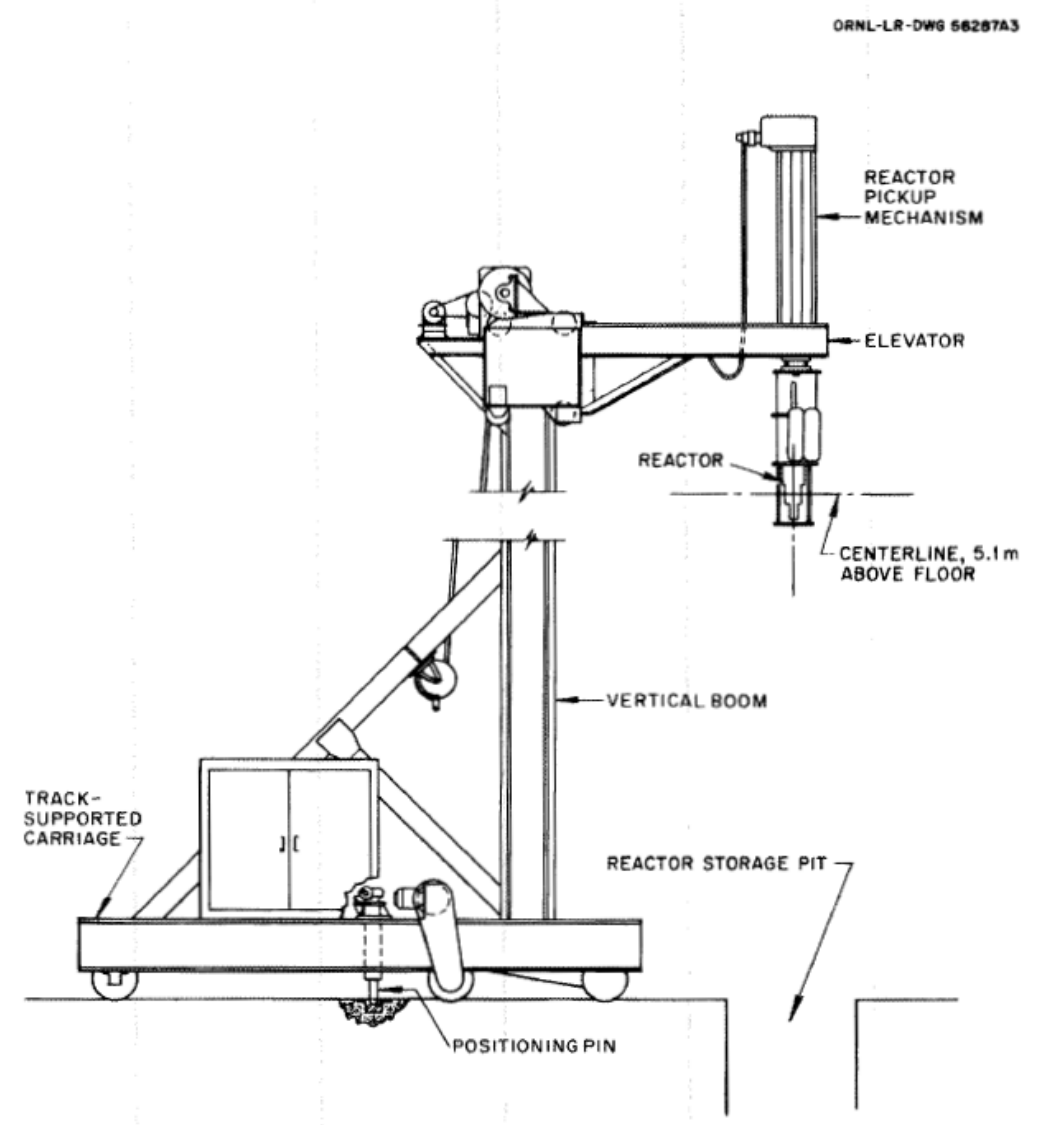

Figure 6. Drawing of the reactor positioning device [6].

\subsubsection{Concrete pad}

The east concrete pad is $70 \mathrm{ft}(2133.60 \mathrm{~cm})$ long and $30 \mathrm{ft}(914.40 \mathrm{~cm})$ wide and is estimated to be $1 \mathrm{ft}$ $(30.48 \mathrm{~cm})$ thick, like the reactor room floor. The pad was used to load and unload large equipment from the reactor building through the east gate, such as the HPRR and the reactor positioning device. This can be seen in Figure 7, which is a photo of the building from the southeast angle. In this picture, the annex room, the east gate, and the reactor positioning device are also observable. 


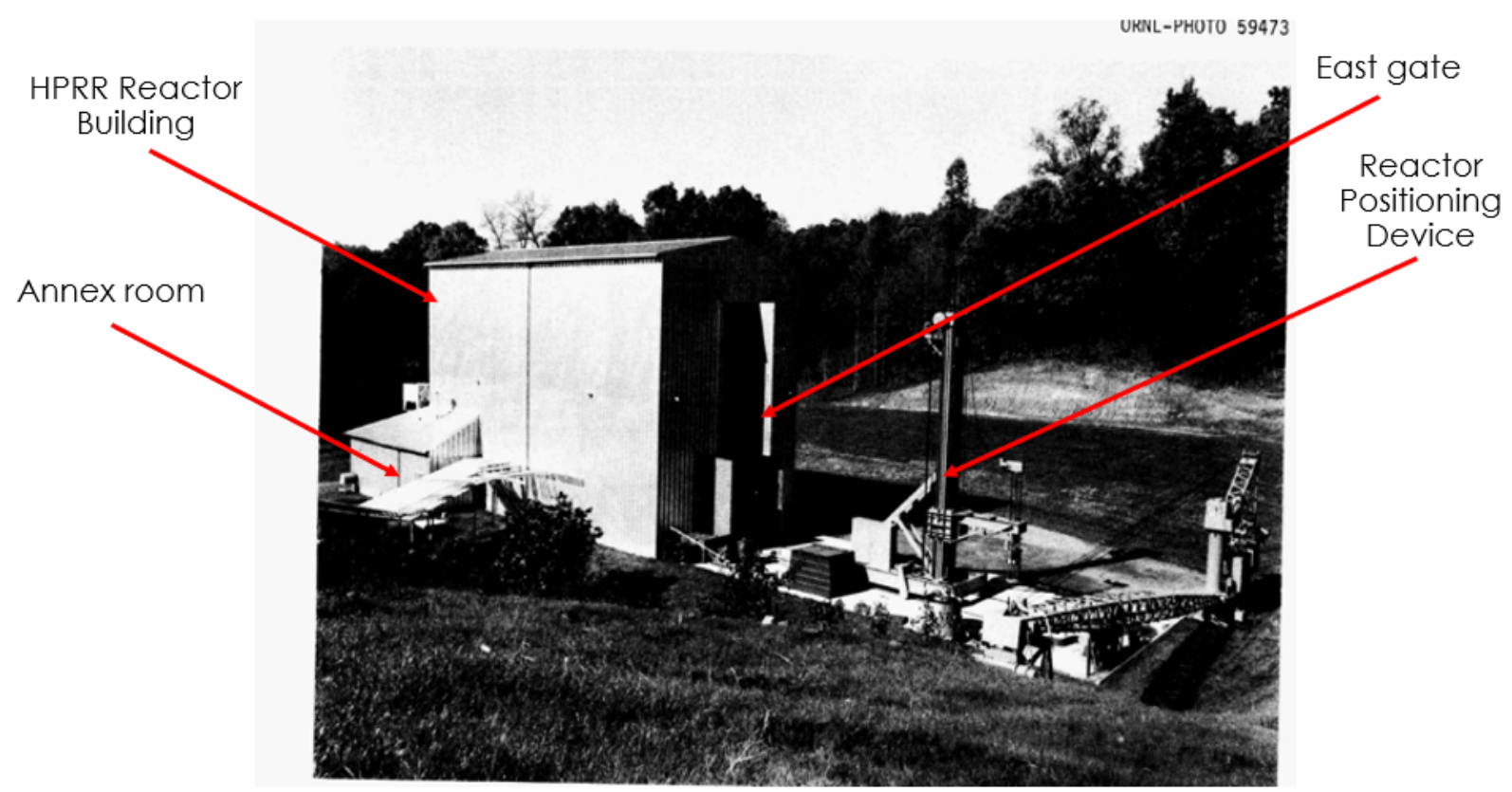

Figure 7. The HPRR reactor building [6].

\subsubsection{Sulfur pellets}

The sulfur pellets used for the experiments are described as standard commercial fuel pellets. According to ORNL-TM-230 [7], the pellets are cylinders of $3.8 \mathrm{~cm}$ diameter and $0.95 \mathrm{~cm}$ thick. The pellets are all positioned at a height of $140 \mathrm{~cm}$ from the concrete floor. No information about their orientation or the way they were held at a height of $140 \mathrm{~cm}$ has been found, but it is assumed that the cylinders were oriented on a west-east axis.

\subsubsection{Steel Shield}

The information about the steel shield is all contained in ORNL-6240 and is shown in Figure 8. The shield is formed by 3 cuboids of equal weight, $213 \mathrm{~cm}$ in height, and $13 \mathrm{~cm}$ in thickness. The angle subtended by the shield is $80^{\circ}$. The width of each of the 3 cuboids is not known, but it is estimated to be approximately $92 \mathrm{~cm}$ according to the other dimensions, weight, and density. The shield front face is placed $2 \mathrm{~m}$ from the HPRR centerline. The only picture of the shield found is shown in Figure 9, where the three blocks are apparent. 
Date of delivery to DOSAR 1967

Normal placement distance from the HPRR -....... $\mathrm{m}^{*}$

Number of pieces making up shield....................

Arc subtended by shield-180)

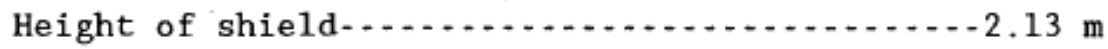

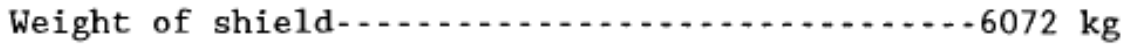

(3 - $2024 \mathrm{~kg}$ sections)

Shield neutron attenuation factors at $3 \mathrm{~m}$

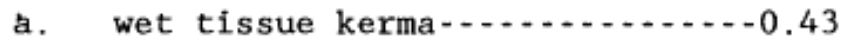

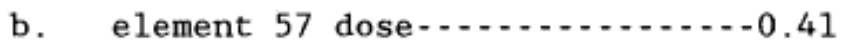

c. element 57 dose equivalent-1--0.44

d. ICRP 21 dose equivalent.......... 0.44

e. effective dose equivalent.....-0.41

f. fluence-1-20.5

Figure 8. Steel shield information [5]. 


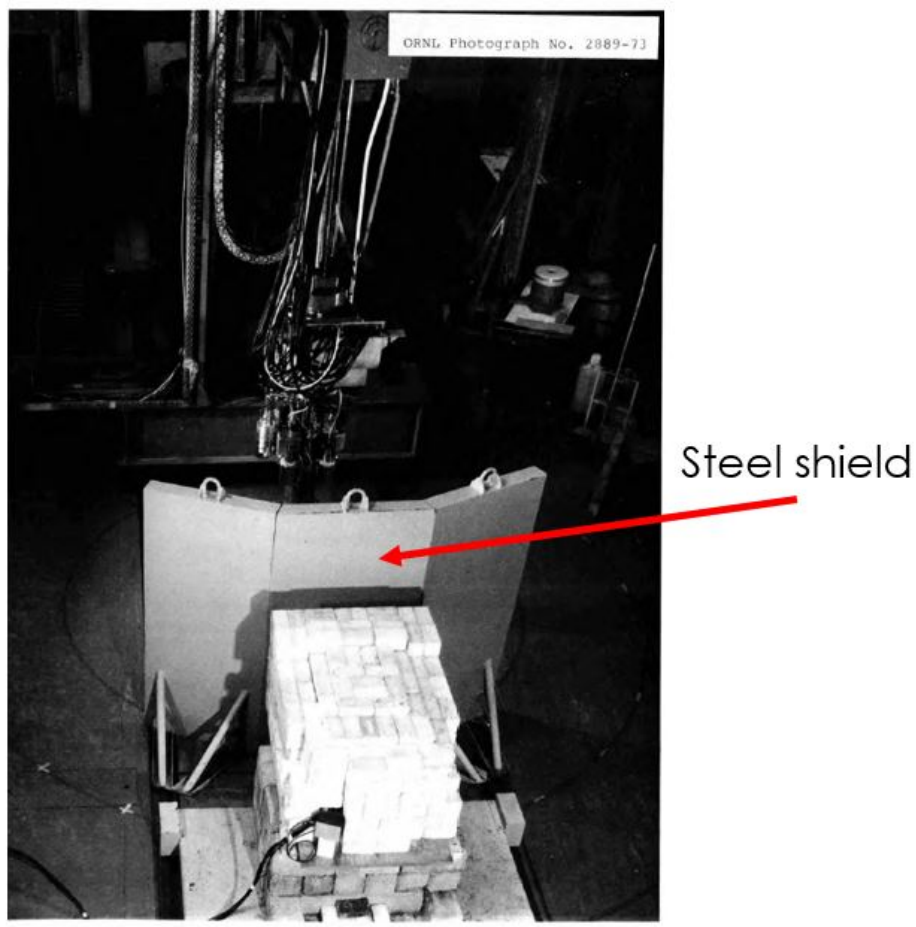

Figure 9. Picture of the steel shield [5].

\subsection{DESCRIPTION OF MATERIAL DATA}

The following subsections discuss the available materials information of the HPRR reactor building and components, including the building walls, floor, soil, etc. Overall, there is no detailed material data information available for the HPRR reactor building. The HPRR materials are described in Section 1.4.

\subsubsection{HPRR Reactor Building}

\subsubsection{Reactor and annex rooms}

The floor of the building and the east pad are made of concrete which is thought to correspond to the "Oak Ridge Concrete" material composition usually used in such calculations, designated as "orconcrete" in the SCALE 6.2 manual's "Alloys and mixtures" section [8], as shown in Table 3. The Oak Ridge concrete density is $2.2994 \mathrm{~g} / \mathrm{cm}^{3}$. No information has been found about the composition of the soil below the concrete and around the reactor pits. No measurement of pressure or humidity was made during the experiments, but information about the air temperature is available from the logbooks. 


\begin{tabular}{lc}
\multicolumn{2}{c}{$\begin{array}{c}\text { Table 3. Oak Ridge concrete } \\
\text { material composition }[8]\end{array}$} \\
\hline Element & $\begin{array}{c}\text { Weight } \\
\text { percent }\end{array}$ \\
\hline $\mathrm{Fe}$ & 0.7784 \\
$\mathrm{H}$ & 0.6187 \\
$\mathrm{C}$ & 17.52 \\
$\mathrm{O}$ & 41.02 \\
$\mathrm{Na}$ & 0.0271 \\
$\mathrm{Mg}$ & 3.265 \\
$\mathrm{Al}$ & 1.083 \\
$\mathrm{Si}$ & 3.448 \\
$\mathrm{~K}$ & 0.1138 \\
$\mathrm{Ca}$ & 32.13 \\
Density & $2.2994 \mathrm{~g} / \mathrm{cm}^{3}$ \\
\hline
\end{tabular}

\subsubsection{Building walls}

The HPRR reactor building walls are formed by one layer of structural steel and another layer of corrugated aluminum on the outside of the building which provides isolation. There is no detailed material composition available for the walls.

\subsubsection{Reactor storage pits}

The pit's interior is lined with Oak Ridge concrete, as detailed in Table 3. There is no information about the material composition of the top steel door, but it is thought to be 304 stainless steel. From ASTMA240 [9], the material composition is shown in Table 4.

\begin{tabular}{|c|c|}
\hline Element & Weight percent \\
\hline $\mathrm{C}$ & 0.07 \\
\hline $\mathrm{Si}$ & $<0.75$ \\
\hline $\mathrm{P}$ & 0.045 \\
\hline $\mathrm{Cr}$ & $17.5-19.5$ \\
\hline $\mathrm{Mn}$ & $<2$ \\
\hline $\mathrm{Fe}$ & Balance \\
\hline $\mathrm{Ni}$ & $8-10.5$ \\
\hline Density & $7.94 \mathrm{~g} / \mathrm{cm}^{3}$ \\
\hline
\end{tabular}

\subsubsection{Gates and door}

No material information about any gate or door is available. It is thought to be 304 stainless steel as described in Table 4.

\subsubsection{Catwalk}

No material information about the catwalk is available. It is thought to be 304 stainless steel as described in Table 4. 


\subsubsection{Crane}

No material information about the crane is available. It is thought to be 304 stainless steel as described in Table 4.

\subsubsection{Hydraulic lift}

No material information about the hydraulic lift is available. It is thought to be 304 stainless steel as described in Table 4.

\subsubsection{Reactor positioning device}

No material information about the reactor positioning device is available. It is estimated to be stainless steel as described in Table 4.

\subsubsection{Concrete pad}

The concrete pad is estimated to be Oak Ridge concrete as described in Table 3.

\subsubsection{Sulfur pellets}

From ORNL-TM_6240 [5], the pellets' weight is $22 \mathrm{~g}$. No information about the material composition has been found, but knowing the dimensions and the mass, the calculated density would be $2.04 \mathrm{~g} / \mathrm{cm}^{3}$, which is close to the natural sulfur density of $2.07 \mathrm{~g} / \mathrm{cm}^{3}$. Therefore, it is probable that the pellets' isotopic composition corresponds to that of natural sulfur.

\subsubsection{Steel Shield}

No precise information about the steel shield material composition has been found, but considering that most of the steel components of the reactor are 304 stainless steel, which was widely used at the time of the experiments, the steel shield is considered to be 304 stainless steel from ASTME [9] as described previously in Table 4.

\subsection{DESCRIPTION OF THE SOURCE}

The HPRR is essentially a right circular annulus consisting of 11 nickel-coated highly enriched uranium $\left(93.14 \%{ }^{235} \mathrm{U}\right)$ and molybdenum alloy plates. The alloy composition is 10 weight percent molybdenum and 90 weight percent uranium. The critical assembly is approximately $23 \mathrm{~cm}$ high and $20 \mathrm{~cm}$ in diameter. Aside from the 11 annuli, the critical assembly is formed by many other elements. A safety block is placed at the center of the annuli. The safety block is another U-Mo annulus with a stainless-steel cylinder in its center, known as the center plug. This plug is ejected down after burst operations of the HPRR. To hold the annuli together and to adjust the quantity of fuel in the core, 9 U-Mo hollow bolts and bolt plugs are threaded into the bottom annulus. The U-Mo plugs can be replaced with 304 stainless-steel inserts. A sample irradiation hole goes through the 11 annuli and can be filled with U-Mo or plugs made of other materials or of different lengths. Three control rods are used to adjust the total fission yield expected during a burst and to start the burst during pulse operation of the HPRR. The control rods are UMo cylinders of different diameters, known as the mass adjustment rod (MAR), the regulating rod (RR) and the burst rod (BR). Other non-U-Mo components of the assembly can be noted. Two thermocouples are inserted inside two of the annuli and are used to monitor the temperature increase during operation, removing a few grams of U-Mo from the critical assembly. The U-Mo bolts are hooked onto the 
mounting bracket, which is a stainless-steel plate located on top of the critical assembly. An aluminum safety grid cage is placed around the HPRR. A safety tube is placed below the HPRR to hold the safety block when it falls after burst operation. Finally, the control rod mechanisms, starting source, and other devices are all placed on top of the mounting bracket and are referred to herein as the superstructure. The dimensions of these elements are discussed in the following subsections. The inventory of the U-Mo parts is shown in Figure 10 and Figure 11 from ORNL-9870 [6]. Drawings and pictures of the HPRR are shown in Figure 12, Figure 13 and Figure 14. Figure 14 was a key resource that provided the drawing numbers of all the important parts of the core. 
Table 2.1. Inventory of uranium in August 1985

\begin{tabular}{|c|c|c|c|}
\hline Component & $\begin{array}{c}\text { Drawing } \\
\text { No. } \\
\end{array}$ & $\begin{array}{l}\text { Process } \\
\text { batch No. }\end{array}$ & $\begin{array}{l}\text { Wejght } 0 \\
\mathrm{U}^{235}(\mathrm{~g})\end{array}$ \\
\hline \multicolumn{4}{|c|}{ Inventory of fully loaded core No. 1} \\
\hline \multicolumn{4}{|l|}{$\begin{array}{l}\text { Disksa } \\
\text { No. } 1,3 / 16 \text { in. thick } \\
\text { No. } 2,15 / 16 \text { in. thick } \\
\text { No. } 3,7 / 16 \text { in. thick } \\
\text { No. } 4,7 / 16 \text { in. thick } \\
\text { No. } 5,15 / 16 \text { in. thick } \\
\text { No. } 6,15 / 16 \text { in. thick } \\
\text { No. } 7,1 \text { in. thick } \\
\text { No. } 8,15 / 16 \text { in. thick } \\
\text { No. } 9,15 / 16 \text { in. thick } \\
\text { No. } 10,15 / 16 \text { in. thick } \\
\text { No. } 11,1 \text { in. thick }\end{array}$} \\
\hline Bolts (nine) & -12076 & $\begin{array}{l}-1503 \text { thru }-1508 \\
-1524 \text { thru }-1526\end{array}$ & 8,590 \\
\hline Bolt inserts (nine) & -12077 & $\begin{array}{l}-1512 \text { thru }-1519 \\
\text { and }-1533\end{array}$ & 1,005 \\
\hline Mass adjustment rod & -12078 & -1521 & 994 \\
\hline Burst rod & -12078 & -1523 & 899 \\
\hline Regulating rod & -12078 & -1522 & 613 \\
\hline $\begin{array}{c}\text { Sample-irradiation-hole } \\
\text { plug, } 81 / 4 \mathrm{in.} \text { long }\end{array}$ & -12080 & -1578 & 105 \\
\hline Safety block & -12074 & -1531 & $\frac{9,416}{95,890}$ \\
\hline \multicolumn{4}{|c|}{ Inventory of spare parts and samples } \\
\hline $\begin{array}{l}\text { Sample-irradiation-hole pluc } \\
9.06 \text { in. long (one) } \\
4.53 \text { in. long (one) } \\
9.06 \text { in. long (one) }\end{array}$ & $\begin{array}{r}\text { NDA-12080d } \\
-12080^{d} \\
-12080^{d}\end{array}$ & $\begin{array}{r}883-1594 \\
-1598\end{array}$ & $\begin{array}{r}121 \\
63 \\
121\end{array}$ \\
\hline Bolts (three) & $\begin{array}{l}-12076 \\
-12076 \\
-12076\end{array}$ & $\begin{array}{l}-1819 \\
-1821 \\
-1832\end{array}$ & $\begin{array}{l}959 \\
958 \\
959\end{array}$ \\
\hline
\end{tabular}

Figure 10. HPRR uranium inventory, part 1 [6]. 
Table 2.1. Continued

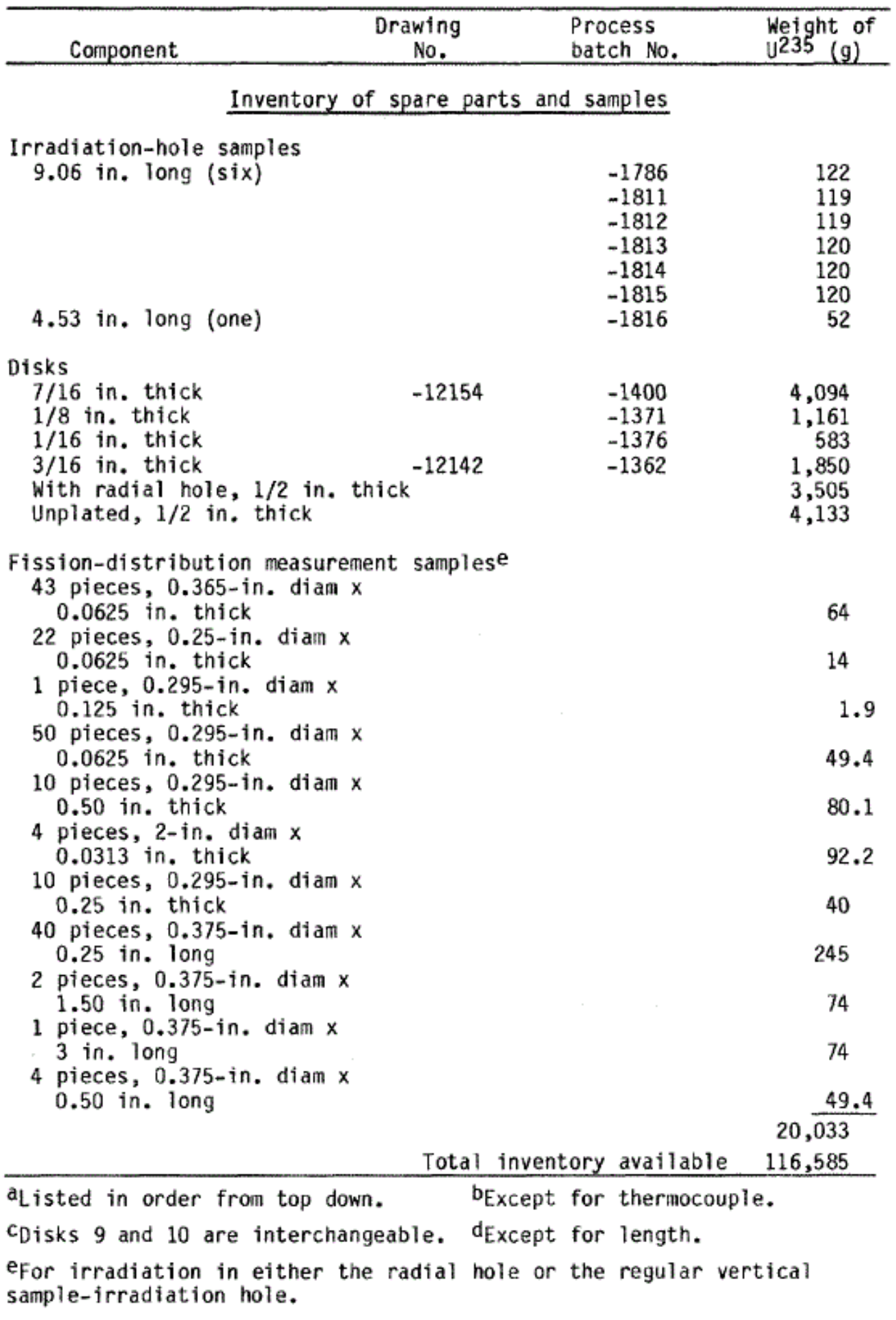

Figure 11. HPRR uranium inventory, part 2 [6]. 


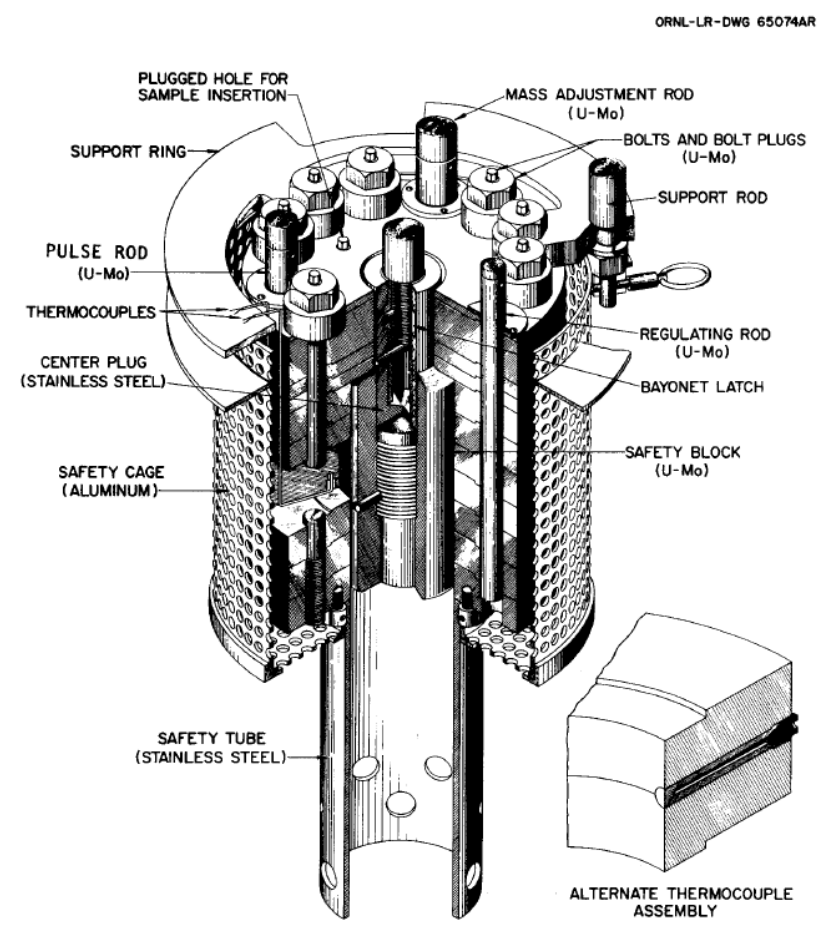

Figure 12. HPRR drawing [6].

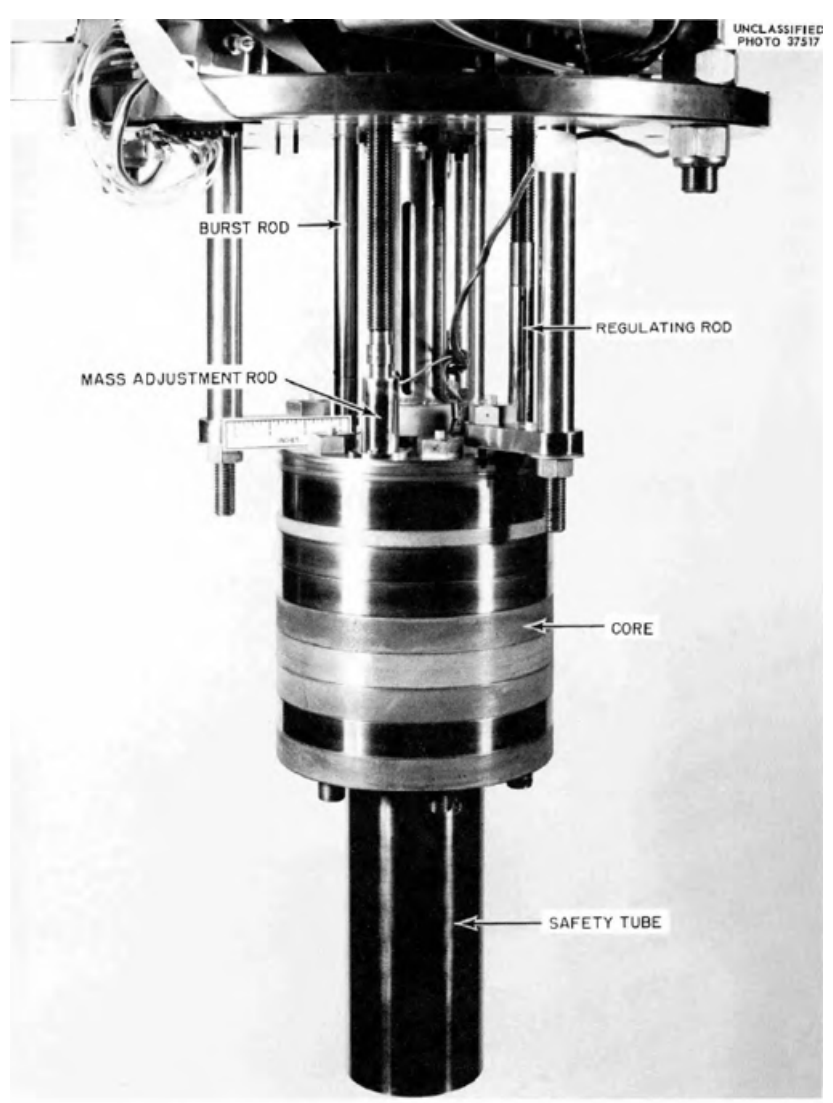

Figure 13. Photo of HPRR without aluminum safety cage [6]. 


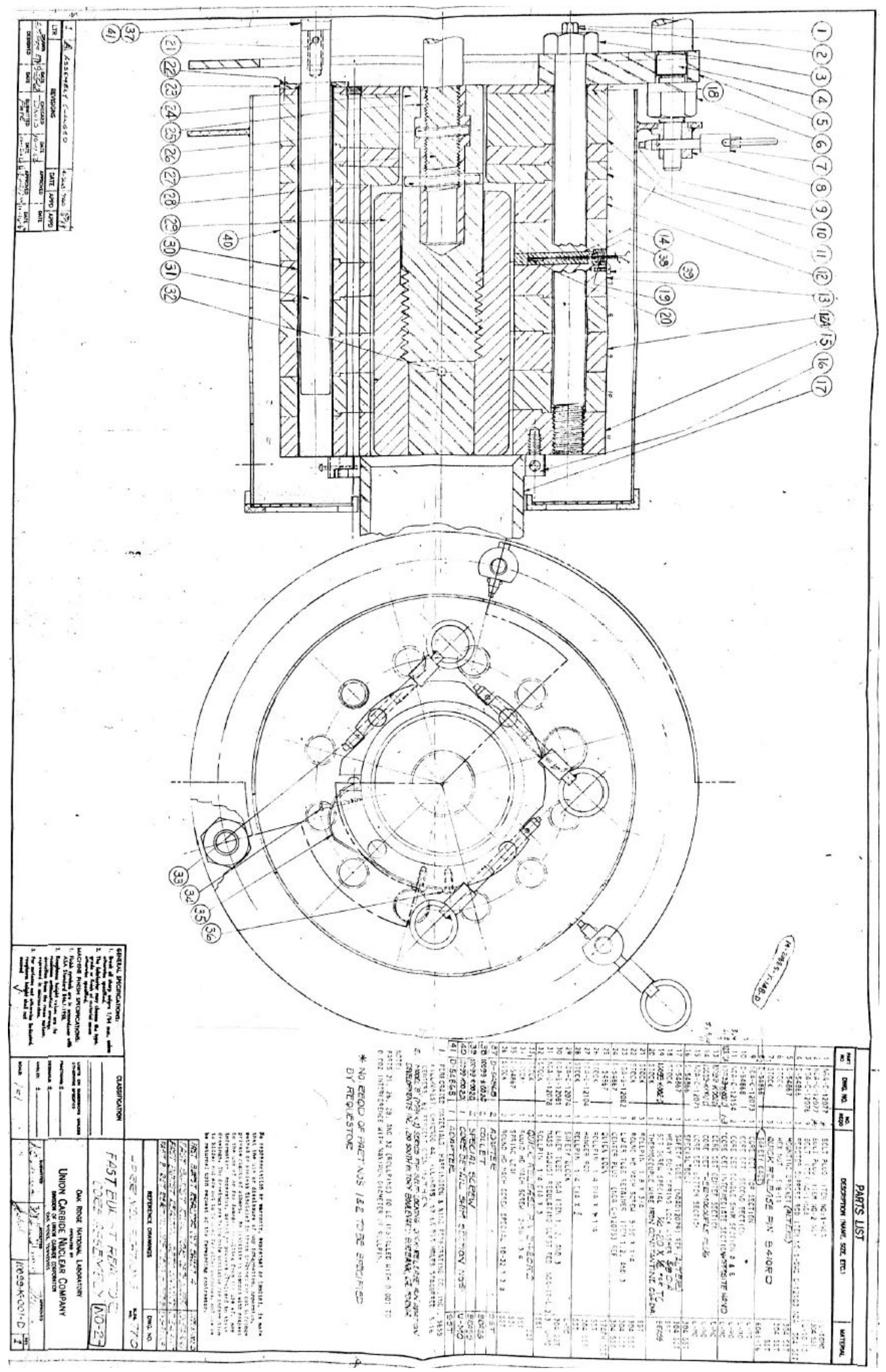

Figure 14. HPRR overview (Drawing 10099-K-001-D). 


\subsubsection{HPRR Dimensions}

\subsubsection{Coating}

Before providing detailed descriptions of the core elements, the fuel coating information is presented here. Based on various drawings and written sources, all the U-Mo elements were coated with nickel for oxidation protection, including all drilled holes. The coating thickness is not precisely known; it is described as between 0.001 in. $(0.00254 \mathrm{~cm})$ and 0.005 in. $(0.0127 \mathrm{~cm})$. Additionally, the three control rods, MAR, RR, and BR, along with the safety block and the bolt threads, have been chromium-plated over the nickel plating to reduce sliding friction, and the bolt threads are over-coated with a third layer of gold [6] to reduce galling. Because the coating thicknesses of the chromium and gold are unknown, they will be assumed to be $0.001 \mathrm{in} .(0.00254 \mathrm{~cm})$. Since the critical assembly was decommissioned, it is impossible to measure the thicknesses of any of the coatings. All the dimensions given in Section 1.4.1 do not include coating.

\subsubsection{U-Mo annuli}

The dimensions of the 11 annuli were found in various drawings. The annulus numbering convention used in Figure 14 is maintained in this report, with the annuli numbered 11 to 1 from bottom to top. The 11 annuli are similar, with different thicknesses and slight geometry differences. Each annulus is described individually, but the dimensions are not repeated if they are the same as previous ones. Note that when assembled, the annuli are concentric and stacked on top of each other, but they do not stack perfectly, as narrow spaces exist between them. Additionally, none of the corners or edges are flat, and a curve radius is shown in the drawings.

\section{Annulus 11: Bottom Section}

Annulus 11, which is the bottom section, is shown in the drawing provided in Figure 15. The outside diameter measures 8 in. $(20.32 \mathrm{~cm})$, and the inside diameter is $3.531 \mathrm{in} .(8.96874 \mathrm{~cm})$. The bottom of the center hole edge has a curve radius of $0.25 \mathrm{in} .(0.635 \mathrm{~cm})$. The top of the center hole edge and the outside top and bottom edges of the annulus have a curve radius of $0.032 \mathrm{in.}(0.08128 \mathrm{~cm})$. None of the annuli are perfectly flat, as they all contain inner and/or outer protrusions on the top and/or bottom. The total thickness of annulus 11, including the protrusion, is $1 \mathrm{in} .(2.54 \mathrm{~cm})$, and the protrusion is in the inner part of the annulus and is $0.060 \mathrm{in} .(0.1524 \mathrm{~cm})$ thick. Therefore, the outer thickness without the protrusion is 0.94 in. $(2.3876 \mathrm{~cm})$. The protrusion diameter is $4.991 \mathrm{in} .(12.67714 \mathrm{~cm})$. The curve radius between the protrusion and the regular annulus is $0.015 \mathrm{in} .(0.0381 \mathrm{~cm})$. Each annulus is drilled through with at least 9 holes for the bolts, 3 holes for the control rods, and a hole for the sample irradiation plug. The bolt hole diameter is $0.8 \mathrm{in} .(2.032 \mathrm{~cm})$, the MAR hole diameter is $1.094 \mathrm{in} .(2.77876 \mathrm{~cm})$, the RR hole diameter is 0.719 in. $(1.82626 \mathrm{~cm})$, the BR hole diameter is $0.859 \mathrm{in} .(2.18186 \mathrm{~cm})$, and the sample irradiation hole plug is 0.313 in. $(0.79502 \mathrm{~cm})$. The 12 holes for the 9 bolts and 3 control rods holes are drilled on a circle with a radius of $3.125 \mathrm{in} .(7.9375 \mathrm{~cm})$ which is centered on the annulus, equally spaced. A pattern of 3 bolt holes and 1 control rod hole is followed. Considering an $\mathrm{x}-\mathrm{y}$ coordinate system from Figure 15 with 0 at the annulus center, the sample irradiation hole is drilled $2.21 \mathrm{in}$. $(5.6134 \mathrm{~cm})$ from the annulus center at a location 1.563 in. $(3.97002 \mathrm{~cm})$ away in the $-x$ and $-y$ direction. Since Annulus 11 is at the bottom of the critical assembly, it has 4 more holes than the other annuli, which are used to hook the annulus to the bottom safety tube with so-called special bolts. The dimensions of the holes for the special bolts are shown in Figure 15, but the quality of the drawing makes it difficult to discern the thread counts and diameter. It is assumed that the hole diameter is $0.3125 \mathrm{in} .(0.79375 \mathrm{~cm})$ and that the holes are drilled $5.83406 \mathrm{~cm}$ from the annulus center, equally spaced in all 4 directions $(x=5.83406 \mathrm{~cm},-x=5.83406 \mathrm{~cm}$, $\mathrm{y}=5.83406 \mathrm{~cm}, \mathrm{y}=-5.83406 \mathrm{~cm}$ on an $\mathrm{x}-\mathrm{y}$ coordinate system). The 4 holes are not drilled through; they start from the bottom of the annulus and are 0.5 in. $(0.127 \mathrm{~cm})$ deep. 


\section{Annulus 10: Intermediate Section 1}

Annulus 10, or intermediate section 1, is shown on the left of the drawing presented in Figure 16. A lot of information can be gleaned from this drawing, including the dimensions of annuli 5-10 and the thermocouple apparatus. Annulus 11 is similar to Annulus 10, with the difference of having two protrusions: an outer protrusion on the bottom and an inner protrusion on the top. The top inner protrusion diameter is 5 in. $(12.7 \mathrm{~cm})$ and the thickness is 0.066 in. $(0.16764 \mathrm{~cm})$. The bottom outer protrusion diameter is $4.991 \mathrm{in}$. $(12.67714 \mathrm{~cm})$, and the thickness is $0.060 \mathrm{in} .(0.1524 \mathrm{~cm})$. The total thickness of the annulus with protrusions is 1 in. $(2.54 \mathrm{~cm})$, or 0.874 in. $(2.21996 \mathrm{~cm})$ without protrusions. The only difference in curve radius from Annulus 11 is that the bottom of the center hole becomes the same as the top at $0.032 \mathrm{in} .(0.08128 \mathrm{~cm})$. The curve radius of the bottom protrusion is the same as the top protrusion, as in Annulus 11 and is 0.015 in. $(0.0381 \mathrm{~cm})$. The diameters and positions of the 13 holes in the annulus previously described ( 9 bolts, 3 control rods, 1 sample irradiation) are the same as in Annulus 11, and there are no special bolt holes or other holes in the annulus.

\section{Annulus 9: Intermediate Section 2}

Annulus 9, or intermediate section 2, is the same as Annulus 10 and is shown in Figure 16 on the left side of the drawing.

\section{Annulus 8: Intermediate Section 3}

Annulus 8, or intermediate section 3, is the same as Annulus 9 and Annulus 10 and is shown in Figure 16 on the left side of the drawing.

\section{Annulus 7: Center Section}

Annulus 7, or center section, is shown in Figure 16 on the right side of the drawing. Annulus 7 has two peculiarities: both the top and bottom protrusions are outer protrusions and are $0.066 \mathrm{in} .(0.16764 \mathrm{~cm})$ thick and 5 in. $(12.7 \mathrm{~cm})$ in diameter. Parts of the annulus are drilled to make room for two U-Mo thermocouple plugs to house the two thermocouples. Each thermocouple plug is inserted into the annulus radially, half in annulus 7 and the other half in annulus 6 . The thermocouple plug holes are drilled through the annulus radially, and they include an outer part on the outside of the annulus which is $0.431 \mathrm{in}$. $(1.09474 \mathrm{~cm})$ in diameter and $0.375 \mathrm{in} .(0.9525 \mathrm{~cm})$ deep and an inner part on the inside of the annulus which is $0.3 \mathrm{in} .(0.762 \mathrm{~cm})$ in diameter and $1.85938 \mathrm{in} .(4.72281 \mathrm{~cm})$ deep. The holes are positioned $15^{\circ}$ and $105^{\circ}$ from the $\mathrm{x}$ axis clockwise. The thermocouples, thermocouple plugs, and apparatus will be described in greater detail in Section 1.4.1.8.

\section{Annulus 6: Intermediate Section 4}

Annulus 6, or intermediate section 4, is shown in Figure 17 in the middle of the drawing. Annulus 6 is of same shape as the annuli/intermediate sections 1-3, with the top and bottom protrusions mirrored: the top outer protrusion diameter is $5 \mathrm{in} .(12.7 \mathrm{~cm})$ and its thickness is $0.066 \mathrm{in} .(0.16764 \mathrm{~cm})$ and the bottom inner protrusion diameter is $4.991 \mathrm{in} .(12.67714 \mathrm{~cm})$ and its thickness is $0.060 \mathrm{in}$. $(0.1524 \mathrm{~cm})$. Annulus 6 also contains the second half of the thermocouple plug holes.

\section{Annulus 5: Intermediate Section 5}

Annulus 5, or intermediate section 5, is shown in Figure 16 on the left side of the drawing. Annulus 5 is the same as annulus 6 without the thermocouple plug holes. 


\section{Annulus 4: Shim Section 1}

Annulus 4, or shim section 1, is shown in Figure 17. Annulus 4 is of similar shape as annulus 5, except the total annulus thickness, including the protrusions, is $0.5 \mathrm{in} .(1.27 \mathrm{~cm})$ and the central hole diameter is 2.156 in. $(5.47624 \mathrm{~cm})$.

\section{Annulus 3: Shim Section 2}

Annulus 3, or shim section 2, is the same as Annulus 4 and is shown in Figure 17.

\section{Annulus 2: Second Section}

Annulus 2, or the second section, is shown in Figure 18. Annulus 2 is of the same shape as Annulus 4 and 3 , except the total annulus thickness, including the protrusions, is $1.372 \mathrm{in} .(3.48488 \mathrm{~cm})$ and the top outer protrusion thickness is 0.064 in. $(0.16256 \mathrm{~cm})$.

\section{Annulus 1: Top Section}

Annulus 1, or the top section, is shown in Figure 19. Annulus 1 is the mirrored shape of Annulus 11. The top of the annulus is flat and the bottom inner protrusion thickness is $0.06 \mathrm{in} .(0.1524 \mathrm{~cm})$ and the diameter is 4.991 in. $(12.67714 \mathrm{~cm})$. Annulus 1 is 0.25 in. $(0.635 \mathrm{~cm})$ thick, including the bottom protrusion. Additionally, nine holes ( 3 holes per control rod) are drilled through annulus 1 and are used to attach the top section to the control rod tube retainers with screws. The holes are approximately $0.11 \mathrm{in}$. $(0.2794 \mathrm{~cm})$ in diameter and are equally spaced around each control rod hole, $0.71875 \mathrm{in} .(1.82563 \mathrm{~cm})$ from each control rod hole center. 


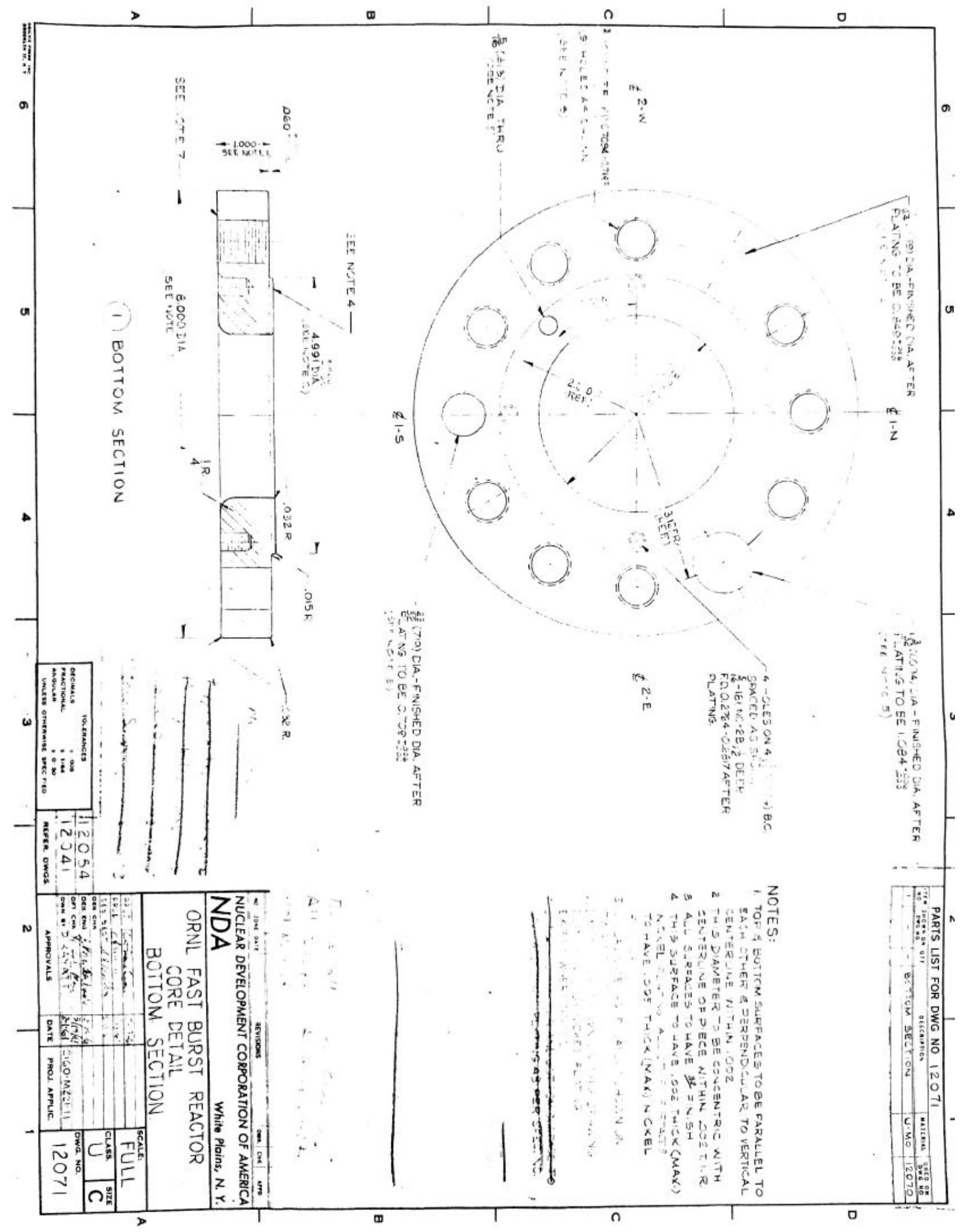

Figure 15. HPRR Annulus 11 (Drawing 12071). 


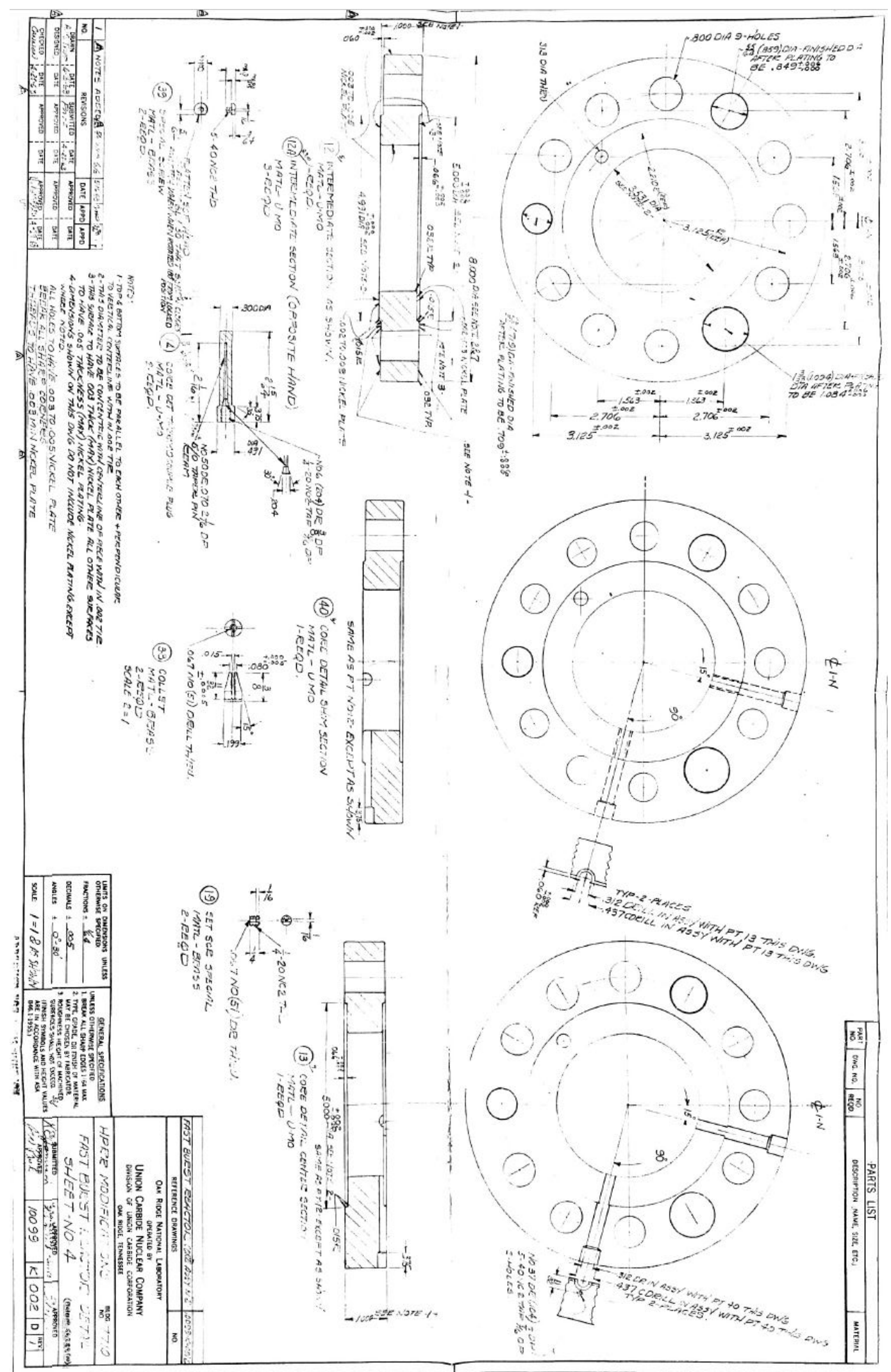

Figure 16. HPRR Annuli 10-5 and thermocouples (Drawing 10099-K-002-D). 


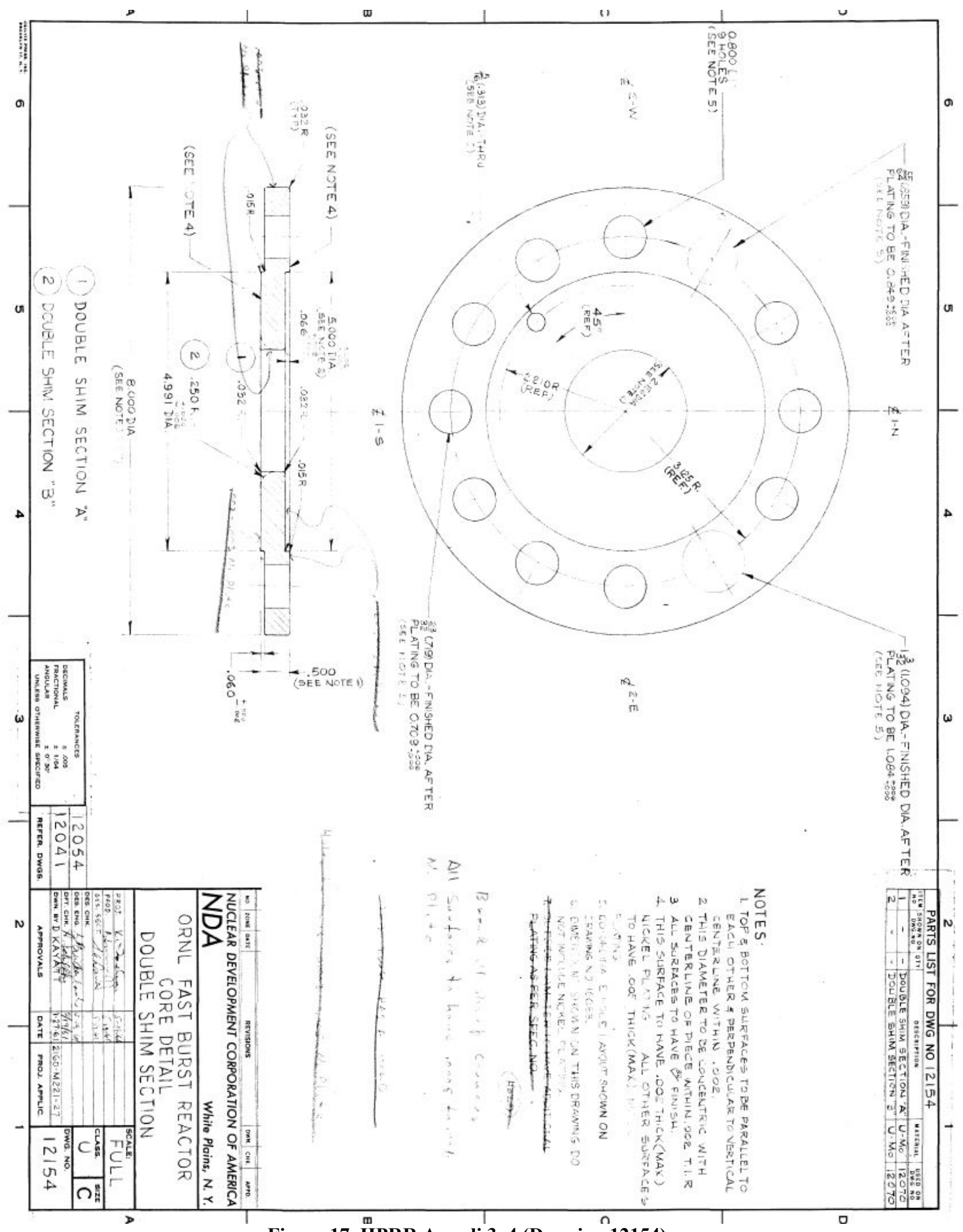

Figure 17. HPRR Annuli 3-4 (Drawing 12154). 


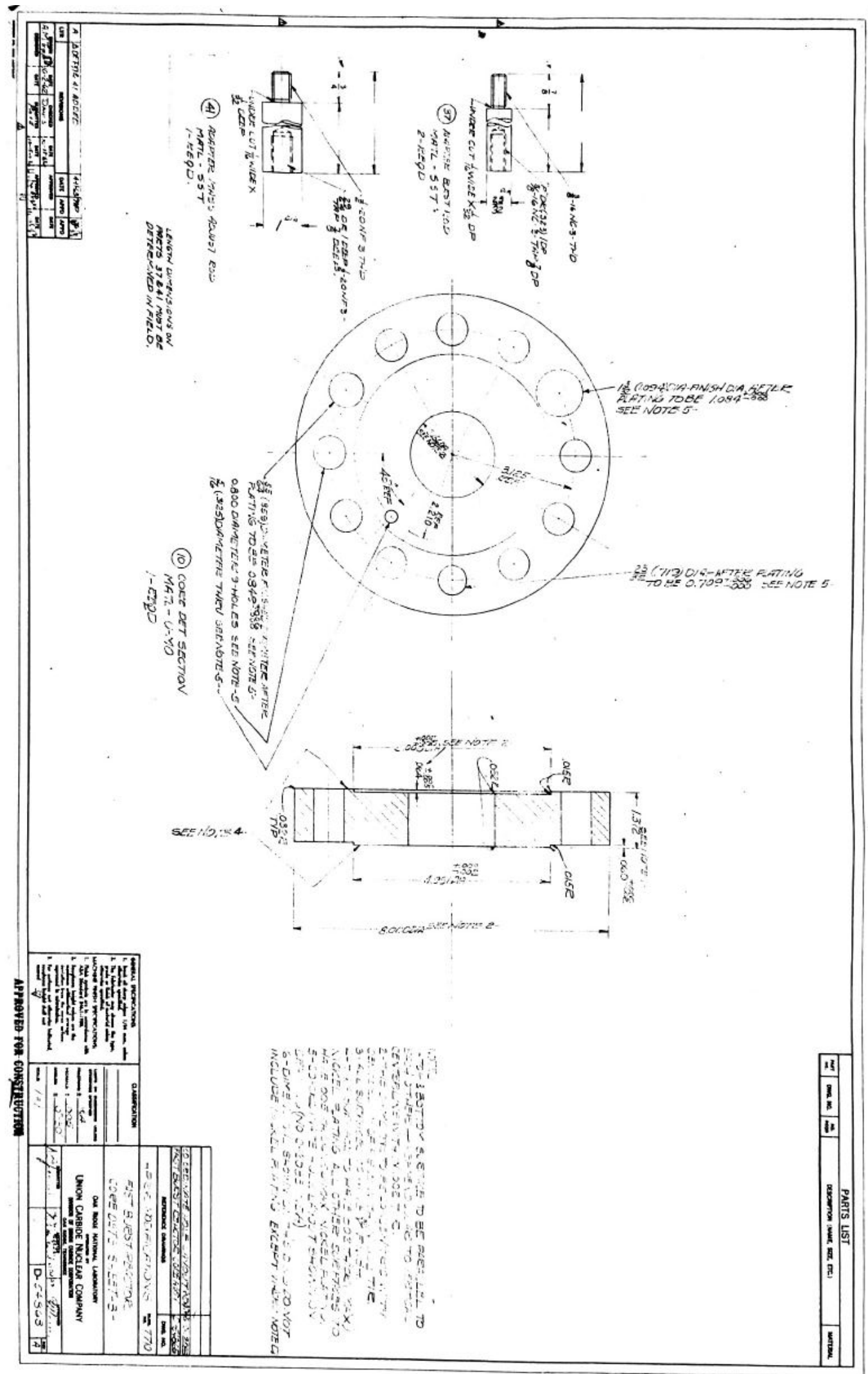

Figure 18. HPRR Annulus 2 (Drawing D-54868). 


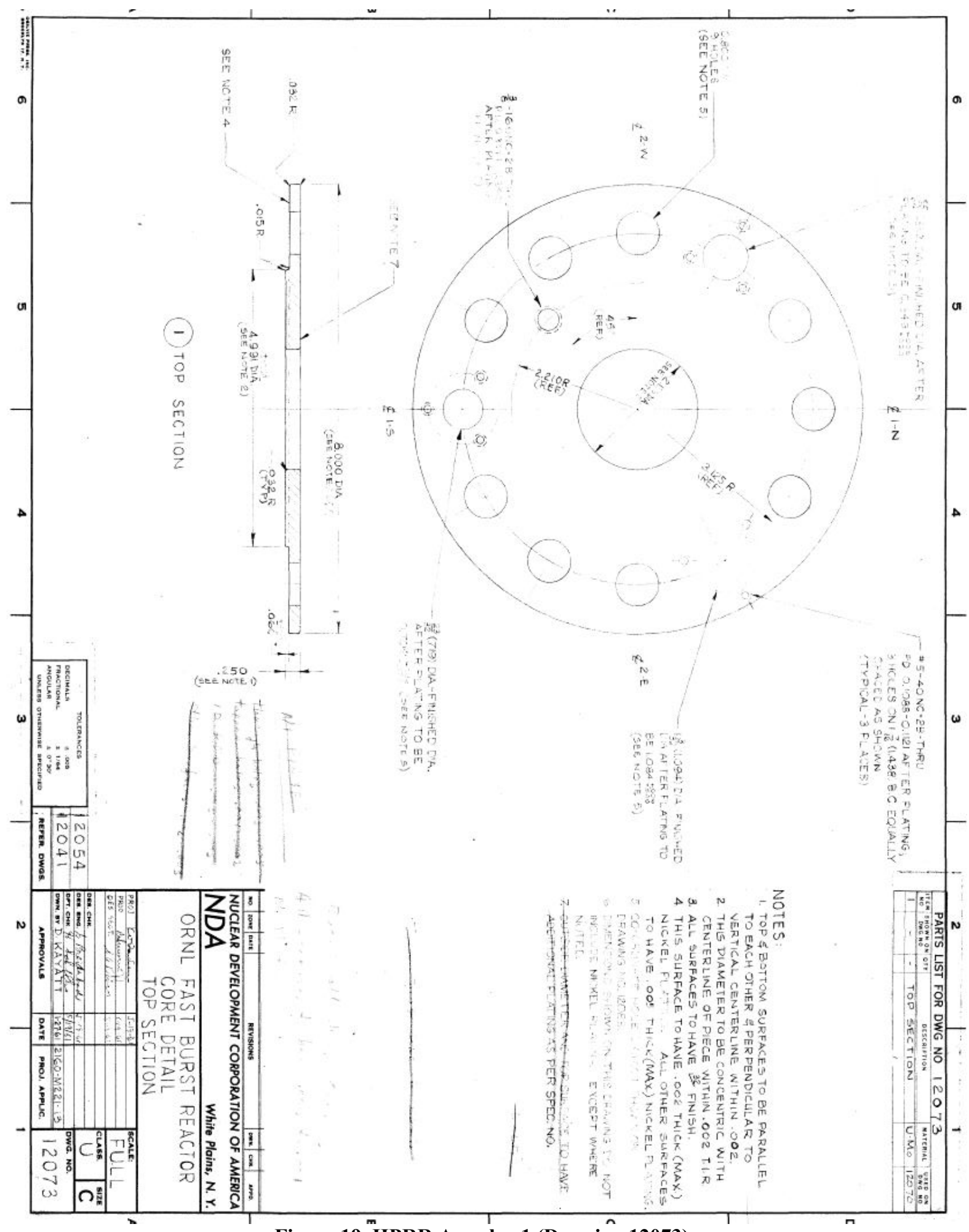

Figure 19. HPRR Annulus 1 (Drawing 12073). 


\subsubsection{Safety block}

\section{U-Mo Annulus}

The U-Mo part of the safety block is shown in Figure 20. It is another annulus with an outside diameter of $3.375 \mathrm{in} .(8.5725 \mathrm{~cm})$ and a height of $6.5 \mathrm{in} .(16.51 \mathrm{~cm})$ with 3 different inside diameters depending on the height. On the lower 2.25 in. $(5.715 \mathrm{~cm})$ section of the safety block, the inside diameter is 1.656 in. $(4.20624 \mathrm{~cm})$. On the middle 2 in. $(5.08 \mathrm{~cm})$ section, the inside diameter is between $1.781 \mathrm{in} .(4.52374$ $\mathrm{cm})$ without threading and $1.85 \mathrm{in} .(4.699 \mathrm{~cm})$ with threading. On the top $2.25 \mathrm{in} .(5.715 \mathrm{~cm})$, the inside diameter is $2.031 \mathrm{in} .(5.15874 \mathrm{~cm})$. The curve radius of the top and bottom outer edges of the safety block is $0.25 \mathrm{in} .(0.635 \mathrm{~cm})$, and the curve radius of the top and bottom inner edges is $0.032 \mathrm{in} .(0.08128 \mathrm{~cm})$. 


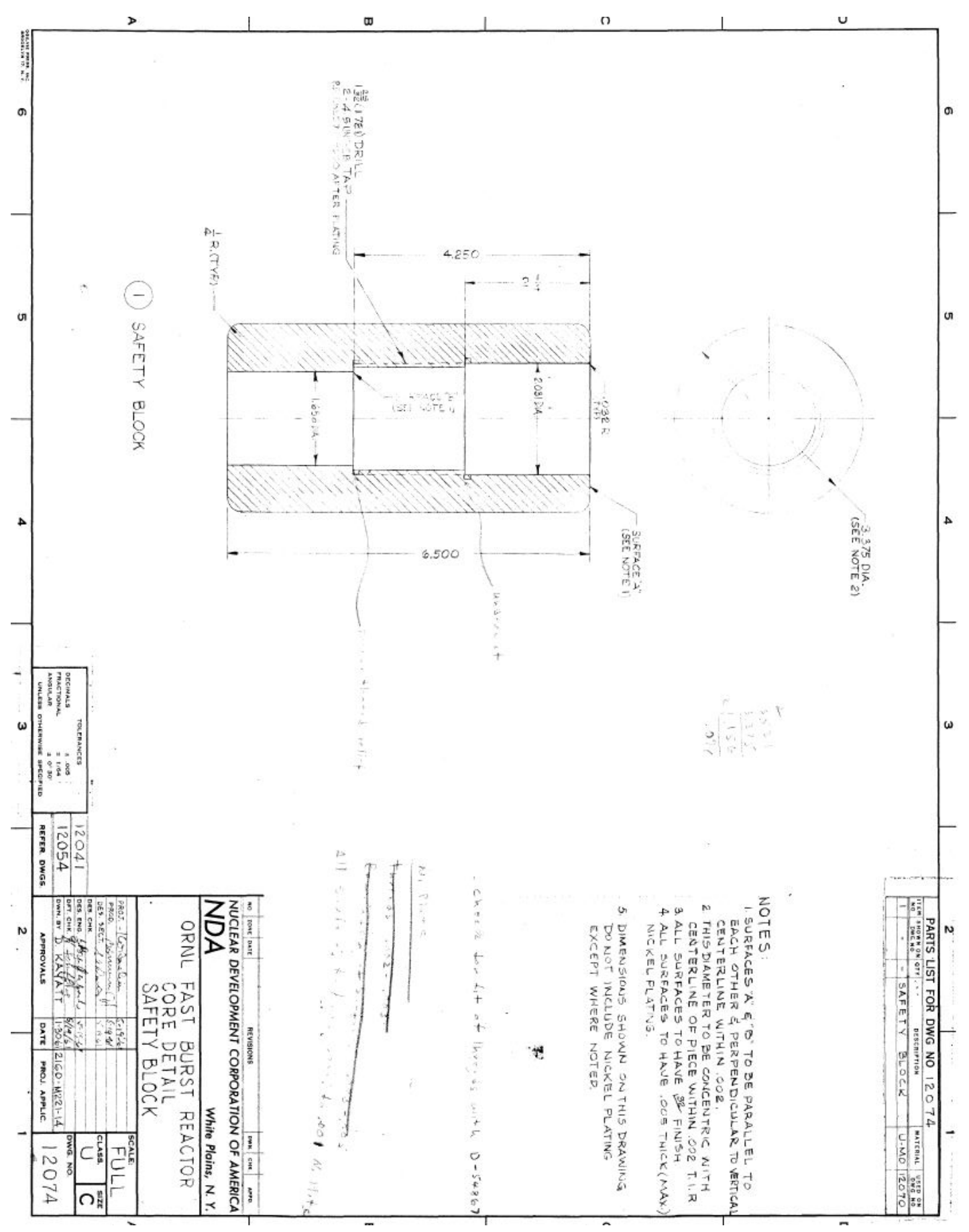

Figure 20. HPRR U-Mo safety block (Drawing 12074).

\section{Center Plug and Quick Lock}

The center plug and quick lock are both shown in Figure 21. They are used to secure the U-Mo part of the safety block to the superstructure during reactor operation. The center plug is basically a hollow 304 stainless steel cylinder in which the 17-4 PH stainless steel cylinder quick lock is inserted. The central 304 stainless steel hanger rod is also inserted into the quick lock, and the 3 pieces are secured to the superstructure. The center plug and quick lock geometries are complex, so only the main components are detailed here. More details on the dimensions are provided in Figure 21. The center plug is 9.06 in. 
$(23.0124 \mathrm{~cm})$ long and has a varying outside diameter depending on the height matching the U-Mo safety block diameters. The lower 2.25 in. $(5.715 \mathrm{~cm})$ section of the center plug outside diameter is 1.625 in. $(4.20624 \mathrm{~cm})$. The middle 2.25 in. $(5.715 \mathrm{~cm})$ section outside diameter is threaded and is about 1.85 in. $(4.699 \mathrm{~cm})$, matching the U-Mo safety block. The top 4.56 in. $(11.5824 \mathrm{~cm})$ section outside diameter is 2 in. $(5.08 \mathrm{~cm})$, with a protrusion around the top of the plug. Simplifying the geometry, a hole of approximately $1.125 \mathrm{in}$. $(2.8575 \mathrm{~cm})$ is drilled from the top of the plug to a depth of $3.9375 \mathrm{in}$. $(10.00125$ $\mathrm{cm})$ to allow for insertion of the quick lock. The quick lock outside diameter matches the center plug top hole diameter and is around $1.125 \mathrm{in} .(2.8575 \mathrm{~cm})$ and the length is $3.875 \mathrm{in} .(9.8425 \mathrm{~cm})$. The quick lock is drilled through with a hole of 0.814 in. $(2.06756 \mathrm{~cm})$ diameter to lock the central hanger rod. 


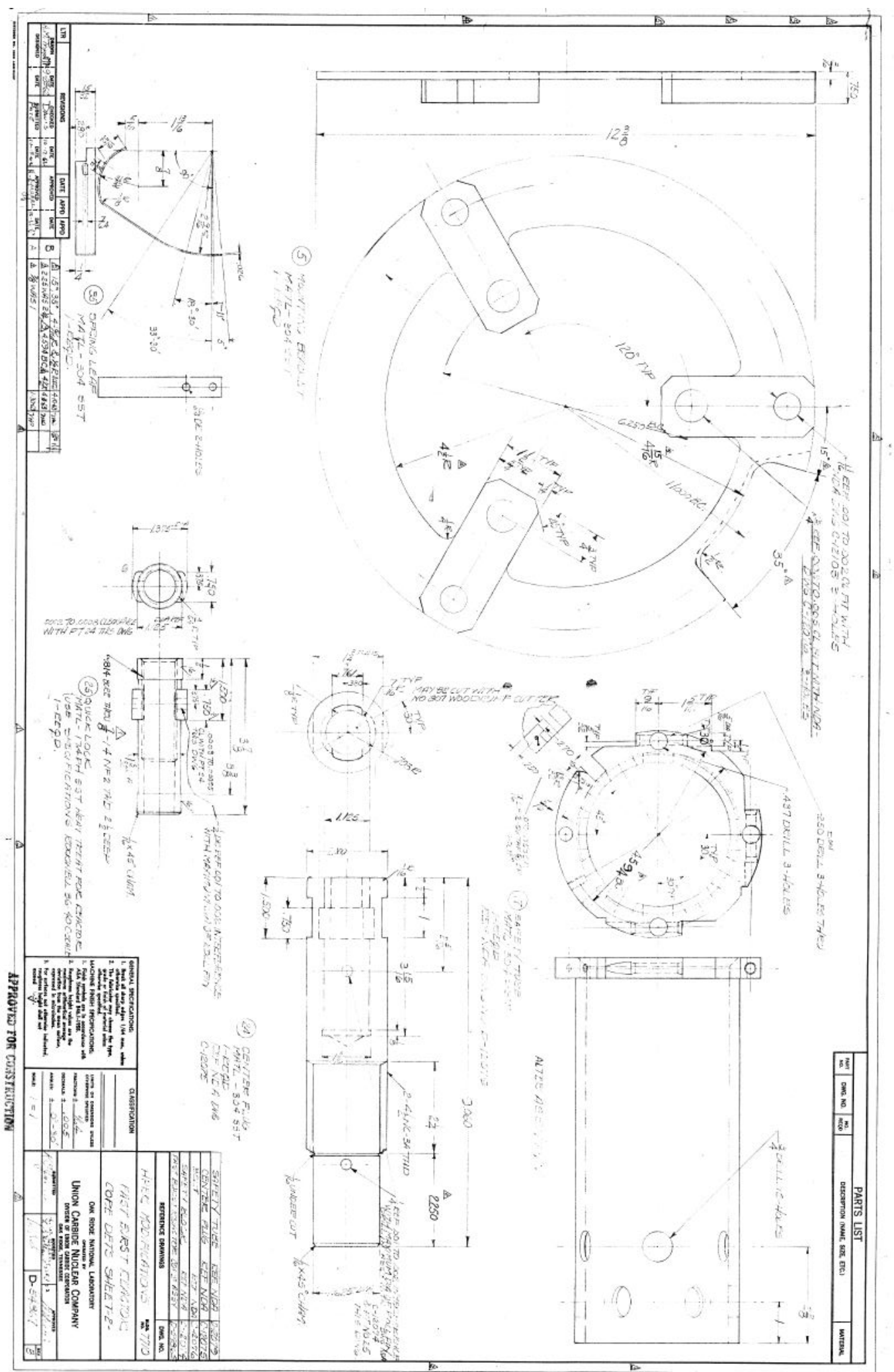

Figure 21. HPRR center plug, quick lock, mounting bracket, and safety tube (Drawing D-54867). 


\subsubsection{U-Mo bolts}

The U-Mo bolt drawing is shown in Figure 22. The 9 U-Mo bolts were inserted through the 11 annuli and threaded to the lower annuli, thus locking them together. Three of the bolts were also inserted through the mounting bracket, securing the core to the superstructure from above. The bolts are basically hollow UMo cylinders with hexagonal heads. The bolts are $10.3125 \mathrm{in} .(26.19375 \mathrm{~cm})$ long with a $0.75 \mathrm{in}$. (1.905 $\mathrm{cm})$ base diameter. The threading is $1.25 \mathrm{in} .(3.175 \mathrm{~cm})$ high starting from the bottom of the bolt. The bolt head is 0.5 in. $(1.27 \mathrm{~cm})$ high and the hexagon face-to-face length is 1.125 in. (2.8575). The holes inside the bolts could be filled with U-Mo or bolt plugs made of other materials. The holes in the bolts are 7.4375 in. $(18.89252 \mathrm{~cm})$ deep from the top of the bolt and 0.332 in. $(0.84238 \mathrm{~cm})$ in diameter. A small hole of 0.0625 in. $(0.15875 \mathrm{~cm})$ is drilled through the plug head radially $0.25 \mathrm{in} .(0.635 \mathrm{~cm})$ from the top of the bolt. As described above, 3 of the 9 bolts are inserted through the mounting bracket, as detailed in Section 1.4.1.9, whereas the remaining 6 bolts are inserted into stainless steel washers. No precise dimensions of the washers were found, so these dimensions were inferred from Drawing 10099-K-001-D, which is shown in Figure 14, as well as the mounting bracket drawing shown in Figure 21. The washers are assumed to be 0.75 in. $(1.905 \mathrm{~cm})$ thick with a 1.5 in. $(3.81 \mathrm{~cm})$ outside diameter and $0.75 \mathrm{in} .(1.905$ $\mathrm{cm})$ inside diameter, similar to the mounting bracket cuboid elements. 


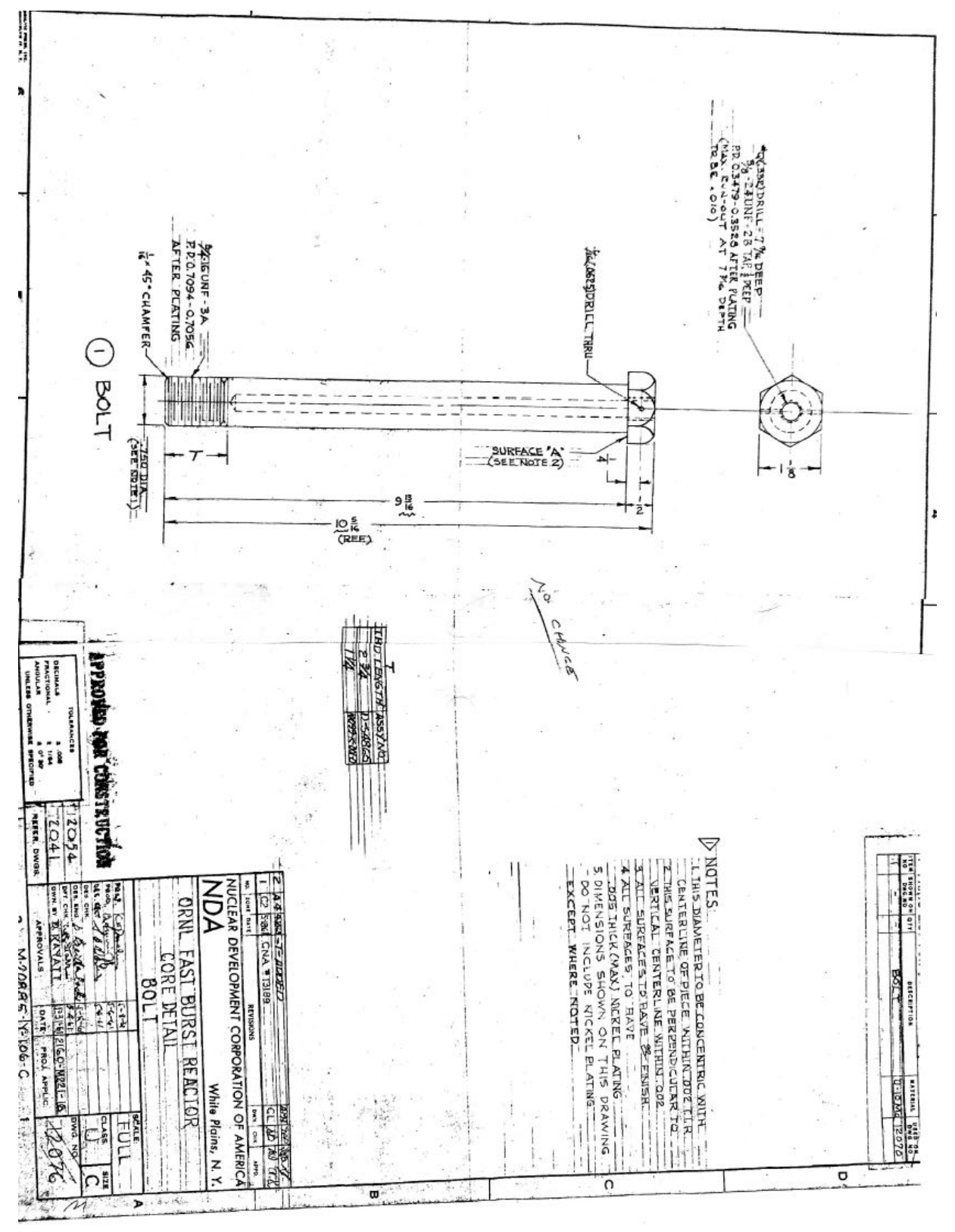

Figure 22. HPRR U-Mo bolt (Drawing 12076).

\subsubsection{U-Mo bolt plugs}

The bolt plug is shown in Figure 23. Up to 9 U-Mo or 304 stainless steel bolt plugs can be inserted into the U-Mo bolts. The bolt plugs are cylinders with chamfers at the bottom and threads and hexagonal heads at the top. The bolt plugs are $7.625 \mathrm{in} .(19.3675 \mathrm{~cm})$ long with a $0.281 \mathrm{in} .(0.71374 \mathrm{~cm})$ base diameter from the bottom of the plug to $7 \mathrm{in}$. $(17.78 \mathrm{~cm})$ height. Above this height, the bolts are threaded on $0.375 \mathrm{in} .(0.635 \mathrm{~cm})$ height. Above the threads, the hexagonal head is $0.25 \mathrm{in} .(0.635 \mathrm{~cm})$ high and the hexagon face-to-face length is 0.25 in. $(0.635 \mathrm{~cm})$. A hole similar to the $0.0625 \mathrm{in} .(0.15875 \mathrm{~cm})$ hole in the U-Mo bolts is drilled through the threads radially, $0.5 \mathrm{in} .(1.27 \mathrm{~cm})$ from the top of the plug. 


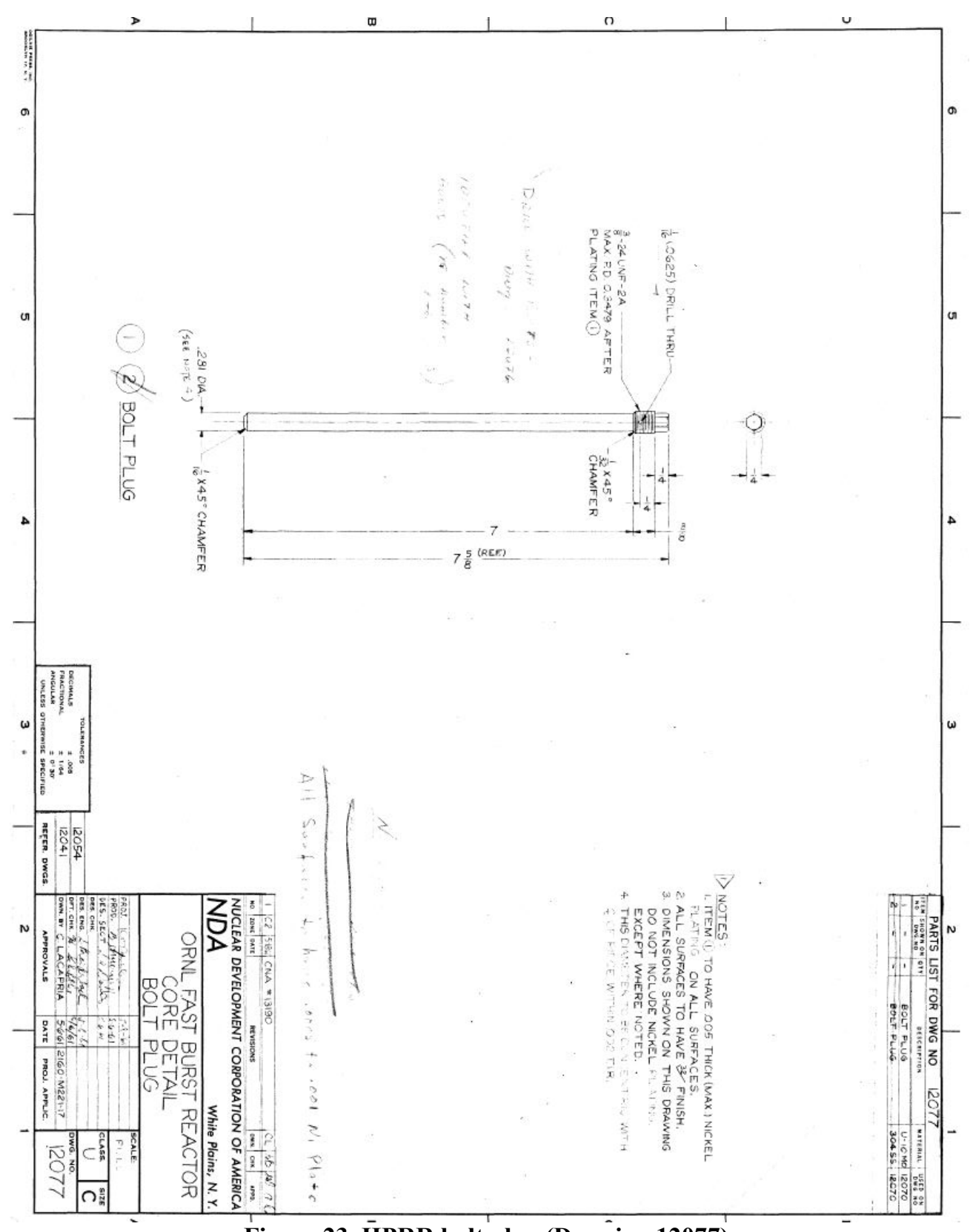

Figure 23. ḦPRR bolt plug (Drawing 12077).

\subsubsection{Sample irradiation hole plug}

The sample irradiation hole plug could be made of U-Mo or another material. The plugs could be inserted into the sample irradiation hole through the 11 annuli to increase the U-Mo mass in the core or to irradiate various samples. The drawings of the irradiation hole plugs are not available, so the dimensions introduced in this section are deduced from assumptions made based on written materials and drawings. For example, in Drawing 10099-K-001-D, shown in Figure 14, the sample irradiation hole plug is visible, and the dimensions and geometry information can be inferred from the drawing. The U-Mo sample irradiation hole plug is 0.263 in. $(0.66802 \mathrm{~cm})$ diameter. Three different U-Mo plugs with different lengths are available as $4.78 \mathrm{in} .(12.1412 \mathrm{~cm}), 8.25 \mathrm{in} .(20.955 \mathrm{~cm})$ or $9.06 \mathrm{in}$. $(23.0124 \mathrm{~cm})$. The top of the plugs are threaded on $0.25 \mathrm{in} .(0.635 \mathrm{~cm})$, corresponding to the Annulus 1 thickness. No information 
is available about which sample irradiation plug was inserted during the experiments of interest in this benchmark.

\subsubsection{Control Rods}

The three U-Mo control rods were placed in 304 stainless steel liner tubes, secured on Annulus 1 by a 304 stainless steel tube retainer and three 304 stainless steel screws. The control rods can slide through the liner tubes based on the amount of criticality needed for operation. Drawings of the three control rods, control rod tubes, and tube retainers were not found, so the dimensions introduced in this section are based on assumptions made from written materials and drawings. For example, in Drawing 10099-K-001D shown in Figure 14, the regulating rod, liner tube, and liner tube retainer are visible, so the dimensions and geometry information can be inferred from the drawing.

\section{Mass Adjustment Rod}

The MAR is a U-Mo cylinder of 9 in. $(22.86 \mathrm{~cm})$ length and $1 \mathrm{in.}(2.54 \mathrm{~cm})$ diameter. Its liner tube is assumed to be a hollow cylinder drilled through with a length of $8.375 \mathrm{in} .(21.2725 \mathrm{~cm})$, an inside diameter of $1.002 \mathrm{in} .(2.54508 \mathrm{~cm})$, and a thickness of $0.035 \mathrm{in} .(0.0889 \mathrm{~cm})$. The tube retainer is placed on top of Annulus 1 and is centered around the MAR. It is assumed to be $0.1875 \mathrm{in} .(0.47625 \mathrm{~cm})$ thick and 0.875 in. $(2.2225 \mathrm{~cm})$ in diameter. The three screws go through both the tube retainer and Annulus 1 , are equally spaced around the MAR, and are assumed to be $0.0625 \mathrm{in} .(0.15875 \mathrm{~cm})$ long and $0.09375 \mathrm{in}$. $(0.23813 \mathrm{~cm})$ in diameter.

\section{Regulating Rod}

The RR is a U-Mo cylinder 9 in. $(22.86 \mathrm{~cm})$ long and $0.625 \mathrm{in} .(1.5875 \mathrm{~cm})$ in diameter. Its liner tube is assumed to be a hollow cylinder drilled through with a length of $8.375 \mathrm{in} .(21.2725 \mathrm{~cm})$, an inside diameter of 0.627 in. $(1.59258 \mathrm{~cm})$, and a thickness of $0.035 \mathrm{in} .(0.0889 \mathrm{~cm})$. The tube retainer and the three screws are the same as those used for the MAR.

\section{Burst Rod}

The BR is a U-Mo cylinder 9 in. $(22.86 \mathrm{~cm})$ long and 0.75 in. $(1.905 \mathrm{~cm})$ in diameter. Its liner tube is assumed to be a hollow cylinder drilled through with a length of $8.375 \mathrm{in} .(21.2725 \mathrm{~cm})$, an inside diameter of 0.752 in. $(1.91008 \mathrm{~cm})$, and a thickness of 0.035 in. $(0.0889 \mathrm{~cm})$. The tube retainer and the three screws are the same as those used for the MAR and RR.

\subsubsection{Thermocouples}

Both thermocouples placed inside the core are used to measure the fuel temperature before, during, and after reactor operation and are referred to as Thermocouple 4 and Thermocouple 5. They are inserted in the two U-Mo thermocouple plugs and attached to special brass screws and a brass collet. The thermocouple parts are shown in Figure 16. The U-Mo thermocouple plug dimensions match the thermocouple plug hole dimensions as described in Section 1.4.1.2. They can be separated in two parts: an outer part on the outside of the annulus with a diameter of $0.431 \mathrm{in} .(1.09474 \mathrm{~cm})$ and $0.375 \mathrm{in}$. $(0.9525 \mathrm{~cm})$ long, and an inner part on the inside of the annulus with a diameter of $0.3 \mathrm{in} .(0.762 \mathrm{~cm})$ and $1.85938 \mathrm{in} .(4.72281 \mathrm{~cm})$ long, for a total length of $2.23438 \mathrm{in} .(5.67531 \mathrm{~cm})$. A hole with a diameter of $0.066 \mathrm{in} .(0.16764 \mathrm{~cm})$ and $2.0625 \mathrm{in} .(5.23875 \mathrm{~cm})$ deep is drilled in the center of the plugs to receive the inserted thermocouples. The screws and collet will not be detailed in the report, but their dimensions are available in Figure 16. The thermocouples are 0.066 in. $(0.16764 \mathrm{~cm})$ in diameter and are ironConstantine, commonly referred to as Type J thermocouples. 


\subsubsection{Mounting bracket}

The mounting bracket drawing is shown in Figure 21. It is a 304 stainless steel structure that is used to safely lock the core to the superstructure on top of it. The mounting bracket contact with the core is achieved by 3 of the 9 bolts, as described above. The mounting bracket can be divided in two sectionsthe bottom and the top. The bottom section includes the 3 elements holding the 3 bolts, which are approximated to cuboids. The cuboid length is assumed to be $3.8125 \mathrm{in} .(9.68375 \mathrm{~cm})$, the width $1.5 \mathrm{in}$. $(3.81 \mathrm{~cm})$, and the thickness 0.5623 in. $(1.42875 \mathrm{~cm})$. The bolt holes are $0.75 \mathrm{in} .(1905 \mathrm{~cm})$ in diameter and are located 0.75 in. $(1.905 \mathrm{~cm})$ from the inner edge of the cuboids. Each of the cuboid elements is drilled through with a hole of $0.6875 \mathrm{in} .(1.74625 \mathrm{~cm})$ located at approximately $0.6875 \mathrm{in} .(1.74625 \mathrm{~cm})$ from the cuboid outer edge; this hole is used to attach the aluminum safety cage to the core. The cuboids are equally spaced around the center of the HPRR, $120^{\circ}$ apart. The top section is an annulus with an inside diameter of 9 in. $(22.86 \mathrm{~cm})$, an outside diameter of $12.375 \mathrm{in} .(31.4325 \mathrm{~cm})$, and a thickness of $0.1875 \mathrm{in} .(0.47625 \mathrm{~cm})$. The top section is attached to the bottom section. A part of the annulus is removed, as seen in Figure 21.

\subsubsection{Aluminum safety cage}

The aluminum safety cage is made of a 6061-T6 aluminum alloy grid of $62 \%$ void placed radially around the core to protect it from incidents. No drawing of the aluminum safety cage was found. Therefore, the dimensions provided in this section are based on assumptions made from written materials and drawings/photos. For example, the aluminum safety cage is visible in Drawing 10099-K-001-D as shown in Figure 14 and in the photo of the core shown in Figure 24. The aluminum cage is attached to the critical assembly from the mounting bracket in three locations using 304 stainless steel and 6061-T6 aluminum elements. The cage is assumed to have a 9.3125 in. $(23.65375 \mathrm{~cm})$ inside diameter and 0.0625 in. $(0.15875 \mathrm{~cm})$ thickness. The aluminum grid also covers the bottom of the critical assembly, extending 1.15625 in. $(2.93688 \mathrm{~cm})$ below the bottom of annulus 11 and forming a right angle to get closer to the bottom safety tube. The bottom part of the grid is 2.4375 in. $(6.19125 \mathrm{~cm})$, extending radially between the safety tube and the inside diameter of the aluminum safety cage grid. The bottom part of the grid is also supported by 304 stainless steel elements. 


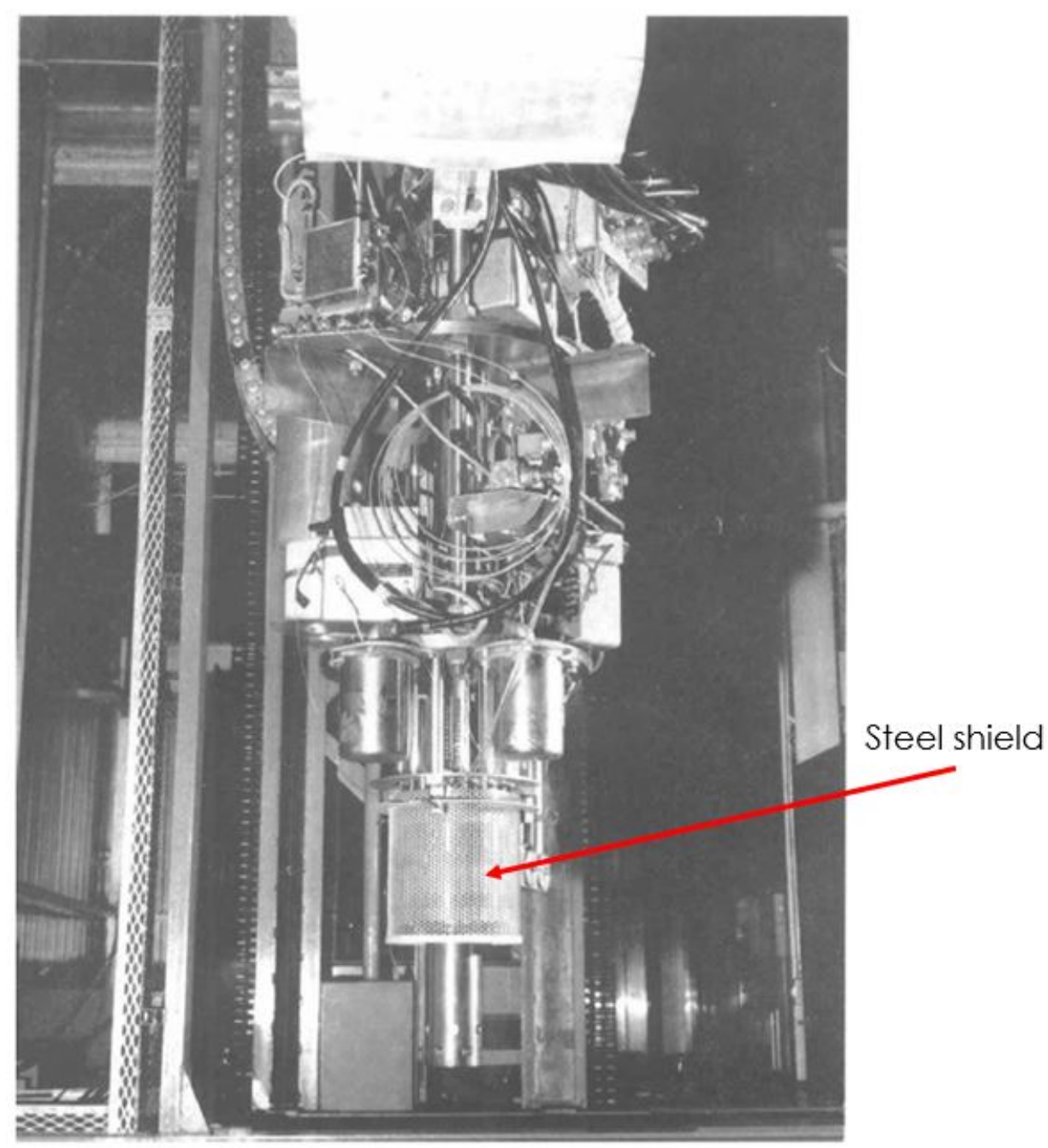

Figure 24. HPRR aluminum safety cage [10].

\subsubsection{Safety tube}

The safety tube drawing is shown in Figure 21. The safety tube was used to guide and hold the safety block following an ejection from the critical assembly after reactor operation. It was formed by a 304 stainless steel thin tube mounted on a thicker and more complex top tube, threaded to annulus 11 with 4 screws. The bottom section of the safety tube has a 3.5625 in. $(9.04875 \mathrm{~cm})$ inside diameter, $0.25 \mathrm{in}$. $(0.635 \mathrm{~cm})$ thickness and 9.5 in. $(24.13 \mathrm{~cm})$ length. Twelve holes of 0.75 in. $(1.905 \mathrm{~cm})$ diameter were drilled through the bottom $2.375 \mathrm{in} .(6.985 \mathrm{~cm})$ of the safety tube. The top tube had a complex geometry and can be approximated as two annuli of varying internal diameter from $3.5625 \mathrm{in} .(9.04875 \mathrm{~cm})$ to 3.8125 in. $(9.68376 \mathrm{~cm})$, constant external diameter of 5.375 in. $(13.6525 \mathrm{~cm})$ and $0.5 \mathrm{in} .(1.27 \mathrm{~cm})$ thickness.

\subsubsection{Superstructure}

The superstructure is the name given to all the other components located above the core related to the its operation, like rod drives, starting source, and detectors. No drawing with dimensions of the superstructure elements was found, but schematics of an old calculation model from 1974 [11] is shown 
in Figure 25, and an overview drawing of the HPRR with the superstructure attached is shown in Figure 26. From those pictures, a few assumptions can be made. Three different 304 stainless steel plates were located above the core, approximately $19 \mathrm{~cm}, 74 \mathrm{~cm}$, and $130 \mathrm{~cm}$ above the mounting bracket respectively. Each of these top plates is about $50.8 \mathrm{~cm}$ in diameter and $2.54 \mathrm{~cm}$ thick. The 304 stainless steel central hanger rod, of $0.8 \mathrm{in} .(2.032 \mathrm{~cm})$ diameter, extends from the safety block nearly up to the $3^{\text {rd }}$ top plate.

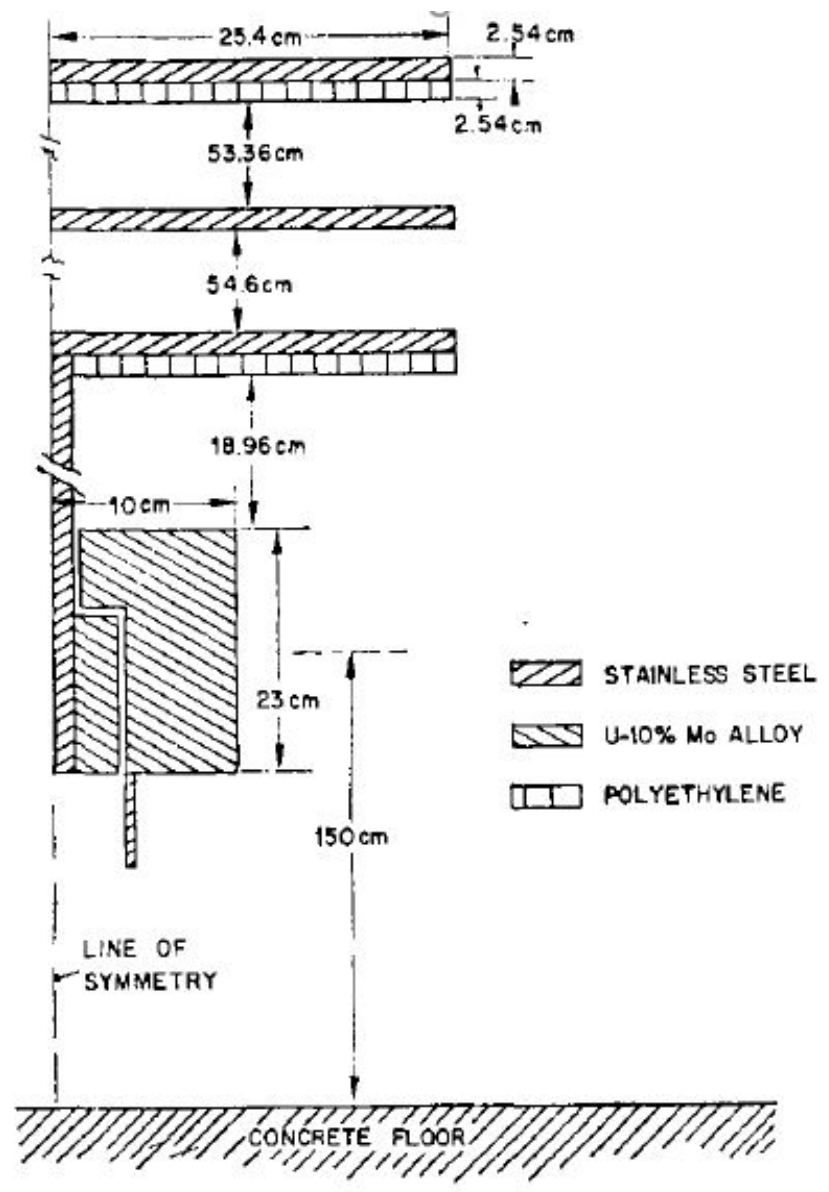

Figure 25. Calculation model of the HPRR [11]. 


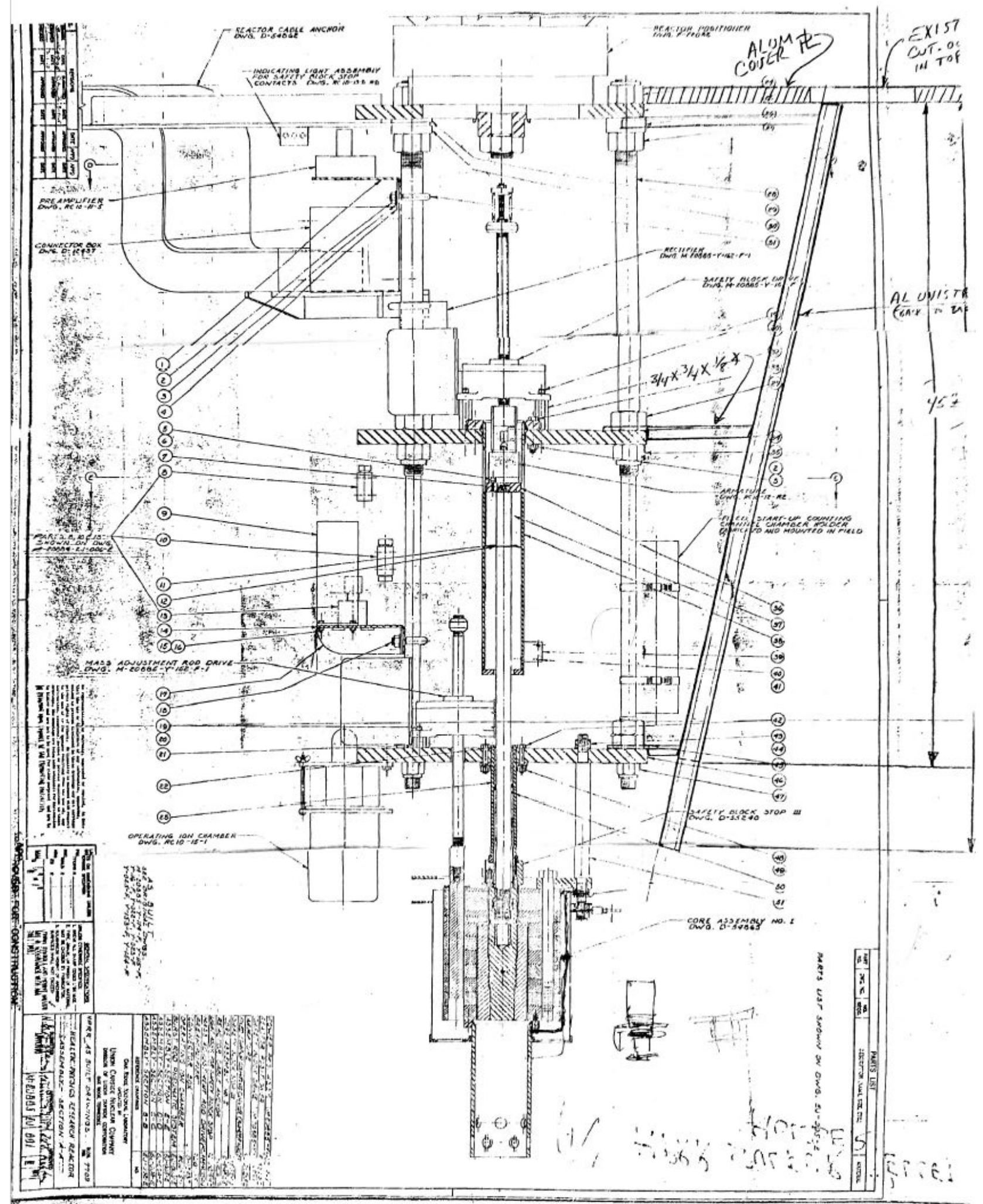

Figure 26. HPRR overview with superstructure drawing. 


\subsubsection{HPRR Materials}

The following subsections discuss the available materials information of the HPRR and related components. Overall, there is no detailed material data information available for the HPRR.

\subsubsection{Coating}

No precise information about the Nickel, Chromium and Gold coatings were found. All three coatings isotopic composition will be assumed to be natural and their density is shown in Table 5.

Table 5. Coating materials information

\begin{tabular}{lc}
\hline Element & Density $\left(\mathbf{g} / \mathbf{c m}^{\mathbf{3}}\right)$ \\
\hline $\mathrm{Ni}$ & 8.90 \\
$\mathrm{Cr}$ & 7.20 \\
$\mathrm{Au}$ & 18.88 \\
\hline
\end{tabular}

\subsubsection{U-Mo elements}

All the U-Mo elements are assumed to have the same isotopic composition. The alloy is 10 weight percent natural Molybdenum and 90 weight percent highly enriched Uranium. The enrichment proportion is varying between 93.14 and 93.17 weight percent ${ }^{235} \mathrm{U}$, depending on the source [6][10][12][13]. The density of the alloy is also varying depending on the source, between 17.08 and $17.10 \mathrm{~g} / \mathrm{cm}^{3}[12][13]$. The estimated standard composition of all the U-Mo elements is shown in Table 6.

Table 6. Standard composition of all the U-Mo elements

\begin{tabular}{lc}
\hline Element & Weight percent \\
\hline $\mathrm{Mo}$ & 10 \\
${ }^{235} \mathrm{U}$ & 83.826 to 83.853 \\
${ }^{238} \mathrm{U}$ & 6.174 to 6.47 \\
Density & 17.08 to $17.10 \mathrm{~g} / \mathrm{cm}^{3}$ \\
\hline
\end{tabular}

\subsubsection{304 stainless steel elements}

All the 304 stainless steel elements standard composition are assumed to be the same as described in Section 1.3.1.3 for the reactor building, following ASTM-A240 and shown in Table 4.

\subsubsection{Quick lock}

From the available drawings, the quick lock material is 17-4 PH stainless steel, also known as stainless steel type 630, or UNS 17400. The standard composition of 17-4 PH stainless steel is obtained from ASTM-A564/A564M [14] and is shown in Table 7. 
Table 7. Standard composition of 17-4 PH stainless

steel from ASTM-A564/A564M [14]

\begin{tabular}{lc}
\hline Element & Weight percent \\
\hline $\mathrm{C}$ & 0.07 \\
$\mathrm{Mn}$ & 1 \\
$\mathrm{P}$ & 0.04 \\
$\mathrm{~S}$ & 0.03 \\
$\mathrm{Si}$ & 1 \\
$\mathrm{Cr}$ & $15-17.5$ \\
$\mathrm{Ni}$ & $3-5$ \\
$\mathrm{Cu}$ & $3-5$ \\
$\mathrm{Nb}$ & $0.15-0.45$ \\
$\mathrm{Fe}$ & Balance \\
Density & $7.8 \mathrm{~g} / \mathrm{cm}^{3}$ \\
\hline
\end{tabular}

\subsubsection{Aluminum safety cage}

From the available drawings, the aluminum safety cage material is 6061-T6 aluminum. The standard composition of 6061-T6 aluminum is obtained from ASTM-B221 [15] and is shown in Table 8.

Table 8. Standard composition of aluminum 6061-T6 from ASTM-B221 [15]

\begin{tabular}{lc}
\hline \multicolumn{1}{c}{ Element } & Weight percent \\
\hline $\mathrm{Si}$ & $0.4-0.8$ \\
$\mathrm{Fe}$ & 0.7 \\
$\mathrm{Cu}$ & $0.15-0.4$ \\
$\mathrm{Mn}$ & 0.15 \\
$\mathrm{Mg}$ & $0.8-1.2$ \\
$\mathrm{Cr}$ & $0.04-0.35$ \\
$\mathrm{Zn}$ & 0.25 \\
$\mathrm{Ti}$ & 0.15 \\
$\mathrm{Al}$ & Balance \\
Density & $2.7 \mathrm{~g} / \mathrm{cm}^{3}$ \\
\hline
\end{tabular}

\subsubsection{Thermocouples}

Both thermocouples placed inside the core are referred to as Thermocouple 4 and Thermocouple 5. The thermocouples are type J, iron-Constantine. Constantine is defined as a 45 weight percent Nickel and 55 weight percent Copper alloy, and the standard composition of the thermocouples is assumed to be half iron and half Constantine, as shown in Table 9.

Table 9. Standard composition of iron-Constantine

\begin{tabular}{lc}
\hline Element & Weight percent \\
\hline $\mathrm{Fe}$ & 50 \\
$\mathrm{Ni}$ & 22.5 \\
$\mathrm{Cu}$ & 27.5 \\
Density & $8.36 \mathrm{~g} / \mathrm{cm}^{3}$ \\
\hline
\end{tabular}

\subsection{MEASUREMENT TECHNIQUES}

The HPRR could be operated either in steady-state or burst/pulse mode. The sulfur pellet activation experiments of interest in this benchmark originated from burst mode operation. To start a burst, the core 
must be near the delayed-critical level, which is achieved by adjusting the safety block and the mass adjustment rod and regulating rod heights. Then the burst rod is inserted in a few microseconds, and the reactivity increases to a few cents above prompt critical, with a fission yield typically around $10^{17}$. Temperature is increased by several hundreds of degrees, ranging between 400 and $700{ }^{\circ} \mathrm{F}$, and the thermal expansion and negative coefficient of reactivity help to expel the safety block from the assembly, quickly reducing the criticality of the core to subcritical. Depending on the fission yield goal during a burst, the reactor operators can adjust the different rods' heights. During each burst, core characteristics such as rod height, target fission yield, and core temperature are recorded on burst log sheets. The target fission yield is then compared to a measured fission yield that is calculated using the temperature increase in the core and a specific sulfur pellet: this sulfur pellet differs from those used to measure the sulfur fluence, which is the object of the benchmark. A summary of HPRR performance during burst operation is shown in Figure 27, from ORNL-TM-9870 [6].

\begin{tabular}{|c|c|c|c|}
\hline & \multirow{2}{*}{$\begin{array}{l}\text { Calculateda } \\
\text { for pulse } \\
\text { yield of } \\
1 \times 1017 \\
\text { fissions } \\
\end{array}$} & \multicolumn{2}{|c|}{$\begin{array}{c}\text { Experimental, for pulse } \\
\text { yield of }\end{array}$} \\
\hline & & $\begin{array}{l}1.8 \times 10^{17} \\
\text { fissions }\end{array}$ & $\begin{array}{c}1.05 \times 10^{17} \\
\text { fissions } \\
\end{array}$ \\
\hline \multicolumn{4}{|l|}{ Pulse performance characteristics } \\
\hline $\begin{array}{l}\text { Initial reactivity insertion } \\
\text { above prompt critical, cents }\end{array}$ & 7.6 & 11 & 9 \\
\hline $\begin{array}{l}\text { Integrated neutron current } 1 \text { in. } \\
\text { from reactor surface, } \\
\text { neutrons } / \mathrm{cm}^{2}\end{array}$ & $2 \times 1013$ & & \\
\hline Total neutron leakage & $1.3 \times 10^{17}$ & & \\
\hline Peak power, MN & 63,000 & 100,000 & 42,000 \\
\hline Initial reactor period, $\mathbf{s}$ & 13 & 16 & 20 \\
\hline Pulse half-width, s & 38 & 48 & 63 \\
\hline Maximum temperature rise, ${ }^{\circ} \mathrm{F}$ & 740 & 720 & 415 \\
\hline Average temperature rise, ${ }^{\circ} \mathrm{F}$ & 360 & 380 & 220 \\
\hline $\begin{array}{l}\text { Cooling time (forced } \\
\text { convection), } h\end{array}$ & 2.5 & & \\
\hline Cooling air required, $\mathrm{cfm}$ & $1500-2000$ & & \\
\hline \multicolumn{4}{|c|}{ Steady-state performance characteristics } \\
\hline \multicolumn{4}{|l|}{ Natural-convection cooling } \\
\hline Maximum power, W & 1000 & & \\
\hline $\begin{array}{l}\text { Maximum reactor } \\
\text { temperature, }{ }^{\circ} \mathrm{F}\end{array}$ & 600 & & \\
\hline $\begin{array}{l}\text { Reactor surface } \\
\text { temperature, }{ }^{\circ} \mathrm{F}\end{array}$ & 480 & & \\
\hline
\end{tabular}

acalculations are for reference design2.

Figure 27. HPRR performance during burst.

In each of the experiments of interest, a few sulfur pellets were simultaneously placed at different distances from the HPRR at a height of $140 \mathrm{~cm}$ from the concrete floor and were irradiated during burst operations. It is not known how the pellets were suspended at such a height, nor their orientation. The irradiated sulfur pellets were activated by the ${ }^{32} \mathrm{~S}(\mathrm{n}, \mathrm{p}){ }^{32} \mathrm{P}$ reaction, and the resulting ${ }^{32} \mathrm{P}$ beta minus decay activity from the pellets could then be counted and converted back to a neutron flux value proportional to the distance of the pellet from the HPRR. The detailed procedure to obtain the neutron fluence from 
activated sulfur pellets could not be located; however, a few reports mention the procedure as ORNL4114 [16]. The experiment results of interest in this benchmark are displayed in a peculiar unit, which is sulfur fluence per $10^{17}$ fissions. To understand the meaning of this unit, the results of other experiments from ORNL-6240 were analyzed. It was observed that neutron fluence and sulfur fluence measurement results were not the same at the same location, as shown in Figure 28. In this example, the threshold detector unit (TDU) measurements at $0.62 \mathrm{~m}$ for $10^{17}$ fissions produced a result of $3.39 \times 10^{12}$ neutron fluence as opposed to the $6.77 \times 10^{11}$ sulfur fluence result obtained at the same location with the sulfur pellet. Based on this observation, it is clear that the neutron fluence and sulfur fluence are not the same unit. Looking at the ${ }^{32} \mathrm{~S}(\mathrm{n}, \mathrm{p})^{32} \mathrm{P}$ reaction cross section shown in Figure 29 from ENDF/B-VIII.0, the probability of interaction of neutrons of energy under 2 to $3 \mathrm{MeV}$ is very low. This indicates that a significant part of the outgoing scattered neutrons does not contribute to the sulfur pellet activation. If the sulfur fluence is related to the activation rate of the sulfur pellets, then this could explain why the sulfur fluence results are all lower than the neutron fluence at same location. Therefore, it will be assumed that the sulfur fluence is defined as the number of sulfur pellet activations per fissions per unit area instead of the classic neutron fluence being the number of neutrons per fissions per unit area. As described above, the number of fissions during a burst operation is not constant and can be modified by the reactor operators. In both neutron fluence and sulfur fluence cases, the results are given for exactly $10^{17}$ fissions from the HPRR, implying that a normalization was performed. The choice of fluence instead of flux can also be explained: during a burst, the neutron flux increases and decreases very quickly, so the time component is not as important as the total number of fissions and or neutrons. This explains the choice of unit to fluence $\left(\right.$ per $\mathrm{cm}^{2}$ ) instead of the usual flux (per $\mathrm{cm}^{2}$ per s) that is typical in nuclear reactor operation.
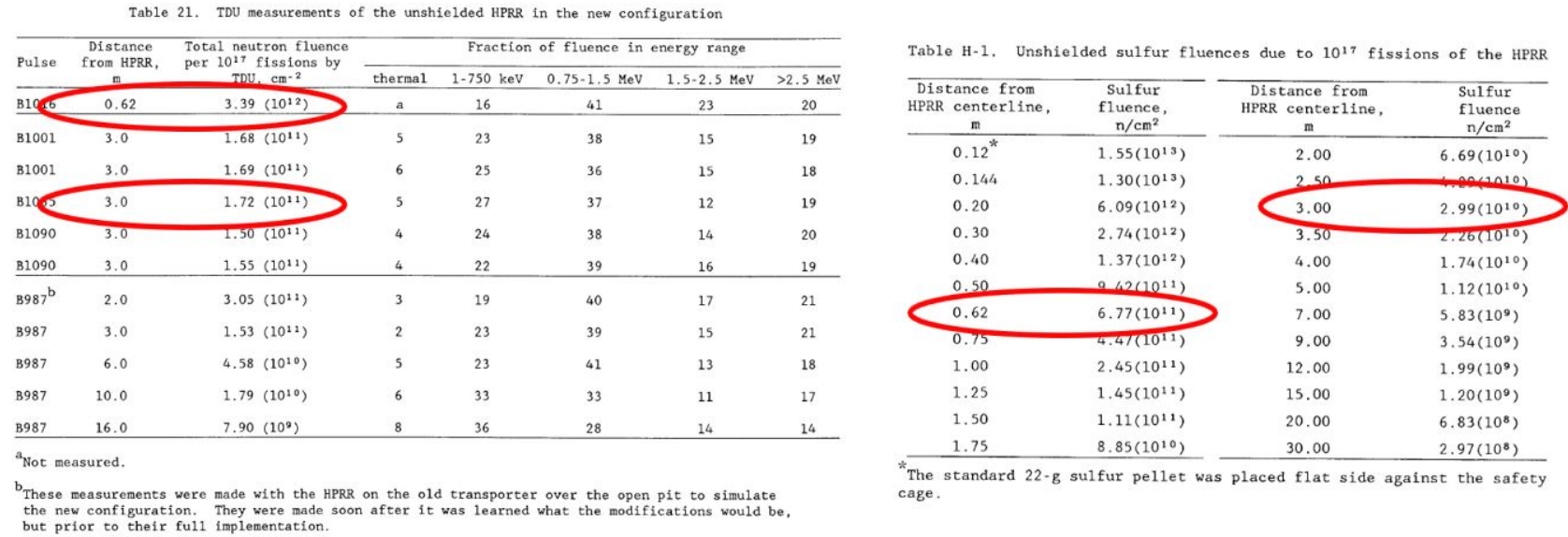

Figure 28. HPRR fluence results using TDU and sulfur pellets. 


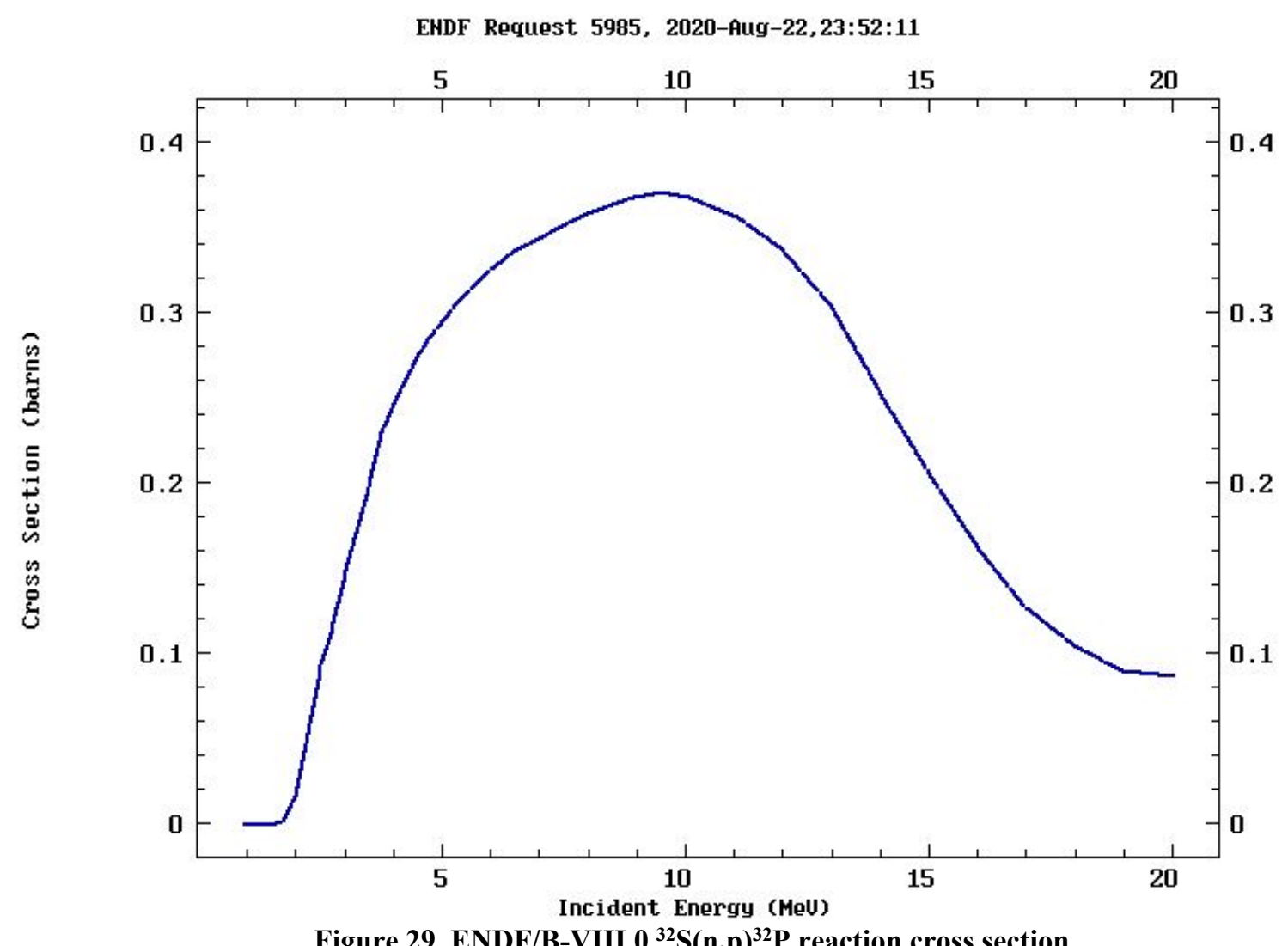

Figure 29. ENDF/B-VIII.0 ${ }^{32} \mathrm{~S}(\mathrm{n}, \mathrm{p})^{32} \mathrm{P}$ reaction cross section.

\subsection{MEASUREMENT RESULTS}

The sulfur fluence results from $10^{17}$ fissions of the HPRR at 24 different locations for the bare configuration and 7 locations for the steel shield configuration are shown in Figure 30 from ORNL-6240. 
Table H-1. Unshielded sulfur fluences due to $10^{17}$ fissions of the HPRR

\begin{tabular}{|c|c|c|c|}
\hline $\begin{array}{c}\text { Distance from } \\
\text { HPRR centerline, } \\
\text { m } \\
\end{array}$ & $\begin{array}{c}\text { Sulfur } \\
\text { fluence, } \\
\mathrm{n} / \mathrm{cm}^{2}\end{array}$ & $\begin{array}{l}\text { Distance from } \\
\text { HPRR centerline, } \\
\text { m }\end{array}$ & $\begin{array}{l}\text { Sulfur } \\
\text { fluence } \\
\mathrm{n} / \mathrm{cm}^{2}\end{array}$ \\
\hline $0.12^{*}$ & $1.55\left(10^{13}\right)$ & 2.00 & $6.69\left(10^{10}\right)$ \\
\hline 0.144 & $1.30\left(10^{13}\right)$ & 2.50 & $4.29\left(10^{10}\right)$ \\
\hline 0.20 & $6.09\left(10^{12}\right)$ & 3.00 & $2.99\left(10^{10}\right)$ \\
\hline 0.30 & $2.74\left(10^{12}\right)$ & 3.50 & $2.26\left(10^{10}\right)$ \\
\hline 0.40 & $1.37\left(10^{12}\right)$ & 4.00 & $1.74\left(10^{10}\right)$ \\
\hline 0.50 & $9.42\left(10^{11}\right)$ & 5.00 & $1.12\left(10^{10}\right)$ \\
\hline 0.62 & $6.77\left(10^{11}\right)$ & 7.00 & $5.83\left(10^{9}\right)$ \\
\hline 0.75 & $4.47\left(10^{11}\right)$ & 9.00 & $3.54\left(10^{9}\right)$ \\
\hline 1.00 & $2.45\left(10^{11}\right)$ & 12.00 & $1.99\left(10^{9}\right)$ \\
\hline 1.25 & $1.45\left(10^{11}\right)$ & 15.00 & $1.20\left(10^{9}\right)$ \\
\hline 1.50 & $1.11\left(10^{11}\right)$ & 20.00 & $6.83\left(10^{8}\right)$ \\
\hline 1.75 & $8.85\left(10^{10}\right)$ & 30.00 & $2.97\left(10^{8}\right)$ \\
\hline
\end{tabular}

Table H-3. Sulfur fluences due to $10^{17}$ fissions of the HPRR measured behind the $13-\mathrm{cm}$ thick steel shield

\begin{tabular}{cc}
\hline $\begin{array}{c}\text { Distance from } \\
\text { HPRR centerline, } \\
\mathrm{m}\end{array}$ & $\begin{array}{c}\text { Sulfur } \\
\text { fluence, } \\
\mathrm{n} / \mathrm{cm}^{2}\end{array}$ \\
\hline 2.5 & $6.48\left(10^{9}\right)$ \\
3.0 & $4.59\left(10^{9}\right)$ \\
3.5 & $3.41\left(10^{9}\right)$ \\
4.0 & $2.59\left(10^{9}\right)$ \\
5.0 & $1.68\left(10^{9}\right)$ \\
7.0 & $8.91\left(10^{8}\right)$ \\
9.0 & $5.09\left(10^{8}\right)$ \\
\hline
\end{tabular}

Figure 30. Sulfur fluence tables from ORNL-6240.

The bare configuration measurements were made during 5 different bursts (B1014, B1015, B1016, B1017 and B1022). The steel shield measurements were made during burst B1024 only. Using those burst references, important information about the core during each specific experiment was extracted from the HPRR burst log sheets. As an example, the burst log sheet of the burst B1017 is shown in Figure 31 and Figure 32. Burst B1017 was performed on December 19, 1985, with a target fission yield of $7 \times 10^{16}$. A total of 10 sulfur pellets were placed at distances between $1.75 \mathrm{~m}$ and $12 \mathrm{~m}$. The core was located $1.42 \mathrm{~m}$ above the concrete floor, the safety block $0.116 \mathrm{in} .(0.29464 \mathrm{~cm})$ below its nominal position, and the $9 \mathrm{U}$ Mo bolts were inserted. The burst log sheets corresponding to the 6 bursts of interest were all located and the extracted information is shown in Table 10. Note that thermocouples 1 and 2 were located far from the core and were used to measure the ambient room temperature, whereas thermocouples 4 and 5 were located inside the core; their dimensions and materials are described in Section 1.4.2.6. Because the burst $\log$ sheets are timeworn, some writings are barely readable. Comparing the sulfur pellet number and location information in ORNL-6240 results tables shown in Figure 30 with the burst log sheets, it appears 
that some sulfur pellet distances were tested multiple times during different bursts. Therefore, the updated results in Table 11 and Table 12 with burst numbers are used as the experiment's results reference. 
HPRR BURST LOG SHEET

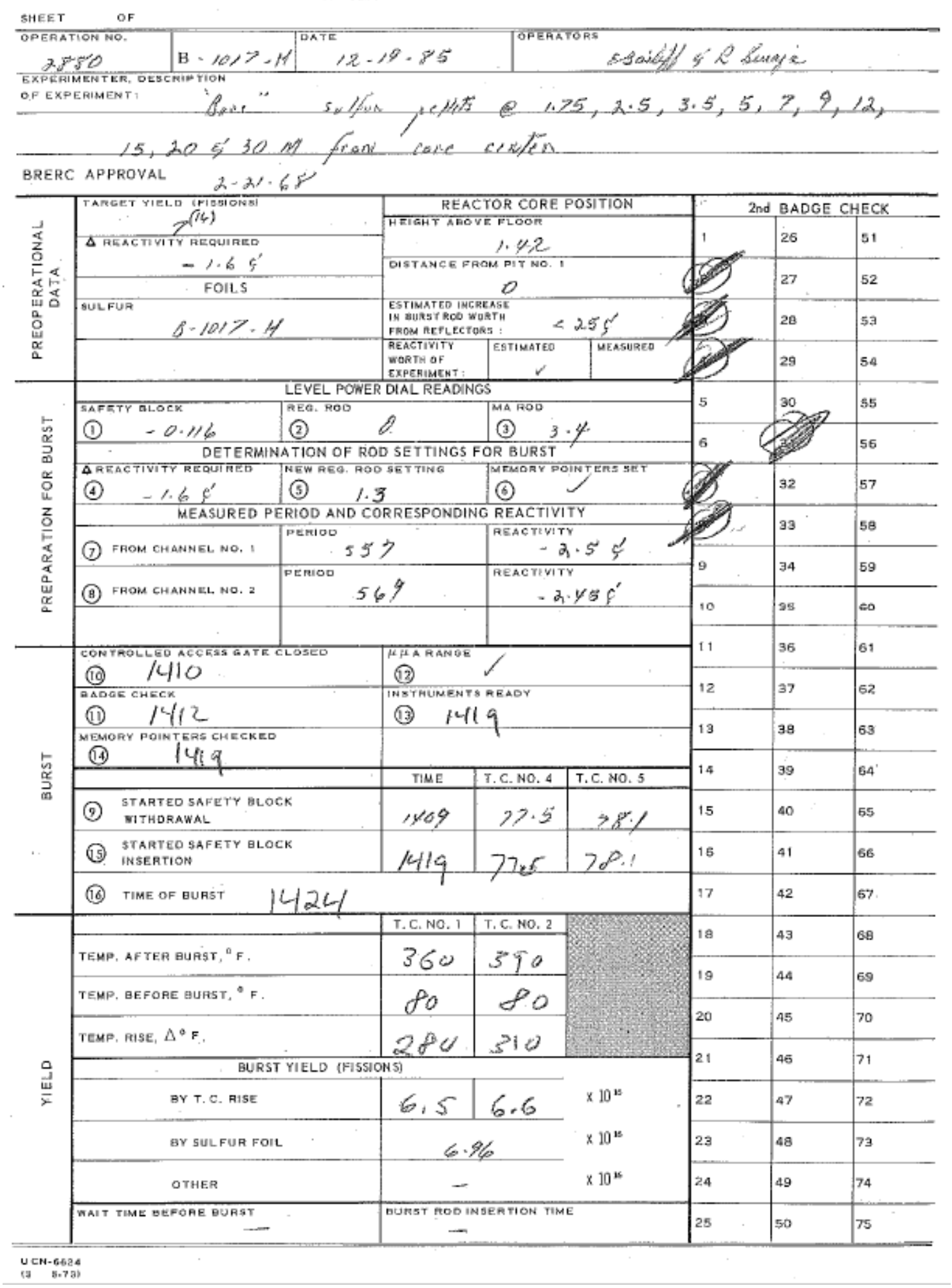

Figure 31. Burst B1017 Burst Log Sheet-Page 1. 
HPRR CHECK OUT AND DATA SHEET

$\frac{4930.7}{1.3}$

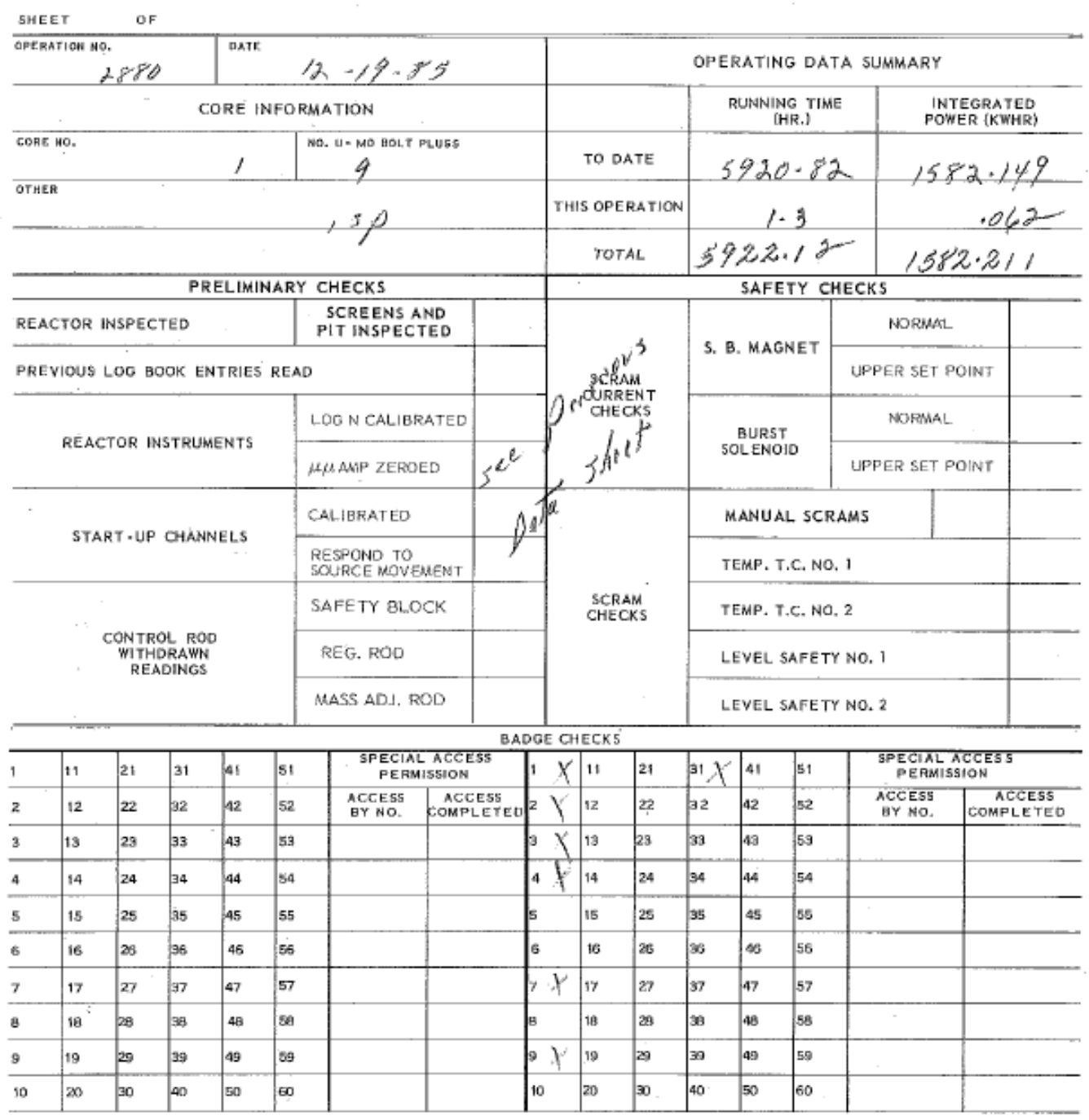

Figure 32. Burst B1017 Burst Log Sheet-Page 2. 
Table 10. Bursts information extracted from Burst Log Sheets

\begin{tabular}{|c|c|c|c|c|c|c|}
\hline Pulse number & B1014 & B1015 & B1016 & B1017 & B1022 & B1024 \\
\hline Date of operation & $10 / 29 / 1985$ & $11 / 20 / 1985$ & $12 / 11 / 1985$ & $12 / 19 / 1985$ & $1 / 8 / 1986$ & $1 / 20 / 1986$ \\
\hline Target fissions & $6.70 \mathrm{E}+16$ & $4.00 \mathrm{E}+16$ & $7.50 \mathrm{E}+16$ & $7.00 \mathrm{E}+16$ & $2.00 \mathrm{E}+16$ & $8.00 \mathrm{E}+16$ \\
\hline $\begin{array}{l}\text { Reactivity required } \\
\text { before burst (cents) }\end{array}$ & -2.4 & -3.8 & -1.35 & -1.6 & -5.3 & -1.1 \\
\hline $\begin{array}{l}\text { Core height above floor } \\
\text { (cm) }\end{array}$ & 144 & 140 & 140 & 142 & 140 & 140 \\
\hline $\begin{array}{l}\text { Safety block position } \\
(\mathrm{cm})\end{array}$ & -0.28448 & -0.28448 & -0.29210 & -0.29464 & -0.30480 & -0.34798 \\
\hline $\begin{array}{l}\text { Regulating rod position } \\
(\mathrm{cm})\end{array}$ & 0 & 17.78 & 0 & 0 & 0 & 0 \\
\hline $\begin{array}{l}\text { New regulating rod } \\
\text { position }(\mathrm{cm})\end{array}$ & 3.55600 & 6.04520 & 2.79400 & 3.30200 & 8.12800 & 2.03200 \\
\hline $\begin{array}{l}\text { Mass adjustment rod } \\
\text { position }(\mathrm{cm})\end{array}$ & 8.58520 & 9.32688 & 9.75360 & 8.63600 & 8.75792 & 8.83666 \\
\hline Thermocouple $4\left({ }^{\circ} \mathrm{C}\right)$ & 27.8 & 25.8 & 24.4 & 25.3 & 23.2 & 23.2 \\
\hline Thermocouple $5\left({ }^{\circ} \mathrm{C}\right)$ & 27.8 & 25.7 & 24.6 & 25.6 & 23.1 & 23.3 \\
\hline $\begin{array}{l}\text { Thermocouple } 1 \text { before } \\
\text { burst }\left({ }^{\circ} \mathrm{C}\right)\end{array}$ & 26.7 & 26.7 & 25.6 & 26.7 & 23.9 & 23.9 \\
\hline $\begin{array}{l}\text { Thermocouple } 1 \text { after } \\
\text { burst }\left({ }^{\circ} \mathrm{C}\right)\end{array}$ & 175.6 & 126.7 & 223.9 & 182.2 & 77.8 & 221.1 \\
\hline $\begin{array}{l}\text { Thermocouple } 1 \\
\text { temperature rise from } \\
\text { burst }\left({ }^{\circ} \mathrm{C}\right)\end{array}$ & 148.9 & 100.0 & 198.3 & 155.6 & 53.9 & 197.2 \\
\hline $\begin{array}{l}\text { Thermocouple } 2 \text { before } \\
\text { burst }\left({ }^{\circ} \mathrm{C}\right)\end{array}$ & 26.7 & 26.7 & 25.6 & 26.7 & 22.2 & 23.9 \\
\hline $\begin{array}{l}\text { Thermocouple } 2 \text { after } \\
\text { burst }\left({ }^{\circ} \mathrm{C}\right)\end{array}$ & 187.8 & 132.2 & 243.3 & 198.9 & 82.2 & 232.2 \\
\hline $\begin{array}{l}\text { Thermocouple } 2 \\
\text { temperature rise from } \\
\text { burst }\left({ }^{\circ} \mathrm{C}\right)\end{array}$ & 143.3 & 87.8 & 200.0 & 154.4 & 42.2 & 190.6 \\
\hline $\begin{array}{l}\text { Fission burst yield from } \\
\text { Thermocouple } 1 \text { rise }\end{array}$ & $6.10 \mathrm{E}+16$ & $4.05 \mathrm{E}+16$ & $8.25 \mathrm{E}+16$ & $6.50 \mathrm{E}+16$ & $2.17 \mathrm{E}+16$ & $8.10 \mathrm{E}+16$ \\
\hline $\begin{array}{l}\text { Fission burst yield from } \\
\text { Thermocouple } 2 \text { rise }\end{array}$ & $6.20 \mathrm{E}+16$ & $4.05 \mathrm{E}+16$ & $8.35 \mathrm{E}+16$ & $6.60 \mathrm{E}+16$ & $2.27 \mathrm{E}+16$ & $8.00 \mathrm{E}+16$ \\
\hline $\begin{array}{l}\text { Fission burst yield from } \\
\text { sulfur foil }\end{array}$ & $6.39 \mathrm{E}+16$ & $4.09 \mathrm{E}+16$ & $8.85 \mathrm{E}+16$ & $6.96 \mathrm{E}+16$ & $2.37 \mathrm{E}+16$ & $8.52 \mathrm{E}+16$ \\
\hline
\end{tabular}


Table 11. Updated sulfur fluence experiment results table with burst number for the bare configuration

\begin{tabular}{cccc}
\hline $\begin{array}{c}\text { Position } \\
\text { number }\end{array}$ & $\begin{array}{c}\text { Distance from } \\
\text { HPR centerline } \\
(\mathbf{m})\end{array}$ & $\begin{array}{c}\text { Sulfur fluence } \\
\left(\mathbf{n} / \mathbf{c m}^{2}\right)\end{array}$ & $\begin{array}{c}\text { Burst experiment } \\
\text { reference number }\end{array}$ \\
\hline 1 & 0.12 & $1.55 \mathrm{E}+13$ & $\mathrm{~B} 1015$ \\
2 & 0.144 & $1.30 \mathrm{E}+13$ & $\mathrm{~B} 1016$ \\
3 & 0.2 & $6.09 \mathrm{E}+12$ & $\mathrm{~B} 1015$ \\
4 & 0.3 & $2.74 \mathrm{E}+12$ & $\mathrm{~B} 1015$ \\
5 & 0.4 & $1.37 \mathrm{E}+12$ & $\mathrm{~B} 1015$ \\
6 & 0.5 & $9.42 \mathrm{E}+11$ & $\mathrm{~B} 1014, \mathrm{~B} 1015$ \\
7 & 0.62 & $6.77 \mathrm{E}+11$ & $\mathrm{~B} 1016$ \\
8 & 0.75 & $4.47 \mathrm{E}+11$ & $\mathrm{~B} 1015$ \\
9 & 1 & $2.54 \mathrm{E}+11$ & $\mathrm{~B} 1014, \mathrm{~B} 1015$ \\
10 & 1.25 & $1.45 \mathrm{E}+11$ & $\mathrm{~B} 1015$ \\
11 & 1.5 & $1.11 \mathrm{E}+11$ & $\mathrm{~B} 1015, \mathrm{~B} 1022$ \\
12 & 1.75 & $8.85 \mathrm{E}+10$ & $\mathrm{~B} 1017$ \\
13 & 2 & $6.69 \mathrm{E}+10$ & $\mathrm{~B} 1014, \mathrm{~B} 1015, \mathrm{~B} 1022$ \\
14 & 2.5 & $4.29 \mathrm{E}+10$ & $\mathrm{~B} 1017, \mathrm{~B} 1022$ \\
15 & 3 & $2.99 \mathrm{E}+10$ & $\mathrm{~B} 1014, \mathrm{~B} 1022$ \\
16 & 3.5 & $2.26 \mathrm{E}+10$ & $\mathrm{~B} 1017, \mathrm{~B} 1022$ \\
17 & 4 & $1.74 \mathrm{E}+10$ & $\mathrm{~B} 1022$ \\
18 & 5 & $1.12 \mathrm{E}+10$ & $\mathrm{~B} 1017, \mathrm{~B} 1022$ \\
19 & 7 & $5.83 \mathrm{E}+09$ & $\mathrm{~B} 1017$ \\
20 & 9 & $3.54 \mathrm{E}+09$ & $\mathrm{~B} 1017$ \\
21 & 12 & $1.99 \mathrm{E}+09$ & $\mathrm{~B} 1017$ \\
22 & 15 & $1.20 \mathrm{E}+09$ & $\mathrm{~B} 1017$ \\
23 & 20 & $6.83 \mathrm{E}+08$ & $\mathrm{~B} 1017$ \\
24 & 30 & $2.97 \mathrm{E}+08$ & $\mathrm{~B} 1017$ \\
\hline
\end{tabular}

Table 12. Updated Sulfur fluence experiment results table with burst number for the steel shield

\begin{tabular}{cccc}
\hline $\begin{array}{c}\text { Position } \\
\text { number }\end{array}$ & Distance $(\mathbf{m})$ & $\begin{array}{c}\text { Sulfur fluence } \\
\left(\mathbf{n} / \mathbf{c m}^{\mathbf{2}}\right)\end{array}$ & $\begin{array}{c}\text { Burst experiment } \\
\text { reference number }\end{array}$ \\
\hline 1 & 2.5 & $6.48 \mathrm{E}+09$ & $\mathrm{~B} 1024$ \\
2 & 3 & $4.59 \mathrm{E}+09$ & $\mathrm{~B} 1024$ \\
3 & 3.5 & $3.41 \mathrm{E}+09$ & $\mathrm{~B} 1024$ \\
4 & 4 & $2.59 \mathrm{E}+09$ & $\mathrm{~B} 1024$ \\
5 & 5 & $1.68 \mathrm{E}+09$ & $\mathrm{~B} 1024$ \\
6 & 7 & $8.91 \mathrm{E}+08$ & $\mathrm{~B} 1024$ \\
7 & 9 & $5.09 \mathrm{E}+08$ & $\mathrm{~B} 1024$ \\
\hline
\end{tabular}




\section{EVALUATION OF EXPERIMENTAL DATA}

This section provides a review of the experimental data to evaluate the experimental uncertainties. The goal is to determine if the data are of adequate quality to be used in a benchmark. Because the experiments dating from 1986 and the HPRR has been decommissioned, essentially no uncertainty values are available on the HPRR material, its dimensions or the sulfur fluence experiment results. The experimental uncertainties were calculated with SCALE MAVRIC 6.2.3 using continuous energy and multigroup (28 neutron 19 gammas groups) ENDF/B-VII.1 cross section libraries in a multistep calculation method.

\subsection{INITIAL EVALUATION OF THE EXPERIMENTALLY MEASURED DATA}

There are several unknowns related to the experimentally measured data. The counting method used for the activated sulfur pellets is not known in detail, and the sulfur fluence experimental results are reported without associated uncertainty. The burst log sheets provide more insight about the experiments and allow us to separate them by burst, but some information is still missing. The number of fissions of each burst varies between approximately $10^{16}$ and $10^{17}$ in the log burst sheets, but in the sulfur fluence results tables from ORNL-6240, the number of fissions is constant at $10^{17}$. Obviously, the sulfur fluences were normalized to $10^{17}$, but an explanation about this could not be located. It will be assumed that all the bursts create $10^{17}$ fissions. Finally, some sulfur fluence experimental results are unusual, such as those for the pellets located outside the reactor building at 20 and $30 \mathrm{~m}$ from the HPRR. These points are detailed in the following subsections.

\subsubsection{Sulfur Fluence Determination}

It is not known precisely how the activated sulfur pellets were counted and how the conversion to a sulfur fluence was performed. There is also an ambiguity regarding the exact meaning of sulfur fluence; the assumed definition was given in Section 1.5 as the number of sulfur pellet activations per fissions per unit area instead of the typical neutron fluence being the number of neutrons per fissions per unit area. HPRR technical reports and more recent literature [17][18] suggest that sulfur pellets should only be used to detect high-energy neutrons above 2.5 to $3.0 \mathrm{MeV}$. The ENDF/B-VIII.0 ${ }^{32} \mathrm{~S}(\mathrm{n}, \mathrm{p})^{32} \mathrm{P}$ reaction cross section, as shown in Figure 29 and as presented in Table 13, is very low below those energies, but it is not insignificant. Note that the uncertainty of the cross section is defined as being $1 \%$ of the cross section value. A study of lower end neutrons' contribution to the activation of the sulfur pellets was performed using SCALE MAVRIC 6.2.3, and the conclusion is that lower energy neutrons contribute significantly to the tally results. As a test, the cutoff energy for the flux values was changed from none (using the ${ }^{32} \mathrm{~S}(\mathrm{n}, \mathrm{p})^{32} \mathrm{P}$ reaction ENDF/B-VIII.0 cross section library as it is), to removing 2 and 4 groups from the library, corresponding to $2 \mathrm{MeV}$ and $2.5 \mathrm{MeV}$ cutoffs. As a result of these changes, the sulfur fluence results were radically different, with at least a $30 \%$ tally value decrease with each increasing cutoff threshold at the same distance from the HPRR. As there is no certainty about which cutoff should be used, the results of the sample calculations will show all the different cutoff energy cases tested. The cutoff energies are also shown in Table 13. As an additional check on the ENDF/B-VIII.0 cross section veracity, MAVRIC calculations of sulfur fluence were performed using JEFF-3.3 and IRDF 2002 ${ }^{32} \mathrm{~S}(\mathrm{n}, \mathrm{p})^{32} \mathrm{P}$ reaction cross sections. The sulfur fluence results obtained are similar between the three different cross section libraries. In the rest of the report, only the ENDF/B-VIII.0 ${ }^{32} \mathrm{~S}(\mathrm{n}, \mathrm{p})^{32} \mathrm{P}$ reaction cross section will be used. 
Table 13. ENDF/B-VIII.0 ${ }^{32} \mathrm{~S}(\mathrm{n}, \mathrm{p})^{32} \mathrm{P}$ reaction cross section and cutoff definition

\begin{tabular}{|c|c|c|c|}
\hline $\begin{array}{c}\text { Energy } \\
(\mathrm{eV})\end{array}$ & $\begin{array}{c}\text { Cross section } \\
\text { (barns) }\end{array}$ & $\begin{array}{c}\text { Uncertainty } \\
\text { (barns) }\end{array}$ & Cutoff definition \\
\hline $2.00 \mathrm{E}+07$ & $8.6800 \mathrm{E}-02$ & $8.6800 \mathrm{E}-04$ & \multirow{30}{*}{ No cutoff } \\
\hline $1.90 \mathrm{E}+07$ & $8.9500 \mathrm{E}-02$ & $8.9500 \mathrm{E}-04$ & \\
\hline $1.80 \mathrm{E}+07$ & $1.0400 \mathrm{E}-01$ & $1.0400 \mathrm{E}-03$ & \\
\hline $1.70 \mathrm{E}+07$ & $1.2600 \mathrm{E}-01$ & $1.2600 \mathrm{E}-03$ & \\
\hline $1.60 \mathrm{E}+07$ & $1.6200 \mathrm{E}-01$ & $1.6200 \mathrm{E}-03$ & \\
\hline $1.50 \mathrm{E}+07$ & $2.0500 \mathrm{E}-01$ & $2.0500 \mathrm{E}-03$ & \\
\hline $1.40 \mathrm{E}+07$ & $2.5400 \mathrm{E}-01$ & $2.5400 \mathrm{E}-03$ & \\
\hline $1.30 \mathrm{E}+07$ & $3.0400 \mathrm{E}-01$ & $3.0400 \mathrm{E}-03$ & \\
\hline $1.20 \mathrm{E}+07$ & $3.3700 \mathrm{E}-01$ & $3.3700 \mathrm{E}-03$ & \\
\hline $1.10 \mathrm{E}+07$ & $3.5700 \mathrm{E}-01$ & $3.5700 \mathrm{E}-03$ & \\
\hline $1.00 \mathrm{E}+07$ & $3.6800 \mathrm{E}-01$ & $3.6800 \mathrm{E}-03$ & \\
\hline $9.50 \mathrm{E}+06$ & $3.7000 \mathrm{E}-01$ & $3.7000 \mathrm{E}-03$ & \\
\hline $9.00 \mathrm{E}+06$ & $3.6800 \mathrm{E}-01$ & $3.6800 \mathrm{E}-03$ & \\
\hline $8.00 \mathrm{E}+06$ & $3.5900 \mathrm{E}-01$ & $3.5900 \mathrm{E}-03$ & \\
\hline $7.20 \mathrm{E}+06$ & $3.4700 \mathrm{E}-01$ & $3.4700 \mathrm{E}-03$ & \\
\hline $7.00 \mathrm{E}+06$ & $3.4400 \mathrm{E}-01$ & $3.4400 \mathrm{E}-03$ & \\
\hline $6.50 \mathrm{E}+06$ & $3.3700 \mathrm{E}-01$ & $3.3700 \mathrm{E}-03$ & \\
\hline $6.00 \mathrm{E}+06$ & $3.2600 \mathrm{E}-01$ & $3.2600 \mathrm{E}-03$ & \\
\hline $5.40 \mathrm{E}+06$ & $3.0800 \mathrm{E}-01$ & $3.0800 \mathrm{E}-03$ & \\
\hline $5.25 \mathrm{E}+06$ & $3.0300 \mathrm{E}-01$ & $3.0300 \mathrm{E}-03$ & \\
\hline $5.00 \mathrm{E}+06$ & $2.9400 \mathrm{E}-01$ & $2.9400 \mathrm{E}-03$ & \\
\hline $4.70 \mathrm{E}+06$ & $2.8300 \mathrm{E}-01$ & $2.8300 \mathrm{E}-03$ & \\
\hline $4.50 \mathrm{E}+06$ & $2.7400 \mathrm{E}-01$ & $2.7400 \mathrm{E}-03$ & \\
\hline $4.25 \mathrm{E}+06$ & $2.6000 \mathrm{E}-01$ & $2.6000 \mathrm{E}-03$ & \\
\hline $4.00 \mathrm{E}+06$ & $2.4500 \mathrm{E}-01$ & $2.4500 \mathrm{E}-03$ & \\
\hline $3.75 \mathrm{E}+06$ & $2.2700 \mathrm{E}-01$ & $2.2700 \mathrm{E}-03$ & \\
\hline $3.50 \mathrm{E}+06$ & $2.0000 \mathrm{E}-01$ & $2.0000 \mathrm{E}-03$ & \\
\hline $3.00 \mathrm{E}+06$ & $1.4500 \mathrm{E}-01$ & $1.4500 \mathrm{E}-03$ & \\
\hline $2.75 \mathrm{E}+06$ & $1.1500 \mathrm{E}-01$ & $1.1500 \mathrm{E}-03$ & \\
\hline $2.50 \mathrm{E}+06$ & 8.9500E-02 & 8.9500E-04 & \\
\hline $2.40 \mathrm{E}+06$ & $7.5000 \mathrm{E}-02$ & $7.5000 \mathrm{E}-04$ & \multirow{2}{*}{ Cutoff 2} \\
\hline $2.00 \mathrm{E}+06$ & $1.7152 \mathrm{E}-02$ & $1.7152 \mathrm{E}-04$ & \\
\hline $1.75 \mathrm{E}+06$ & $2.3456 \mathrm{E}-03$ & $2.3456 \mathrm{E}-05$ & \multirow{2}{*}{ Cutoff 1} \\
\hline $1.50 \mathrm{E}+06$ & $8.3705 \mathrm{E}-05$ & $8.3705 \mathrm{E}-07$ & \\
\hline
\end{tabular}

\subsubsection{Separation of the Experiments by Burst}

The information in the burst log sheets makes it possible to separate the experiments by burst and each associated core configuration is known. By applying this approach, 7 different bursts were identified and can be modeled separately. Some information is still missing, including data on the presence, length, and type of the sample irradiation hole plug used during the different experiments, and other parts of the information are timeworn and barely readable. Because the critical assembly emits a lot of high-energy neutrons from fissions, and because the HPRR configuration differences between bursts are small, it is possible that the core configuration does not have any influence on the sulfur fluences. The sulfur fluences were obtained using a 2-step calculation as detailed in Section 2.3.3. The 7 bursts were modeled separately to create 7 different fission sources, and the same geometry was used to create 7 MAVRIC shielding calculations to obtain the specific sulfur fluences from each burst. Each fission source was associated with its corresponding shielding model. The first test was to check the influence of the fission source on the sulfur fluence results. To do so, two different fission sources were used with the same 
shielding model, and the sulfur fluence results obtained were statistically the same. From this, it appears that the fission sources do not have to be modeled separately by burst. The second test was to check the influence of the shielding model on the sulfur fluence results. To do so, two different modeled bursts (fission source and associated shielding model) were used to calculate the sulfur fluence at the same sulfur pellet locations. The sulfur fluence results obtained are statistically the same between the pellets at the same location in the two different bursts. This proves that the burst configuration does not have any influence on the sulfur fluence results. In the benchmark model, only one burst configuration and one corresponding fission source will be used to simplify the models. The burst configuration chosen for this work is Burst B1024.

\subsubsection{Case of the Pellets outside the East Gate}

The bare configuration sulfur pellets experiment results at 20 and $30 \mathrm{~m}$ from the HPRR centerline are located outside the reactor building, suggesting that the east steel door could have been open during operation. Performing experiments with this door open means that the dose rate was higher than expected outside the reactor building. No information was found regarding the east door during reactor operation. These two pellets introduce another uncertainty in the benchmark. To check the influence of the east door on the benchmark results, MAVRIC calculations were performed to obtain the sulfur fluence at 20 and 30 $m$ from the HPRR centerline with the east door open and closed. The open door was simply removed from the model and replaced by air. In the case with the door closed, the sulfur fluences at 20 and $30 \mathrm{~m}$ from the HPRR centerline are close to zero. With the door open, the sulfur fluences at 20 and $30 \mathrm{~m}$ from the HPRR centerline are closer to the experimentally measured values, suggesting that the door was open during operation. However, this also modifies the sulfur fluence values of the other sulfur pellets close to the door inside the reactor building, at 9,12 and $15 \mathrm{~m}$. After analysis of those values, it was decided to ignore those two data points and to always model the configuration with the east door closed. In the benchmark, only 22 of the 24 sulfur fluence datapoints were evaluated in the bare configuration.

\subsection{MISSING AND CONTRADICTORY DATA AND RESOLUTION OF THESE DATA}

The main challenge for the creation of this benchmark is the obvious lack of information. The main reasons for this are the date of the experiments and the decommissioning of the HPRR. The experiments were performed in 1985, and at that time, less ways of dimensions/materials characterization were available and less care was given to uncertainty analysis. In 1987, the HPRR was decommissioned, and most of the reactor building elements were removed, limiting the ability to perform dimension/material measurements and analysis today. For these reasons, no uncertainty values are available for any data previously reported in Section 1. All the dimensions provided in Section 1 are from mechanical drawings, documents, or logical assumptions. The accuracy of the drawings and writings is unknown. Moreover, the HPRR was reconfigured multiple times over the years, so care was given to use data from the latest reconfiguration, but sometimes the data were not available. Similarly, all the material composition information found are from documents: no isotopic composition analysis was performed at the time and cannot be performed today. In some cases, contradictory information was found between drawings and technical reports, and in other cases, no dimensions or material data were available, so total assumptions were necessary. A hierarchy of data confidence was established, privileging mechanical drawings first, followed by the most recent writings, and then the inferred dimensions from drawings to scale, with logical assumptions being the last resort if no information could be located. The following subsections detail the origin of the data and how the missing and contradictory data issues were resolved. 


\subsubsection{HPRR Reactor Building}

Most of the dimensional information about the HPRR reactor building was extracted from the reactor building drawing (Drawing 7709), which is shown in Figure 4. Aside from the room components detailed in the following subsections, many other items were present in the reactor room during burst operation, but there are no dimensions or material information available. These other items will be ignored for the benchmark.

\subsubsection{Reactor and annex rooms}

The reactor building wedge shaped roof dimensions are not exactly known, but the top height of the building and at which height the roof is placed is known. No detailed information is available on what was inside the annex room. The floor of the reactor building is concrete with a thickness of $30.48 \mathrm{~cm}$, and it is assumed that soil is below the floor at a depth of $213.36 \mathrm{~cm}$, which corresponds to the reactor storage pits' depth. The room temperature was measured by thermocouples during the experiments of interest and was between $22^{\circ} \mathrm{C}$ and $27^{\circ} \mathrm{C}$, but no pressure or humidity measurements were performed. The air's elemental composition is assumed to be "dryair" from the SCALE 6.2 manual's "Alloys and mixtures" table, provided here as Table 14. The elemental composition of the concrete floor is assumed to be "ORNL Concrete" as shown in Table 3, and the soil's elemental composition was obtained from literature and is provided in Table 15.

Table 14. Elemental composition of air from

\begin{tabular}{lc}
\multicolumn{2}{c}{ the SCALE 6.2 manual [8] } \\
\hline Element & Weight percent \\
\hline $\mathrm{C}$ & 0.0126 \\
$\mathrm{~N}$ & 76.5081 \\
$\mathrm{O}$ & 23.4793 \\
Density & $1.2 \mathrm{E}-03 \mathrm{~g} / \mathrm{cm}^{3}$ \\
\hline
\end{tabular}

Table 15. Elemental composition of soil [19]

\begin{tabular}{lc}
\hline Element & Weight percent \\
\hline $\mathrm{O}$ & 51.3713 \\
$\mathrm{Na}$ & 0.6140 \\
$\mathrm{Mg}$ & 1.3303 \\
$\mathrm{Al}$ & 6.8563 \\
$\mathrm{Si}$ & 27.1183 \\
$\mathrm{~K}$ & 1.4327 \\
$\mathrm{Ca}$ & 5.1167 \\
$\mathrm{Ti}$ & 0.4605 \\
$\mathrm{Mn}$ & 0.0716 \\
$\mathrm{Fe}$ & 5.6283 \\
\hline
\end{tabular}

\subsubsection{Building walls}

The dimensional information for the building walls was contradictory: Drawing 7709 of the reactor building specifies that the walls consist of two layers of structural steel and corrugated aluminum, each of which is $50.8 \mathrm{~cm}$ thick, for a total wall thickness of $101.6 \mathrm{~cm}$. ORNL staff members consider the walls' thickness to be much less. From a technical report (ORNL-TM-9870), the wall's total thickness appears to be $30.48 \mathrm{~cm}$, with $15.24 \mathrm{~cm}$ for each layer. Considering the difference between the three sources of information, the wall's thickness could either be $101.6 \mathrm{~cm}$ or $30.48 \mathrm{~cm}$. It seems that $101.6 \mathrm{~cm}$ is too 
high, so in this case priority is given to the technical report and the walls are assumed to have a total thickness of $30.48 \mathrm{~cm}$, keeping in mind that a high uncertainty exists. Detailed material information about the wall layers is not available. The corrugated aluminum layer is assumed to be pure aluminum of 2.702 $\mathrm{g} / \mathrm{cm}^{3}$ density. The structural steel layer is assumed to be "carbonsteel" as given in the SCALE 6.2 manual "Alloys and mixtures" table, with a density divided by two to approximate the fact that the steel layer is not flat. The structural steel's assumed composition is given in Table 16.

Table 16. Estimated composition of structural steel, modified from the SCALE 6.2 manual [8]

\begin{tabular}{lc}
\hline Element & Weight percent \\
\hline $\mathrm{Fe}$ & 99 \\
$\mathrm{C}$ & 1 \\
Density & $3.9106 \mathrm{~g} / \mathrm{cm}^{3}$ \\
\hline
\end{tabular}

\subsubsection{Reactor storage pits}

The only missing piece of information about the reactor storage pits is the exact location of the pits related to the building walls or to the HPRR centerline. Considering the scale given in Drawing 7709, the center of the west pit is estimated to be located $838.2 \mathrm{~cm}$ from the west end of the reactor room, 411.48 $\mathrm{cm}$ from where the west cavity starts. The east pit center is estimated to be 594.36 from the east end of the building. The pit doors are assumed to be 304 stainless steel of nominal $7.94 \mathrm{~g} / \mathrm{cm}^{3}$ density, and the elemental composition is obtained from the SCALE 6.2 manual's "Alloys and mixtures" table as "ss304s," as shown in Table 17. The difference between the "ss304s" and STM-A240 304 stainless steel elemental compositions is that the SCALE composition takes an average of the varying elemental weight percents.

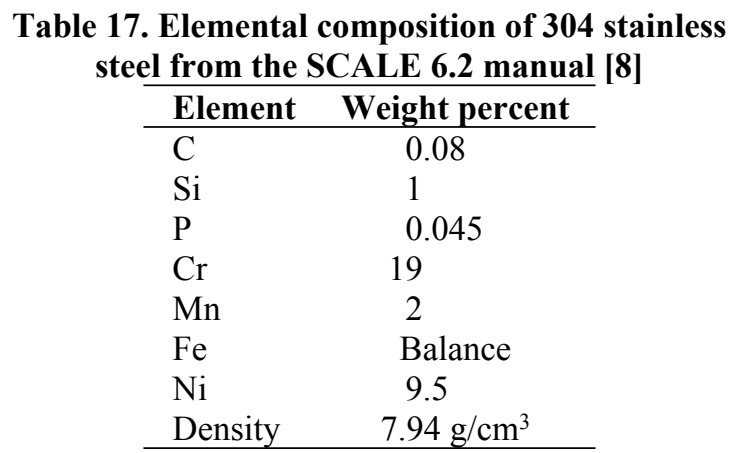

\subsubsection{Gates and door}

The thicknesses of the west door, the east door, and the east gate are not known. They are estimated to be the same as the building walls at $30.48 \mathrm{~cm}$. The gates and doors are assumed to be 304 stainless steel of nominal $7.94 \mathrm{~g} / \mathrm{cm}^{3}$ density, with an elemental composition obtained from the SCALE 6.2 manual.

\subsubsection{Catwalk}

The catwalk dimensions were inferred from the scale provided in Drawing 7709. The catwalk material is not known, so it is assumed to be 304 stainless steel with an elemental composition obtained from the SCALE 6.2 manual. The catwalk is a grid, but the percentage of void is not known, so the 304 stainless steel density was divided by 4 to approximate the grid at $1.985 \mathrm{~g} / \mathrm{cm}^{3}$. 


\subsubsection{Crane}

No dimensional information about the crane was found. The only information available is about the ladder and platform that were used to access the crane. The crane platform is assumed to be of the same material and void percentage as the catwalk, which is 304 stainless steel with the elemental composition from the SCALE 6.2 manual of nominal $7.94 \mathrm{~g} / \mathrm{cm}^{3}$ density. The crane is ignored in the benchmark model.

\subsubsection{Hydraulic lift}

No dimensions or materials information about the hydraulic lift was found. Because it is close to the HPRR, its influence on the sulfur fluence is assumed to be statistically significant, so an approximation needs to be included in the benchmark model. The hydraulic lift dimensions are inferred from a picture of the HPRR shown in Figure 26 and Figure 5. The hydraulic lift is assumed to be 304 stainless steel with an elemental composition obtained from the SCALE 6.2 manual of nominal $7.94 \mathrm{~g} / \mathrm{cm}^{3}$ density.

\subsubsection{Reactor positioning device}

No dimensions or materials information about the reactor positioning device was found. It is possible that the reactor positioning device was outside the building during the experiments of interest for this benchmark. The reactor positioning device will be ignored in the benchmark.

\subsubsection{Concrete pad}

The concrete pad is assumed to be as thick and of the same material composition as the reactor building floor, $30.48 \mathrm{~cm}$ ORNL concrete.

\subsubsection{Sulfur Pellets}

The sulfur pellets are described as "standard commercial fuel pellets" with a diameter of $3.8 \mathrm{~cm}$ and a thickness of $0.95 \mathrm{~cm}$. This information is from an early technical report, ORNL-TM-230. No confirmation of this description was found for the pellets used in 1985 for the experiments of interest, so these dimensions are assumed to be correct. The pellets are positioned at $140 \mathrm{~cm}$ from the concrete floor, and no information about their free field location stand was found. The stands are assumed to be sticks of $1.27 \mathrm{~cm}$ diameter and $140 \mathrm{~cm}$ height, of 304 stainless steel material composition, with a nominal 7.94 $\mathrm{g} / \mathrm{cm}^{3}$ density. The orientation of the pellets is not known, so it is assumed that each cylinder's axis is oriented in a west-east direction. The sulfur pellets are assumed to be $100 \%$ natural sulfur. The abundance of ${ }^{32} \mathrm{~S}$ in natural Sulfur is $94.99 \%$, but ${ }^{33} \mathrm{~S}$ and ${ }^{34} \mathrm{~S}$ also undergo the same $(\mathrm{n}, \mathrm{p})$ reaction with an abundance of $0.75 \%$ and $4.25 \%$ respectively, contributing to the sulfur fluence tally. Because of this, the sulfur pellets can be approximated as $100 \%{ }^{32} \mathrm{~S}$ in the calculations without inducing a statistically significant uncertainty.

\subsubsection{Steel Shield}

Information about the steel shield is scarce. The height, thickness, and weight are known, but the exact material composition is not known and is assumed to be 304 stainless steel with an elemental composition obtained from the SCALE 6.2 manual and a nominal $7.94 \mathrm{~g} / \mathrm{cm}^{3}$ density. Using this knowledge and the fact that the shield is formed by 3 equal parts, the volume and width of each part can be approximated. The angle subtended by the shield is $80^{\circ}$ from an assumed distance of $200 \mathrm{~cm}$. Since the shield is formed of three cuboid parts, it is difficult to reproduce an $80^{\circ}$ subtended angle without more information. Different steel shield angle possibilities must be considered in the uncertainty study. 


\subsection{UNCERTAINTY OF THE HPRR FISSION SOURCE}

\subsubsection{Coating Uncertainties}

The greatest uncertainty about the HPRR critical assembly dimensions and material is regarding the coating. As previously described, different layers of coatings were created around the U-Mo parts of the core, and the thicknesses are not known. To resolve this issue, it was decided to create two versions of the model: a first version without any coating and a second version with the maximum coating thickness possible, which is described as being $0.00508 \mathrm{~cm}$ on the sides of the U-Mo parts, $0.0127 \mathrm{~cm}$ on the top and bottom for the nickel, and $0.00254 \mathrm{~cm}$ for the chromium and gold. The nickel, chromium, and gold were assumed to be of natural compositions and of $8.9 \mathrm{~g} / \mathrm{cm}^{3}, 7.2 \mathrm{~g} / \mathrm{cm}^{3}$ and $18.88 \mathrm{~g} / \mathrm{cm}^{3}$ densities, respectively. The influence of the coating on the sulfur fluence results will be analyzed by comparing those two models results.

\subsubsection{HPRR Components}

Aside from the coating, most of the HPRR component dimensions are thoroughly described in different drawings, so the confidence in those dimensions is high. The different parts' dimensions and/or materials are described in the following subsections.

\subsubsection{U-Mo elements}

There is no missing dimension information on the U-Mo elements. The only information that is missing is about which elements were placed in the core during the experiments of interest in this benchmark. For example, it is possible that the sample irradiation hole plug was not placed in the core, and the plug can be of three different lengths $(11.506,20.955$ and $23.012 \mathrm{~cm})$. There is no way to know about the exact configuration of the core, so different cases must be tested, and the influence on the sulfur fluence results will be determined. The ${ }^{235} \mathrm{U}$ enrichment and the U-Mo alloy density information were slightly different in different sources. The most recent report is assumed to be the most trustworthy source, and the U-Mo alloy composition is shown in Table 18.

Table 18. Assumed composition of all the U-Mo elements

\begin{tabular}{ll}
\hline Element & Weight percent \\
\hline Mo & 10 \\
${ }^{235} \mathrm{U}$ & 83.826 \\
${ }^{238} \mathrm{U}$ & 6.174 \\
Density & $17.1 \mathrm{~g} / \mathrm{cm}^{3}$ \\
\hline
\end{tabular}

\subsubsection{304 stainless steel elements}

All the 304 stainless steel elements are assumed to be of the composition obtained from the SCALE 6.2 manual of nominal $7.94 \mathrm{~g} / \mathrm{cm}^{3}$ density.

\subsubsection{Control rods}

No drawings of the control rods were found, so the dimensions were extracted from technical reports and other written information. The rods U-Mo parts' dimensions are assumed to be correct, but the dimensions of the associated liner tubes, tube retainers, and screws had to be inferred from drawings. The liner tubes, tube retainers, and screws are assumed to be 304 stainless steel with the elemental composition from SCALE 6.2 manual of nominal $7.94 \mathrm{~g} / \mathrm{cm}^{3}$ density. 


\subsubsection{Quick lock}

The quick lock dimensions were obtained from a drawing. The quick lock material is defined to be 17-4 $\mathrm{PH}$ stainless steel of $7.8 \mathrm{~g} / \mathrm{cm}^{3}$ density, and the assumed elemental composition is given in Table 19 as inferred from ASTM-A564/A564M.

Table 19. Assumed composition of 17-4 PH stainless steel

\begin{tabular}{lc}
\hline Element & Weight percent \\
\hline $\mathrm{C}$ & 0.07 \\
$\mathrm{Mn}$ & 1 \\
$\mathrm{P}$ & 0.04 \\
$\mathrm{~S}$ & 0.03 \\
$\mathrm{Si}$ & 1 \\
$\mathrm{Cr}$ & 16.25 \\
$\mathrm{Ni}$ & 4 \\
$\mathrm{Cu}$ & 4 \\
$\mathrm{Nb}$ & 0.30 \\
$\mathrm{Fe}$ & Balance \\
Density & $7.8 \mathrm{~g} / \mathrm{cm}^{3}$ \\
\hline
\end{tabular}

\subsubsection{Aluminum safety cage}

No drawing of the aluminum safety cage was found, so the dimensions were all inferred from documents and Drawing 10099-K-001_D overview. From technical reports, the grid is 62\% void. As 6061-T6 aluminum has a density of $\overline{2} .7 \mathrm{~g} / \mathrm{cm}^{3}$, the density of the grid part of the aluminum safety cage was changed to be $1.026 \mathrm{~g} / \mathrm{cm}^{3}$. The assumed elemental composition is given in Table 20 as inferred from ASTM-B221. Small 6061-T6 aluminum and 304 stainless steel elements of nominal densities were also used to attach the cage to the mounting bracket of the core.

Table 20. Assumed composition of 6061-T6 aluminum

\begin{tabular}{lc}
\hline Element & Weight percent \\
\hline $\mathrm{Si}$ & 0.6 \\
$\mathrm{Fe}$ & 0.7 \\
$\mathrm{Cu}$ & 0.275 \\
$\mathrm{Mn}$ & 0.15 \\
$\mathrm{Mg}$ & 1.0 \\
$\mathrm{Cr}$ & 0.195 \\
$\mathrm{Zn}$ & 0.25 \\
$\mathrm{Ti}$ & 0.15 \\
$\mathrm{Al}$ & Balance \\
Density & $2.7 \mathrm{~g} / \mathrm{cm} 3$ \\
\hline
\end{tabular}

\subsubsection{Safety tube}

The safety tube dimensions were obtained from a drawing; the tube and was assumed to be 304 stainless steel with an elemental composition obtained from the SCALE 6.2 manual of nominal $7.94 \mathrm{~g} / \mathrm{cm}^{3}$ density. The bottom $6.985 \mathrm{~cm}$ portion of the safety tube is drilled with 12 holes of $1.905 \mathrm{~cm}$ diameter. The total volume of matter removed from the tube by these holes is calculated to be $16.1 \%$, and the estimated density is corrected to be $83.9 \%$ of the nominal value for 304 stainless steel. The estimated density of the bottom section of the safety tube is $6.66 \mathrm{~g} / \mathrm{cm}^{3}$. 


\subsubsection{Superstructure}

No drawing of the superstructure was found. The only information available is from pictures, schematics of an old calculation model from 1974, and a drawing without dimensions. The main and most probable elements of the superstructure are three 304 stainless steel plates located above the HPRR. The material of the three main top plates is estimated to be 304 stainless steel with an elemental composition obtained from SCALE 6.2 manual of nominal density $7.94 \mathrm{~g} / \mathrm{cm}^{3}$. The remainder of the elements located between those three plates are difficult to define, as they are complex, and there is no associated information. The approximation chosen considers the totality of the regions between the three top plates to be 304 stainless steel with a density value divided by 4 to approximate void introduction. The assumed density of the superstructure elements is $1.985 \mathrm{~g} / \mathrm{cm}^{3}$.

\subsubsection{Propagation of Fixed Source Uncertainties}

As described above, the number of fission events in all the simulations in this work is $10^{17}$, which corresponds to the probable normalization performed by the experimentalists in charge of the sulfur pellets counting and conversion to sulfur fluence. The simulation results presented in this work are based on a 2-step method. The first step is an eigenvalue calculation performed using SCALE 6.2.3 KENO-VI which creates a spatial and energy distribution of the fission events in the HPRR critical assembly and calculates the average number of neutrons created per fission event, $\bar{v}$. The distributions are then transformed into a fission source. The second step is the use of the fission source created in the first step as a fixed source to calculate the sulfur fluence in different locations with SCALE 6.2.3 MAVRIC, corresponding to the experiments of interest for this benchmark. The MAVRIC computation time is reduced by using the FORWARD-CADIS variance reduction method, using the sulfur pellets as an adjoint source. The fission source selected to be used in the MAVRIC calculations is described in Section 4.1. To determine whether the precision of the fission source has an influence on the sulfur fluence result, two MAVRIC calculations were performed on tallies at the same location with two different fission sources. The first fission source was fine (200 energy groups and 1,083,750 mesh cells), and the second fission source was coarser (56 energy groups and 905,418 mesh cells). Both simulations produced sulfur fluence results that were statistically the same. It was decided to use the coarser fission source (56 energy groups and 905,418 mesh cells) in all of the uncertainty and sample calculations to gain computation time. The uncertainty introduced by the number of fission events normalization and the fission source on the sulfur fluence is defined as $5 \%$.

\subsection{EXPERIMENTAL AND BENCHMARK MODEL PARAMETER UNCERTAINTIES}

The following subsections detail the uncertainties of the individual parameters evaluated in the sensitivity/uncertainty analysis described in Section 2.5. As there is no uncertainty available on any dimension, material density/composition, or even some important geometry details, the uncertainties were all evaluated following the "ICSBEP Guide to the Expression of Uncertainties" [20], except for a few particular cases that are specifically detailed. When no uncertainty is provided, the "ICSBEP Guide to the Expression of Uncertainties" suggests using an uncertainty equal to half the last significant figure provided. This rule is modified in some cases to consider the low trust in the parameters and to avoid underestimating the uncertainty.

\subsubsection{Geometric Dimension Uncertainties}

Except for the particular case of the building walls, the rule from the "ICSBEP Guide to the Expression of Uncertainties" is used to determine the geometric dimension uncertainties. For example, there is no precise measurement of the steel shield's thickness, which is described as being $13 \mathrm{~cm}$. Based on the ICSBEP rule, the uncertainty for this parameter is $0.5 \mathrm{~cm}$. The exception to this rule is the building wall 
thickness, which is not certain. The building wall is illustrated as being $101.6 \mathrm{~cm}$ thick in a drawing and $30.48 \mathrm{~cm}$ in written materials, and it could be even less. A thickness of $30 \mathrm{~cm}$ and an uncertainty of $10 \mathrm{~cm}$ were assumed.

\subsubsection{Material Density Uncertainties}

The "ICSBEP Guide to the Expression of Uncertainties" rule is modified to determine the density dimension uncertainties. Instead of using half of the last significant digit, half of the digits following the decimal point was used. For example, the 304 stainless steel density is assumed to be $7.94 \mathrm{~g} / \mathrm{cm}^{3}$, so the uncertainty of this parameter is $0.47 \mathrm{~g} / \mathrm{cm}^{3}$. The building wall density was averaged between the two different materials to be $3.3063 \mathrm{~g} / \mathrm{cm}^{3}$, and using this rule gives an uncertainty of $0.8063 \mathrm{~g} / \mathrm{cm}^{3}$.

\subsubsection{Material Elemental Composition Uncertainties}

For a few materials, ASTME or other sources provide a range of possible weight fractions for material elemental composition. If this is the case, then the range is used as the weight fraction uncertainty. For example, ASTME states that the chromium content of 304 stainless steel is between 18 and $20 \%$, so the uncertainty for this parameter is $1 \%$. If no range is available, then the "ICSBEP Guide to the Expression of Uncertainties" is used to determine the geometric dimension uncertainties. For example, the U-Mo fuel alloy is stated to be $10 \%$ uranium, so the uncertainty of this parameter will be $0.5 \%$.

\subsubsection{Coating Uncertainties}

The coating uncertainties cannot be simplified as an uncertainty value. As described previously, two model versions were created with maximum and minimum coating thickness values. The results of this study show that sulfur fluence results are higher for the coated version, with a difference of about $5 \%$ between the two models for the different tallies positions. Based on this information, it was decided to keep the fuel coating in the benchmark model and to introduce a $5 \%$ relative uncertainty to the total experimental uncertainty of each tally result.

\subsubsection{Irradiation Sample Plug Uncertainties}

The irradiation sample plug issue cannot be simplified as an uncertainty value. As described previously, three model versions were created corresponding to the three possible plug lengths. The results of this study show statistically insignificant differences between the sulfur fluences coming from the three different models. From this, the uncertainty linked to the irradiation sample plug is judged to be negligible, and the benchmark model will include the $20.955 \mathrm{~cm}$ length plug version only, as it is between the two extreme length values.

\subsection{EVALUATION OF EXPERIMENTAL DATA UNCERTAINTIES}

Evaluation of the experimental data uncertainties is provided in the following subsections for the bare and steel shield configuration and for a sample of sulfur pellet positions. No extensive sensitivity/uncertainty analysis was performed, as only the most significant component uncertainty influence on the sulfur fluence tally results were analyzed. To calculate the experimental uncertainty for the sulfur fluence $s$, defined as $\sigma_{\text {tot }}^{s}$, the uncertainty of each parameter previously determined as $\sigma_{i}$ must be used. The absolute sensitivity of the sulfur fluence $s$, defined as $S_{i}^{S}$, is obtained by perturbing a parameter $i$ and observing the influence on the corresponding sulfur fluence result. Then, due to this perturbation, the absolute uncertainty of the sulfur fluence $s$, defined as $\sigma_{i}^{S}$, is equal to the product of the parameter uncertainty $\sigma_{i}$ by the corresponding sensitivity $S_{i}^{S}$. The experimental uncertainty $\sigma_{t o t}^{S}$ is then obtained by summing in 
quadrature the different uncertainties $\sigma_{i}^{S}$ obtained by sensitivity analysis. The experimental uncertainty is evaluated with the regular ENDF/B VIII.0 ${ }^{32} \mathrm{~S}(\mathrm{n}, \mathrm{p})^{32} \mathrm{P}$ reaction cross section data without any of the energy cutoffs previously introduced.

\subsubsection{Uncertainty Dependencies}

Before performing parameter perturbations, the benchmark model sensitivity was assessed by removing different elements one by one and observing the effect on the sulfur fluence results. If the sulfur fluence results were statistically the same when a particular element was removed, then it was judged that this element could be entirely removed from the benchmark, and no sensitivity study would be necessary. If it was not, then the perturbation/sensitivity study was performed. The list of elements removed from the benchmark model through this process is shown in Table 21, along with and their influence on the sulfur fluence results. Because the only difference between the bare and steel shield configuration is the steel shield and the number and position of the sulfur pellets, Table 21 is valid for both configurations except for the steel shield information, which is not in the bare configuration model.

Table 21. Sensitivity / Uncertainty Dependency Table

\begin{tabular}{lc}
\hline Benchmark model element & $\begin{array}{c}\text { Influence on sulfur } \\
\text { fluence result }\end{array}$ \\
\hline Annex room & Insignificant \\
\hline East door & Insignificant \\
\hline West cavity wedge roof & Insignificant \\
\hline East gate alignment & Insignificant \\
\hline Catwalk & Insignificant \\
\hline Crane platform & Insignificant \\
\hline Crane ladder & Insignificant \\
\hline Hydraulic lift & Insignificant \\
\hline Sulfur pellets stands & Insignificant \\
\hline All material temperature & Insignificant \\
\hline Thermocouples & Insignificant \\
\hline Superstructure elements approximation & Insignificant \\
\hline Building walls thickness & Significant \\
\hline Building walls material & Significant \\
\hline Concrete floor & Significant \\
\hline Concrete east pad & Significant \\
\hline Soil below concrete & Significant \\
\hline West gate & Significant \\
\hline East gate & Significant \\
\hline Core 304 stainless steel elements & Significant \\
\hline Sulfur pellets position & Significant \\
\hline Sulfur pellets dimensions & Significant \\
\hline U-Mo fuel composition & Significant \\
\hline Steel shield position & Significant \\
\hline Steel shield dimensions & Significant \\
\hline Steel shield composition & Significant \\
\hline
\end{tabular}

All the items listed as "Insignificant" have been removed from the benchmark model or have been ignored, and the other items were the subject of a sensitivity study described in more detail below. 


\subsubsection{Bare Configuration Uncertainties}

The sensitivity study was performed on only three tallies out of the 22 sulfur fluence of interest. The sulfur pellet positions chosen for the study were located at $0.12,2.5$, and $15 \mathrm{~m}$. The results of the study performed for the bare configuration benchmark model are shown in Table 22, Table 23 and Table 24. In addition to the perturbed parameters' inferred uncertainties, the fission source, and the coating uncertainties were included in the total experimental uncertainty calculation. As seen in Table 22, Table 23 and Table 24, some of the parameters' relative sensitivities have high uncertainty. This is explained by the perturbation not having a significant effect on the sulfur fluence results compared to the calculation uncertainty. Those parameter contributions are judged to be negligible if the sensitivity uncertainty is higher than $80 \%$. The largest contribution to the total experimental uncertainty is that of the sulfur pellet position in the $0.12 \mathrm{~m}$ sulfur pellet case, as well as the coating uncertainties for the 2.5 and $15 \mathrm{~m}$ cases.

Table 22. Bare configuration sulfur fluence experimental uncertainties for the sulfur pellet located at $0.12 \mathrm{~m}$ from the HPRR centerline

\begin{tabular}{|c|c|c|c|c|}
\hline \multirow[b]{2}{*}{ Uncertainty source } & \multirow[b]{2}{*}{$\begin{array}{l}\text { Uncertainty } \\
\text { value } \sigma_{i}\end{array}$} & \multicolumn{2}{|c|}{ Sensitivity $S_{i}^{S}$ (abs) } & \multirow{2}{*}{$\begin{array}{c}\text { Sulfur } \\
\text { fluence } \\
\text { uncertainty } \\
\sigma_{i}^{s} \text { (abs) } \\
\end{array}$} \\
\hline & & Value & $\begin{array}{l}\text { Uncertainty } \\
\text { (rel \%) }\end{array}$ & \\
\hline Fission source & $5 \%$ & & & $1.64 \mathrm{E}+12$ \\
\hline U-Mo fuel coating & $5 \%$ & & & $1.64 \mathrm{E}+12$ \\
\hline Sulfur pellet position $(\mathrm{cm})$ & 0.5 & $-5.16 \mathrm{E}+12$ & $7 \%$ & $-2.58 \mathrm{E}+12$ \\
\hline Reactor building walls density $\left(\mathrm{g} / \mathrm{cm}^{3}\right)$ & 0.8063 & $-1.33 \mathrm{E}+12$ & $44 \%$ & $-1.07 \mathrm{E}+12$ \\
\hline $\begin{array}{l}\text { Core elements } 304 \text { stainless steel Ni content } \\
(\mathrm{w} \%)\end{array}$ & 1.25 & $-7.12 \mathrm{E}+11$ & $63 \%$ & $-8.90 \mathrm{E}+11$ \\
\hline Soil density $\left(\mathrm{g} / \mathrm{cm}^{3}\right)$ & 0.26 & $-2.71 \mathrm{E}+12$ & $71 \%$ & $-7.04 \mathrm{E}+11$ \\
\hline Reactor building walls carbon content (w\%) & 0.5 & $1.32 \mathrm{E}+12$ & $47 \%$ & $6.60 \mathrm{E}+11$ \\
\hline $\begin{array}{l}\text { Core elements } 304 \text { stainless steel } \mathrm{Cr} \text { content } \\
(\mathrm{w} \%)\end{array}$ & 1 & $3.83 \mathrm{E}+11$ & $72 \%$ & $3.83 \mathrm{E}+11$ \\
\hline Concrete density $\left(\mathrm{g} / \mathrm{cm}^{3}\right)$ & 0.1497 & $-1.82 \mathrm{E}+12$ & $77 \%$ & $-2.72 \mathrm{E}+11$ \\
\hline Sulfur pellet diameter $(\mathrm{cm})$ & 0.05 & $-4.40 \mathrm{E}+12$ & $>80 \%$ & $-2.20 \mathrm{E}+11$ \\
\hline Fuel alloy density $\left(\mathrm{g} / \mathrm{cm}^{3}\right)$ & 0.05 & $1.55 \mathrm{E}+12$ & $12 \%$ & $7.73 \mathrm{E}+10$ \\
\hline Concrete $\mathrm{H}$ content $(\mathrm{w} \%)$ & 0.00035 & $-4.69 \mathrm{E}+12$ & $>80 \%$ & Negligible \\
\hline Gates 304 stainless steel $\mathrm{Cr}$ content (w\%) & 1 & $-1.45 \mathrm{E}+11$ & $>80 \%$ & Negligible \\
\hline Gates 304 stainless steel Ni content (w\%) & 1.25 & $1.47 \mathrm{E}+11$ & $>80 \%$ & Negligible \\
\hline Gates 304 stainless steel density $\left(\mathrm{g} / \mathrm{cm}^{3}\right)$ & 0.47 & $-4.79 \mathrm{E}+09$ & $>80 \%$ & Negligible \\
\hline Reactor building walls thickness (cm) & 10 & $-1.32 \mathrm{E}+10$ & $>80 \%$ & Negligible \\
\hline Fuel alloy Uranium content (w\%) & 0.5 & $2.36 \mathrm{E}+11$ & $>80 \%$ & Negligible \\
\hline $\begin{array}{l}\text { Core elements } 304 \text { stainless steel density } \\
\left(\mathrm{g} / \mathrm{cm}^{3}\right)\end{array}$ & 0.47 & $1.90 \mathrm{E}+11$ & $>80 \%$ & Negligible \\
\hline Sulfur pellet thickness $(\mathrm{cm})$ & 0.005 & $-4.79 \mathrm{E}+12$ & $>80 \%$ & Negligible \\
\hline Total experimental uncertainty $\sigma_{\text {tot }}^{s}(\mathrm{abs})$ & & & & $3.89 \mathrm{E}+12$ \\
\hline Experimental sulfur fluence result at 0.12 & f bare config & ation & & $1.55 \mathrm{E}+13$ \\
\hline Total experimental uncertainty $\sigma_{\text {tot }}^{s}($ rel) & & & & $25.12 \%$ \\
\hline
\end{tabular}


Table 23. Bare configuration sulfur fluence experimental uncertainties for the sulfur pellet located at $2.5 \mathrm{~m}$ from the HPRR centerline

\begin{tabular}{|c|c|c|c|c|}
\hline \multirow[b]{2}{*}{ Uncertainty source } & \multirow[b]{2}{*}{$\begin{array}{l}\text { Uncertainty } \\
\text { value } \sigma_{i}\end{array}$} & \multicolumn{2}{|c|}{ Sensitivity $S_{i}^{S}$ (abs) } & \multirow{2}{*}{$\begin{array}{c}\text { Sulfur } \\
\text { fluence } \\
\text { uncertainty } \\
\sigma_{i}^{S}(\text { abs) } \\
\end{array}$} \\
\hline & & Value & $\begin{array}{c}\text { Uncertainty } \\
\text { (rel \%) }\end{array}$ & \\
\hline Fission source & $5 \%$ & & & $4.32 \mathrm{E}+09$ \\
\hline U-Mo fuel coating & $5 \%$ & & & $4.32 \mathrm{E}+09$ \\
\hline Gates 304 stainless steel Ni content (w\%) & 1.25 & $-9.87 \mathrm{E}+08$ & $59 \%$ & $-1.23 \mathrm{E}+09$ \\
\hline Sulfur pellet position $(\mathrm{cm})$ & 0.5 & $-9.24 \mathrm{E}+08$ & $40 \%$ & $-4.62 \mathrm{E}+08$ \\
\hline Sulfur pellet diameter $(\mathrm{cm})$ & 0.05 & $8.22 \mathrm{E}+09$ & $35 \%$ & $4.11 \mathrm{E}+08$ \\
\hline Gates 304 stainless steel density $\left(\mathrm{g} / \mathrm{cm}^{3}\right)$ & 0.47 & $6.54 \mathrm{E}+08$ & $72 \%$ & $3.07 \mathrm{E}+08$ \\
\hline Fuel alloy density $\left(\mathrm{g} / \mathrm{cm}^{3}\right)$ & 0.05 & $4.23 \mathrm{E}+09$ & $5 \%$ & $2.11 \mathrm{E}+08$ \\
\hline Concrete density $\left(\mathrm{g} / \mathrm{cm}^{3}\right)$ & 0.1497 & $-1.83 \mathrm{E}+09$ & $>80 \%$ & Negligible \\
\hline Concrete $\mathrm{H}$ content $(\mathrm{w} \%)$ & 0.00035 & $-3.97 \mathrm{E}+09$ & $>80 \%$ & Negligible \\
\hline Soil density $\left(\mathrm{g} / \mathrm{cm}^{3}\right)$ & 0.26 & $-1.24 \mathrm{E}+09$ & $>80 \%$ & Negligible \\
\hline Gates 304 stainless steel $\mathrm{Cr}$ content (w\%) & 1 & $-1.54 \mathrm{E}+07$ & $>80 \%$ & Negligible \\
\hline Reactor building walls thickness (cm) & 10 & $-1.08 \mathrm{E}+06$ & $>80 \%$ & Negligible \\
\hline Reactor building walls density $\left(\mathrm{g} / \mathrm{cm}^{3}\right)$ & 0.8063 & $-2.23 \mathrm{E}+08$ & $>80 \%$ & Negligible \\
\hline Reactor building walls carbon content (w\%) & 0.5 & $-1.49 \mathrm{E}+08$ & $>80 \%$ & Negligible \\
\hline Fuel alloy Uranium content (w\%) & 0.5 & $1.80 \mathrm{E}+08$ & $>80 \%$ & Negligible \\
\hline $\begin{array}{l}\text { Core elements } 304 \text { stainless steel } \mathrm{Cr} \text { content } \\
(\mathrm{w} \%)\end{array}$ & 1 & $-4.80 \mathrm{E}+07$ & $>80 \%$ & Negligible \\
\hline $\begin{array}{l}\text { Core elements } 304 \text { stainless steel Ni content } \\
(\mathrm{w} \%)\end{array}$ & 1.25 & $1.23 \mathrm{E}+08$ & $>80 \%$ & Negligible \\
\hline $\begin{array}{l}\text { Core elements } 304 \text { stainless steel density } \\
\left(\mathrm{g} / \mathrm{cm}^{3}\right)\end{array}$ & 0.47 & $-4.86 \mathrm{E}+08$ & $>80 \%$ & Negligible \\
\hline Sulfur pellet thickness $(\mathrm{cm})$ & 0.005 & $3.19 \mathrm{E}+09$ & $>80 \%$ & Negligible \\
\hline Total experimental uncertainty $\sigma_{\text {tot }}^{S}(\mathrm{abs})$ & & & & $6.27 \mathrm{E}+09$ \\
\hline Experimental sulfur fluence result at $2.5 \mathrm{~m}$ & bare confi & & & $4.29 \mathrm{E}+10$ \\
\hline Total experimental uncertainty $\sigma_{t o t}^{S}$ (rel) & & & & $14.62 \%$ \\
\hline
\end{tabular}


Table 24. Bare configuration sulfur fluence experimental uncertainties for the sulfur pellet located at $15 \mathrm{~m}$ from the HPRR centerline

\begin{tabular}{|c|c|c|c|c|}
\hline \multirow[b]{2}{*}{ Uncertainty source } & \multirow[b]{2}{*}{$\begin{array}{l}\text { Uncertainty } \\
\text { value } \sigma_{i}\end{array}$} & \multicolumn{2}{|c|}{ Sensitivity $S_{i}^{S}$ (abs) } & \multirow{2}{*}{$\begin{array}{c}\text { Sulfur } \\
\text { fluence } \\
\text { uncertainty } \\
\sigma_{i}^{S}(\mathbf{a b s}) \\
\end{array}$} \\
\hline & & Value & $\begin{array}{c}\text { Uncertainty } \\
\text { (rel \%) }\end{array}$ & \\
\hline Fission source & $5 \%$ & & & $1.91 \mathrm{E}+08$ \\
\hline U-Mo fuel coating & $5 \%$ & & & $1.91 \mathrm{E}+08$ \\
\hline Reactor building walls thickness $(\mathrm{cm})$ & 10 & $-3.38 \mathrm{E}+06$ & $74 \%$ & $-3.38 \mathrm{E}+07$ \\
\hline Fuel alloy density $\left(\mathrm{g} / \mathrm{cm}^{3}\right)$ & 0.05 & $1.87 \mathrm{E}+08$ & $11 \%$ & $9.35 \mathrm{E}+06$ \\
\hline Sulfur pellet thickness $(\mathrm{cm})$ & 0.005 & $6.81 \mathrm{E}+08$ & $74 \%$ & $3.41 \mathrm{E}+06$ \\
\hline Concrete $\mathrm{H}$ content $(\mathrm{w} \%)$ & 0.00035 & $-4.48 \mathrm{E}+08$ & $67 \%$ & $-1.57 \mathrm{E}+05$ \\
\hline Sulfur pellet position $(\mathrm{cm})$ & 0.5 & $-1.71 \mathrm{E}+07$ & $>80 \%$ & Negligible \\
\hline Concrete density $\left(\mathrm{g} / \mathrm{cm}^{3}\right)$ & 0.1497 & $1.41 \mathrm{E}+08$ & $>80 \%$ & Negligible \\
\hline Soil density $\left(\mathrm{g} / \mathrm{cm}^{3}\right)$ & 0.26 & $-2.92 \mathrm{E}+07$ & $>80 \%$ & Negligible \\
\hline Gates 304 stainless steel $\mathrm{Cr}$ content (w\%) & 1 & $1.51 \mathrm{E}+07$ & $>80 \%$ & Negligible \\
\hline Gates 304 stainless steel Ni content (w\%) & 1.25 & $2.01 \mathrm{E}+07$ & $>80 \%$ & Negligible \\
\hline Gates 304 stainless steel density $\left(\mathrm{g} / \mathrm{cm}^{3}\right)$ & 0.47 & $1.23 \mathrm{E}+07$ & $>80 \%$ & Negligible \\
\hline Reactor building walls density $\left(\mathrm{g} / \mathrm{cm}^{3}\right)$ & 0.8063 & $1.74 \mathrm{E}+07$ & $>80 \%$ & Negligible \\
\hline Reactor building walls carbon content (w\%) & 0.5 & $-4.54 \mathrm{E}+07$ & $>80 \%$ & Negligible \\
\hline Fuel alloy Uranium content (w\%) & 0.5 & $-6.78 \mathrm{E}+06$ & $>80 \%$ & Negligible \\
\hline $\begin{array}{l}\text { Core elements } 304 \text { stainless steel } \mathrm{Cr} \text { content } \\
(\mathrm{w} \%)\end{array}$ & 1 & $-1.78 \mathrm{E}+07$ & $>80 \%$ & Negligible \\
\hline $\begin{array}{l}\text { Core elements } 304 \text { stainless steel Ni content } \\
(\mathrm{w} \%)\end{array}$ & 1.25 & $-3.25 \mathrm{E}+07$ & $>80 \%$ & Negligible \\
\hline $\begin{array}{l}\text { Core elements } 304 \text { stainless steel density } \\
\left(\mathrm{g} / \mathrm{cm}^{3}\right)\end{array}$ & 0.47 & $1.23 \mathrm{E}+07$ & $>80 \%$ & Negligible \\
\hline Sulfur pellet diameter $(\mathrm{cm})$ & 0.05 & $-3.69 \mathrm{E}+08$ & $>80 \%$ & Negligible \\
\hline \multicolumn{4}{|l|}{ Total experimental uncertainty $\sigma_{\text {tot }}^{S}$ (abs) } & $2.72 \mathrm{E}+08$ \\
\hline \multicolumn{4}{|c|}{ Experimental sulfur fluence result at $15 \mathrm{~m}$ of bare configuration } & $1.20 \mathrm{E}+09$ \\
\hline \multicolumn{4}{|l|}{ Total experimental uncertainty $\sigma_{\text {tot }}^{S}$ (rel) } & $22.67 \%$ \\
\hline
\end{tabular}

Based on those results, the total experimental uncertainty seems to be higher for the pellets that were near and far from the HPRR centerline. This can be explained by the presence of more elements around the pellets that can account for sulfur fluence uncertainty. The pellets around the middle of the HPRR reactor room are more isolated from the HPRR and the east wall. Since the sensitivity study was not performed for all the sulfur pellet positions, a conservative approach was used, and the highest total experimental uncertainty determined from this study will be used for all the sulfur fluence results at different locations. The benchmark model sulfur fluences and associated total experimental uncertainties for the 22 sulfur fluences of the bare configuration are shown in Table 25 . 
Table 25. Benchmark model of sulfur fluence data for the bare configuration

\begin{tabular}{ccccc}
\hline $\begin{array}{c}\text { Position } \\
\text { number }\end{array}$ & $\begin{array}{c}\text { Distance from } \\
\text { HPRR centerline } \\
(\mathbf{m})\end{array}$ & $\begin{array}{c}\text { Sulfur fluence } \\
\left(\mathbf{n} / \mathbf{c m}^{\mathbf{2}}\right)\end{array}$ & $\begin{array}{c}\text { Absolute } \\
\text { uncertainty }\end{array}$ & $\begin{array}{c}\text { Relative } \\
\text { uncertainty }\end{array}$ \\
\hline 1 & 0.12 & $1.55 \mathrm{E}+13$ & $4.00 \mathrm{E}+12$ & $25.12 \%$ \\
2 & 0.144 & $1.30 \mathrm{E}+13$ & $3.35 \mathrm{E}+12$ & $25.12 \%$ \\
3 & 0.2 & $6.09 \mathrm{E}+12$ & $1.57 \mathrm{E}+12$ & $25.12 \%$ \\
4 & 0.3 & $2.74 \mathrm{E}+12$ & $7.06 \mathrm{E}+11$ & $25.12 \%$ \\
5 & 0.4 & $1.37 \mathrm{E}+12$ & $3.53 \mathrm{E}+11$ & $25.12 \%$ \\
6 & 0.5 & $9.42 \mathrm{E}+11$ & $2.43 \mathrm{E}+11$ & $25.12 \%$ \\
7 & 0.62 & $6.77 \mathrm{E}+11$ & $1.75 \mathrm{E}+11$ & $25.12 \%$ \\
8 & 0.75 & $4.47 \mathrm{E}+11$ & $1.15 \mathrm{E}+11$ & $25.12 \%$ \\
9 & 1 & $2.54 \mathrm{E}+11$ & $6.55 \mathrm{E}+10$ & $25.12 \%$ \\
10 & 1.25 & $1.45 \mathrm{E}+11$ & $3.74 \mathrm{E}+10$ & $25.12 \%$ \\
11 & 1.5 & $1.11 \mathrm{E}+11$ & $2.86 \mathrm{E}+10$ & $25.12 \%$ \\
12 & 1.75 & $8.85 \mathrm{E}+10$ & $2.28 \mathrm{E}+10$ & $25.12 \%$ \\
13 & 2 & $6.69 \mathrm{E}+10$ & $1.72 \mathrm{E}+10$ & $25.12 \%$ \\
14 & 2.5 & $4.29 \mathrm{E}+10$ & $1.11 \mathrm{E}+10$ & $25.12 \%$ \\
15 & 3 & $2.99 \mathrm{E}+10$ & $7.71 \mathrm{E}+09$ & $25.12 \%$ \\
16 & 3.5 & $2.26 \mathrm{E}+10$ & $5.83 \mathrm{E}+09$ & $25.12 \%$ \\
17 & 4 & $1.74 \mathrm{E}+10$ & $4.49 \mathrm{E}+09$ & $25.12 \%$ \\
18 & 5 & $1.12 \mathrm{E}+10$ & $2.89 \mathrm{E}+09$ & $25.12 \%$ \\
19 & 7 & $5.83 \mathrm{E}+09$ & $1.50 \mathrm{E}+09$ & $25.12 \%$ \\
20 & 9 & $3.54 \mathrm{E}+09$ & $9.13 \mathrm{E}+08$ & $25.12 \%$ \\
21 & 12 & $1.99 \mathrm{E}+09$ & $5.13 \mathrm{E}+08$ & $25.12 \%$ \\
22 & 15 & $1.20 \mathrm{E}+09$ & $3.09 \mathrm{E}+08$ & $25.12 \%$ \\
\hline
\end{tabular}

\subsubsection{Steel Shield Configuration Uncertainties}

For the steel shield configuration, it was also decided to study only three tallies out of the 7 sulfur fluences of interest. The sulfur pellet positions chosen for the study were located at 2, 5, and $9 \mathrm{~m}$. The results of the sensitivity study performed for the steel shield configuration benchmark model are shown in Table 26, Table 27 and Table 28. In addition to the perturbed parameters' inferred uncertainties, the fission source and the coating uncertainties were included in the total experimental uncertainty calculation. As seen in Table 26, Table 27 and Table 28, some of the parameters' relative sensitivities have high uncertainty. This is explained by the perturbation not having a significant effect on the sulfur fluence results compared to the calculation uncertainty. Those parameter contributions are judged to be negligible if the sensitivity uncertainty is higher than $80 \%$. The largest non-negligible contribution to the total experimental uncertainty is that of the sulfur pellet diameter in the 2.5 and $9 \mathrm{~m}$ sulfur pellet cases, as well as the steel shield density in the $5 \mathrm{~m}$ case. 
Table 26. Steel shield configuration sulfur fluence experimental uncertainties for the sulfur pellet located at $\mathbf{2 . 5} \mathrm{m}$ from the HPRR centerline

\begin{tabular}{|c|c|c|c|c|}
\hline \multirow[b]{2}{*}{ Uncertainty source } & \multirow{2}{*}{$\begin{array}{l}\text { Uncertainty } \\
\text { value } \sigma_{i}\end{array}$} & \multicolumn{2}{|c|}{ Sensitivity $S_{i}^{S}$ (abs) } & \multirow{2}{*}{$\begin{array}{c}\text { Sulfur fluence } \\
\text { uncertainty } \\
\sigma_{i}^{s}(\text { abs) }\end{array}$} \\
\hline & & Value & $\begin{array}{l}\text { Uncertainty } \\
\text { (rel \%) }\end{array}$ & \\
\hline Fission source & $5 \%$ & & & $1.18 \mathrm{E}+09$ \\
\hline U-Mo fuel coating & $5 \%$ & & & $1.18 \mathrm{E}+09$ \\
\hline $\begin{array}{l}\text { Steel shield } 304 \text { stainless steel density } \\
\left(\mathrm{g} / \mathrm{cm}^{3}\right)\end{array}$ & 0.47 & $4.43 \mathrm{E}+09$ & $11 \%$ & $2.08 \mathrm{E}+09$ \\
\hline Steel shield thickness $(\mathrm{cm})$ & 0.5 & $2.41 \mathrm{E}+09$ & $16 \%$ & $1.21 \mathrm{E}+09$ \\
\hline Reactor building walls thickness (cm) & 10 & $-7.04 \mathrm{E}+07$ & $47 \%$ & $-7.04 \mathrm{E}+08$ \\
\hline Reactor building walls density $\left(\mathrm{g} / \mathrm{cm}^{3}\right)$ & 0.8063 & $-8.48 \mathrm{E}+08$ & $71 \%$ & $-6.84 \mathrm{E}+08$ \\
\hline Gates 304 stainless steel $\mathrm{Cr}$ content (w\%) & 1 & $4.36 \mathrm{E}+08$ & $80 \%$ & $4.36 \mathrm{E}+08$ \\
\hline Gates 304 stainless steel density $\left(\mathrm{g} / \mathrm{cm}^{3}\right)$ & 0.47 & $-7.49 \mathrm{E}+08$ & $64 \%$ & $-3.52 \mathrm{E}+08$ \\
\hline Sulfur pellet diameter $(\mathrm{cm})$ & 0.05 & $6.05 \mathrm{E}+09$ & $59 \%$ & $3.03 \mathrm{E}+08$ \\
\hline Steel shield position $(\mathrm{cm})$ & 0.5 & $5.82 \mathrm{E}+08$ & $59 \%$ & $2.91 \mathrm{E}+08$ \\
\hline Sulfur pellet position $(\mathrm{cm})$ & 0.5 & $-4.19 \mathrm{E}+08$ & $75 \%$ & $-2.10 \mathrm{E}+08$ \\
\hline Concrete density $\left(\mathrm{g} / \mathrm{cm}^{3}\right)$ & 0.1497 & $-1.40 \mathrm{E}+09$ & $>80 \%$ & Negligible \\
\hline Concrete $\mathrm{H}$ content $(\mathrm{w} \%)$ & 0.00035 & $-1.61 \mathrm{E}+09$ & $>80 \%$ & Negligible \\
\hline Soil density $\left(\mathrm{g} / \mathrm{cm}^{3}\right)$ & 0.26 & $8.10 \mathrm{E}+07$ & $>80 \%$ & Negligible \\
\hline Gates 304 stainless steel Ni content (w\%) & 1.25 & $-1.43 \mathrm{E}+08$ & $>80 \%$ & Negligible \\
\hline Reactor building walls carbon content (w\%) & 0.5 & $8.48 \mathrm{E}+07$ & $>80 \%$ & Negligible \\
\hline $\begin{array}{l}\text { Steel shield } 304 \text { stainless steel } \mathrm{Cr} \text { content } \\
\text { (w\%) }\end{array}$ & 1 & $\mathrm{E}+08$ & $>80 \%$ & Negligible \\
\hline $\begin{array}{l}\text { Steel shield } 304 \text { stainless steel Ni content } \\
(\mathrm{w} \%)\end{array}$ & 1.25 & $3.96 \mathrm{E}+08$ & $>80 \%$ & Negligible \\
\hline Sulfur pellet thickness $(\mathrm{cm})$ & 0.005 & $-4.40 \mathrm{E}+09$ & $>80 \%$ & Negligible \\
\hline Total experimental uncertainty $\sigma_{\text {tot }}^{s}(\mathrm{abs})$ & & & & $3.18 \mathrm{E}+09$ \\
\hline Experimental sulfur fluence result at $2.5 \mathrm{~m}$ & eel shield & guration & & $6.49 \mathrm{E}+09$ \\
\hline Total experimental uncertainty $\sigma_{\text {tot }}^{S}$ (rel) & & & & $49.00 \%$ \\
\hline
\end{tabular}


Table 27. Steel shield configuration sulfur fluence experimental uncertainties for the sulfur pellet located at $5 \mathrm{~m}$ from the HPRR centerline

\begin{tabular}{|c|c|c|c|c|}
\hline \multirow[b]{2}{*}{ Uncertainty source } & \multirow{2}{*}{$\begin{array}{l}\text { Uncertainty } \\
\text { value } \sigma_{i}\end{array}$} & \multicolumn{2}{|c|}{ Sensitivity $S_{i}^{S}$ (abs) } & \multirow{2}{*}{$\begin{array}{c}\text { Sulfur fluence } \\
\text { uncertainty } \\
\sigma_{i}^{S}(a b s)\end{array}$} \\
\hline & & Value & $\begin{array}{l}\text { Uncertainty } \\
(\text { rel \%) }\end{array}$ & \\
\hline Fission source & $5 \%$ & & & $3.71 \mathrm{E}+08$ \\
\hline U-Mo fuel coating & $5 \%$ & & & $3.71 \mathrm{E}+08$ \\
\hline $\begin{array}{l}\text { Steel shield } 304 \text { stainless steel density } \\
\left(\mathrm{g} / \mathrm{cm}^{3}\right)\end{array}$ & 0.47 & $8.46 \mathrm{E}+08$ & $8 \%$ & $3.98 \mathrm{E}+08$ \\
\hline Steel shield thickness $(\mathrm{cm})$ & 0.5 & $4.66 \mathrm{E}+08$ & $12 \%$ & $2.33 \mathrm{E}+08$ \\
\hline Reactor building walls density $\left(\mathrm{g} / \mathrm{cm}^{3}\right)$ & 0.8063 & $-1.48 \mathrm{E}+08$ & $62 \%$ & $-1.20 \mathrm{E}+08$ \\
\hline Reactor building walls thickness $(\mathrm{cm})$ & 10 & $-8.30 \mathrm{E}+06$ & $60 \%$ & $-8.30 \mathrm{E}+07$ \\
\hline Concrete density $\left(\mathrm{g} / \mathrm{cm}^{3}\right)$ & 0.1497 & $3.71 \mathrm{E}+08$ & $65 \%$ & $5.56 \mathrm{E}+07$ \\
\hline Reactor building walls carbon content (w\%) & 0.5 & $-7.70 \mathrm{E}+07$ & $68 \%$ & $-3.85 \mathrm{E}+07$ \\
\hline Sulfur pellet diameter $(\mathrm{cm})$ & 0.05 & $7.13 \mathrm{E}+08$ & $75 \%$ & $3.56 \mathrm{E}+07$ \\
\hline Sulfur pellet position $(\mathrm{cm})$ & 0.5 & $-6.13 \mathrm{E}+07$ & $79 \%$ & $-3.07 \mathrm{E}+07$ \\
\hline Concrete $\mathrm{H}$ content $(\mathrm{w} \%)$ & 0.00035 & $1.10 \mathrm{E}+08$ & $>80 \%$ & Negligible \\
\hline Soil density $\left(\mathrm{g} / \mathrm{cm}^{3}\right)$ & 0.26 & $-1.70 \mathrm{E}+08$ & $>80 \%$ & Negligible \\
\hline Gates 304 stainless steel $\mathrm{Cr}$ content (w\%) & 1 & $-1.46 \mathrm{E}+07$ & $>80 \%$ & Negligible \\
\hline Gates 304 stainless steel Ni content (w\%) & 1.25 & $-5.10 \mathrm{E}+07$ & $>80 \%$ & Negligible \\
\hline Gates 304 stainless steel density $\left(\mathrm{g} / \mathrm{cm}^{3}\right)$ & 0.47 & $-6.16 \mathrm{E}+07$ & $>80 \%$ & Negligible \\
\hline Steel shield position $(\mathrm{cm})$ & 0.5 & $2.76 \mathrm{E}+07$ & $>80 \%$ & Negligible \\
\hline $\begin{array}{l}\text { Steel shield } 304 \text { stainless steel Cr content } \\
(\mathrm{w} \%)\end{array}$ & 1 & $1.69 \mathrm{E}+07$ & $>80 \%$ & Negligible \\
\hline $\begin{array}{l}\text { Steel shield } 304 \text { stainless steel Ni content } \\
(\text { w\%) }\end{array}$ & 1.25 & $-9.10 \mathrm{E}+06$ & $>80 \%$ & Negligible \\
\hline Sulfur pellet thickness $(\mathrm{cm})$ & 0.005 & $-2.60 \mathrm{E}+08$ & $>80 \%$ & Negligible \\
\hline Total experimental uncertainty $\sigma_{\text {tot }}^{S}(\mathrm{abs})$ & & & & $7.19 \mathrm{E}+08$ \\
\hline Experimental sulfur fluence result at $5 \mathrm{~m}$ & el shield c & ration & & $1.68 \mathrm{E}+09$ \\
\hline Total experimental uncertainty $\sigma_{\text {tot }}^{S}(\mathrm{rel})$ & & & & $42.80 \%$ \\
\hline
\end{tabular}


Table 28. Steel shield configuration sulfur fluence experimental uncertainties for the sulfur pellet located at $9 \mathrm{~m}$ from the HPRR centerline

\begin{tabular}{|c|c|c|c|c|}
\hline \multirow[b]{2}{*}{ Uncertainty source } & \multirow[b]{2}{*}{$\begin{array}{l}\text { Uncertainty } \\
\text { value } \sigma_{i}\end{array}$} & \multicolumn{2}{|c|}{ Sensitivity $S_{i}^{S}$ (abs) } & \multirow{2}{*}{$\begin{array}{c}\text { Sulfur fluence } \\
\text { uncertainty } \\
\sigma_{i}^{S}(a b s)\end{array}$} \\
\hline & & Value & $\begin{array}{l}\text { Uncertainty } \\
\text { (rel \%) }\end{array}$ & \\
\hline Fission source & $5 \%$ & & & $1.47 \mathrm{E}+08$ \\
\hline U-Mo fuel coating & $5 \%$ & & & $1.47 \mathrm{E}+08$ \\
\hline $\begin{array}{l}\text { Steel shield } 304 \text { stainless steel density } \\
\left(\mathrm{g} / \mathrm{cm}^{3}\right)\end{array}$ & 0.47 & $2.72 \mathrm{E}+08$ & $12 \%$ & $1.28 \mathrm{E}+08$ \\
\hline Steel shield thickness $(\mathrm{cm})$ & 0.5 & $1.21 \mathrm{E}+08$ & $24 \%$ & $6.05 \mathrm{E}+07$ \\
\hline Reactor building walls carbon content (w\%) & 0.5 & $-5.31 \mathrm{E}+07$ & $45 \%$ & $-2.65 \mathrm{E}+07$ \\
\hline Sulfur pellet diameter $(\mathrm{cm})$ & 0.05 & $4.19 \mathrm{E}+08$ & $65 \%$ & $2.10 \mathrm{E}+07$ \\
\hline Concrete $\mathrm{H}$ content $(\mathrm{w} \%)$ & 0.00035 & $3.63 \mathrm{E}+08$ & $64 \%$ & $1.27 \mathrm{E}+05$ \\
\hline Sulfur pellet position $(\mathrm{cm})$ & 0.5 & $2.88 \mathrm{E}+07$ & $>80 \%$ & Negligible \\
\hline Concrete density $\left(\mathrm{g} / \mathrm{cm}^{3}\right)$ & 0.1497 & $8.65 \mathrm{E}+07$ & $>80 \%$ & Negligible \\
\hline Soil density $\left(\mathrm{g} / \mathrm{cm}^{3}\right)$ & 0.26 & $-7.19 \mathrm{E}+07$ & $>80 \%$ & Negligible \\
\hline Gates 304 stainless steel $\mathrm{Cr}$ content (w\%) & 1 & $1.62 \mathrm{E}+07$ & $>80 \%$ & Negligible \\
\hline Gates 304 stainless steel Ni content (w\%) & 1.25 & $-2.29 \mathrm{E}+07$ & $>80 \%$ & Negligible \\
\hline Gates 304 stainless steel density $\left(\mathrm{g} / \mathrm{cm}^{3}\right)$ & 0.47 & $-3.38 \mathrm{E}+07$ & $>80 \%$ & Negligible \\
\hline Reactor building walls thickness $(\mathrm{cm})$ & 10 & $-2.79 \mathrm{E}+06$ & $>80 \%$ & Negligible \\
\hline Reactor building walls density $\left(\mathrm{g} / \mathrm{cm}^{3}\right)$ & 0.8063 & $-5.94 \mathrm{E}+07$ & $>80 \%$ & Negligible \\
\hline Steel shield position $(\mathrm{cm})$ & 0.5 & $-2.90 \mathrm{E}+07$ & $>80 \%$ & Negligible \\
\hline $\begin{array}{l}\text { Steel shield } 304 \text { stainless steel Cr content } \\
(\mathrm{w} \%)\end{array}$ & 1 & $2.61 \mathrm{E}+06$ & $>80 \%$ & Negligible \\
\hline $\begin{array}{l}\text { Steel shield } 304 \text { stainless steel Ni content } \\
(\mathrm{w} \%)\end{array}$ & 1.25 & $1.06 \mathrm{E}+07$ & $>80 \%$ & Negligible \\
\hline Sulfur pellet thickness $(\mathrm{cm})$ & 0.005 & $4.52 \mathrm{E}+07$ & $>80 \%$ & Negligible \\
\hline Total experimental uncertainty $\sigma_{\text {tot }}^{s}(\mathrm{abs})$ & & & & $2.54 \mathrm{E}+08$ \\
\hline Experimental sulfur fluence result at $9 \mathrm{~m}$ & eel shield co & guration & & $5.09 E+08$ \\
\hline Total experimental uncertainty $\sigma_{\text {tot }}^{S}(\mathrm{rel})$ & & & & $49.84 \%$ \\
\hline
\end{tabular}

As in the bare configuration results, the total experimental uncertainty seems to be higher for the pellets near and far from the HPRR centerline. This can be explained by the presence of more elements around the pellets that can account for sulfur fluence uncertainty. The pellets around the middle of the HPRR reactor room are more isolated from the HPRR and the east wall. Since the sensitivity study was not performed for all the sulfur pellet positions, a conservative approach was used, and the highest total experimental uncertainty determined from this study will be used for all the sulfur fluence results. The benchmark model sulfur fluences and associated total experimental uncertainties for the 7 sulfur fluences of the steel configuration are shown in Table 29.

Table 29. Benchmark model sulfur fluence data for the steel shield configuration

\begin{tabular}{lcccc}
\hline $\begin{array}{l}\text { Position } \\
\text { number }\end{array}$ & Distance (m) & Sulfur fluence $\left(\mathbf{n} / \mathbf{c m}^{\mathbf{2}}\right)$ & Absolute uncertainty & Relative uncertainty \\
\hline 1 & 2.5 & $6.48 \mathrm{E}+09$ & $3.83 \mathrm{E}+09$ & $49.84 \%$ \\
2 & 3 & $4.59 \mathrm{E}+09$ & $2.71 \mathrm{E}+09$ & $49.84 \%$ \\
3 & 3.5 & $3.41 \mathrm{E}+09$ & $2.02 \mathrm{E}+09$ & $49.84 \%$ \\
4 & 4 & $2.59 \mathrm{E}+09$ & $1.53 \mathrm{E}+09$ & $49.84 \%$ \\
5 & 5 & $1.68 \mathrm{E}+09$ & $9.93 \mathrm{E}+08$ & $49.84 \%$ \\
6 & 7 & $8.91 \mathrm{E}+08$ & $5.27 \mathrm{E}+08$ & $49.84 \%$ \\
7 & 9 & $5.09 \mathrm{E}+08$ & $3.01 \mathrm{E}+08$ & $49.84 \%$ \\
\hline
\end{tabular}




\section{BENCHMARK SPECIFICATIONS}

\subsection{DESCRIPTION OF MODEL}

Because the experimental results of interest include 22 sulfur fluence results from the HPRR in the bare configuration and 7 sulfur fluence results of the HPRR with a steel shield configuration, two separate benchmark models were created. Both models are the same except for the shield and the different number and positions of sulfur pellets. The benchmark model follows the description of the experiment in Sections 1 and 2 as much as possible. An overview of the benchmark model is presented in Section 3.1.1, and a summary of the simplified benchmark compared to the actual experiments is provided in Section 3.1.2.

\subsubsection{Model Overview}

An illustration of the bare configuration benchmark model is shown in Figure 33. The top half of the model is removed, and the air has been hidden to provide a view of the critical assembly and the sulfur pellets inside the reactor building room. The $(\mathrm{x}, \mathrm{y}, \mathrm{z})$ coordinate system is also shown in Figure 33, centered on the HPRR, with the origin $150 \mathrm{~cm}$ above the concrete floor. This corresponds to a $\mathrm{z}=0$ position around the top of Annulus 3. The HPRR, west gate, west cavity, east gate, reactor building walls, west storage pit, soil, concrete floor, and 22 sulfur pellets are visible.

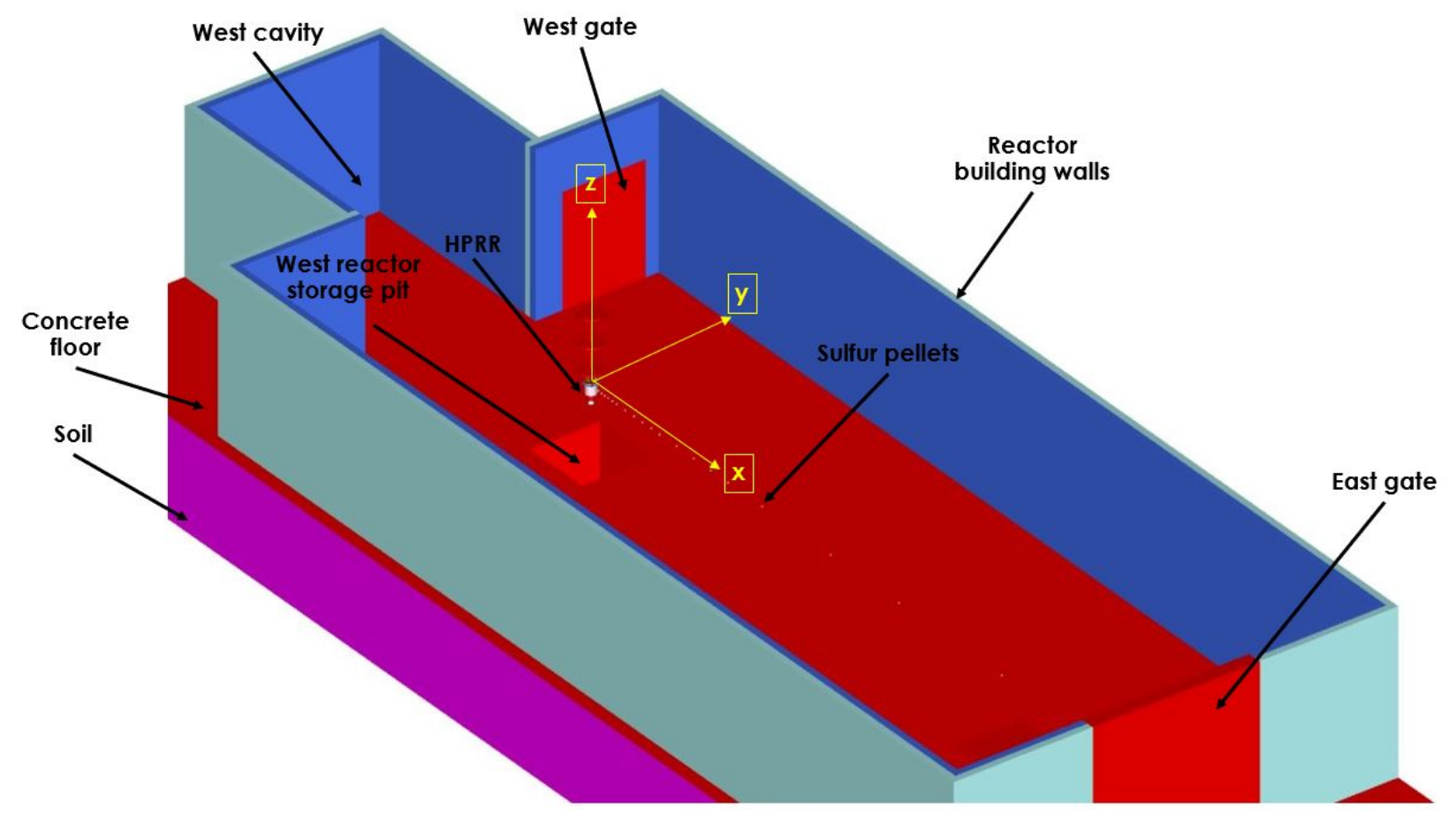

Figure 33. Overview of the bare configuration benchmark model.

A zoomed in view of the benchmark model HPRR is shown in Figure 34. The air, concrete, and soil are hidden to provide a view of the HPRR and the sulfur pellets in greater detail. The (x,y,z) coordinate system is also shown in Figure 34, centered on the HPRR, with the origin around the top of Annulus 3. The HPRR is visible, as well as the surrounding aluminum safety cage. The safety tube is visible below the core. The three top plates and central hanger rod, along with part of the superstructure, are visible above the core. The sulfur pellets are placed on the $\mathrm{x}$ axis at $\mathrm{y}=0$ and $\mathrm{z}=-10$. 


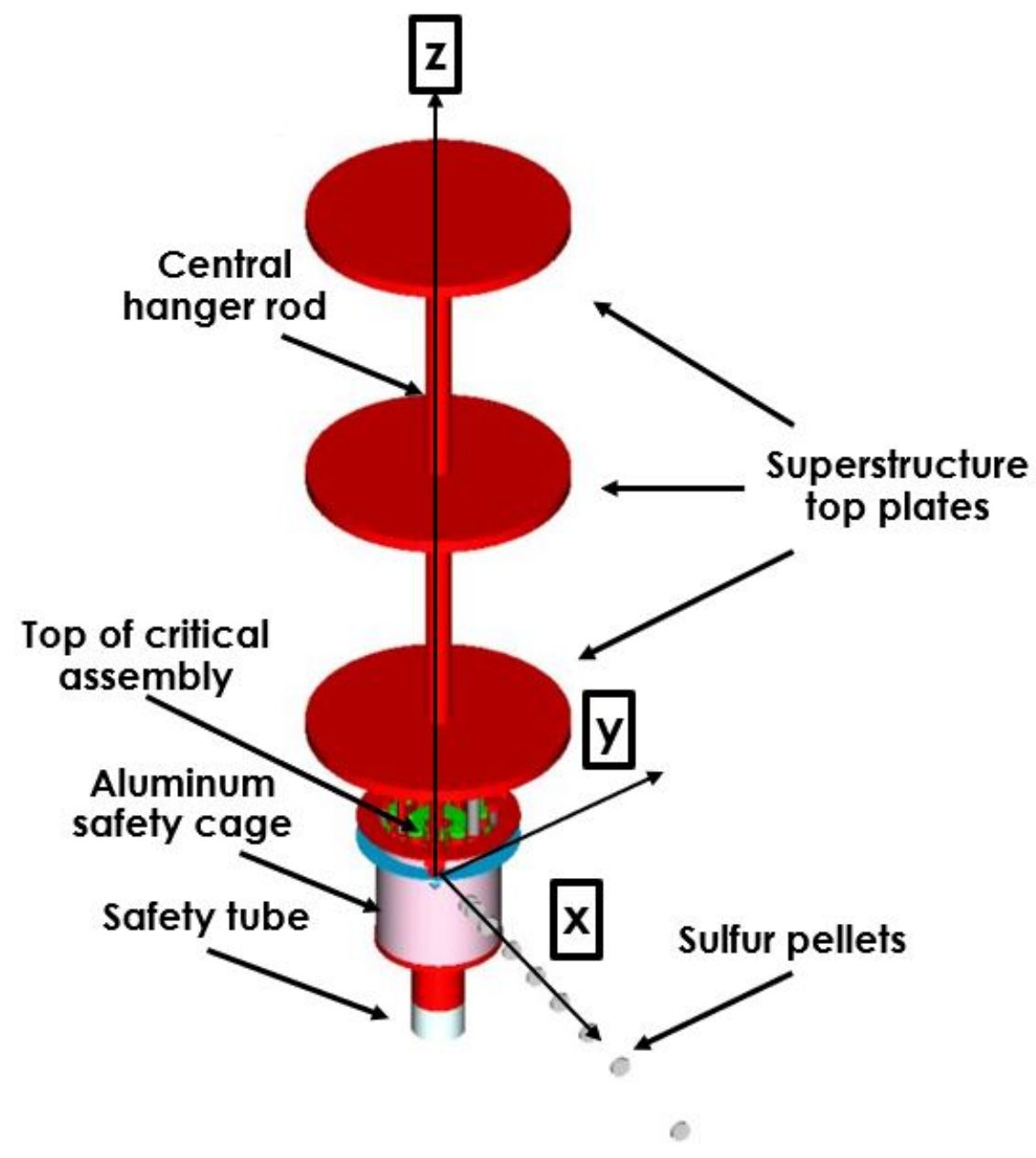

Figure 34. Overview of the bare configuration benchmark model zoomed in on the HPRR.

The HPRR is shown in Figure 35, zoomed in further and on a front-right quarter cutout view. Most of the core components are visible, as are the different U-Mo annuli, the U-Mo bolts, U-Mo bolt plugs, the control rods and their liner tubes, the safety block, the quick lock, the safety tube, the aluminum safety cage, and the mounting bracket. The U-Mo alloy regions are represented in blue. The green color represents the nickel coating, which is visible on the outside of every blue U-Mo region. A visualization error makes the top of the MAR appear gray in the illustration, but it is actually blue like the other U-Mo parts, as it is shown out of the core in the burst B1024 configuration. 


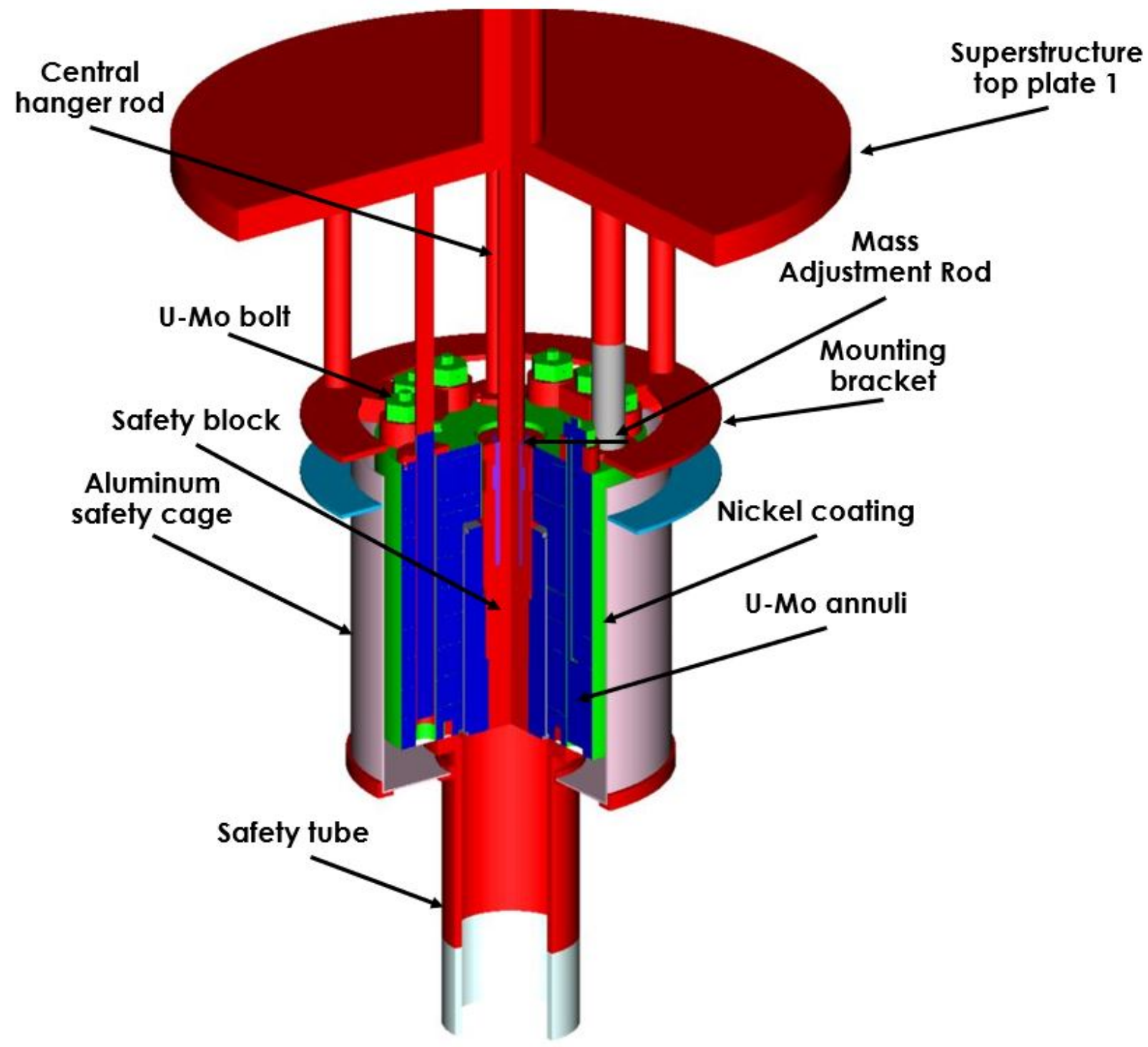

Figure 35. Overview of the bare configuration benchmark model front right quarter zoomed in on the HPRR.

The steel shield configuration is shown in Figure 36. Note the color for 304 stainless steel has been changed from red to green in this picture for clarity. The three separate parts of the steel shield are visible. 


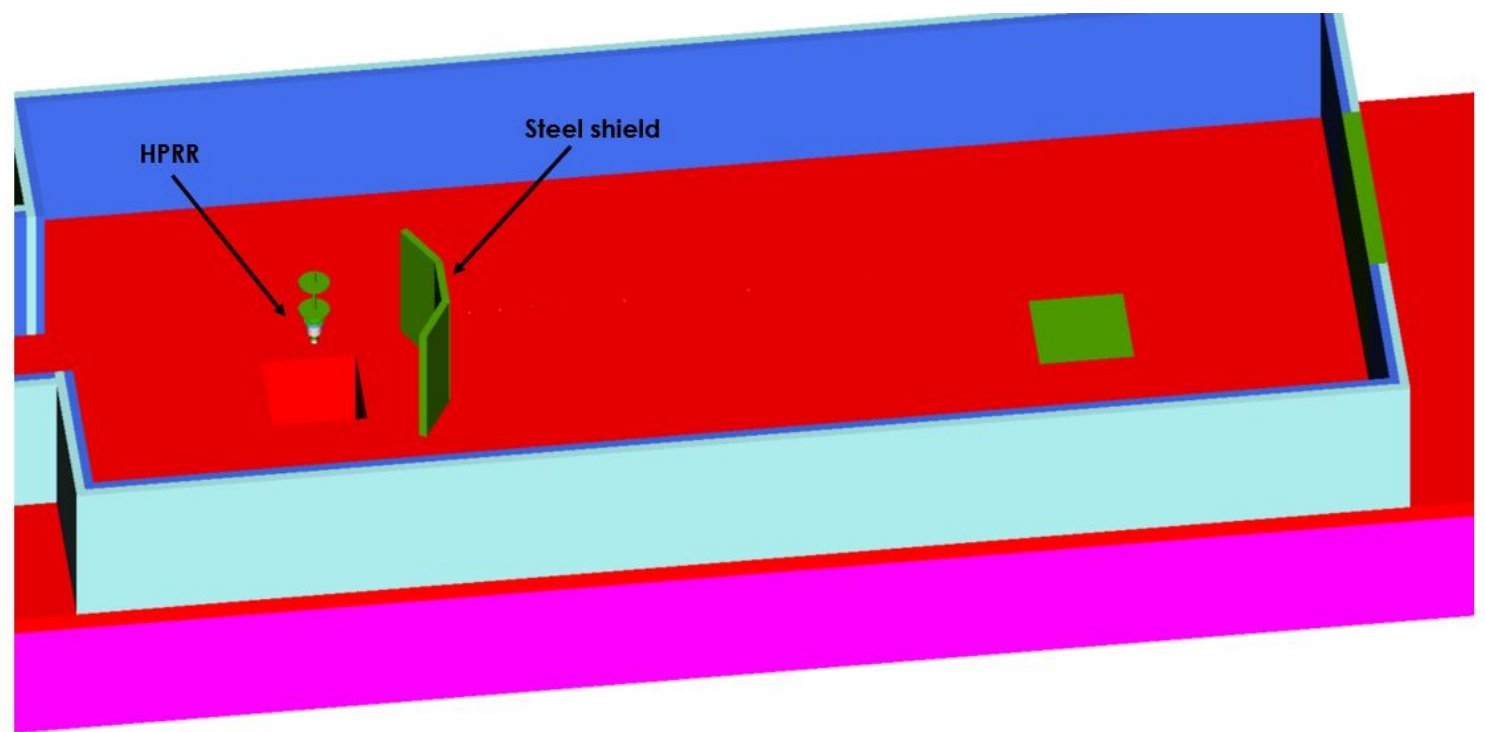

Figure 36. Overview of the steel shield configuration benchmark model.

\subsubsection{Simplifications}

Numerous elements of the reactor building have been removed from the benchmark model. Some of those details are not described in the previous sections, as no information was available, but they could be seen in the pictures of the reactor building room. As a result of the uncertainty analysis described in Section 2, many elements that were initially believed to be important for the sulfur fluence results were removed from the benchmark model. For example, the superstructure, the catwalk, and the hydraulic lift were all removed. The list of the simplifications is detailed by element below:

- Reactor building:

- Removal of the annex room

- Removal of the east door

- The building walls are formed by two layers of carbon steel and aluminum, $15 \mathrm{~cm}$ thick each, simplified from the assumption of $15.24 \mathrm{~cm}$ each

- Simplification of the west cavity wedge roof as a cuboid roof

$\circ$ East gate assumed to be on the same alignment as the building walls

- Removal of the catwalk

- Removal of the crane platform and ladder

○ Removal of the hydraulic lift

- Removal of the sulfur pellet stands

- The room and all materials temperature are constant and set at $20^{\circ} \mathrm{C}$

- HPRR critical assembly:

○ Ignoring of all the U-Mo elements including a curve radius below $0.635 \mathrm{~cm}$, with the assumption that they are edges

$\circ$ Approximation of all the U-Mo elements, including a curve radius above $0.635 \mathrm{~cm}$, by two cuboid/ring shapes

- Replacement of all threads with regions in contact with the surface in which they are to be threaded

- Simplification of the center plug and quick lock as cylinders

- Removal of the thermocouples and thermocouple holes

- Removal of the mounting bracket protrusion

- Removal of the brass parts of the core

- Simplification of the aluminum safety cage attachment elements 
- Simplification of the bottom safety tube as cylinders

- Replacement of the stainless-steel regions between the superstructure top plates with air

$\circ$ Setting the core temperature at a constant of $20^{\circ} \mathrm{C}$

\subsection{DIMENSIONS}

Overall, most of the benchmark model dimensions are the same as the those presented in Section 1. Therefore, only the dimensional differences of the elements from those of the previous descriptions and the benchmark model are given in this section. This is supplemented by a screenshot of the benchmark model element visualized in Fulcrum, which is the geometry visualization tool for SCALE models [21].

\subsubsection{HPRR Reactor Building}

A view of the reactor building portion of the model with the air region hidden is shown in Figure 37. Figure 38 shows a side view (X-Z) of the bare configuration benchmark model. The west reactor storage pit, east reactor storage pit, west cavity, east door, soil, concrete floor, building walls, and concrete pad are visible. Figure 39 shows a top view (X-Y) of the bare configuration benchmark model. The west cavity and west door are visible. Figure 40 shows a front view (Y-Z) of the bare configuration benchmark model, and the wedge roof is visible. The air region around the reactor building is defined to be from -950 to $3,800 \mathrm{~cm}$ on the $\mathrm{x}$ axis, -500 to $500 \mathrm{~cm}$ on the $\mathrm{y}$ axis, and -393.84 to $2,000 \mathrm{~cm}$ on the $\mathrm{z}$ axis, as shown in Figure 38 and Figure 39. The dimensions of the reactor building components are as previously described. The west cavity is simplified to be a cuboid of $487.68 \mathrm{~cm}$ in height with no walls, ignoring the west cavity wedge roof. The reactor building roof starts at a height of $1,191.12 \mathrm{~cm}$ and is formed by 3 wedges of air, structural steel, and aluminum. The roof wedge respective bases are 914.4, 944.4, 974.4 $\mathrm{cm}$, the heights are $182.88,197.88,212.88 \mathrm{~cm}$ and the lengths are $2090.928,2120.928,2150.928 \mathrm{~cm}$. The top part of the wedge is located on the same west-east axis as the centerline of the HPRR. 


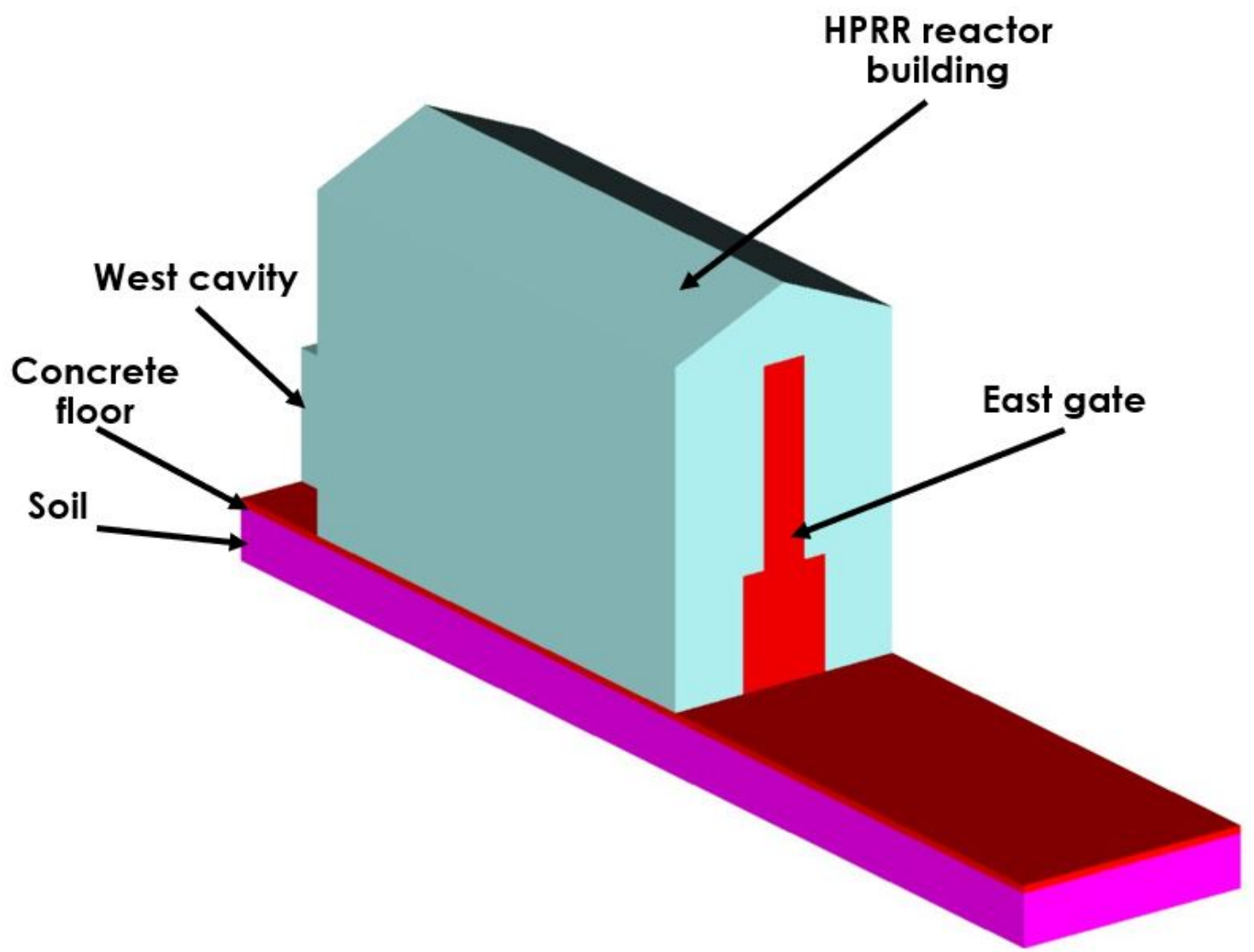

Figure 37. Overview of the reactor building benchmark model.

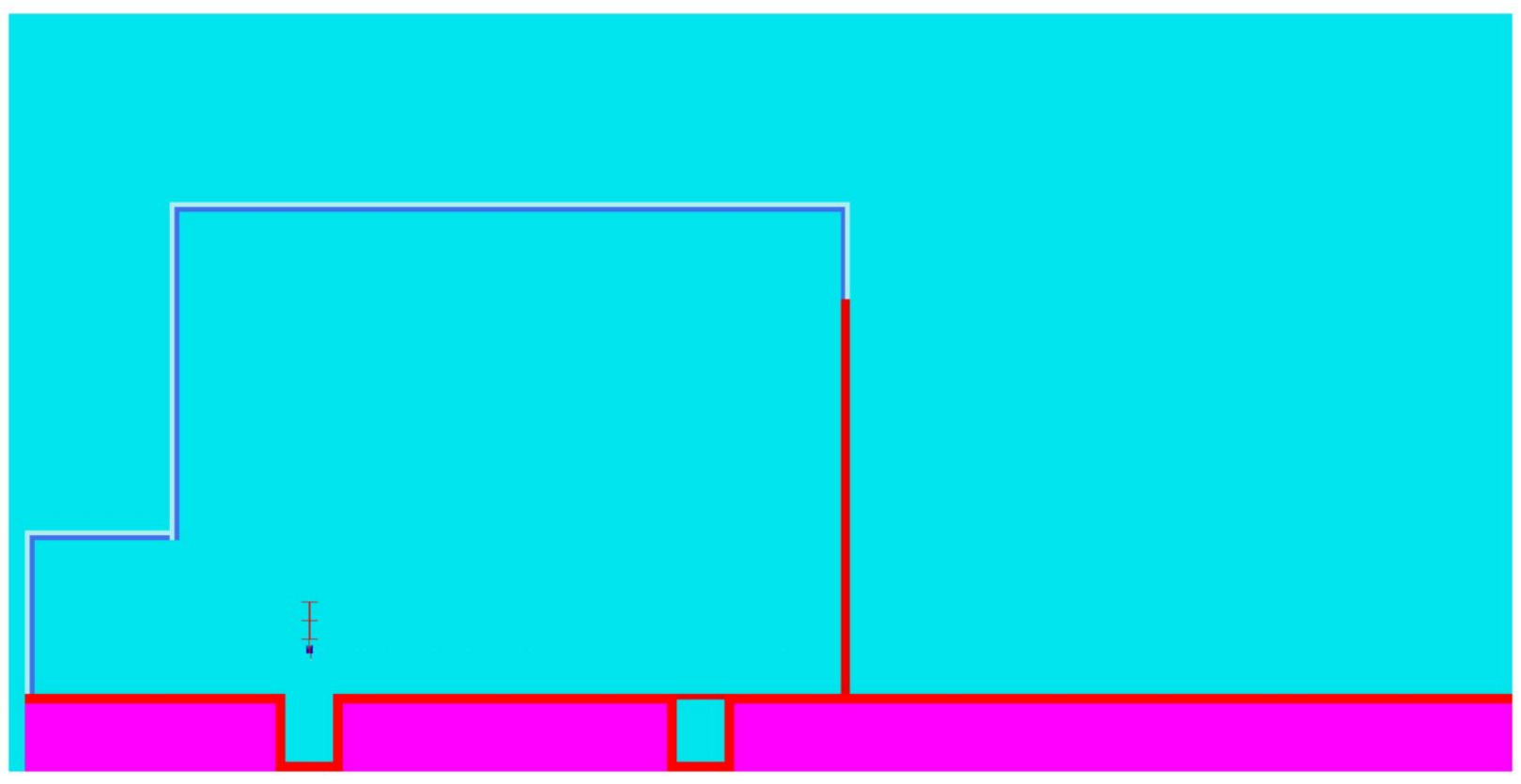

Figure 38. Side view (X-Z) of the bare configuration benchmark model. 


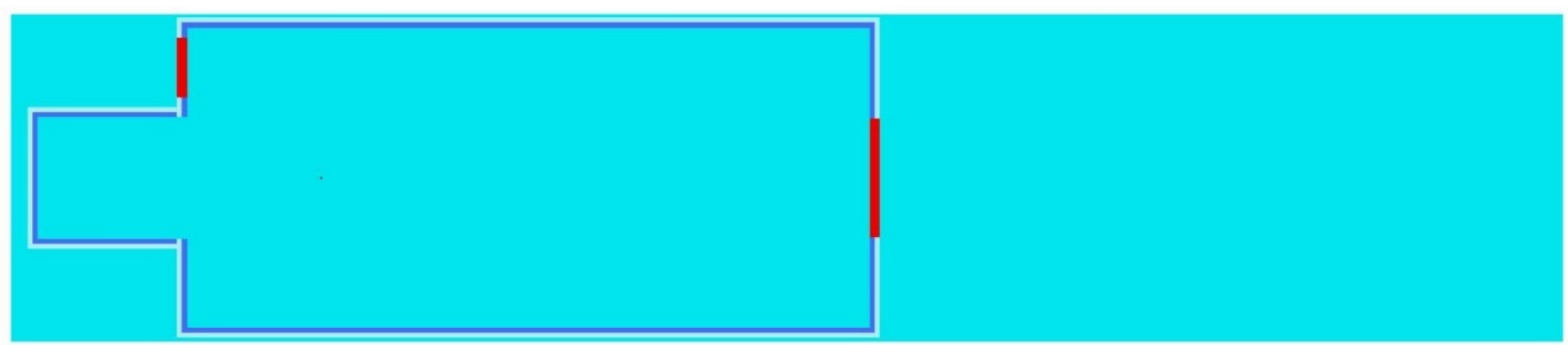

Figure 39. Top view (X-Y) of the bare configuration benchmark model.

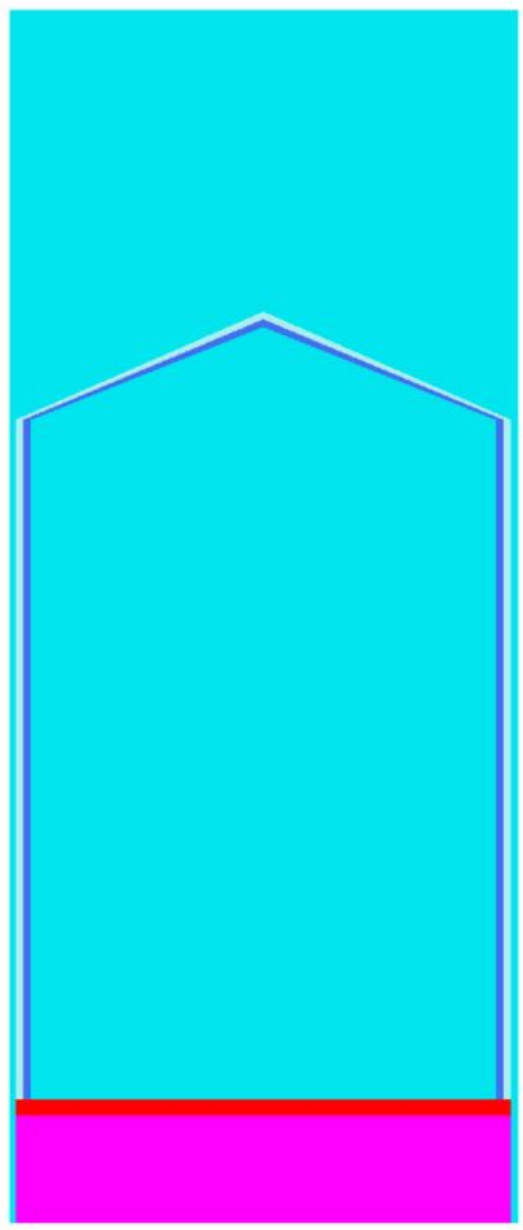

Figure 40. Front view (Y-Z) of the bare configuration benchmark model.

\subsubsection{Sulfur Pellets}

The dimensions of the sulfur pellets are as previously described, with a $0.95 \mathrm{~cm}$ thickness and a $3.8 \mathrm{~cm}$ diameter: an example is given in Figure 41. 


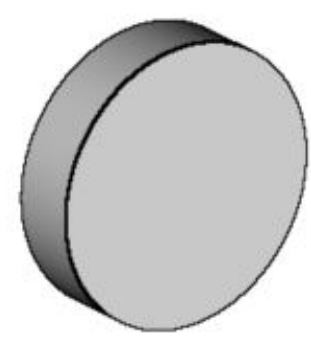

Figure 41. Overview of sulfur pellet benchmark model.

\subsubsection{Steel Shield}

The steel shield is formed by 3 separate steel plates as described above. The top view of the shield is shown in Figure 42. The three steel plates are modeled as cuboids, and two wedges are used to fill the gaps between them. Each plate is $92.06 \mathrm{~cm}$ wide, $13 \mathrm{~cm}$ thick, and $213 \mathrm{~cm}$ high. The north and south plates' closest edges to the HPRR are in contact with the central plate. The angle between the central, north, and south plates is $30^{\circ}$. The wedges' bases are $213 \mathrm{~cm}$ long, $13 \mathrm{~cm}$ wide, and $6.5 \mathrm{~cm}$ high, and the top of the wedge is $11.25833 \mathrm{~cm}$ from the left edge of the wedge. The north wedge and the angle between the north and central plates is shown in Figure 43.

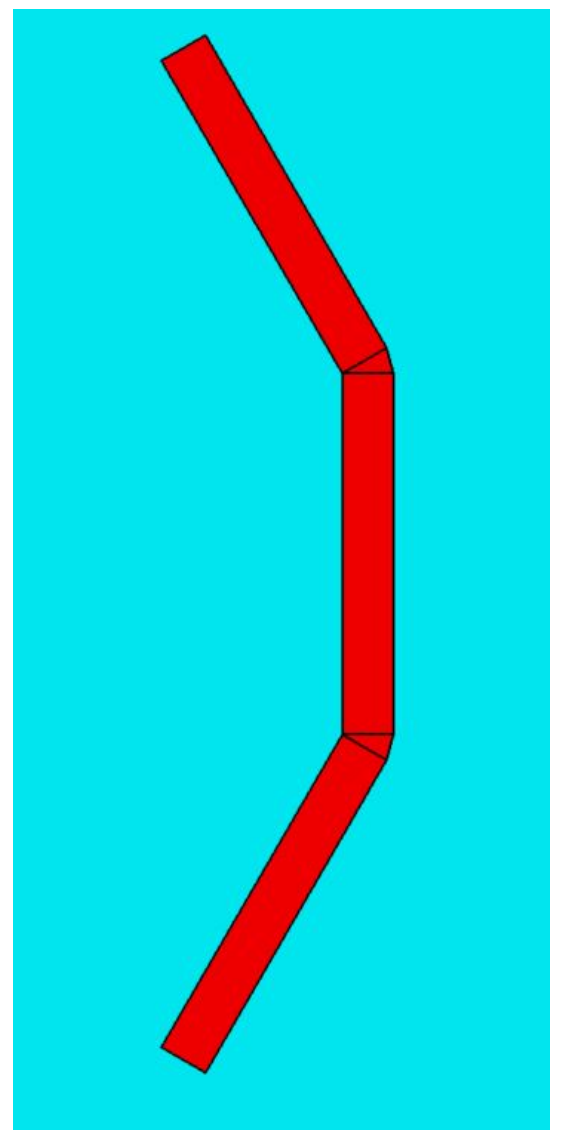

Figure 42. Top view of the steel shield benchmark model. 


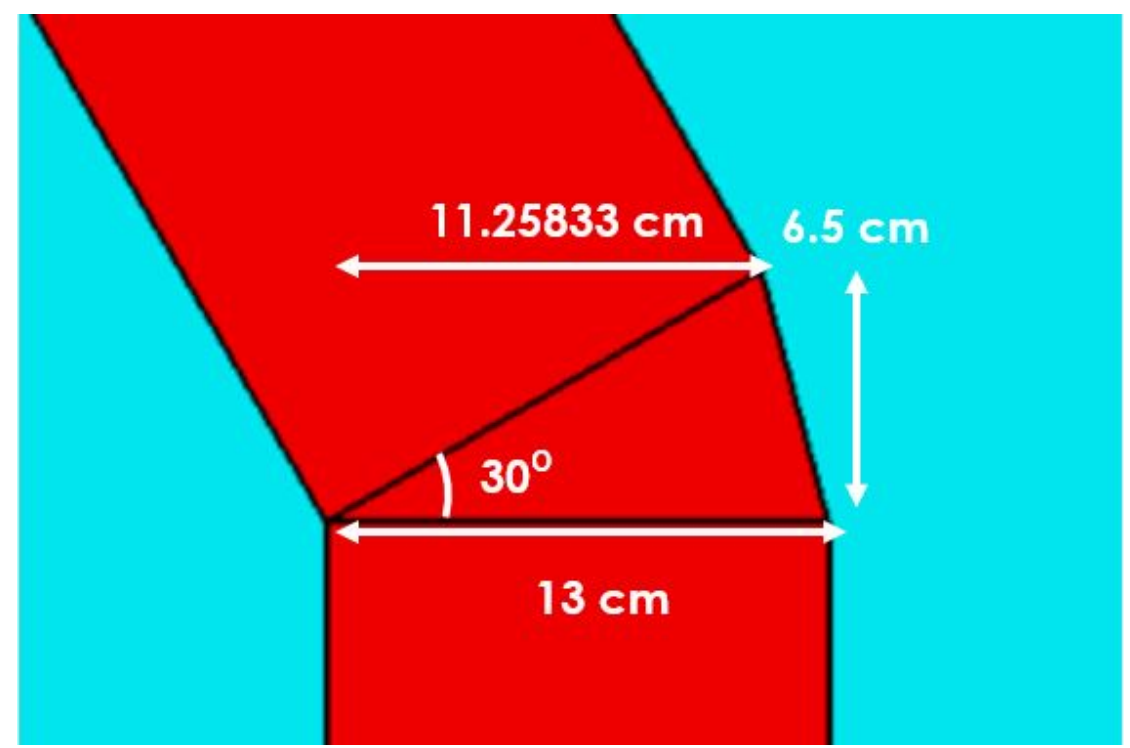

Figure 43. Top view of the steel shield north wedge benchmark model.

\subsubsection{HPRR}

The HPRR benchmark model is the same in the bare and steel shield configurations. The configuration of the core used in the model is burst B1024, which is described in Table 30, with information extracted from Table 10. An overview of the HPRR benchmark model from a front view (Y-Z) is shown in Figure 44. In this picture, most of the core components are visible: the 11 U-Mo annuli, U-Mo safety block, quick lock, bolt, bolt plug, MAR, safety tube, aluminum safety cage, and mounting bracket. Note the significant spaces between the safety block and the remainder of the annuli, which introduce air in the core. The elements' dimensions that differ from those described in the previous sections are given in the following subsections and are supplemented by a screenshot from Fulcrum.

Table 30. Core configuration from Burst B1024

\begin{tabular}{lc}
\hline Pulse number & B1024 \\
\hline Core height above floor $(\mathbf{c m})$ & 140 \\
Safety block position from fully inserted $(\mathrm{cm})$ & -0.34798 \\
Regulating Rod position from fully inserted $(\mathrm{cm})$ & 0 \\
New regulating rod position from fully inserted $(\mathrm{cm})$ & 2.03200 \\
Mass adjustment rod position from fully inserted $(\mathrm{cm})$ & 8.83666 \\
\hline
\end{tabular}




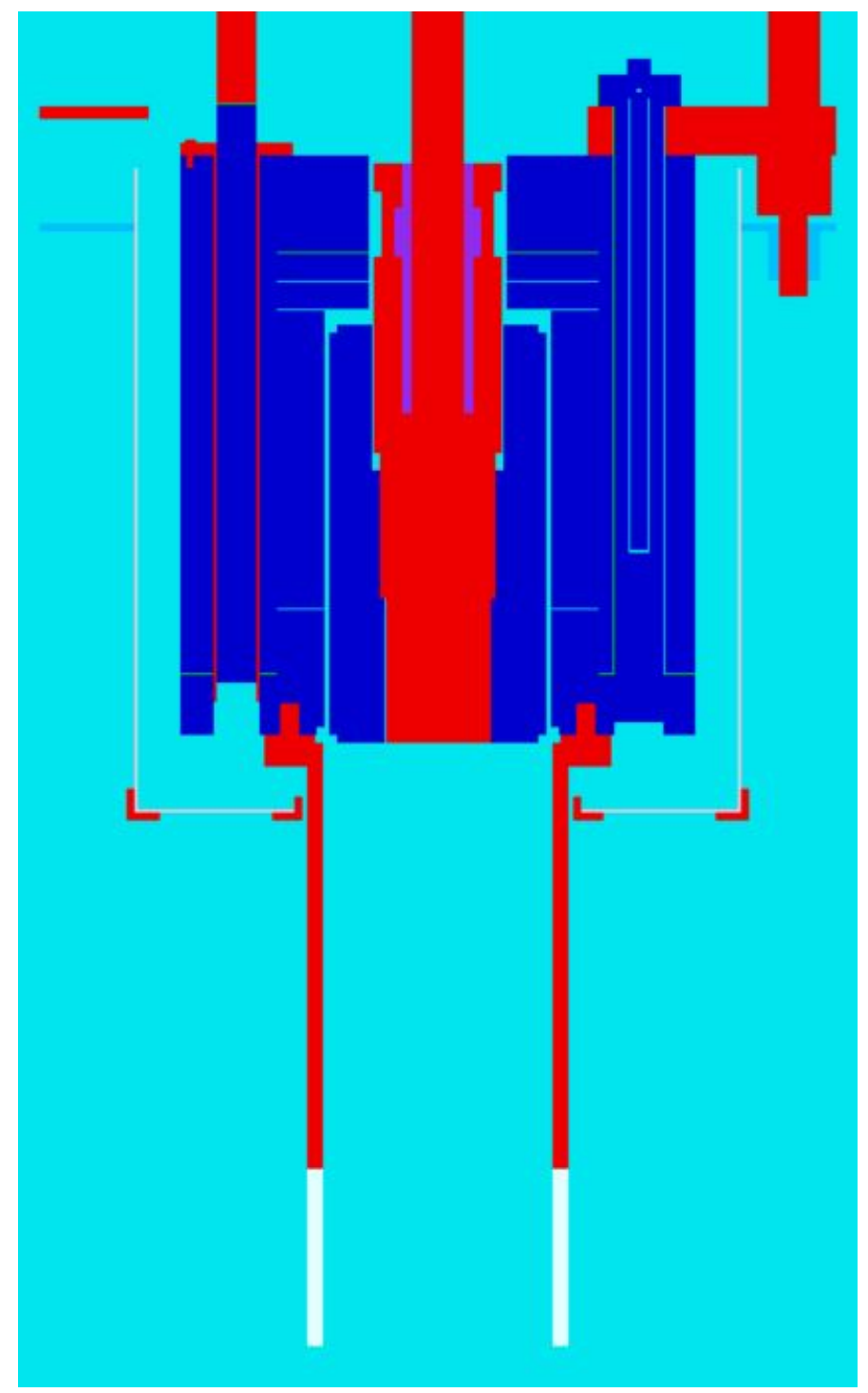

Figure 44. Front view (Y-Z) of the HPRR benchmark model.

\subsubsection{Coating}

As the influence of the fuel coating on the sulfur fluence is statistically significant, it was decided to keep it in the benchmark model. The coating characteristics for all the U-Mo elements are reviewed in the next subsections and are supplemented by a screenshot from Fulcrum.

\section{Nickel coating}

All of the U-Mo pieces are coated with nickel. The nickel coating is modeled with a layer of pure nickel. The nickel is $0.0127 \mathrm{~cm}$ on the sides of the U-Mo parts (radially) and $0.00508 \mathrm{~cm}$ on the top and bottom (axially). An example of nickel coating is shown in Figure 45, showing the junction of U-Mo Annuli 11 and 10 , as well as one of the U-Mo bolts. 


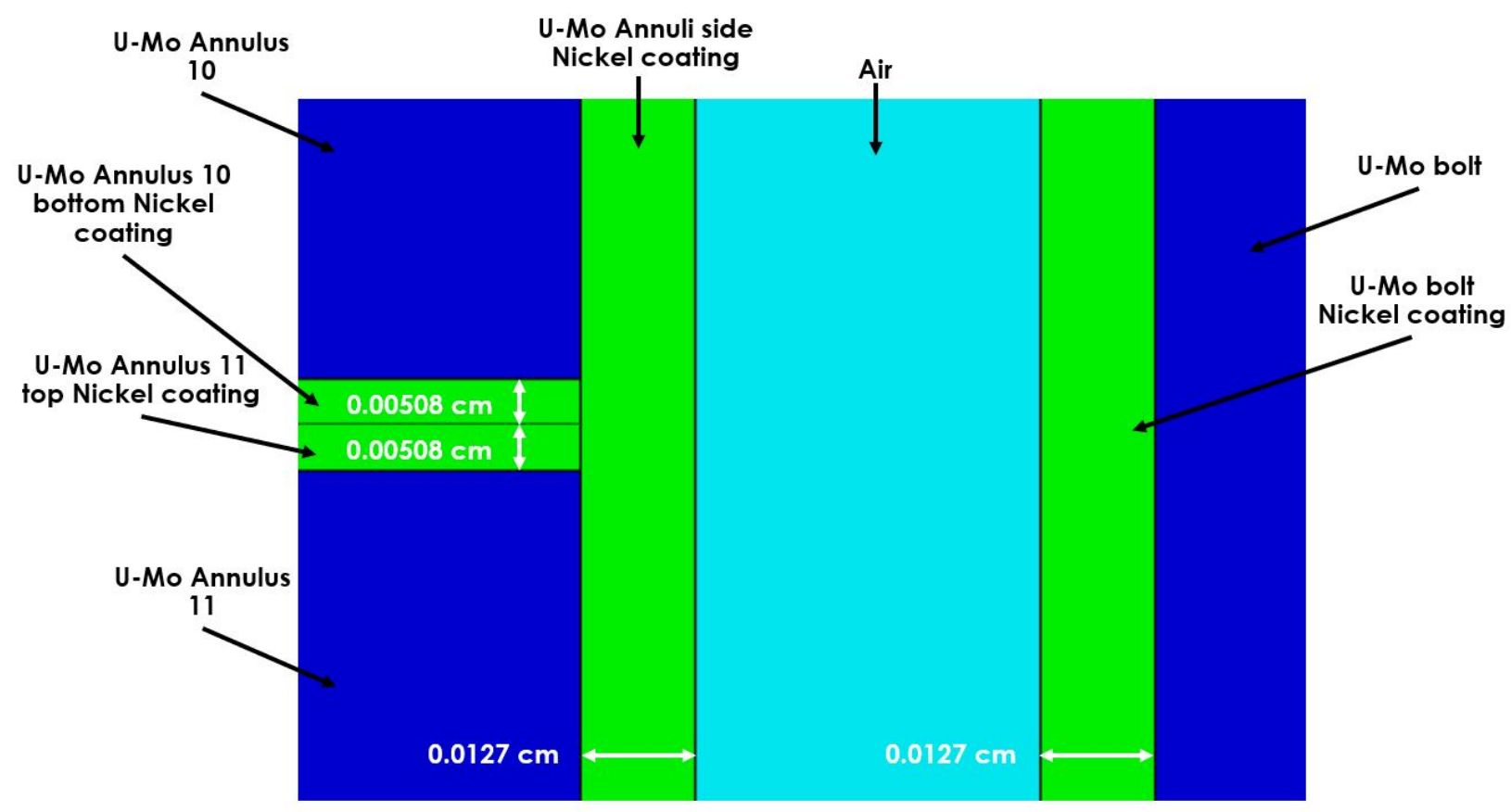

Figure 45. U-Mo Nickel coating example.

\section{Chromium coating}

The U-Mo safety block, the 9 U-Mo bolt threads, and the three control rods are coated with chromium. The chromium coating is modeled with a of $0.00254 \mathrm{~cm}$ layer of chromium on top of the nickel layer. An example of chromium coating is shown in Figure 46, which depicts the bottom of the U-Mo safety block. 


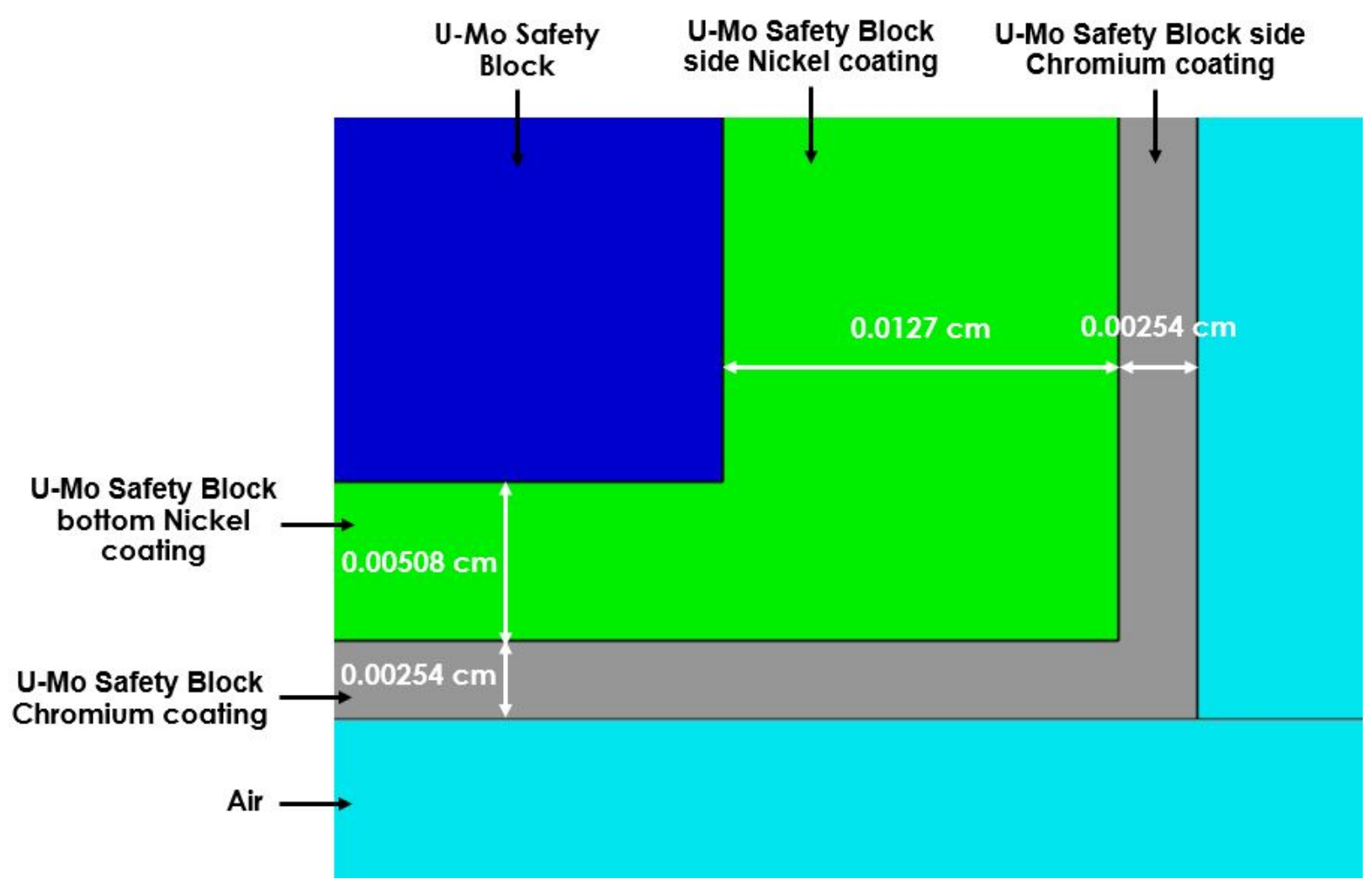

Figure 46. U-Mo Chromium coating example.

\section{Gold coating}

The 9 U-Mo bolt threads are coated with gold. The chromium coating is modeled with a $0.00254 \mathrm{~cm}$ layer of gold on top of the nickel layer. An example of gold coating is shown in Figure 47, which depicts the bottom threading of one of the U-Mo bolts in contact with the U-Mo Annulus 11 . 


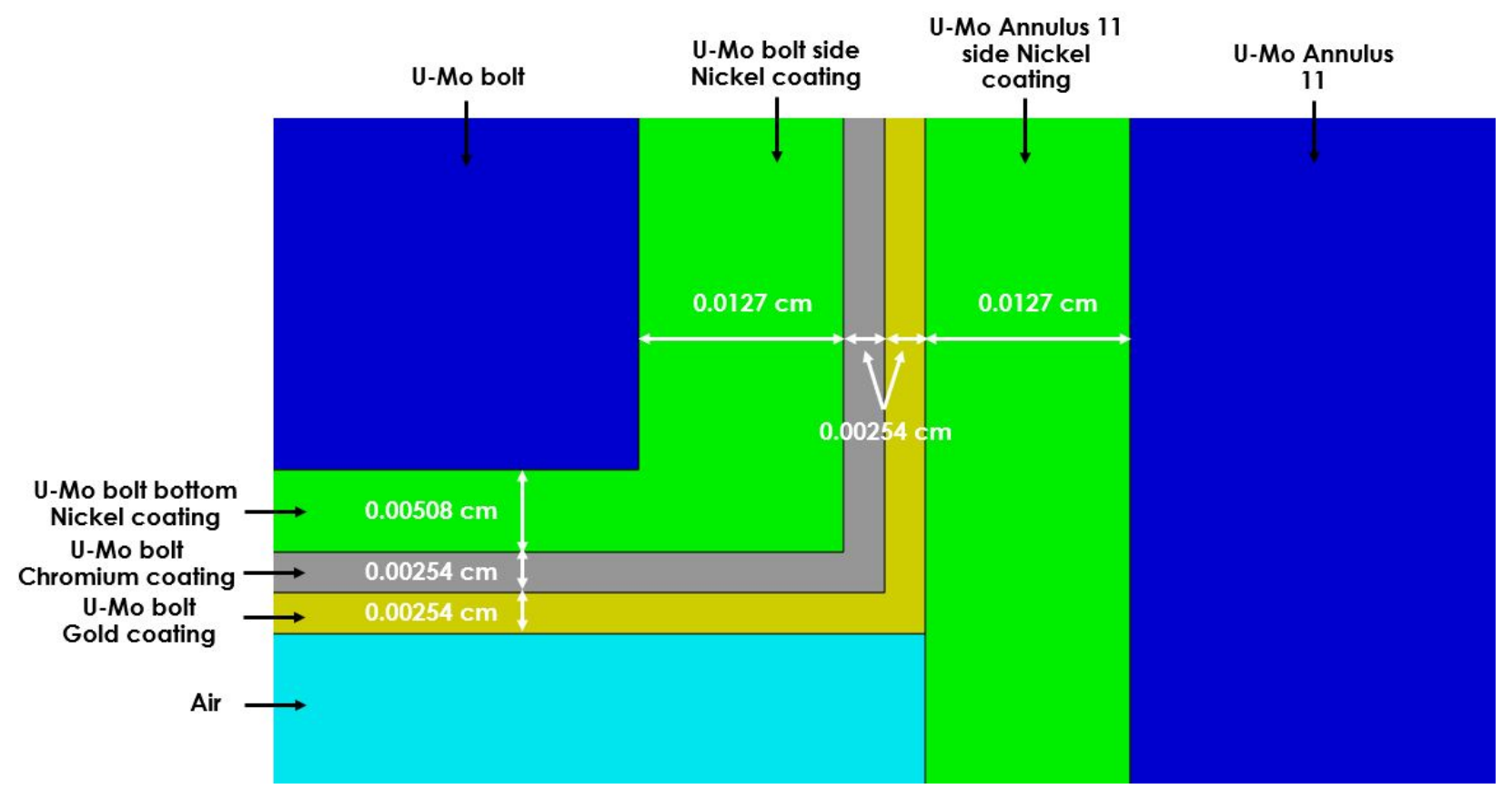

Figure 47. U-Mo Gold coating example.

\subsubsection{U-Mo annuli}

The U-Mo annuli benchmark model dimensions are essentially the same as those described in the previous sections. A difference is the curve radii are removed from the benchmark model if they are below $0.635 \mathrm{~cm}$, and they are replaced by two rings if they are above $0.635 \mathrm{~cm}$. A side view of U-Mo annulus 11 is shown in Figure 48, where such a curve radius simplification is visible. The bottom center corner curve radius of $0.635 \mathrm{~cm}$ is simplified as two rings, with removal of a volume of U-Mo that is equivalent to a ring of air $0.635 \mathrm{~cm}$ thick. A few other elements can be observed in this figure, which include the annuli protrusions, the bolt holes, and the bottom screw holes that are used to attach the annulus to the safety tube. A top view of U-Mo Annulus 11 with no coating or other parts of the core is shown in Figure 49. All the holes previously described are observable in this figure: 9 U-Mo bolt holes, 3 control rods holes, 1 safety block central hole, and the sample irradiation hole. A top view of U-Mo annulus 1 without coating or other parts of the core is shown in Figure 50. The rod tube retainer screw holes are visible, and the central safety block hole diameter is reduced from $8.96874 \mathrm{~cm}$ in plates 11 through 5 to $5.47624 \mathrm{~cm}$ and in plates 4 through 1, as described above. 


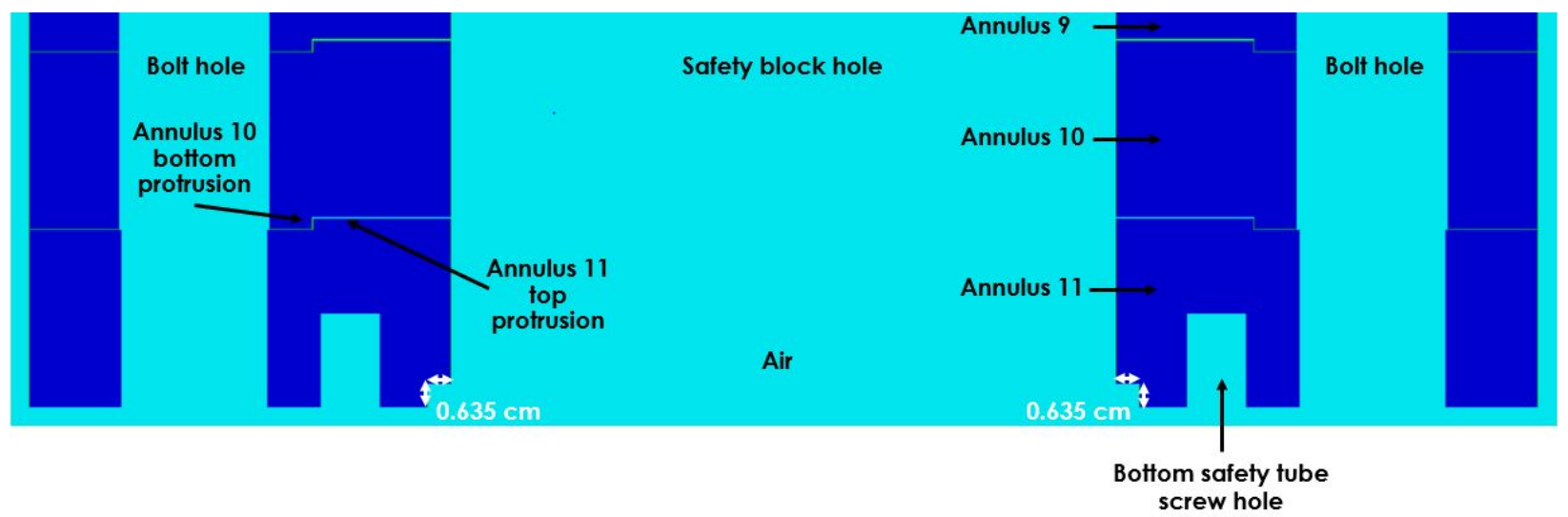

Figure 48. Side view of the U-Mo Annuli 11-10-9 benchmark model.

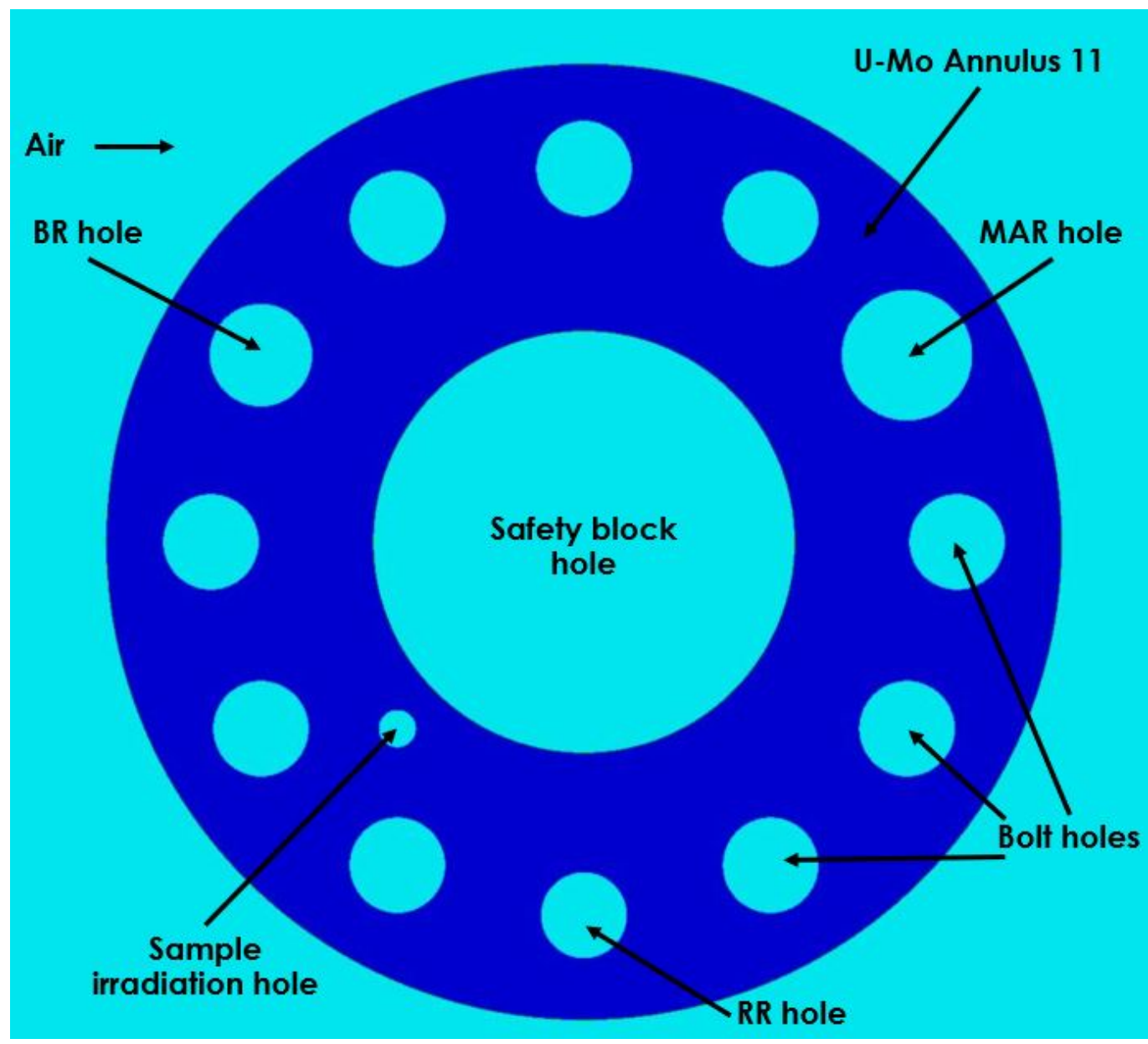

Figure 49. Top view of the U-Mo Annulus 11 benchmark model. 


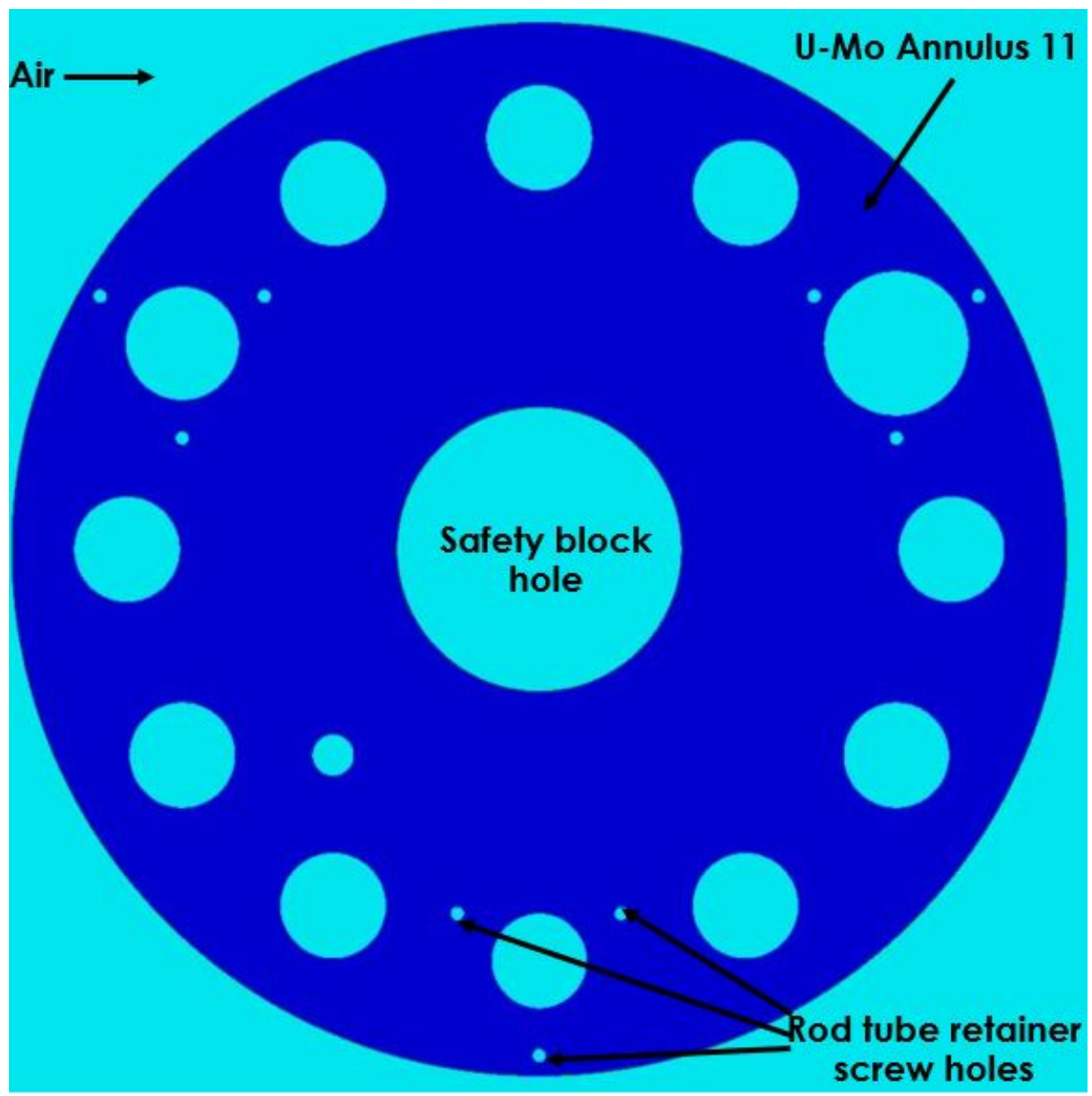

Figure 50. Top view of the U-Mo Annulus 1 benchmark model.

\subsubsection{Safety block}

The safety block benchmark model is simplified from the dimensions previously described, and all of its dimensions are described in the following subsections. The side and top view of the safety block are shown in Figure 51 and Figure 52, in which the different elements are visible. The dimensions given for the U-Mo safety block do not include nickel or chromium coating. 


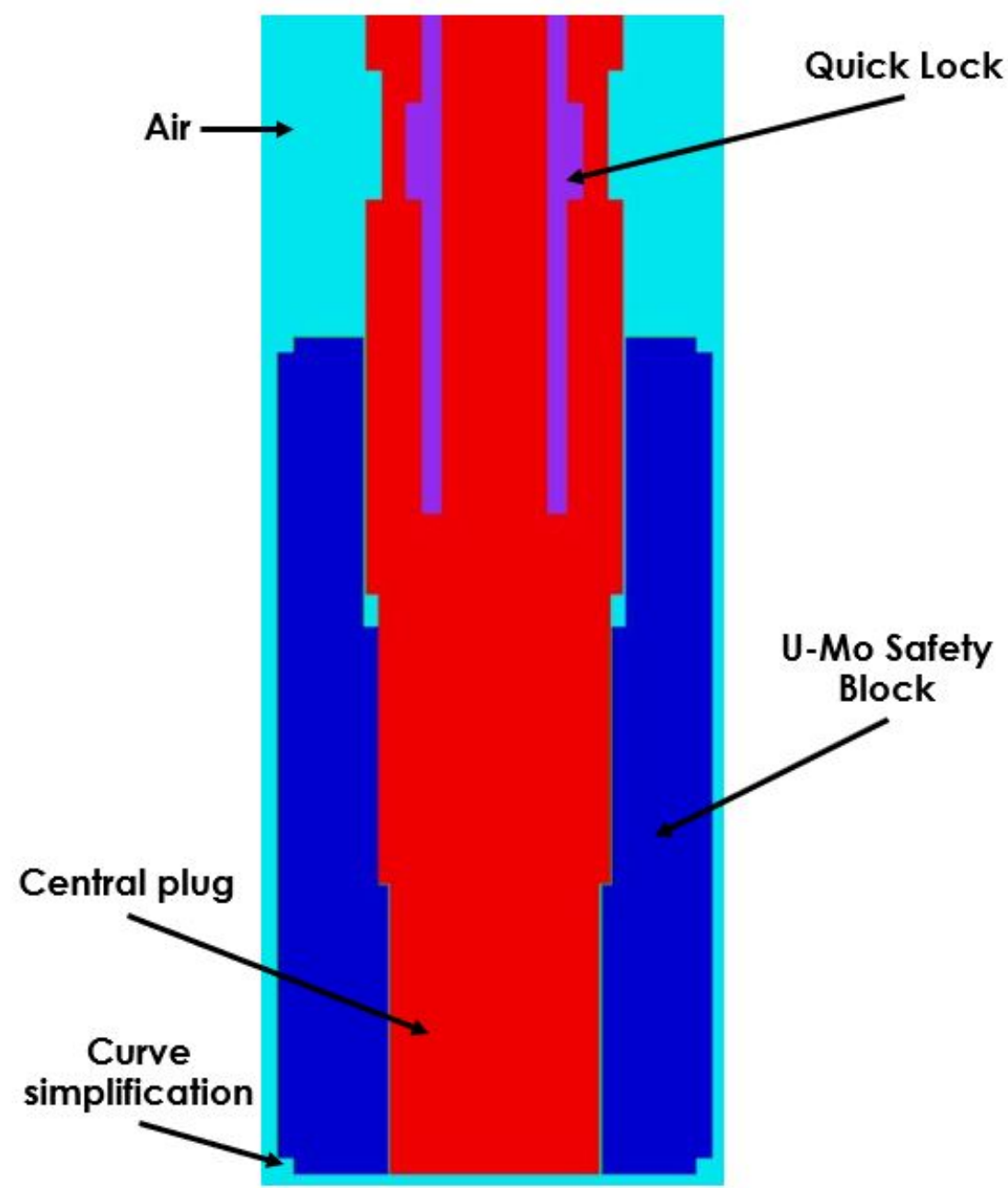

Figure 51. Side view of the safety block benchmark model. 


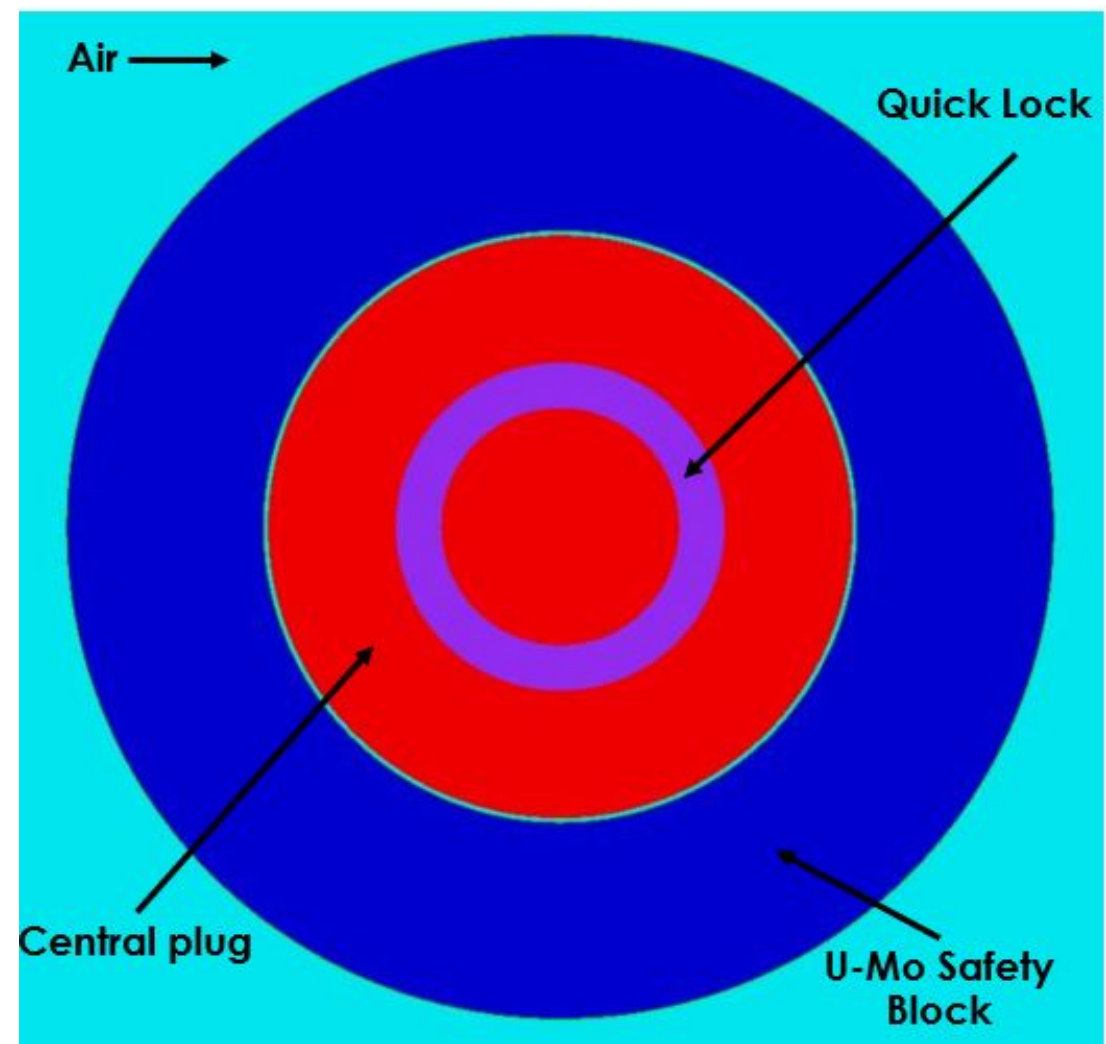

Figure 52. Top view of the safety block benchmark model.

\section{U-Mo Annulus}

The U-Mo annulus is a combination of stacked annuli with different internal diameters. The dimensions of the U-Mo annulus are given in Figure 53. Note the curve simplification at the edges of the annulus. 


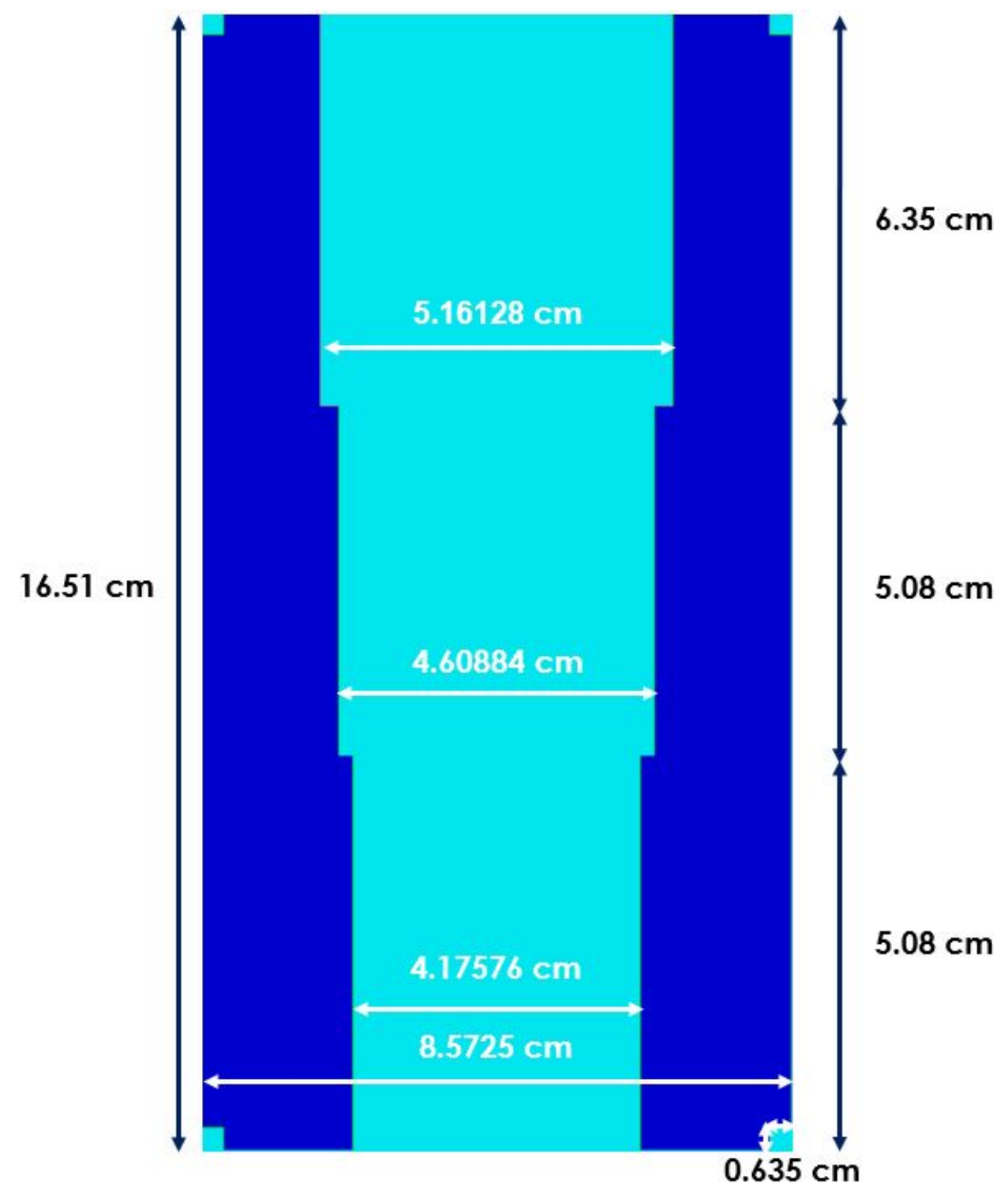

Figure 53. Side view of the U-Mo part of the safety block benchmark model.

\section{Center Plug and Quick Lock}

The center plug and quick lock are a combination of stacked cylinders and annuli with different diameters. The dimensions are given in Figure 54. The red region represents the 304 stainless steel center plug, and the purple represents the 17-4 PH stainless steel of the quick lock. 


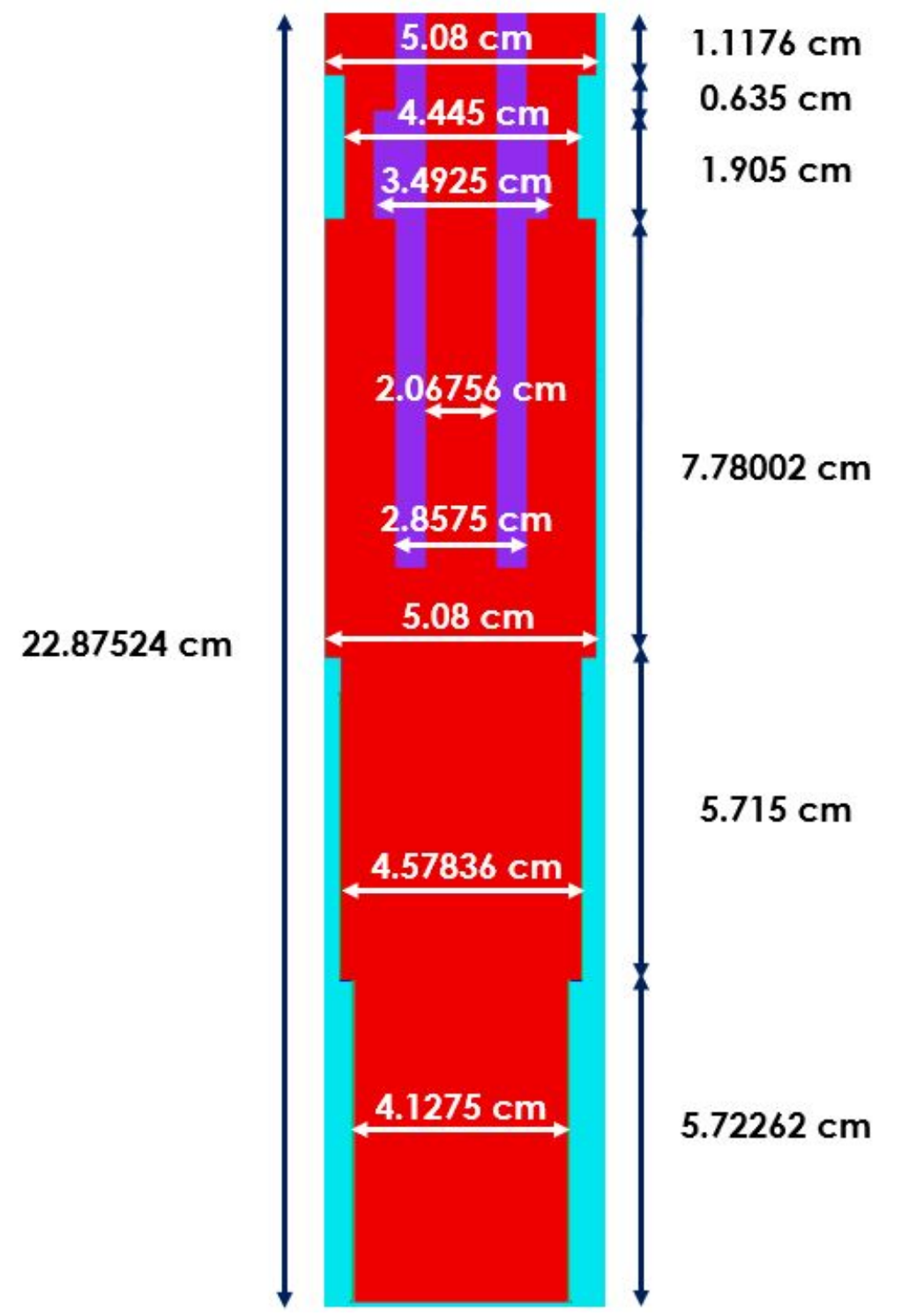

Figure 54. Side view of the center plug and quick lock benchmark model.

\subsubsection{U-Mo bolts}

The U-Mo bolts and bolt plugs benchmark model dimensions are essentially the same as those described in the previous sections. The side view of the U-Mo bolt and bolt plug is shown in Figure 54. 


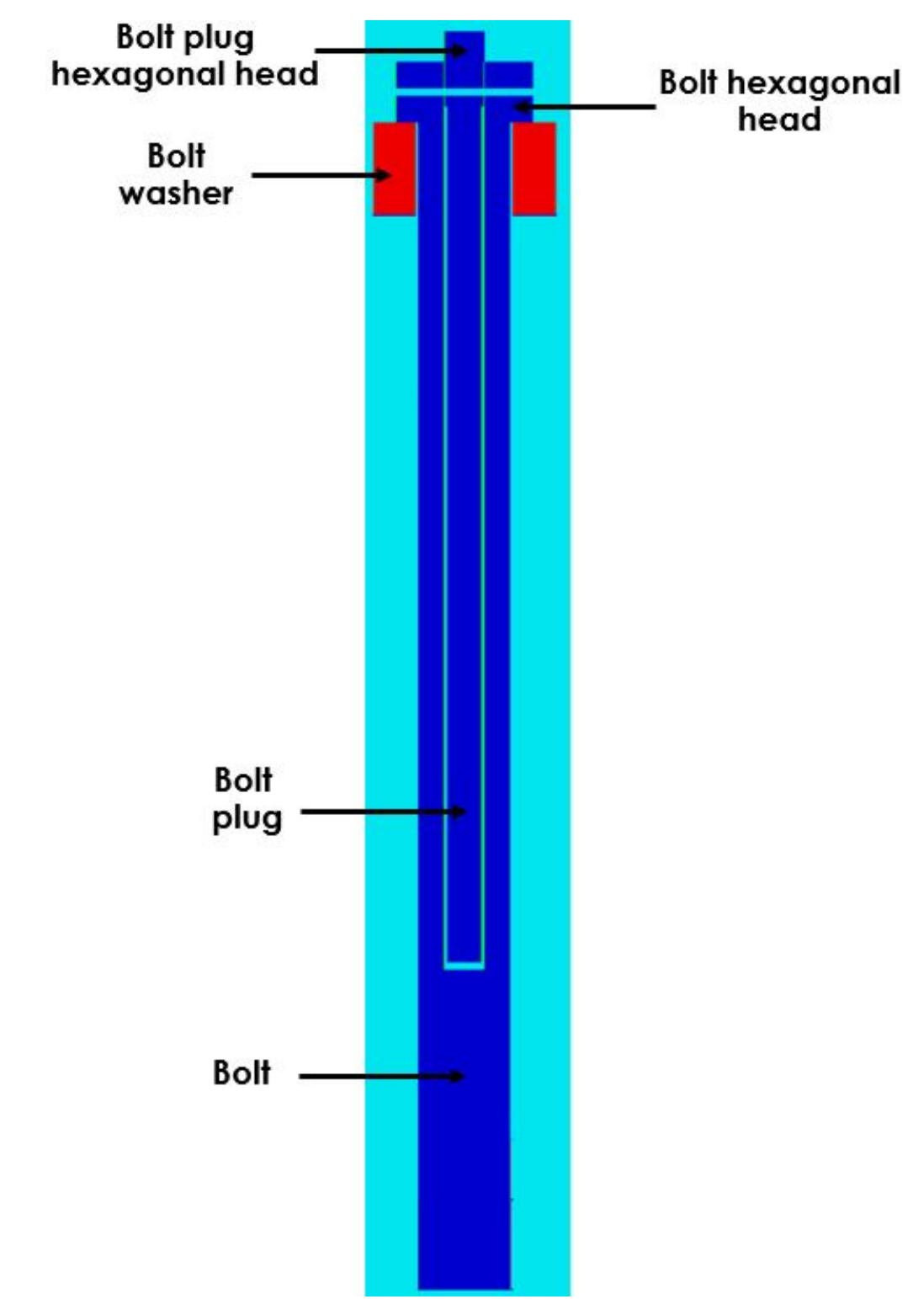

Figure 55. Side view of the bolt, bolt plug, and bolt washer benchmark model.

\subsubsection{Sample irradiation hole plug}

Based on the uncertainty analysis previously performed, the irradiation hole plug benchmark model is $20.955 \mathrm{~cm}$ long. The benchmark model sample irradiation hole plug dimensions are essentially the same as those described in previous sections. The side view of the sample irradiation hole plug is shown in Figure 56. A zoomed in picture of the top of the plug is shown in Figure 57. The top of the plug's hexagonal head face-to-face length is $0.635 \mathrm{~cm}$. 


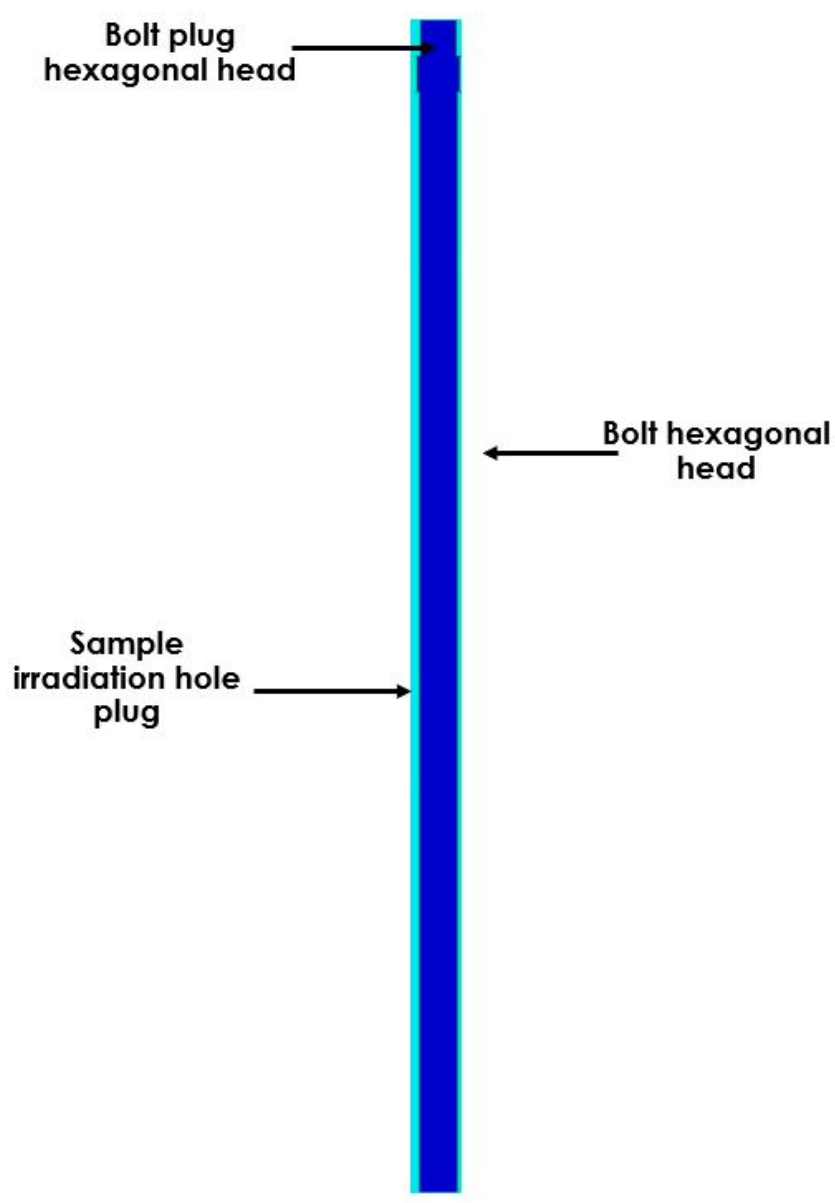

Figure 56. Side view of the sample irradiation hole plug benchmark model. 


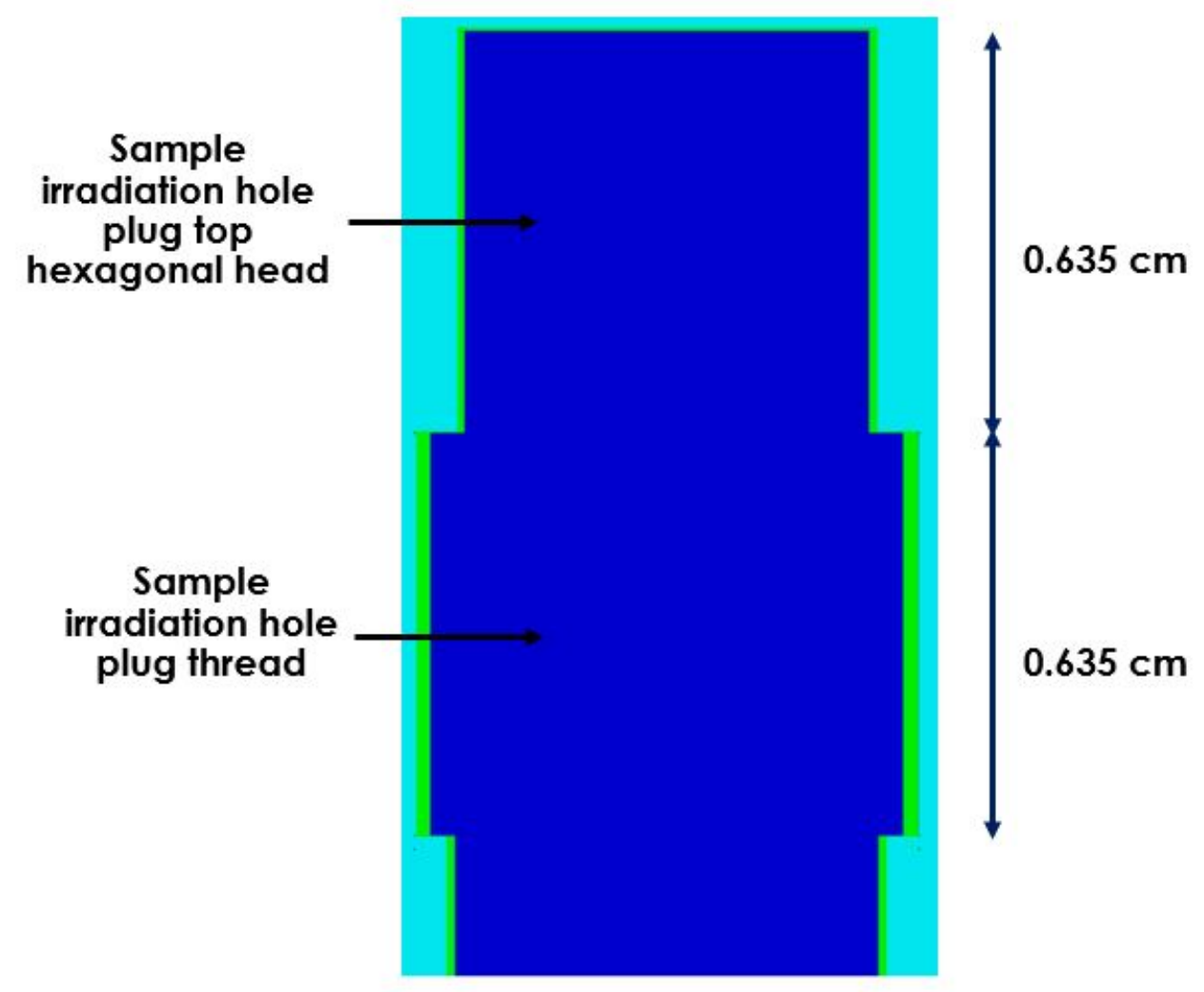

Figure 57. Side view of the sample irradiation hole plug benchmark model, zoomed in.

\subsubsection{Control rods}

The benchmark model dimensions of the control rods are essentially the same as those described in the previous sections. The side view of the MAR and associated components inserted in the core in the burst B1024 configuration is shown in Figure 58. Note that a 304 stainless steel cylinder of the same diameter as the MAR is assumed to be on top of the MAR, proceeding up until the top plate 1 of the superstructure. The other control rods are similarly modeled with the same assumptions, the only differences being the rod's diameter, the liner tube's diameter and thickness, and the rod's position in the core as described in Table 30 . 


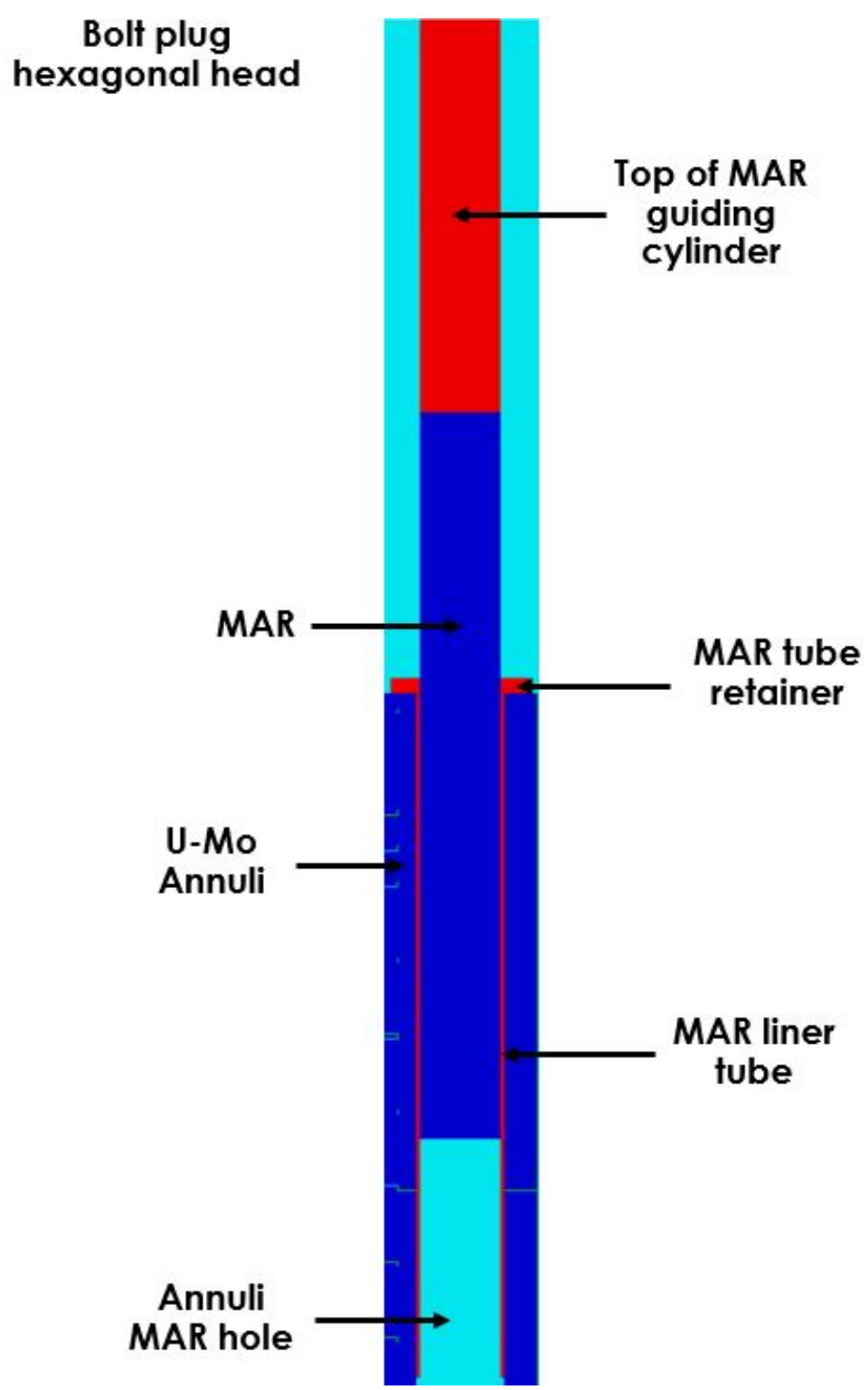

Figure 58. Side view of the MAR and associated components benchmark model.

\subsubsection{Mounting bracket}

The mounting bracket benchmark model dimensions are essentially the same as those described in the previous sections except that the top ring is whole. The top and side views of the mounting bracket are shown in Figure 59 and Figure 60. 


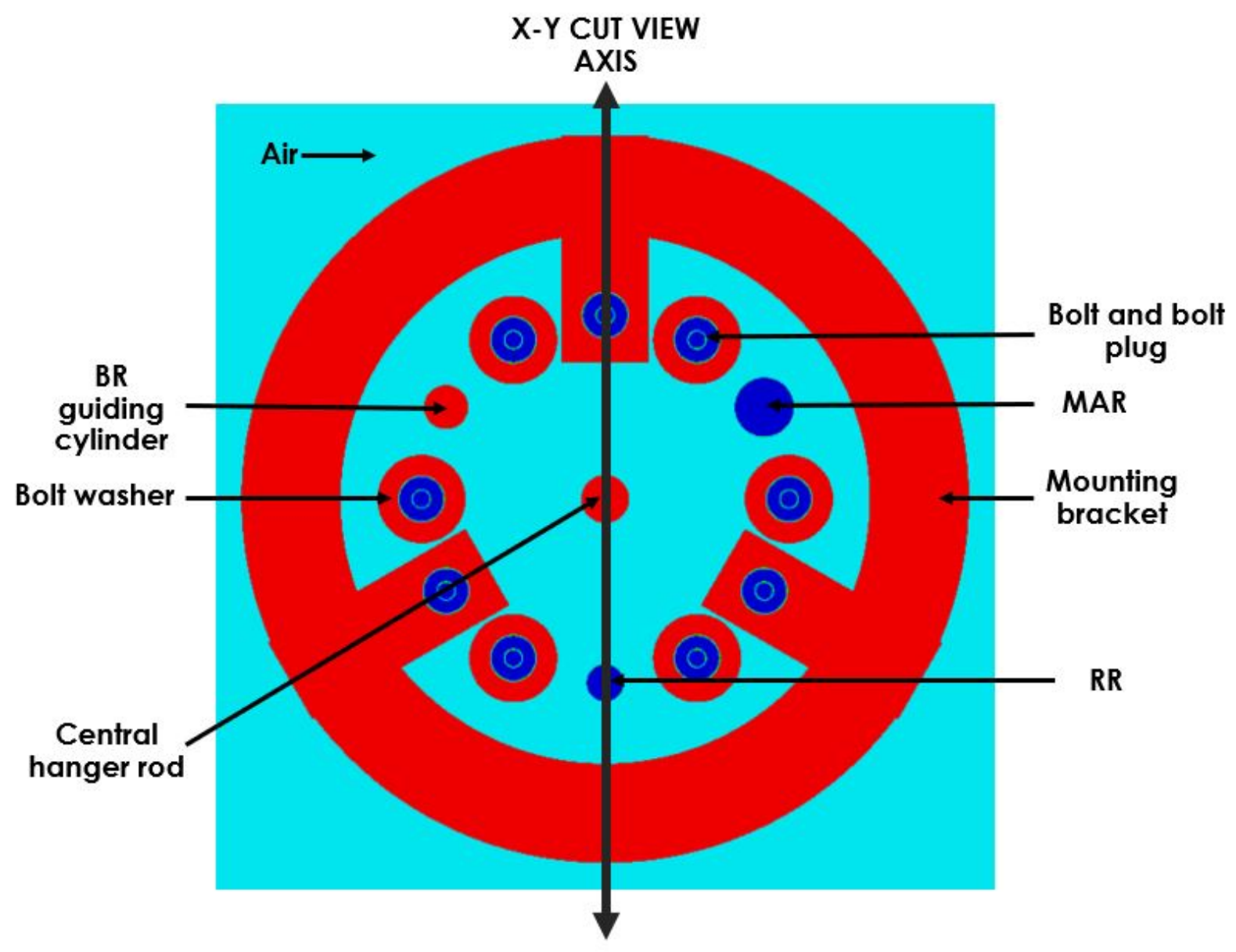

Figure 59. Benchmark model of the top view of the mounting bracket and other close components.

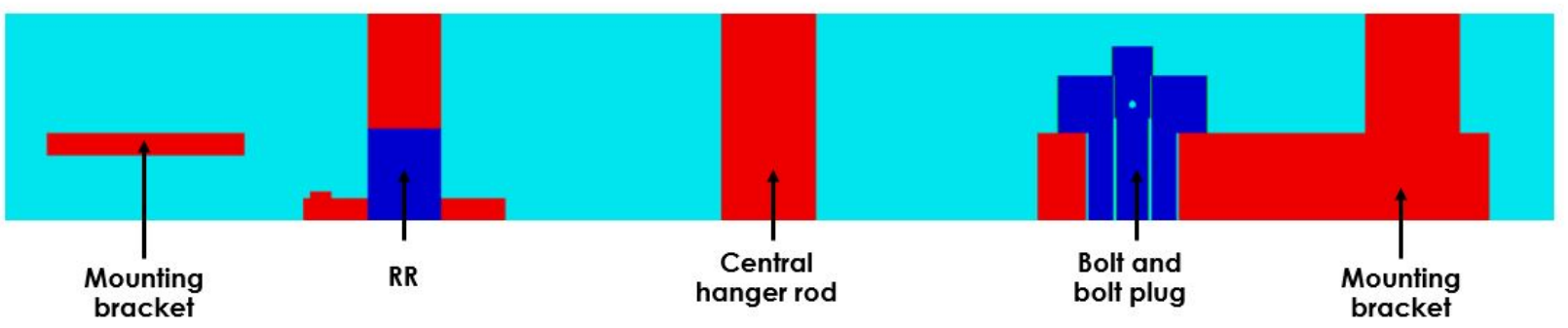

Figure 60. Benchmark model of the side view (X-Y) of the mounting bracket and other close components.

\subsubsection{Aluminum safety cage}

The aluminum safety cage benchmark model dimensions were not detailed previously and were inferred from a drawing. The side view of the aluminum safety cage is shown in Figure 61. For clarity, the HPRR was removed from the figure. In this figure, the 6061-T6 aluminum is shown in light blue, the 304 stainless steel elements are in red, the aluminum grid is shown in pink, and the side attachment to the mounting bracket is visible. The aluminum grid is a 6061-T6 aluminum $62 \%$ void ring with an inside diameter of $23.65375 \mathrm{~cm}$, a thickness of $0.0675 \mathrm{~cm}$ and a total height of $25.47303 \mathrm{~cm}$. The aluminum 
grid's inner edge is $0.9525 \mathrm{~cm}$ from the U-Mo annuli. On the bottom part of the cage, the grid is covering the core from below, and the inner 304 stainless steel attachment element is located $0.15875 \mathrm{~cm}$ from the safety tube. The aluminum cage is hooked up to the mounting bracket under the three stainless steel elements connected to the bolts as shown in Figure 60 on the right of the picture. To simplify the dimensional description, two zoomed in pictures of the bottom and side attachments are shown in Figure 62 and Figure 63, and two X-Z top view cuts are shown in Figure 64 and Figure 65. In Figure 62, the inner and outer 304 stainless steel attachment element rings are visible from the top view. The rings cover the aluminum grid from below and from interior and exterior directions, as shown in Figure 64 in the top view, cut 1. In Figure 63, the top side attachments to the mounting bracket are shown. The elements are a combination of hexagonal head, cylinder, and rings of stainless steel and 6061-T6 aluminum. The top thin aluminum ring is centered on the HPRR centerline, but the other ring is centered around the stainless-steel attachment element. The hexagonal head face-to-face length is $2.612 \mathrm{~cm}$. In Figure 65, the top view, cut 2 , shows another point of view of the outer aluminum ring, and it shows the three different stainless steel elements from the three side attachments to the mounting bracket.

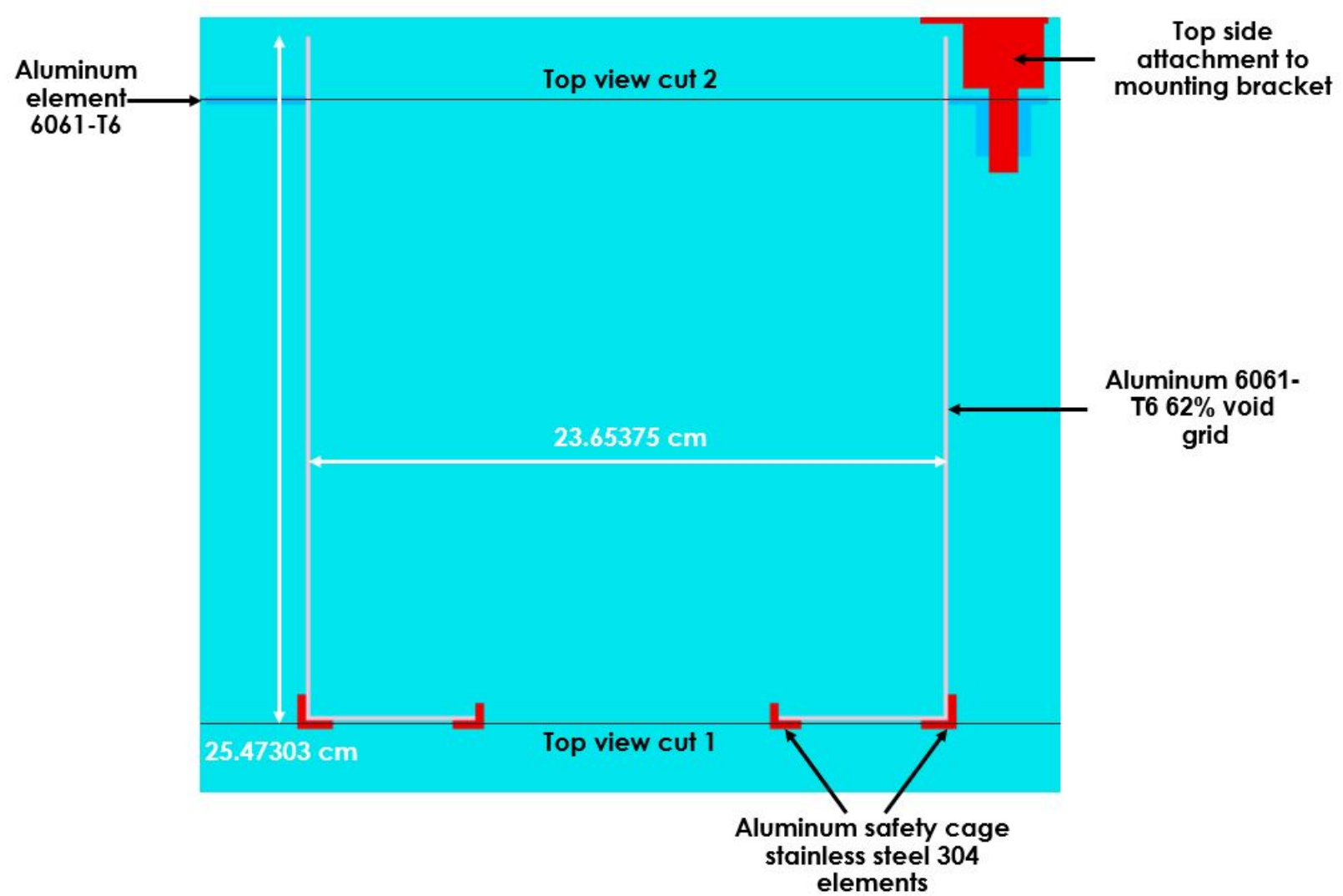

Figure 61. Benchmark model of the side view (X-Y) of the aluminum safety cage and other close components. 


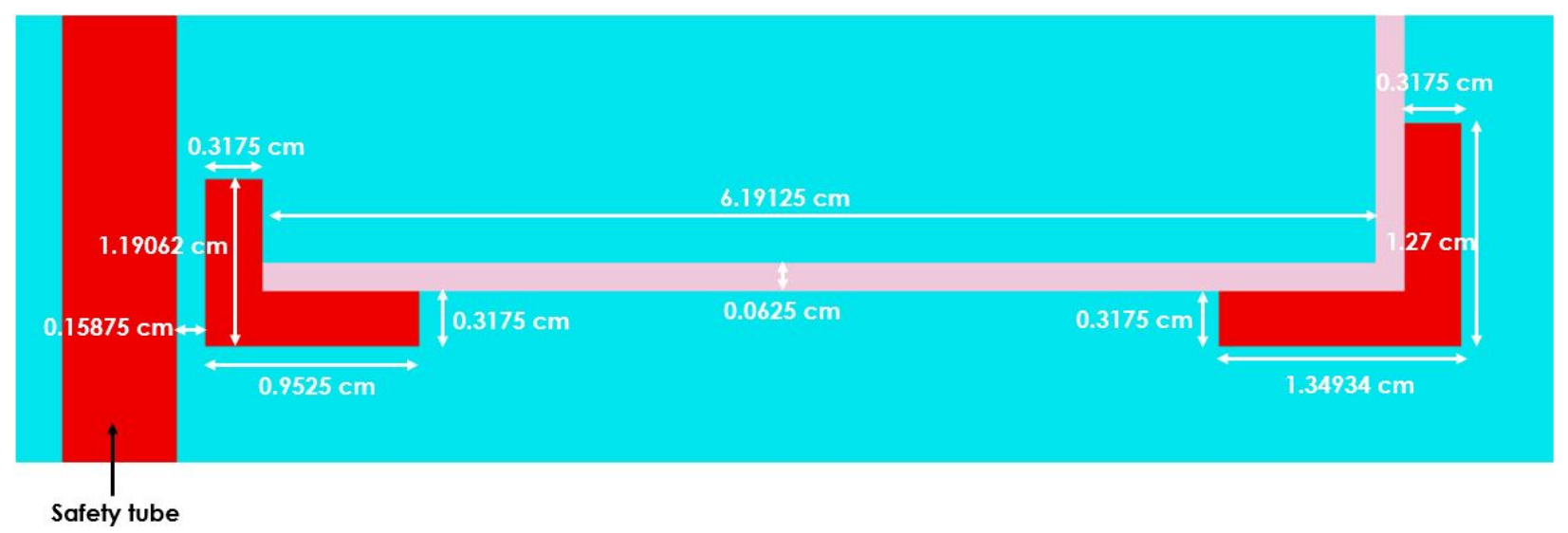

Figure 62. Benchmark model of the side view (X-Y) of the aluminum safety cage zoomed in on the bottom attachment elements.

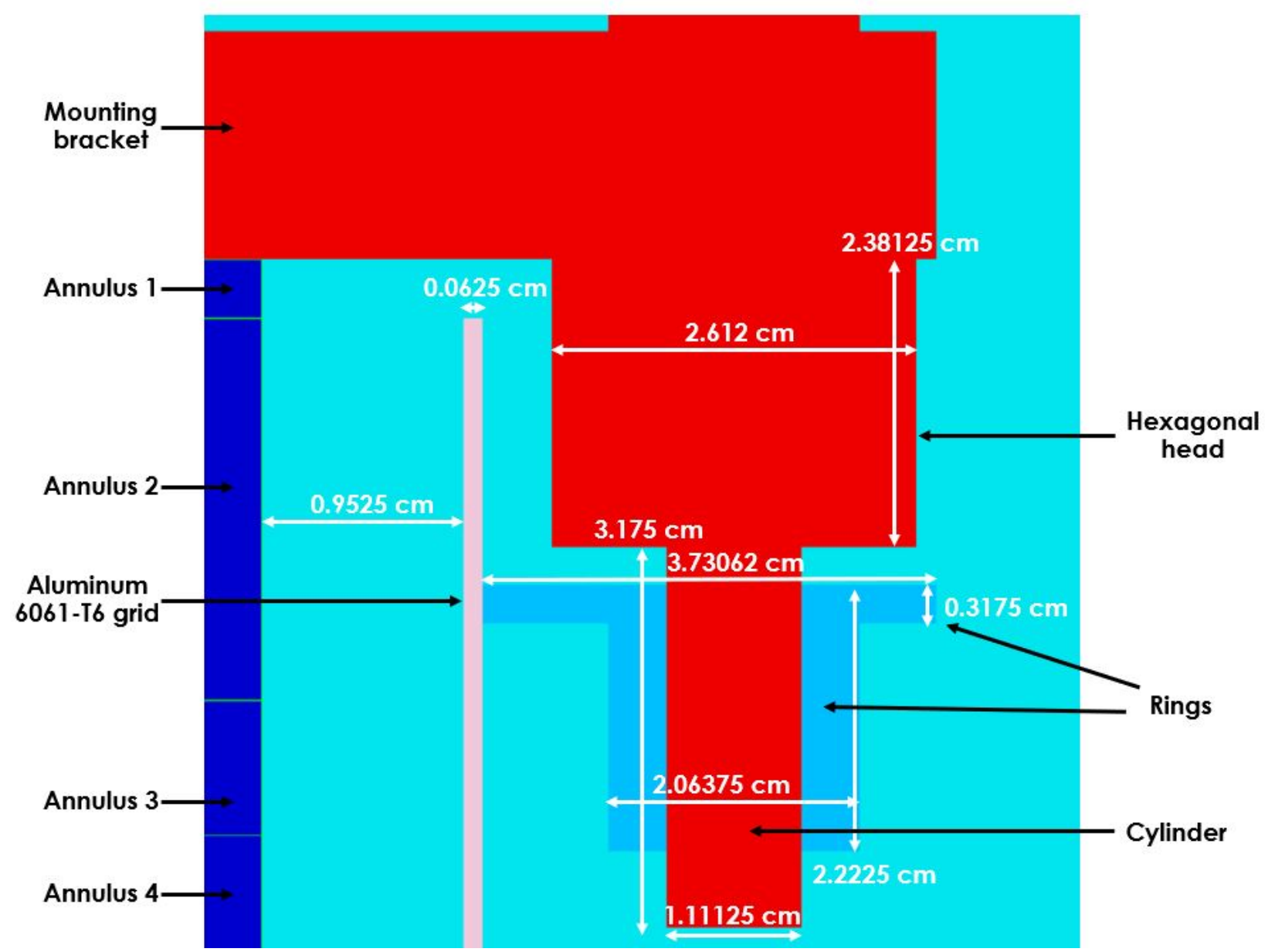

Figure 63. Benchmark model of the side view (X-Y) of the aluminum safety cage zoomed in on the top attachment elements. 


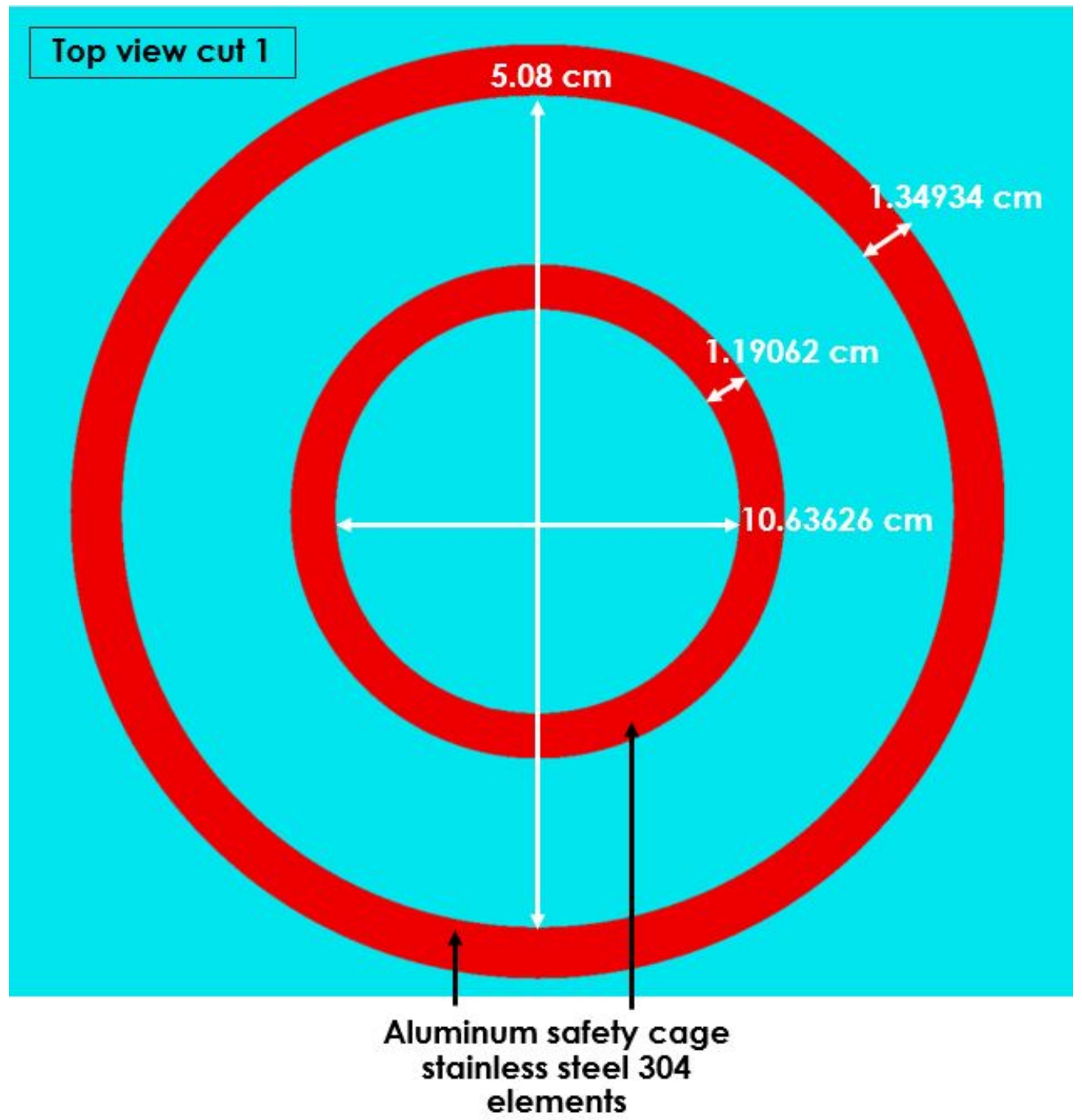

Figure 64. Aluminum safety cage benchmark model, top view, cut 1. 


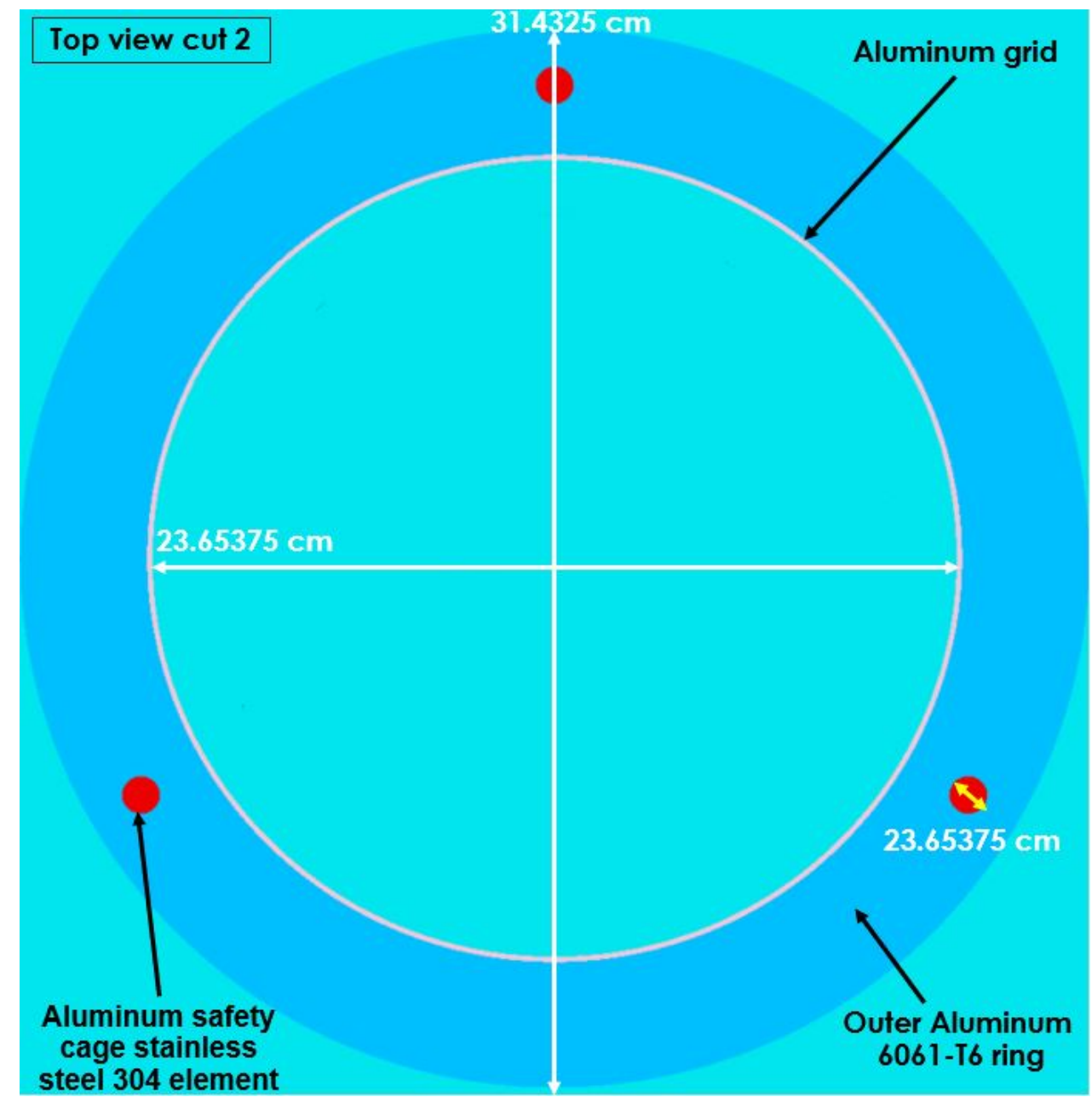

Figure 65. Aluminum safety cage benchmark model, top view, cut 2.

\subsubsection{Safety tube}

The safety tube benchmark model dimensions are essentially the same as those described in the previous sections. The side view of the safety tube is shown in Figure 66. The safety tube is a combination of rings of different internal and external diameters. To clarify the dimensions of the top section of the safety tube, a zoomed-in version of the previous figure is shown in Figure 67. In this figure, a curve radius simplification similar to that implemented before is visible, as well as the safety tube special bolts inserted into the U-Mo Annulus 11. 


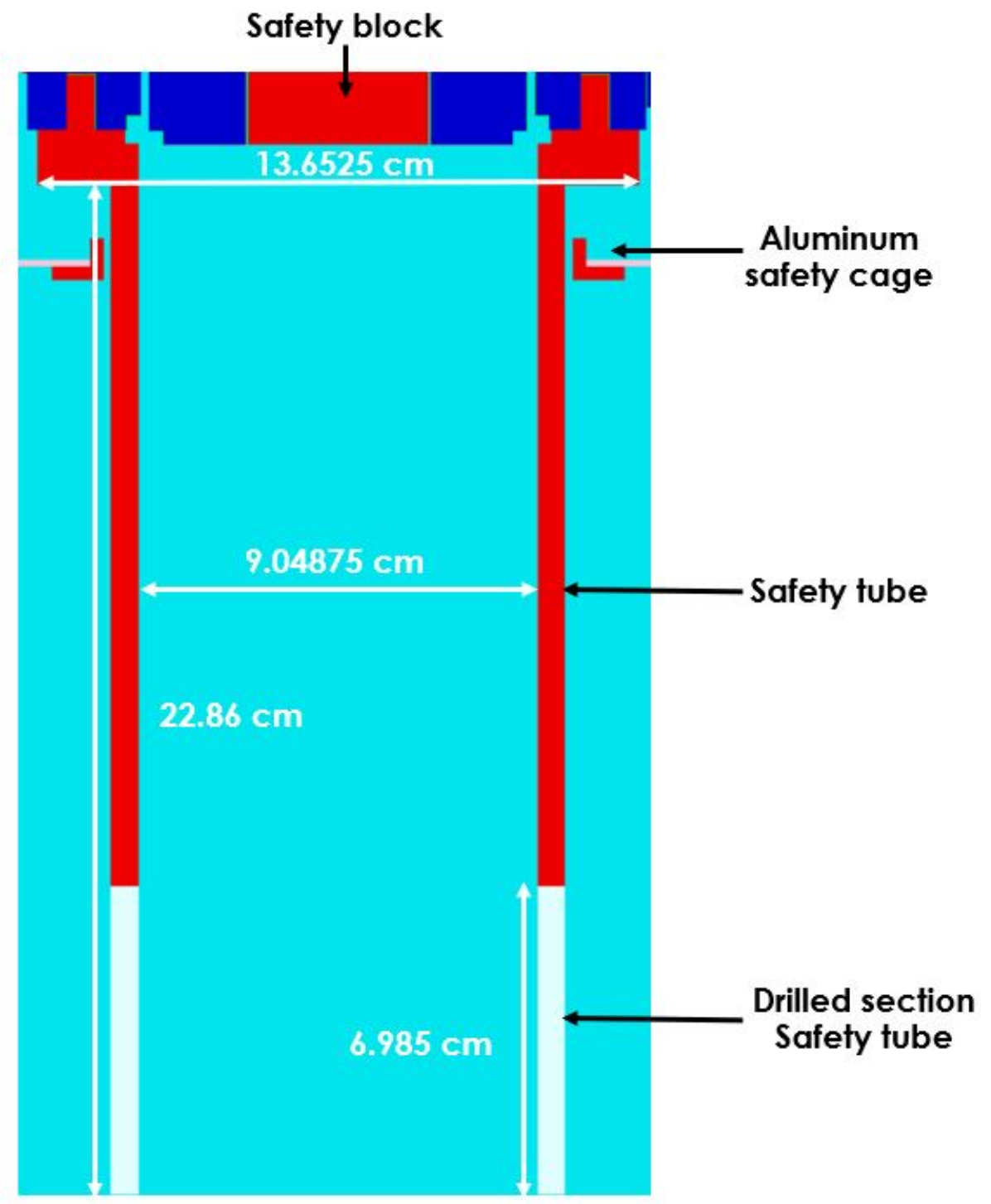

Figure 66. Benchmark model of the side view (X-Y) of the safety tube and other elements.

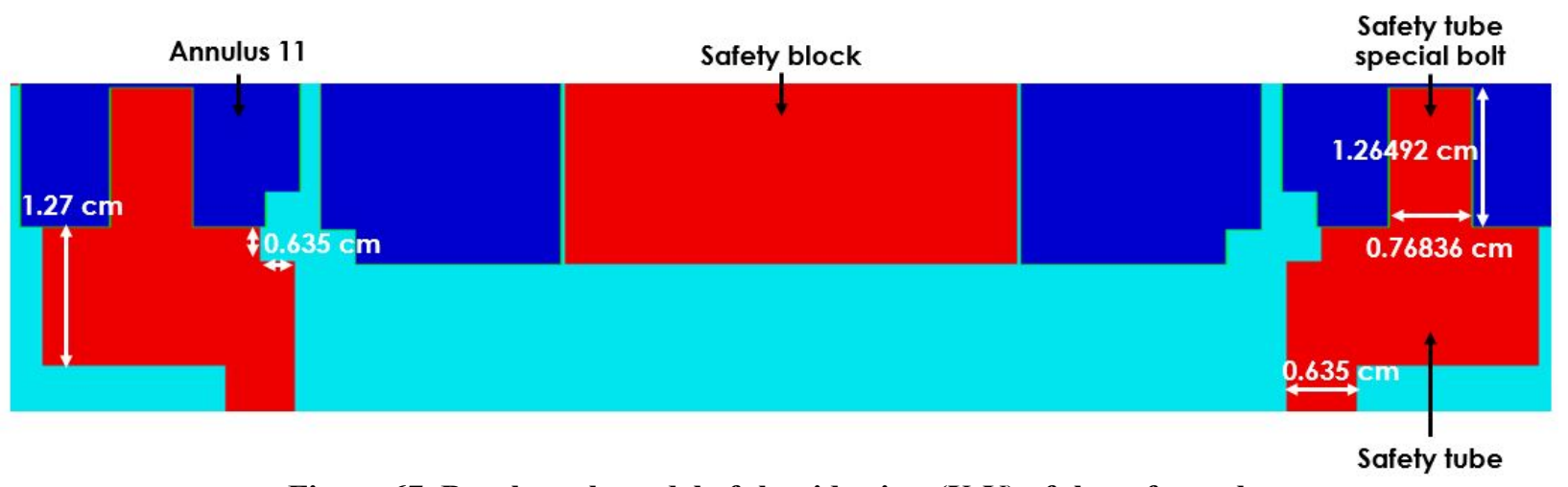

Figure 67. Benchmark model of the side view (X-Y) of the safety tube and other elements zoomed in on the top section. 


\subsubsection{Superstructure}

The superstructure benchmark model dimensions are essentially the same as those described in the previous sections. The side view of the superstructure is shown in Figure 68. Based on the results of the uncertainty study, the superstructure above top plate 1 is simplified to be only three 304 stainless steel cylinder plates of equal diameters of $50.8 \mathrm{~cm}$ and thicknesses of $2.54 \mathrm{~cm}$, connected by a central 304 stainless steel hanger rod of $2.54 \mathrm{~cm}$ in diameter. Below top plate 1, a total of seven 304 stainless steel rods are modeled representing the three control rods' guiding cylinders with diameters equal to the control rod diameters without the coating, the three rods hooked up to the mounting bracket, which is $2.06756 \mathrm{~cm}$ in diameter, and the central hanger rod which is $2.06756 \mathrm{~cm}$ in diameter. The top view of the superstructure cut right below top plate 1 is shown in Figure 69.

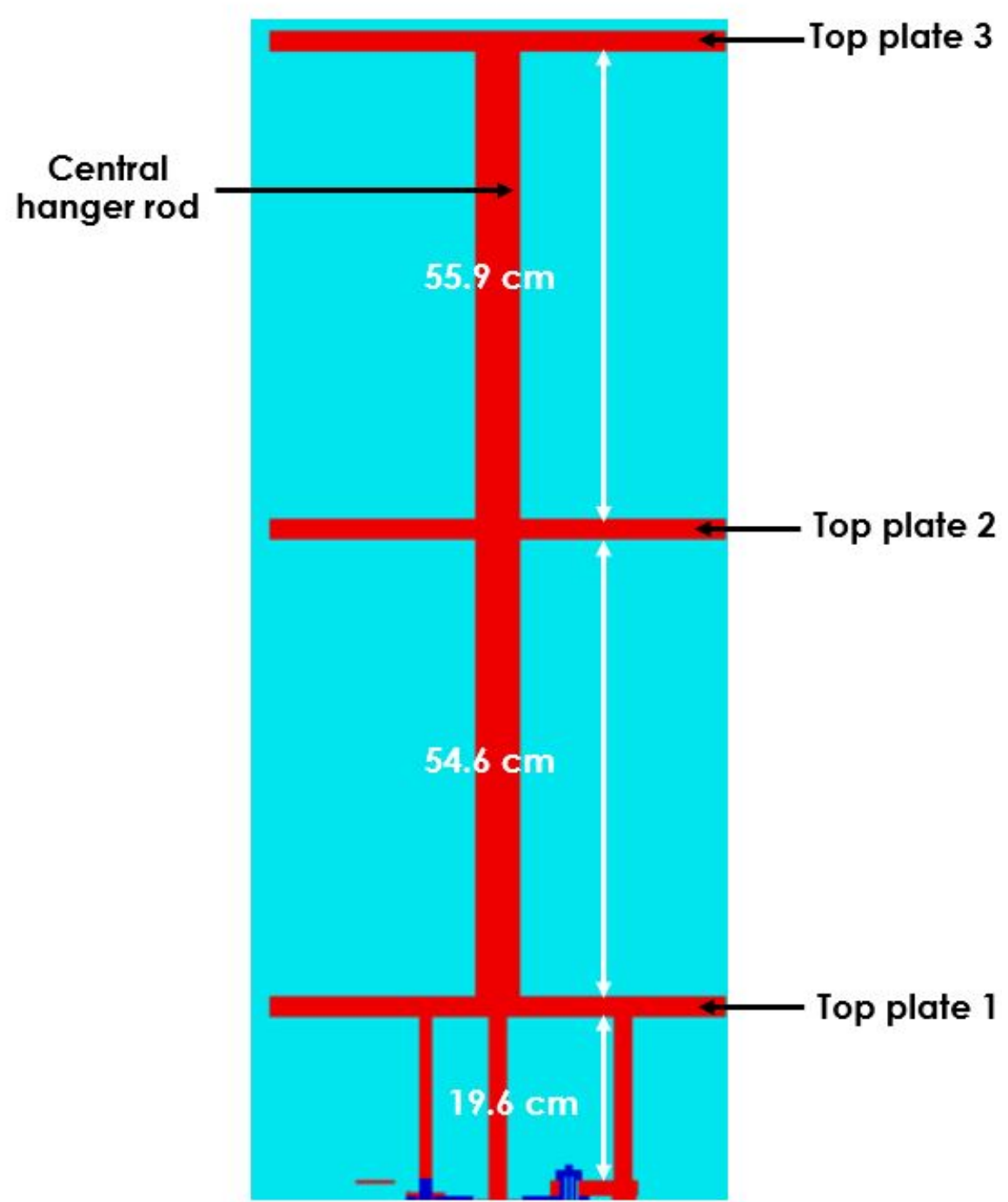

Figure 68. Benchmark model of the side view (X-Y) of the superstructure and other elements. 


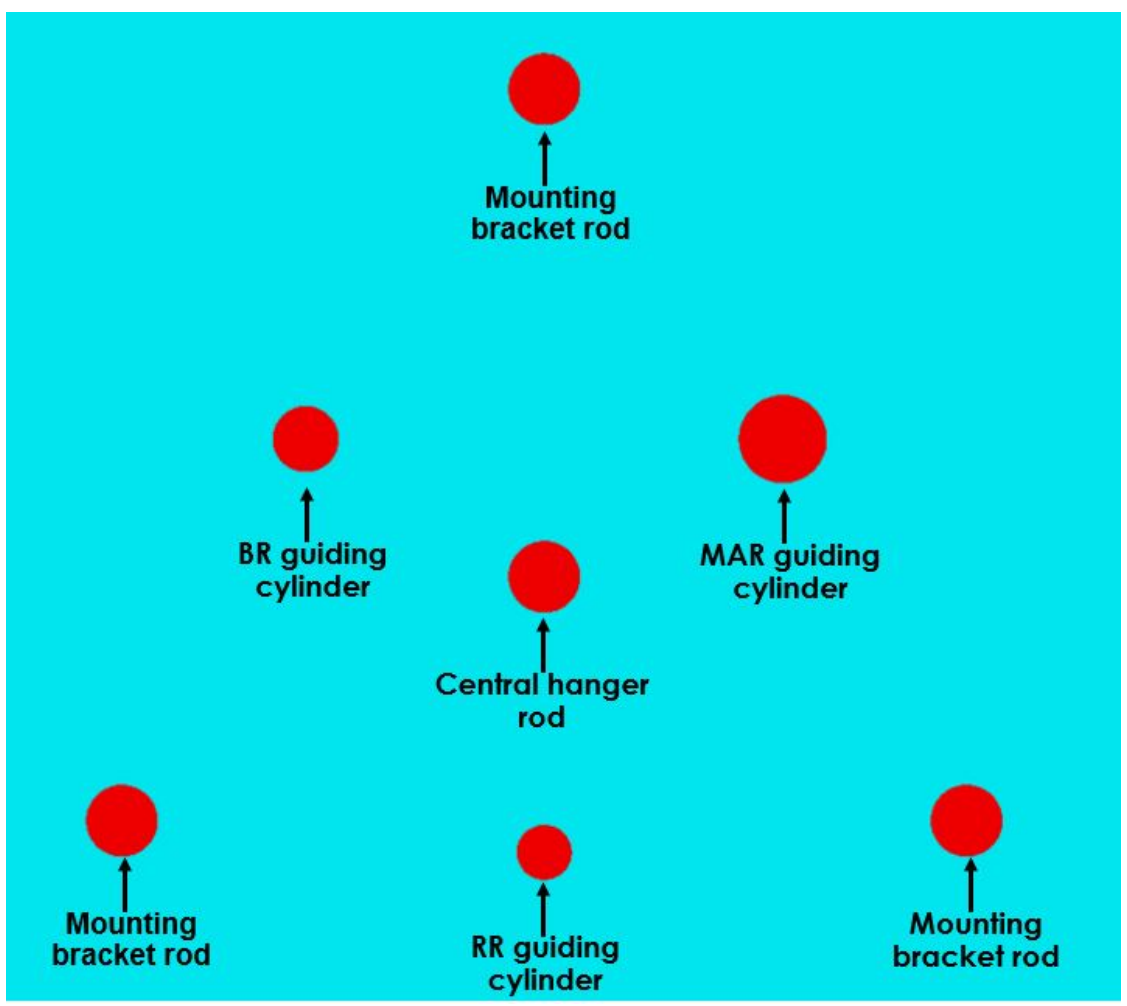

Figure 69. Benchmark model of the top view of the superstructure 304 stainless steel rods below top plate 1.

\subsection{MATERIAL DATA}

The benchmark model materials are exclusively the same as the materials presented in Sections 1 and 2. For clarity, the benchmark model material elemental compositions are provided again in the following subsections.

\subsubsection{HPRR reactor Building}

\subsubsection{Reactor room}

The benchmark model material compositions for the air in the reactor room and outside the reactor building, the concrete floor, and the soil are given in Table 31, Table 32, and Table 33.

Table 31. Benchmark model elemental

\begin{tabular}{lc}
\multicolumn{2}{c}{ composition of air } \\
\hline \multirow{2}{*}{ Element } & $\begin{array}{c}\text { Weight } \\
\text { percent }\end{array}$ \\
\hline $\mathrm{C}$ & 0.0126 \\
$\mathrm{~N}$ & 76.5081 \\
$\mathrm{O}$ & 23.4793 \\
Density & $1.2 \mathrm{E}-03 \mathrm{~g} / \mathrm{cm}^{3}$ \\
\hline
\end{tabular}


Table 32. Benchmark model elemental

composition of concrete

\begin{tabular}{lc}
\hline Element & Weight percent \\
\hline $\mathrm{Fe}$ & 0.7784 \\
$\mathrm{H}$ & 0.6187 \\
$\mathrm{C}$ & 17.52 \\
$\mathrm{O}$ & 41.02 \\
$\mathrm{Na}$ & 0.0271 \\
$\mathrm{Mg}$ & 3.265 \\
$\mathrm{Al}$ & 1.083 \\
$\mathrm{Si}$ & 3.448 \\
$\mathrm{~K}$ & 0.1138 \\
$\mathrm{Ca}$ & 32.13 \\
Density & $2.2994 \mathrm{~g} / \mathrm{cm}^{3}$ \\
\hline
\end{tabular}

Table 33. Benchmark model elemental composition of soil [19]

\begin{tabular}{lc}
\hline Element & Weight percent \\
\hline $\mathrm{O}$ & 51.3713 \\
$\mathrm{Na}$ & 0.6140 \\
$\mathrm{Mg}$ & 1.3303 \\
$\mathrm{Al}$ & 6.8563 \\
$\mathrm{Si}$ & 27.1183 \\
$\mathrm{~K}$ & 1.4327 \\
$\mathrm{Ca}$ & 5.1167 \\
$\mathrm{Ti}$ & 0.4605 \\
$\mathrm{Mn}$ & 0.0716 \\
$\mathrm{Fe}$ & 5.6283 \\
\hline
\end{tabular}

\subsubsection{Building walls}

The benchmark model walls are formed by a layer of pure aluminum with a density of $2.702 \mathrm{~g} / \mathrm{cm}^{3}$ and a layer of structural steel. The structural steel benchmark model elemental composition is given in Table 34.

Table 34. Benchmark model elemental composition of structural steel

\begin{tabular}{lc}
\hline Element & Weight percent \\
\hline $\mathrm{Fe}$ & 99 \\
$\mathrm{C}$ & 1 \\
Density & $3.9106 \mathrm{~g} / \mathrm{cm}^{3}$ \\
\hline
\end{tabular}

\subsubsection{Reactor storage pit}

The storage pit's interior is lined with concrete, as described previously, and it includes a top door of 304 stainless steel. The 304 stainless steel benchmark model's elemental composition is given in Table 35 . 
Table 35. Benchmark model elemental composition

of 304 stainless steel

\begin{tabular}{lc}
\hline Element & Weight percent \\
\hline $\mathrm{C}$ & 0.08 \\
$\mathrm{Si}$ & 1 \\
$\mathrm{P}$ & 0.045 \\
$\mathrm{Cr}$ & 19 \\
$\mathrm{Mn}$ & 2 \\
$\mathrm{Fe}$ & 68.375 \\
$\mathrm{Ni}$ & 9.5 \\
Density & $7.94 \mathrm{~g} / \mathrm{cm}^{3}$ \\
\hline
\end{tabular}

\subsubsection{Gates and doors}

The gates and doors are made of 304 stainless steel as described previously.

\subsubsection{Concrete pad}

The concrete pad is made of concrete as described previously.

\subsubsection{Sulfur pellets}

The sulfur pellet material is void, as the calculation methodology with SCALE MAVRIC involves the use of point detectors.

\subsubsection{Steel shield}

The steel shield material is 304 stainless steel as described previously

\subsubsection{HPRR core}

\subsubsection{Coating}

The different coating materials are pure elemental nickel, chromium, and gold, with densities of 8.9 $\mathrm{g} / \mathrm{cm}^{3}, 7.2 \mathrm{~g} / \mathrm{cm}^{3}$, and $18.88 \mathrm{~g} / \mathrm{cm}^{3}$, respectively.

\subsubsection{U-Mo elements}

All the benchmark model U-Mo elements of the core have the same material compositions as shown in Table 36.

Table 36. Benchmark model compositions of all the U-Mo elements

\begin{tabular}{lc}
\hline Element & Weight percent \\
\hline $\mathrm{Mo}$ & 10 \\
${ }^{235} \mathrm{U}$ & 83.826 \\
${ }^{238} \mathrm{U}$ & 6.174 \\
Density & $17.1 \mathrm{~g} / \mathrm{cm}^{3}$ \\
\hline
\end{tabular}




\subsubsection{Control rods}

The control rods are made of 304 stainless steel as described previously.

\subsubsection{Safety block}

The center plug material is 304 stainless steel as described previously. The quick lock material is $14-4 \mathrm{PH}$ stainless steel as shown in Table 37.

Table 37. Benchmark model composition

of 17-4 PH stainless steel

\begin{tabular}{lc}
\hline Element & Weight percent \\
\hline $\mathrm{C}$ & 0.07 \\
$\mathrm{Mn}$ & 1 \\
$\mathrm{P}$ & 0.04 \\
$\mathrm{~S}$ & 0.03 \\
$\mathrm{Si}$ & 1 \\
$\mathrm{Cr}$ & 16.25 \\
$\mathrm{Ni}$ & 4 \\
$\mathrm{Cu}$ & 4 \\
$\mathrm{Nb}$ & 0.30 \\
$\mathrm{Fe}$ & Balance \\
Density & $7.8 \mathrm{~g} / \mathrm{cm}^{3}$ \\
\hline
\end{tabular}

\subsubsection{Aluminum safety cage}

The stainless-steel elements of the aluminum safety cage are 304 stainless steel as described previously. The aluminum elements of the safety cage are 6061-T6 aluminum as shown in Table 38. With the aluminum safety grid part of the safety cage being $62 \%$ void, the elemental composition is the same as the regular 6061-T6 aluminum and the density is changed to $1.026 \mathrm{~g} / \mathrm{cm}^{3}$.

Table 38. Benchmark model composition of 6061-T6 aluminum

\begin{tabular}{lc}
\hline Element & Weight percent \\
\hline $\mathrm{Si}$ & 0.6 \\
$\mathrm{Fe}$ & 0.7 \\
$\mathrm{Cu}$ & 0.275 \\
$\mathrm{Mn}$ & 0.15 \\
$\mathrm{Mg}$ & 1.0 \\
$\mathrm{Cr}$ & 0.195 \\
$\mathrm{Zn}$ & 0.25 \\
$\mathrm{Ti}$ & 0.15 \\
$\mathrm{Al}$ & Balance \\
Density & $2.7 \mathrm{~g} / \mathrm{cm}^{3}$ \\
\hline
\end{tabular}

\subsubsection{Safety tube}

The stainless-steel elements of the safety tube are 304 stainless steel as described previously. To account for the $16.1 \%$ void introduced by holes drilled through the bottom part of the safety tube, the elemental composition is the same as regular 304 stainless steel, but the density is changed to $6.66 \mathrm{~g} / \mathrm{cm}^{3}$. 


\subsubsection{Superstructure}

The stainless-steel elements of the superstructure are 304 stainless steel as described previously.

\subsection{EXPERIMENTAL AND BENCHMARK MODEL NEUTRON DATA}

The benchmark values to be calculated using the benchmark model are the sulfur fluence in neutrons $/ \mathrm{cm}^{2}$ at different sulfur pellets distances from the HPRR centerline, with and without a steel shield placed in between. The geometry simplifications introduced in this section did not change the results significantly. The data evaluation determined that the sulfur fluence values at 20 and $30 \mathrm{~m}$ from the HPRR centerline in the bare configuration, shown in Table 11, should be removed from the benchmark. Table 39 and Table 40 summarize the experimental and benchmark values and the uncertainties obtained through the uncertainty study.

Table 39. Benchmark model sulfur fluence data for the bare configuration

\begin{tabular}{ccccc}
\hline $\begin{array}{c}\text { Position } \\
\text { Number }\end{array}$ & $\begin{array}{c}\text { Distance from } \\
\text { HPRR centerline } \\
(\mathbf{m})\end{array}$ & $\begin{array}{c}\text { Sulfur fluence } \\
\left(\mathbf{n} / \mathbf{c m}^{\mathbf{2}}\right)\end{array}$ & $\begin{array}{c}\text { Absolute uncertainty } \\
\text { Relative uncertainty }\end{array}$ \\
\hline 1 & 0.12 & $1.55 \mathrm{E}+13$ & $4.00 \mathrm{E}+12$ & $25.12 \%$ \\
2 & 0.144 & $1.30 \mathrm{E}+13$ & $3.35 \mathrm{E}+12$ & $25.12 \%$ \\
3 & 0.2 & $6.09 \mathrm{E}+12$ & $1.57 \mathrm{E}+12$ & $25.12 \%$ \\
4 & 0.3 & $2.74 \mathrm{E}+12$ & $7.06 \mathrm{E}+11$ & $25.12 \%$ \\
5 & 0.4 & $1.37 \mathrm{E}+12$ & $3.53 \mathrm{E}+11$ & $25.12 \%$ \\
6 & 0.5 & $9.42 \mathrm{E}+11$ & $2.43 \mathrm{E}+11$ & $25.12 \%$ \\
7 & 0.62 & $6.77 \mathrm{E}+11$ & $1.75 \mathrm{E}+11$ & $25.12 \%$ \\
8 & 0.75 & $4.47 \mathrm{E}+11$ & $1.15 \mathrm{E}+11$ & $25.12 \%$ \\
9 & 1 & $2.54 \mathrm{E}+11$ & $6.55 \mathrm{E}+10$ & $25.12 \%$ \\
10 & 1.25 & $1.45 \mathrm{E}+11$ & $3.74 \mathrm{E}+10$ & $25.12 \%$ \\
11 & 1.5 & $1.11 \mathrm{E}+11$ & $2.86 \mathrm{E}+10$ & $25.12 \%$ \\
12 & 1.75 & $8.85 \mathrm{E}+10$ & $2.28 \mathrm{E}+10$ & $25.12 \%$ \\
13 & 2 & $6.69 \mathrm{E}+10$ & $1.72 \mathrm{E}+10$ & $25.12 \%$ \\
14 & 2.5 & $4.29 \mathrm{E}+10$ & $1.11 \mathrm{E}+10$ & $25.12 \%$ \\
15 & 3 & $2.99 \mathrm{E}+10$ & $7.71 \mathrm{E}+09$ & $25.12 \%$ \\
16 & 3.5 & $2.26 \mathrm{E}+10$ & $5.83 \mathrm{E}+09$ & $25.12 \%$ \\
17 & 4 & $1.74 \mathrm{E}+10$ & $4.49 \mathrm{E}+09$ & $25.12 \%$ \\
18 & 5 & $1.12 \mathrm{E}+10$ & $2.89 \mathrm{E}+09$ & $25.12 \%$ \\
19 & 7 & $5.83 \mathrm{E}+09$ & $1.50 \mathrm{E}+09$ & $25.12 \%$ \\
20 & $9.54 \mathrm{E}+09$ & $9.13 \mathrm{E}+08$ & $25.12 \%$ \\
21 & 12 & $1.99 \mathrm{E}+09$ & $5.13 \mathrm{E}+08$ & $25.12 \%$ \\
22 & 15 & $1.20 \mathrm{E}+09$ & $3.09 \mathrm{E}+08$ & $25.12 \%$ \\
\hline
\end{tabular}

Table 40. Benchmark model sulfur fluence data for the steel shield configuration

\begin{tabular}{ccccc}
\hline $\begin{array}{c}\text { Position } \\
\text { Number }\end{array}$ & Distance $(\mathbf{m})$ & $\begin{array}{c}\text { Sulfur fluence } \\
\left(\mathbf{n} / \mathbf{c m}^{\mathbf{2}}\right)\end{array}$ & Absolute uncertainty & Relative uncertainty \\
\hline 1 & 2.5 & $6.48 \mathrm{E}+09$ & $3.83 \mathrm{E}+09$ & $49.84 \%$ \\
2 & 3 & $4.59 \mathrm{E}+09$ & $2.71 \mathrm{E}+09$ & $49.84 \%$ \\
3 & 3.5 & $3.41 \mathrm{E}+09$ & $2.02 \mathrm{E}+09$ & $49.84 \%$ \\
4 & 4 & $2.59 \mathrm{E}+09$ & $1.53 \mathrm{E}+09$ & $49.84 \%$ \\
5 & 5 & $1.68 \mathrm{E}+09$ & $9.93 \mathrm{E}+08$ & $49.84 \%$ \\
6 & 7 & $8.91 \mathrm{E}+08$ & $5.27 \mathrm{E}+08$ & $49.84 \%$ \\
7 & 9 & $5.09 \mathrm{E}+08$ & $3.01 \mathrm{E}+08$ & $49.84 \%$ \\
\hline
\end{tabular}




\section{RESULTS OF SAMPLE CALCULATIONS}

The results of the SCALE 6.2.3 KENO-VI and SCALE 6.2.3 MAVRIC sample calculations are presented in this section. All of the simulations are static, excluding all dynamic aspects of the critical burst reaction of the HPRR. All the materials are at $20^{\circ} \mathrm{C}$.

\subsection{SOURCE STRENGTH AND SPECTRA}

The number of neutrons emitted per fission and the spatial and energy distributions were calculated through continuous energy KENO-VI eigenvalue simulations using ENDF/B-VII.1 cross section data at room temperature. As previously described, the configuration of the core is from the burst B1024 description. The calculated number of neutrons emitted per fission, $\bar{v}$, is $2.58226 \pm 0.00003$. The eigenvalue obtained from the simulation is $1.01623 \pm 0.00014$, so the core was significantly above the delayed critical region in this configuration. This corresponds to typical burst reactor criticality conditions. The fission energy distribution plotted from Fulcrum is shown in Figure 70. The radial fission distribution is shown in Figure 71. Note the fission rate is equal to 0 around the centerline of the HPRR, which corresponds to the central 304 stainless steel plug inserted in the core. The axial fission distribution is shown in Figure 72. Note that the fission rate decreases at around $155 \mathrm{~cm}$, which is explained by the space between the U-Mo safety block and the U-Mo annuli. The maximum number of fissions is located around the axial centerline on a ring of about $3.5 \mathrm{~cm}$ radius right outside the center plug. A 3-dimensional front right quarter view of the spatial fission distribution is shown in Figure 73. Note the few fission events happening in the MAR outside the main part of the core. The source strength was set to a constant value of $10^{17}$ fission events for the SCALE MAVRIC calculations. To decrease the sulfur fluence tally calculation uncertainty, five MAVRIC calculations of the same geometry with different random seeds were performed, thus averaging the results of the sample calculations.

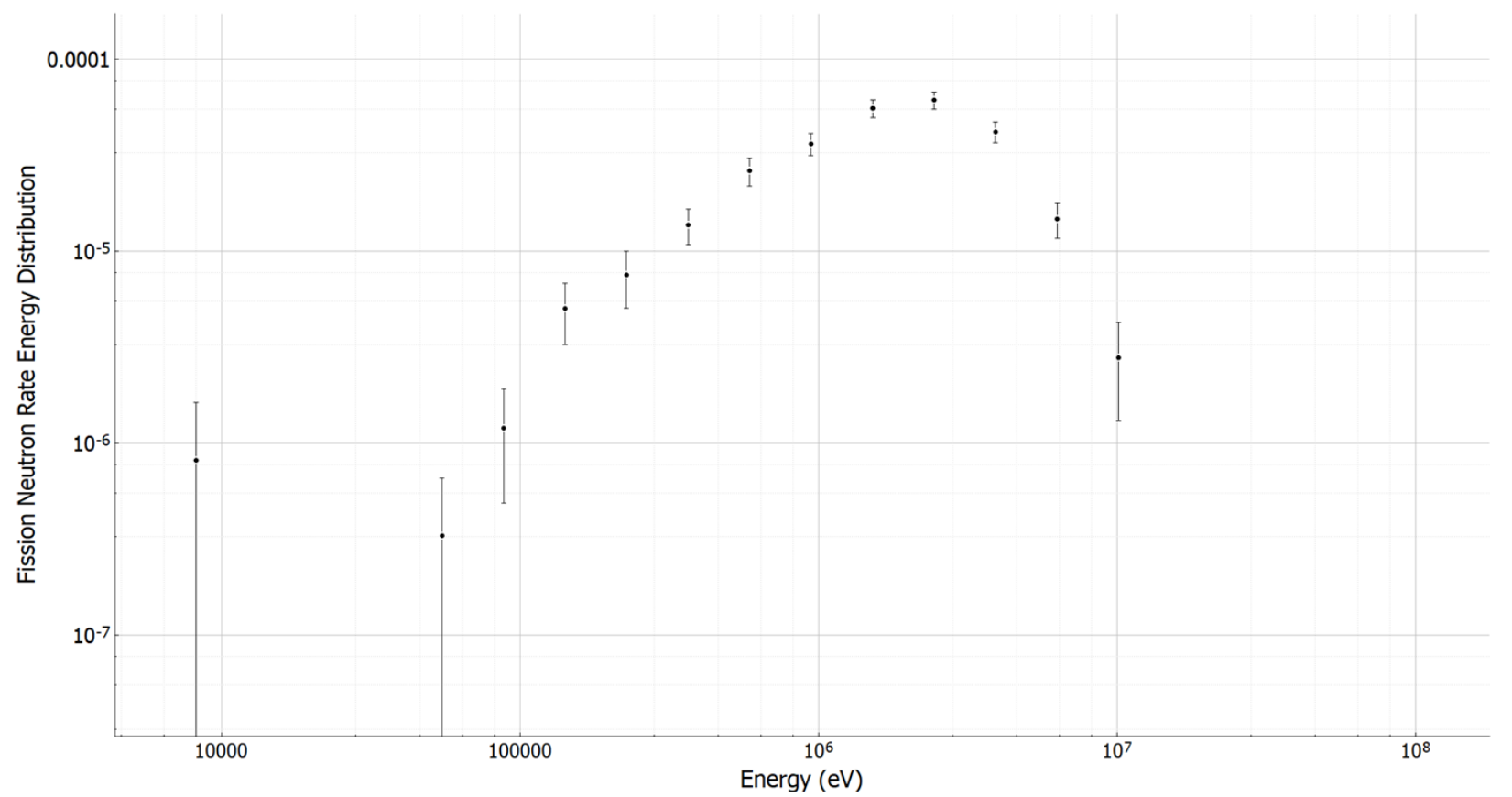

Figure 70. HPRR energy distribution of fission neutrons calculated with KENO-VI using ENDF/B-VII.1 continuous energy cross sections. 


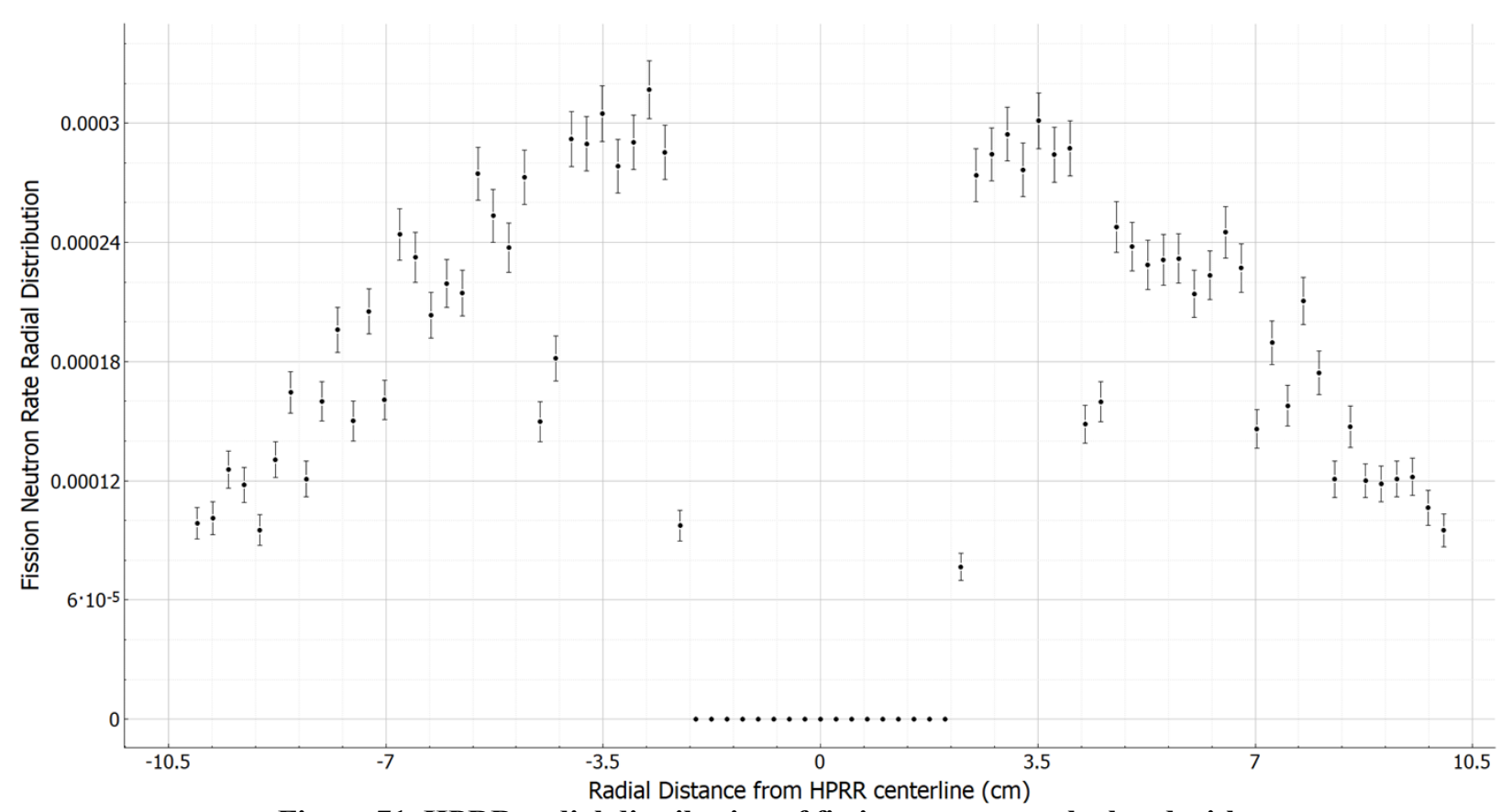

Figure 71. HPRR radial distribution of fission neutrons calculated with KENO-VI using ENDF/B-VII.1 continuous energy cross sections.

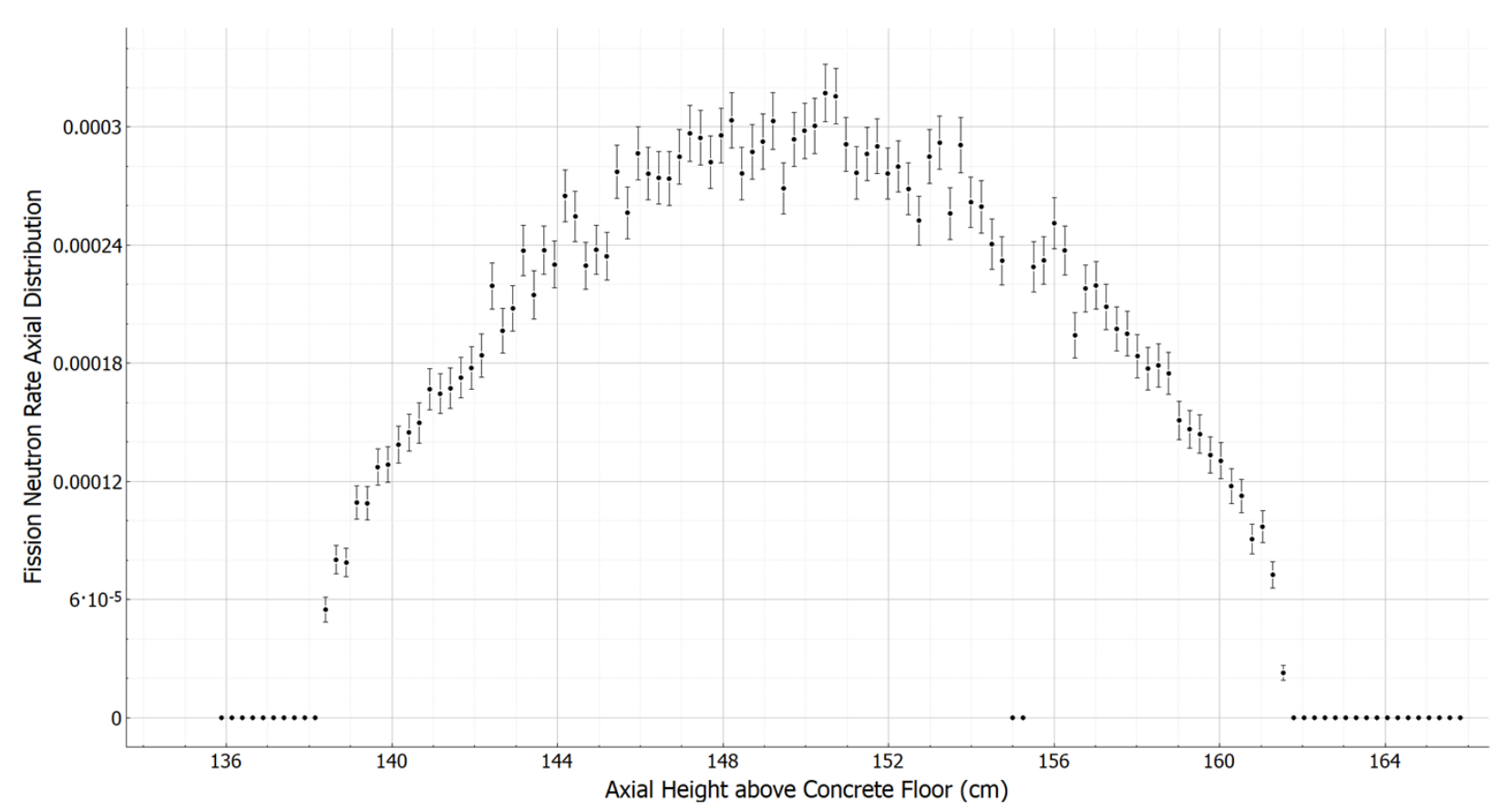

Figure 72. HPRR axial distribution of fission neutrons calculated with KENO-VI using ENDF/B-VII.1 continuous energy cross sections. 


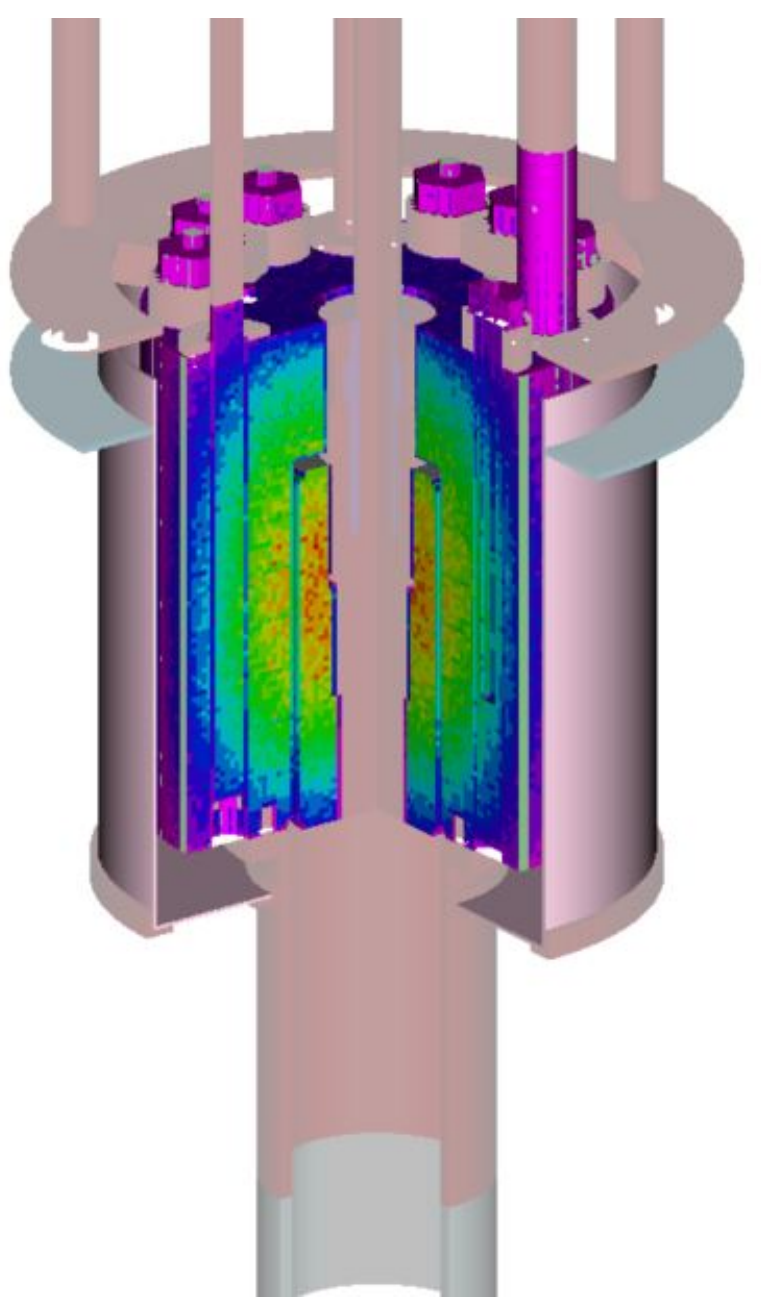

Figure 73. HPRR 3-dimensional spatial distribution of fission neutrons calculated with KENO-VI using ENDF/B-VII.1 continuous energy cross sections.

\subsection{BARE CONFIGURATION RESULTS}

Sample calculation results for the sulfur fluences at different positions and from different ${ }^{32} \mathrm{~S}(\mathrm{n}, \mathrm{p}){ }^{32} \mathrm{P}$ cross section energy cutoffs for the bare configuration of the HPRR are shown in Table 41, Table 42, and 
Table 43. 
Table 41. Sample sulfur fluence calculation results for the bare configuration calculated with MAVRIC with ENDF/B VII.1 cross-section data and the $\operatorname{regular}{ }^{32} \mathrm{~S}(\mathrm{n}, \mathrm{p})^{32} \mathrm{P}$ cross section data from ENDF/B VIII.0

\begin{tabular}{cccccc}
\hline $\begin{array}{c}\text { Position } \\
\text { Number }\end{array}$ & $\begin{array}{c}\text { Distance from } \\
\text { HPRR } \\
\text { centerline (m) }\end{array}$ & $\begin{array}{c}\text { Sulfur } \\
\text { fluence } \\
\text { (n/cm2) }\end{array}$ & $\begin{array}{c}\text { Calculation } \\
\text { uncertainty } \\
\text { (rel) }\end{array}$ & $\begin{array}{c}\text { Calculated- } \\
\text { to } \\
\text { experimental } \\
\text { (C/E) }\end{array}$ & $\begin{array}{c}\text { C/E uncertainty } \\
\text { (rel) }\end{array}$ \\
\hline 1 & 0.12 & $3.27 \mathrm{E}+13$ & 0.0059 & 2.11 & 0.25 \\
2 & 0.144 & $2.27 \mathrm{E}+13$ & 0.0044 & 1.74 & 0.25 \\
3 & 0.2 & $1.18 \mathrm{E}+13$ & 0.0035 & 1.94 & 0.25 \\
4 & 0.3 & $5.21 \mathrm{E}+12$ & 0.0032 & 1.90 & 0.25 \\
5 & 0.4 & $2.92 \mathrm{E}+12$ & 0.0032 & 2.13 & 0.25 \\
6 & 0.5 & $1.86 \mathrm{E}+12$ & 0.0030 & 1.98 & 0.25 \\
7 & 0.62 & $1.21 \mathrm{E}+12$ & 0.0029 & 1.78 & 0.25 \\
8 & 0.75 & $8.30 \mathrm{E}+11$ & 0.0029 & 1.86 & 0.25 \\
9 & 1 & $4.75 \mathrm{E}+11$ & 0.0048 & 1.87 & 0.25 \\
10 & 1.25 & $3.08 \mathrm{E}+11$ & 0.0028 & 2.12 & 0.25 \\
11 & 1.5 & $2.19 \mathrm{E}+11$ & 0.0033 & 1.97 & 0.25 \\
12 & 1.75 & $1.64 \mathrm{E}+11$ & 0.0028 & 1.85 & 0.25 \\
13 & 2 & $1.29 \mathrm{E}+11$ & 0.0028 & 1.92 & 0.25 \\
14 & 2.5 & $8.63 \mathrm{E}+10$ & 0.0032 & 2.01 & 0.25 \\
15 & 3 & $6.22 \mathrm{E}+10$ & 0.0028 & 2.08 & 0.25 \\
16 & 3.5 & $4.75 \mathrm{E}+10$ & 0.0036 & 2.10 & 0.25 \\
17 & 4 & $3.75 \mathrm{E}+10$ & 0.0029 & 2.15 & 0.25 \\
18 & 5 & $2.53 \mathrm{E}+10$ & 0.0029 & 2.26 & 0.25 \\
19 & 7 & $1.40 \mathrm{E}+10$ & 0.0031 & 2.40 & 0.25 \\
20 & 9 & $8.97 \mathrm{E}+09$ & 0.0036 & 2.54 & 0.25 \\
21 & 12 & $5.39 \mathrm{E}+09$ & 0.0037 & 2.71 & 0.25 \\
22 & 15 & $3.81 \mathrm{E}+09$ & 0.0046 & 3.18 & 0.25 \\
\hline
\end{tabular}


Table 42. Sample sulfur fluence calculation results for the bare configuration calculated with MAVRIC with ENDF/B VII.1 cross-section data and the cutoff energy 1 (neutron energy $>2 \mathrm{MeV}$ ) ${ }^{32} \mathrm{~S}(\mathrm{n}, \mathrm{p}){ }^{32} \mathrm{P}$ cross section data from ENDF/B VIII.0

\begin{tabular}{cccccc}
\hline $\begin{array}{c}\text { Position } \\
\text { Number }\end{array}$ & $\begin{array}{c}\text { Distance from } \\
\text { HPRR } \\
\text { centerline }(\mathbf{m})\end{array}$ & $\begin{array}{c}\text { Sulfur } \\
\text { fluence } \\
(\mathbf{n} / \mathbf{c m} \text { ) }\end{array}$ & $\begin{array}{c}\text { Calculation } \\
\text { uncertainty } \\
\text { (rel\%) }\end{array}$ & $\mathbf{C / E}$ & $\begin{array}{c}\text { C/E relative } \\
\text { uncertainty }\end{array}$ \\
\hline 1 & 0.12 & $2.28 \mathrm{E}+13$ & 0.0039 & 1.47 & 0.25 \\
2 & 0.144 & $1.58 \mathrm{E}+13$ & 0.0029 & 1.21 & 0.25 \\
3 & 0.2 & $8.17 \mathrm{E}+12$ & 0.0024 & 1.34 & 0.25 \\
4 & 0.3 & $3.61 \mathrm{E}+12$ & 0.0022 & 1.32 & 0.25 \\
5 & 0.4 & $2.01 \mathrm{E}+12$ & 0.0022 & 1.47 & 0.25 \\
6 & 0.5 & $1.28 \mathrm{E}+12$ & 0.0021 & 1.36 & 0.25 \\
7 & 0.62 & $8.34 \mathrm{E}+11$ & 0.0021 & 1.23 & 0.25 \\
8 & 0.75 & $5.71 \mathrm{E}+11$ & 0.0021 & 1.28 & 0.25 \\
9 & 1 & $3.24 \mathrm{E}+11$ & 0.0021 & 1.27 & 0.25 \\
10 & 1.25 & $2.10 \mathrm{E}+11$ & 0.0020 & 1.45 & 0.25 \\
11 & 1.5 & $1.49 \mathrm{E}+11$ & 0.0034 & 1.34 & 0.25 \\
12 & 1.75 & $1.10 \mathrm{E}+11$ & 0.0020 & 1.25 & 0.25 \\
13 & 2 & $8.63 \mathrm{E}+10$ & 0.0020 & 1.29 & 0.25 \\
14 & 2.5 & $5.70 \mathrm{E}+10$ & 0.0019 & 1.33 & 0.25 \\
15 & 3 & $4.08 \mathrm{E}+10$ & 0.0021 & 1.37 & 0.25 \\
16 & 3.5 & $3.07 \mathrm{E}+10$ & 0.0019 & 1.36 & 0.25 \\
17 & 4 & $2.41 \mathrm{E}+10$ & 0.0019 & 1.38 & 0.25 \\
18 & 5 & $1.60 \mathrm{E}+10$ & 0.0019 & 1.43 & 0.25 \\
19 & 7 & $8.63 \mathrm{E}+09$ & 0.0019 & 1.48 & 0.25 \\
20 & 9 & $5.41 \mathrm{E}+09$ & 0.0019 & 1.53 & 0.25 \\
21 & 12 & $3.16 \mathrm{E}+09$ & 0.0023 & 1.59 & 0.25 \\
22 & 15 & $2.14 \mathrm{E}+09$ & 0.0022 & 1.79 & 0.25 \\
\hline
\end{tabular}


Table 43. Sample sulfur fluence calculation results for the bare configuration calculated with MAVRIC with ENDF/B VII.1 cross-section data and the cutoff energy 2 (neutron energy $>2.5 \mathrm{MeV}$ ) ${ }^{32} \mathrm{~S}(\mathrm{n}, \mathrm{p})^{32} \mathrm{P}$ cross section

\begin{tabular}{cccccc}
\hline $\begin{array}{c}\text { Position } \\
\text { Number }\end{array}$ & $\begin{array}{c}\text { Distance from } \\
\text { HPRR } \\
\text { centerline (m) }\end{array}$ & $\begin{array}{c}\text { Sulfur } \\
\text { fluence } \\
\text { (n/cm2) }\end{array}$ & $\begin{array}{c}\text { Calculation } \\
\text { uncertainty } \\
\text { (rel\%) }\end{array}$ & C/E & $\begin{array}{c}\text { C/E relative } \\
\text { uncertainty }\end{array}$ \\
\hline 1 & 0.12 & $1.80 \mathrm{E}+13$ & 0.0038 & 1.16 & 0.25 \\
2 & 0.144 & $1.24 \mathrm{E}+13$ & 0.0028 & 0.95 & 0.25 \\
3 & 0.2 & $6.42 \mathrm{E}+12$ & 0.0024 & 1.05 & 0.25 \\
4 & 0.3 & $2.83 \mathrm{E}+12$ & 0.0022 & 1.03 & 0.25 \\
5 & 0.4 & $1.58 \mathrm{E}+12$ & 0.0021 & 1.15 & 0.25 \\
6 & 0.5 & $1.00 \mathrm{E}+12$ & 0.0021 & 1.07 & 0.25 \\
7 & 0.62 & $6.51 \mathrm{E}+11$ & 0.0021 & 0.96 & 0.25 \\
8 & 0.75 & $4.45 \mathrm{E}+11$ & 0.0020 & 0.99 & 0.25 \\
9 & 1 & $2.51 \mathrm{E}+11$ & 0.0020 & 0.99 & 0.25 \\
10 & 1.25 & $1.62 \mathrm{E}+11$ & 0.0020 & 1.12 & 0.25 \\
11 & 1.5 & $1.14 \mathrm{E}+11$ & 0.0020 & 1.03 & 0.25 \\
12 & 1.75 & $8.46 \mathrm{E}+10$ & 0.0020 & 0.96 & 0.25 \\
13 & 2 & $6.59 \mathrm{E}+10$ & 0.0019 & 0.98 & 0.25 \\
14 & 2.5 & $4.33 \mathrm{E}+10$ & 0.0020 & 1.01 & 0.25 \\
15 & 3 & $3.08 \mathrm{E}+10$ & 0.0022 & 1.03 & 0.25 \\
16 & 3.5 & $2.30 \mathrm{E}+10$ & 0.0019 & 1.02 & 0.25 \\
17 & 4 & $1.79 \mathrm{E}+10$ & 0.0019 & 1.03 & 0.25 \\
18 & 5 & $1.18 \mathrm{E}+10$ & 0.0019 & 1.06 & 0.25 \\
19 & 7 & $6.31 \mathrm{E}+09$ & 0.0019 & 1.08 & 0.25 \\
20 & 9 & $3.93 \mathrm{E}+09$ & 0.0019 & 1.11 & 0.25 \\
21 & 12 & $2.27 \mathrm{E}+09$ & 0.0023 & 1.14 & 0.25 \\
22 & 15 & $1.51 \mathrm{E}+09$ & 0.0022 & 1.26 & 0.25 \\
\hline
\end{tabular}

\subsection{STEEL SHIELD CONFIGURATION RESULTS}

Sample calculation results for the sulfur fluences at different positions and from different cross section cutoffs for the HPRR steel shield configuration are shown in Table 44, Table 45, and Table 46.

Table 44. Sample sulfur fluence calculation results for the steel shield configuration calculated with MAVRIC with ENDF/B VII.1 cross-section data and the regular ${ }^{32} \mathrm{~S}(\mathrm{n}, \mathrm{p}){ }^{32} \mathrm{P}$ cross section data from ENDF/B VIII.0

\begin{tabular}{cccccc}
\hline $\begin{array}{c}\text { Position } \\
\text { Number }\end{array}$ & $\begin{array}{c}\text { Distance from } \\
\text { HPRR } \\
\text { centerline (m) }\end{array}$ & $\begin{array}{c}\text { Sulfur } \\
\text { fluence } \\
\text { (n/cm2) }\end{array}$ & $\begin{array}{c}\text { Calculation } \\
\text { uncertainty } \\
\text { (rel) }\end{array}$ & $\mathbf{C / E}$ & $\begin{array}{c}\mathbf{C} / \mathbf{E} \\
\text { uncertainty } \\
\text { (rel) }\end{array}$ \\
\hline 1 & 2.5 & $2.37 \mathrm{E}+10$ & 0.0098 & 3.65 & 0.59 \\
2 & 3 & $1.67 \mathrm{E}+10$ & 0.0062 & 3.64 & 0.59 \\
3 & 3.5 & $1.29 \mathrm{E}+10$ & 0.0052 & 3.79 & 0.59 \\
4 & 4 & $1.05 \mathrm{E}+10$ & 0.0049 & 4.04 & 0.59 \\
5 & 5 & $7.42 \mathrm{E}+09$ & 0.0047 & 4.42 & 0.59 \\
6 & 7 & $4.43 \mathrm{E}+09$ & 0.0051 & 4.98 & 0.59 \\
7 & 9 & $2.94 \mathrm{E}+09$ & 0.0060 & 5.78 & 0.59 \\
\hline
\end{tabular}


Table 45. Sample sulfur fluence calculation results for the steel shield configuration calculated with MAVRIC with ENDF/B VII.1 cross-section data and the cutoff energy 1 (neutron energy $>2 \mathrm{MeV}{ }^{32} \mathrm{~S}(\mathrm{n}, \mathrm{p}){ }^{32} \mathrm{P}$ cross section data from ENDF/B VIII.0

\begin{tabular}{cccccc}
\hline $\begin{array}{c}\text { Position } \\
\text { Number }\end{array}$ & $\begin{array}{c}\text { Distance from } \\
\text { HPRR } \\
\text { centerline (m) }\end{array}$ & $\begin{array}{c}\text { Sulfur } \\
\text { fluence } \\
\text { (n/cm2) }\end{array}$ & $\begin{array}{c}\text { Calculation } \\
\text { uncertainty } \\
\text { (rel) }\end{array}$ & $\mathbf{C / E}$ & $\begin{array}{c}\mathbf{C} / \mathbf{E} \\
\text { uncertainty } \\
\text { (rel) }\end{array}$ \\
\hline 1 & 2.5 & $1.13 \mathrm{E}+10$ & 0.0050 & 1.74 & 0.50 \\
2 & 3 & $8.03 \mathrm{E}+09$ & 0.0029 & 1.75 & 0.50 \\
3 & 3.5 & $6.18 \mathrm{E}+09$ & 0.0025 & 1.81 & 0.50 \\
4 & 4 & $4.98 \mathrm{E}+09$ & 0.0023 & 1.92 & 0.50 \\
5 & 5 & $3.49 \mathrm{E}+09$ & 0.0021 & 2.08 & 0.50 \\
6 & 7 & $2.03 \mathrm{E}+09$ & 0.0022 & 2.28 & 0.50 \\
7 & 9 & $1.32 \mathrm{E}+09$ & 0.0025 & 2.59 & 0.50 \\
\hline
\end{tabular}

Table 46. Sample sulfur fluence calculation results for the steel shield configuration calculated with MAVRIC with ENDF/B VII.1 cross-section data and the cutoff energy 2 (neutron energy $>2.5 \mathrm{MeV}){ }^{32} \mathrm{~S}(\mathrm{n}, \mathrm{p})^{32} \mathrm{P}$ cross section data from ENDF/B VIII.0

\begin{tabular}{cccccc}
\hline $\begin{array}{c}\text { Position } \\
\text { number }\end{array}$ & $\begin{array}{c}\text { Distance from } \\
\text { HPRR } \\
\text { centerline (m) }\end{array}$ & $\begin{array}{c}\text { Sulfur } \\
\text { fluence } \\
\text { (n/cm2) }\end{array}$ & $\begin{array}{c}\text { Calculation } \\
\text { uncertainty } \\
\text { (rel) }\end{array}$ & C/E & $\begin{array}{c}\mathbf{C} / \mathbf{E} \\
\text { uncertainty } \\
\text { (rel) }\end{array}$ \\
\hline 1 & 2.5 & $7.46 \mathrm{E}+09$ & 0.0045 & 1.15 & 0.50 \\
2 & 3 & $5.29 \mathrm{E}+09$ & 0.0028 & 1.15 & 0.50 \\
3 & 3.5 & $4.02 \mathrm{E}+09$ & 0.0024 & 1.18 & 0.50 \\
4 & 4 & $3.21 \mathrm{E}+09$ & 0.0022 & 1.24 & 0.50 \\
5 & 5 & $2.21 \mathrm{E}+09$ & 0.0021 & 1.32 & 0.50 \\
6 & 7 & $1.26 \mathrm{E}+09$ & 0.0021 & 1.42 & 0.50 \\
7 & 9 & $8.10 \mathrm{E}+08$ & 0.0023 & 1.59 & 0.50 \\
\hline
\end{tabular}

\subsection{STEEL SHIELD ATTENUATION RATIO}

Another way to analyze and compare the experiment and calculation results it to look at the attenuation ratio induced by the steel shield. The attenuation ratio is the ratio of the sulfur fluence from the steel shield configuration to that of the bare configuration for the same pellet position. The attenuation ratios of the steel shield for the experimental and calculated cases are shown in Figure 74. No neutron energy cutoff is used in those results. In both experimental and calculated cases, the attenuation ratio is almost constant, as expected. Considering the error bars of the benchmark experiment, the ratios are statistically close to each other. 


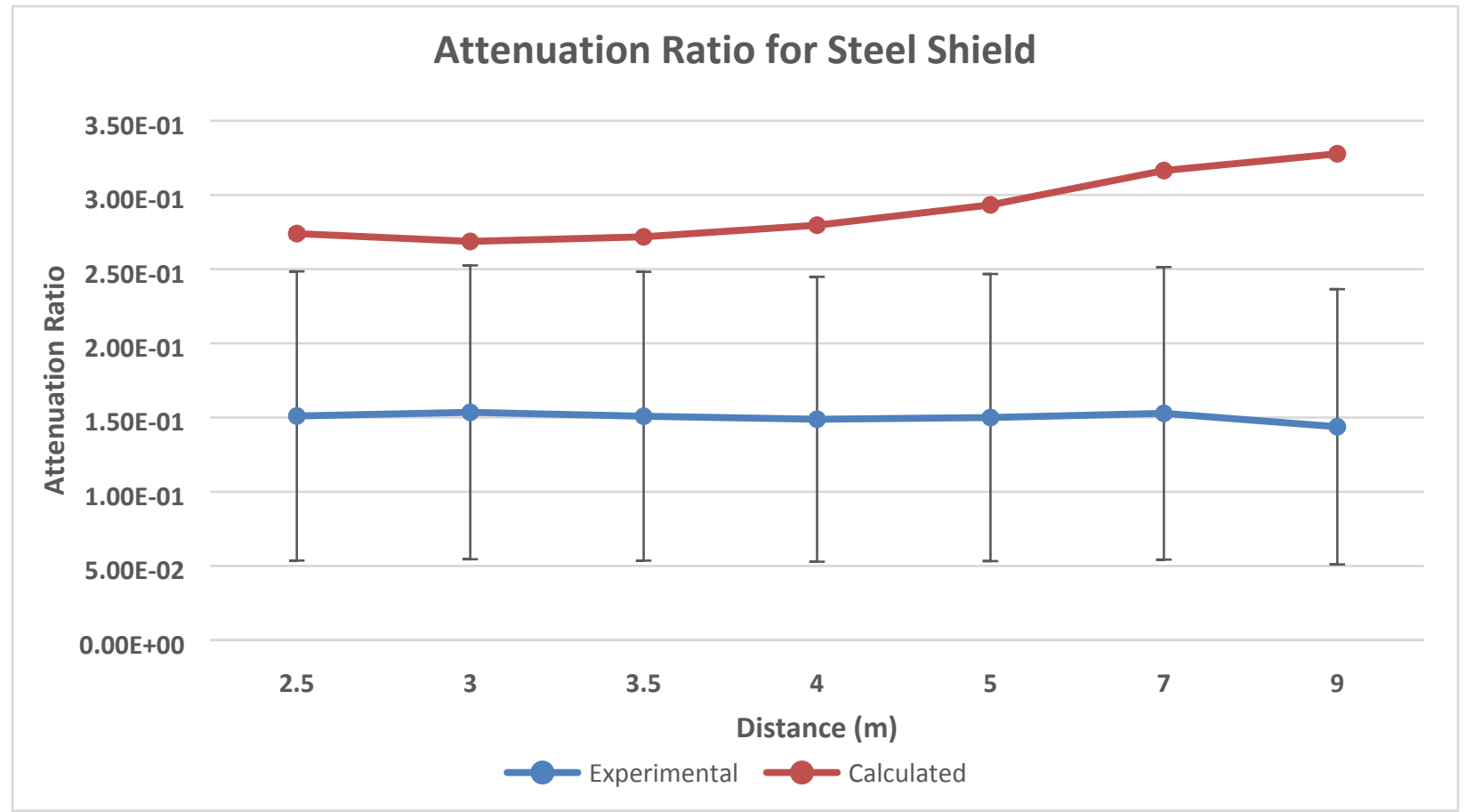

Figure 74. Steel shield attenuation ratio for the experimental and calculated sulfur fluence results

\subsection{RESULTS DISCUSSION}

From both the bare and steel shield sulfur fluence calculated-to-experimental (C/E) ratios, it appears that the experiment and simulations do not agree well, especially when using the regular ENDF/B VIII.0 ${ }^{32} \mathrm{~S}(\mathrm{n}, \mathrm{p}){ }^{32} \mathrm{P}$ reaction cross sections, where the $\mathrm{C} / \mathrm{E}$ ratios are between 1.7 and 3.2 for the bare configuration and between 3.6 and 5.8 for the steel shield configuration. This can be explained by the evident lack of information about the experimental setup. Changing the energy threshold of the ${ }^{32} \mathrm{~S}(\mathrm{n}, \mathrm{p})^{32} \mathrm{P}$ reaction causes the $\mathrm{C} / \mathrm{E}$ ratios to decrease significantly. Considering the calculated $\mathrm{C} / \mathrm{E}$ ratio uncertainties (taking into account both calculation and benchmark experimental uncertainties), all the calculated sulfur fluence results from both the bare and steel shield configurations for cutoff 2 (corresponding to using only neutrons of energy above $2.5 \mathrm{MeV}$ in the SCALE MAVRIC tally), agree with the evaluated benchmark values. The calculated sulfur fluences agree within $26 \%$ for the bare configuration, which approximately corresponds to the bare configuration evaluated experimental uncertainty, and it is within $59 \%$ for the steel shield configuration, which approximately corresponds to the steel shield configuration's evaluated experimental uncertainty. 


\section{REFERENCES}

1. F. W. Sanders et al., "Operation Plan and Hazards Report - Operation BREN," CEX-62.02, Oak Ridge National Laboratory (1962).

2. E. G. Bailiff, C. S. Sims, and R. E. Swaja, "HPRR Operating Experience and Applications," Proc. Fast Burst Reactor Workshop, Albuquerque, New Mexico, April 8-10 (1986).

3. Health Physics Research Reactor," from “A History of Research Reactors Division, p. 46, Oak Ridge National Laboratory (1987).

4. International Handbook of Evaluated Criticality Safety Benchmark Experiments, NEA/NSC/DOC(95)03, NEA Nuclear Science Committee (2016).

5. C. S. Sims and G. E. Ragan, Health Physics Research Reactor Reference Dosimetry, ORNL-6240, Oak Ridge National Laboratory (1987).

6. Operating Manual for the Health Physics Research Reactor, ORNL/TM-9870, Oak Ridge National Laboratory (1985).

7. J. T. Mihalczo, "Super-Prompt-Critical Behavior of an Unmoderated, Unreflected UraniumMolybdenum Alloy Assembly," ORNL-TM-230, Oak Ridge National Laboratory (1962).

8. B. T. Rearden and M. A. Jessee, Eds., SCALE Code System, ORNL/TM-2005/39, Version 6.2.3, Oak Ridge National Laboratory (2018).

9. ASTM A240 / A240M-20, Standard Specification for Chromium and Chromium-Nickel Stainless Steel Plate, Sheet, and Strip for Pressure Vessels and for General Applications, ASTM International, West Conshohocken, PA, 2020, www.astm.org

10. J. A. Auxier, "The Health Physics Research Reactor," Health Physics, 11, pp. 89-93 (1965).

11. J. W. Poston, J. R. Knight, and G. E. Whitesides, "Calculation of the HPRR Neutron Spectrum for Simulated Nuclear Accident Conditions," Health Physics, 26, pp. 217-221 (1965).

12. W. E. Kinney and J. T. Mihalczo, Oak Ridge National Laboratory Fast Burst Reactor: Critical Experiments and Calculations, CFN 61-8-71, Oak Ridge National Laboratory (1974).

13. M. I. Lundin, Health Physics Research Reactor Hazards Summary, ORNL-3248, Oak Ridge National Laboratory (1962).

14. ASTM A564 / A564M-19a, Standard Specification for Hot-Rolled and Cold-Finished AgeHardening Stainless Steel Bars and Shapes, ASTM International, West Conshohocken, PA, 2019, www.astm.org

15. ASTM B221-05, Standard Specification for Aluminum and Aluminum-Alloy Extruded Bars, Rods, Wire, Profiles, and Tubes, ASTM International, West Conshohocken, PA, 2005, www.astm.org

16. D. R. Johnson and J. W. Poston, Radiation Dosimetry Studies at the Health Physics Research Reactor, ORNL-4113, Oak Ridge National Laboratory (1967).

17. F. F. Haywood, 1970 Intercomparison of Nuclear Accident Dosimetry Systems at the Oak Ridge National Laboratory, ORNL-TM-3551, Oak Ridge National Laboratory (1972).

18. C. T. Wong, Evaluation of the Fluence Conversion Factor for 32P in Sulfur, LLNL-TR-764957, Lawrence Livermore National Laboratory (2019).

19. R. J. McConn, Jr., C. J. Gesh, R. T. Pagh, R. A. Rucker and R. G. Williams III, Compendium of Material Composition Data for Radiation Transport Modeling, PNNL-15870 Rev. 1, Radiation Portal Monitor Project, Pacific Northwest National Laboratory (2011).

20. V. F. Dean, Ed., ICSBEP Guide to the Expression of Uncertainties, NEA/NSC/DOC(95)03, Organisation for Economic Co-operation and Development - Nuclear Energy Agency (2019).

21. R. A. Lefebvre, A. B. Thompson, B. R. Langley, and B. T. Rearden, "Fulcrum User Interface for Scale 6.2,", 2017 Topical Meeting of the Nuclear Criticality Safety Division (NCSD) - Carlsbad, New Mexico, United States of America, Sept. 10-15 (2017). 